PNL-5223

UC-95a

\title{
ECORLOG Computer Application Users' and Programmers' Guides
}
C. Winter

September 1984

Prepared for the U.S. Department of Energy under Contract DE-AC06-76RLO 1830

Pacific Northwest Laboratory Operated for the U.S. Department of Energy by Battelle Memorial Institute 


\title{
DISCLAIMER
}

This report was prepared as an account of work sponsored by an agency of the United States Government. Neither the United States Government nor any agency thereof, nor any of their employees, makes any warranty, express or implied, or assumes any legal liability or responsibility for the accuracy, completeness, or usefulness of any information, apparatus, product, or process disclosed, or represents that its use would not infringe privately owned rights. Reference herein to any specific commercial product, process, or service by trade name, trademark, manufacturer, or otherwise, does not necessarily constitute or imply its endorsement, recommendation, or favoring by the United States Government or any agency thereof. The views and opinions of authors expressed herein do not necessarily state or reflect those of the United States Government or any agency thereof.

\author{
PACIFIC NORTHWEST LABORATORY \\ operated by \\ BATTELLE \\ for the \\ UNITED STATES DEPARTMENT OF ENERGY \\ under Contract DE-AC06-76RLO 1830
}

\begin{tabular}{|c|c|}
\hline \multicolumn{2}{|c|}{ Printed in the United States of America } \\
\hline & \\
\hline \multicolumn{2}{|c|}{$\begin{array}{l}\text { Available from } \\
\text { National Technical Information Service }\end{array}$} \\
\hline \multicolumn{2}{|c|}{ United States Depariment of Commerce } \\
\hline 5285 & \\
\hline \multicolumn{2}{|c|}{ Springfield, Virginia 22161} \\
\hline \multirow{2}{*}{\multicolumn{2}{|c|}{$\begin{array}{l}\text { NTIS Price Codes } \\
\text { Microfiche A01 }\end{array}$}} \\
\hline & \\
\hline \multicolumn{2}{|c|}{ Printed Copy } \\
\hline & Price \\
\hline Pages & Codes \\
\hline $001-025$ & $\mathrm{~A} 02$ \\
\hline 026-050 & A03 \\
\hline $051-075$ & $\mathrm{~A} 04$ \\
\hline 076-100 & A05 \\
\hline $101-125$ & $A 06$ \\
\hline $126-150$ & A07 \\
\hline $151-175$ & A08 \\
\hline $176-200$ & $A 09$ \\
\hline $201-225$ & A010 \\
\hline $226-250$ & $A 011$ \\
\hline $251-275$ & $\mathrm{~A} 012$ \\
\hline $276-300$ & $A 013$ \\
\hline
\end{tabular}


C. Winter

September 1984

Prepared for

the U.S. Department of Energy under Contract DE-ACO6-76RLO 1830

Pacific Northwest Laboratory Richland, Washington 99352 


\section{CONTENTS}

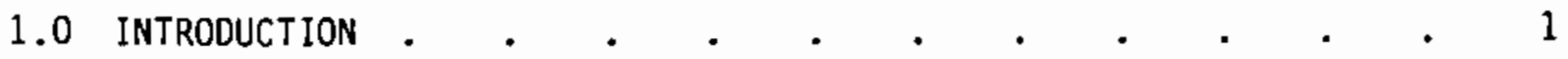

1.1 OVERVIEW OF THE ECORLOG APPLICATION $\quad . \quad \ldots \quad . \quad . \quad . \quad$. 1

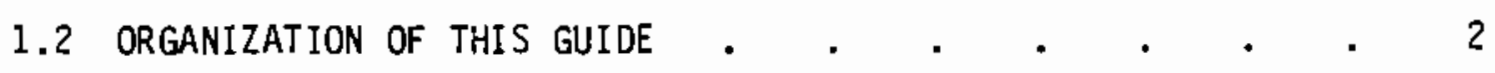

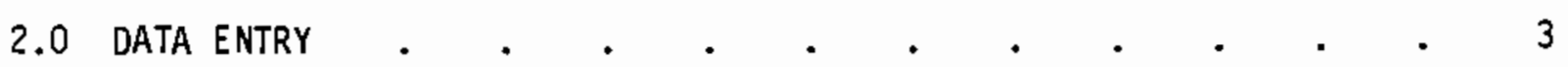

2.1 PROGRAM LEVEL ONE: "SUMMARY FOR ECOR NUMBER" SCREEN • . 4

2.2 PROGRAM LEVEL TWO: "INDIVIDUAL CONTRACT INFORMATION" SCREEN 13

3.0 EDITING THE DATA IN ECORLOG BATCHES . . . . . . . . . . 31

3.1 CHANGING EXISTING RECORDS . • • • • • • • . 31

3.2 ADDING RECORDS TO THE END OF A BATCH . . . . . . . 34

3.3 ADDING RECORDS TO THE MIDDLE OF A BATCH . . . . . 36

3.4 DELETING A RECORD . . . . . . . . . . . . . . . . 39

4.0 RUNNING PROGRAMS TO PROCESS ECORLOG DATA . . • • • • • . 41

4.1 UPDATING A BATCH'S NUMERIC FIELDS: THE ECORUP PROGRAM 42

4.2 PRINTING A REPORT ON ONE BATCH: THE ECRPTI PROGRAM . . 47

4.3 PRINTING A REPORT ON MLTIPLE BATCHES: THE ECRPT2 PROGRAM - 55

4.4 RUNNING ECORUP, ECRPT1 AND ECRPT2 IN ONE OPERATION $\ldots \quad$ • 63

4.5 SAMPLE ECORLOG REPORTS . . . . . . . . . . . . 64

5.0 UTILITY FUNCTIONS FOR THE ECORLOG APPLICATION $\quad * \quad$ • $\quad$ • $\quad$ • 69

5.1 RESETTING THE VISION SYSTEM PRINTER $\quad$ • . . . . . . 69

5.1.1 Resetting the VISION Printer Directly . • • • 69

5.1.2 Resetting the VISION Printer with MASTER, SETPRT . 69

5.2 YEAR-END PROCEDURES FOR STORING ECORLOG BATCHES • • 70

5.2.1 The VISION Commands for Storage, Deletion and Retrieval 71

5.2.2 Editing the Commands in MASTER,ECPURG . . . 73

5.2.3 Storing and Deleting ECORLOG Batches . . . . 75

5.2.4 Retrieving ECORLOG Batches . • . . . . . . 76 
APPENDIX - ECORLOG COMPUTER APPLICATION PROGRAMMERS' GUIDE • • • A.1

A.1 THE ECORLOG JOB $. \quad . \quad . \quad . \quad$. . . . . . A.2

A.2 THE ECORUP PROGRAM . . . . . . . . . . . . A.8

A.3 THE ECRPTI PROGRAM . . . . . . . . . . A.12

A.4 THE ECRPT2 PROGRAM . . . . . . . . . . . . A.16

A.5 SOURCE CODE FOR THE ECORLOG APPLICATION . . . . A. 24

\section{FIGURES}

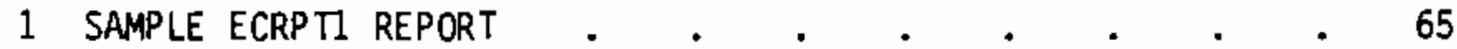

2 SAMPLE ECRPT2 REPORT . . . . . . . . . . 66

A.1 RECORD LAYOUT FOR PROGRAM LEVEL ONE RECORDS . • • • . A.3

A.2 SCREEN LAYOUT FOR PROGRAM LEVEL ONE RECORDS . • • • . A.4

A.3 RECORD LAYOUT FOR PROGRAM LEVEL TWO RECORDS . • • • A.5

A.4 SCREEN LAYOUT FOR PROGRAM LEVEL TWO RECORDS . • • • . A.7

A.5 USE OF SYSTEM RESOURCES BY THE ECORUP PROGRAM • • - A.10

A.6 USE OF SYSTEM RESOURCES BY THE ECRJST SUBROUT INE . • - A.11

A.7 USE OF SYSTEM RESOURCES BY THE ECRPT1 PROGRAM • • . A.14

A.8 PRINT LAYOUT FOR THE ECRPT1 REPORT • • • • . A.15

A.9 USE OF SYSTEM RESOURCES BY THE ECRPT2 PROGRAM • • - A.20

A.10 PRINT LAYOUT FOR THE ECRPT2 REPORT . . • • . . A.22

$\underline{\text { TABLES }}$

1 RECORD LAYOUT FOR PROGRAM LEVEL ONE RECORDS . . . . . 4

2 RECORD LAYOUT FOR PROGRAM LEVEL TWO RECORDS . . . . . 13 
ECORLOG COMPUTER APPLICATION USERS' AND PROGRAMMERS' GUIDES

\subsection{INTRODUCTION}

\subsection{OVERVIEW OF THE ECORLOG APPLICATION}

This document provides information on using the ECORLOG application program available on the Four-Phase Systems VISION package. ECORLOG is used for management contro? of procurements issued by the U.S. Department of Energy's Office of Energy Systems Reseach (DOE/ESR). It provides a structured format for entering and updating individual procurement actions, and two standardized ECORLOG reports. These reports, which provide information on all the procurements under one or more ECOR Number (analogous to the Budget \& Reporting (B\&R) Classifications used more generally at DOE), are used by both office of Energy Systems Research (ESR) personne T and other DOE Offices.

VISION is a distributed processing package which is available on Four-Phase Systems computers. Its features include source data entry, data management and report generation. In VISION, A 'Job' consists of the screen displays used by a particular application, and all the data entered using those screen displays. The Job is a collection of 'Batches', each identified by a unique name (Batch ID) and consisting of a group of entries ('Records') made using the screen displays of the Job. In this case, ECORLOG is the VISION Job; a separate Batch of ECORLOG exists for each ECOR Number, and each Batch contains one Record for each procurement (contract) issued under that ECOR Number as well as a Summary Record for the ECOR Number. Throughout the instructions that follow, the term Job refers to ECORLOG, Batch to the collection of Records for a particular ECOR Number, and Record to an Individual Contract or Summary entry.

The ECORLOG application includes the Job named ECORLOG and three associated programs: ECORUP, ECRPTI and ECRPT2. While the Job is used to store data (in this case, information on each procurement issued by DOE's Office of Energy Systems Research), the programs are executed to process the data contained in Batches of the ECORLOG Job. The ECORUP program updates the numeric fields in each Record of a Batch to incorporate additions or modifications made to that Batch; the ECRPT1 and ECRPT2 programs allow for the printing of two different ECORLOG reports. 


\subsection{ORGANIZATION OF THIS GUIDE}

This document consists of two separate guides to the ECORLOG application. Sections One through Five make up the Users' Guide, while the Programmers' Guide is contained in the Appendix. The Programmer's Guide contains information that will be useful in maintaining or updating the ECORLOG application's capabilities, but is not needed for day-to-day use of the ECORLOG Job and programs.

Each of the following four sections covers a separate aspect of ECORLOG. Section Two explains how data is entered into a Batch of the ECORLOG Job. In Section Three, several common data-editing operations are described. Instructions for running the three ECORLOG programs (ECORUP, ECRPT1 and ECRPT2) are given in Section Four, which also includes samples of the ECORLOG reports. Section Five concludes the Users' Guide with procedures for redirecting the output of ECORLOG reports to different printers, and for storing ECORLOG data at the end of a fiscal year.

The explanations given in the Users' Guide are illustrated by examples. Each example consists of one or more ECORLOG screen displays, and lettered steps describing what is being done in the example. The screen displays here are copies of what the user would see on an actual terminal screen. Information which is being entered by the user is underlined in the screen displays given in the examples; it is not underlined on the actual screen. The position of the cursor on the screen is shown with an open rectangle (D).

This entire Users Guide should be read before attempting to produce reports on real data. It may be helpful to open a test Batch of ECORLOG and follow through the data entry and editing examples step by step, and then to use two test Batches in running the ECORLOG programs. Open a test Batch with which to experiment before trying to enter information in a Batch which will be kept and updated.

This is not a VISION user's manua 1 , and does not attempt to cover all aspects of VISION keyboard operation and data entry, although specific keystroke sequences for most of the operations used in the ECORLOG application are provided. The Four-Phase Systems manuals "Teach Yourself VISION" and "VISION Keyboard Operation" provide further information in this area. 


\subsection{DATA ENTRY}

To enter information on procurements and produce the ECORLOG reports, you must leave Foreword and enter VISION on the Four-Phase computer. While Foreword and VISION utilize the same Four-Phase keyboard, the keyboard keys are used for different functions in the two packages. The Foreword function of a key is written in black letters on the top of the key; the VISION function is written in white letters on the front of the key. For instance, the key referenced here as MODE is same key used to RESET in Foreword; VISION's FIELD REL key corresponds to CURSOR RETURN in Foreword. Another important VISION key, CORR REST (used to clear error messages) is the same key used to TAB in Foreword.

To access VISION from the Foreword idle screen, press CTRL-FIELD REL to get the prompt "TYPE C, I, V, S OR ?" Type V to enter VISION, where the prompt requests a three-character I0. Any three letters or numbers can be entered (pressing FIELD REL is not necessary). The job in which procurement information is stored is called ECORLOG. To enter a Batch of this Job, press the MODE key and type E to access VISION's data Entry mode, type ECORLOG,BATCH (where $B A T C H$ represents the batch $I 0$ and can be up to six letters or numbers in length) and press FIELD REL.

There are two different screen displays (called Program Levels) in ECORLOG. Program Level One displays a screen titled SUMMARY FOR ECOR NUMBER. This screen allows entry of information to be used as the report header. Program Level Two displays a screen called INDIVIDUAL CONTRACT INFORMATION, where information on each procurement is entered. Screen layouts and data entry instructions for each Program Level are detajled in the sections that follow. Record layouts of the contents of each Program Level are also provided.

When a Batch is first opened, the Program Level One SUMMARY screen will be displayed. Once this Record is filled, all subsequent screens will be Program Level Two INDIVIDUAL CONTRACT screens which appear automaticaliy. When a Batch is reopened after data has been entered, an empty screen at the end of the Batch will be displayed -. it is a SUMMARY screen. No information should be entered into a blank SUMMARY screen after reopening a Batch. To add Records at the end of the Batch, press the up arrow once and the down arrow once to display an INOIVIDUAL CONTRACT screen. To add Records in the middle of the Batch, press CTRL and the up arrow simultaneously to go to the beginning of the Batch before continuing. Section Three contains further information on editing ECORLOG data after it has been entered into a Batch.

NOTES ON DATA ENTRY:

1. All entries appear on the screen in capital letters, so it is not necessary to shift into upper case at the beginning of words.

2. If a mistake is made during data entry, an error message (usually selfexplanatory) will flash at the bottom of the screen. The CORR REST key must be pressed (the error message will stop flashing) before the error can be corrected. 


\subsection{PROGRAM LEVEL ONE: "SUMMARY FOR ECOR NUMBER" SCREEN}

The Program Level One Record provides summary information for an ECOR number, and serves as a header for the ECORLOG report. It is important to remember that there should be on ly one Program Level One Record in each ECORLOG Batch, and that it should always be the first Record. The fields contained in the Program Level One Record are listed in Table 1 below.

When a Batch of ECORLOG is first opened, the Program Level One Record is the first screen to appear. The fields in this Record are described on the following pages.

TABLE 1. RECORD LAYOUT FOR PROGRAM LEVEL ONE RECORDS

\begin{tabular}{|c|c|c|c|}
\hline 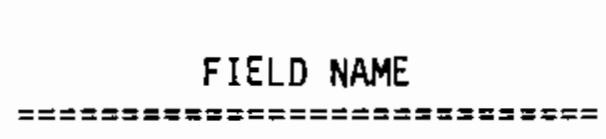 & $\begin{array}{l}\text { FIELD TYPE } \\
======== \pm\end{array}$ & $\begin{array}{l}\text { FIELD } \\
\text { WIDTH } \\
=====\end{array}$ & 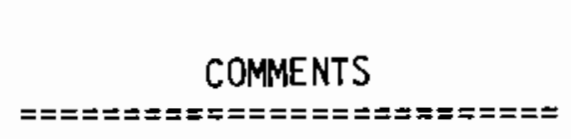 \\
\hline ECOR NUMBER & General & 15 & \\
\hline ANALYST & Genera 1 & 20 & \\
\hline PHONE NUMBER & Genera 1 & 15 & \\
\hline FISCAL YEAR I & Integer & 4 & $\begin{array}{l}\text { Must Be Filled, i.e., all } \\
\text { four digits of the year } \\
\text { must be entered. }\end{array}$ \\
\hline APPROPRIATION AMOUNT & Numeric & 12 & \\
\hline APPROPRIATION NUMBER & Genera 1 & 15 & \\
\hline FISCAL YEAR II & Integer & 4 & $\begin{array}{l}\text { The contents of FISCAL } \\
\text { YEAR I are used to fill } \\
\text { this field automatically. }\end{array}$ \\
\hline UNOBLIGATED CARRYOVER AMOUNT & Numeric & 12 & \\
\hline TOTAL ECOR AVAILABILITY & Numer ic & 12 & \\
\hline
\end{tabular}


a. You start at the MFE screen, and type $V$ to enter VISION, then enter a threeletter user ID.

b. To open the new Batch called TEST, you press the MODE key and type E. Message Line: TYPE JOBNAME, BATCH \#

c. Type 'ECORLOG, TEST' and press FIELD REL, which leads to the Status Line and screen display below.

Status Line: $\quad 0010 G, A S D, P 1, E, E C O R L O G, T E S T$ UID 1

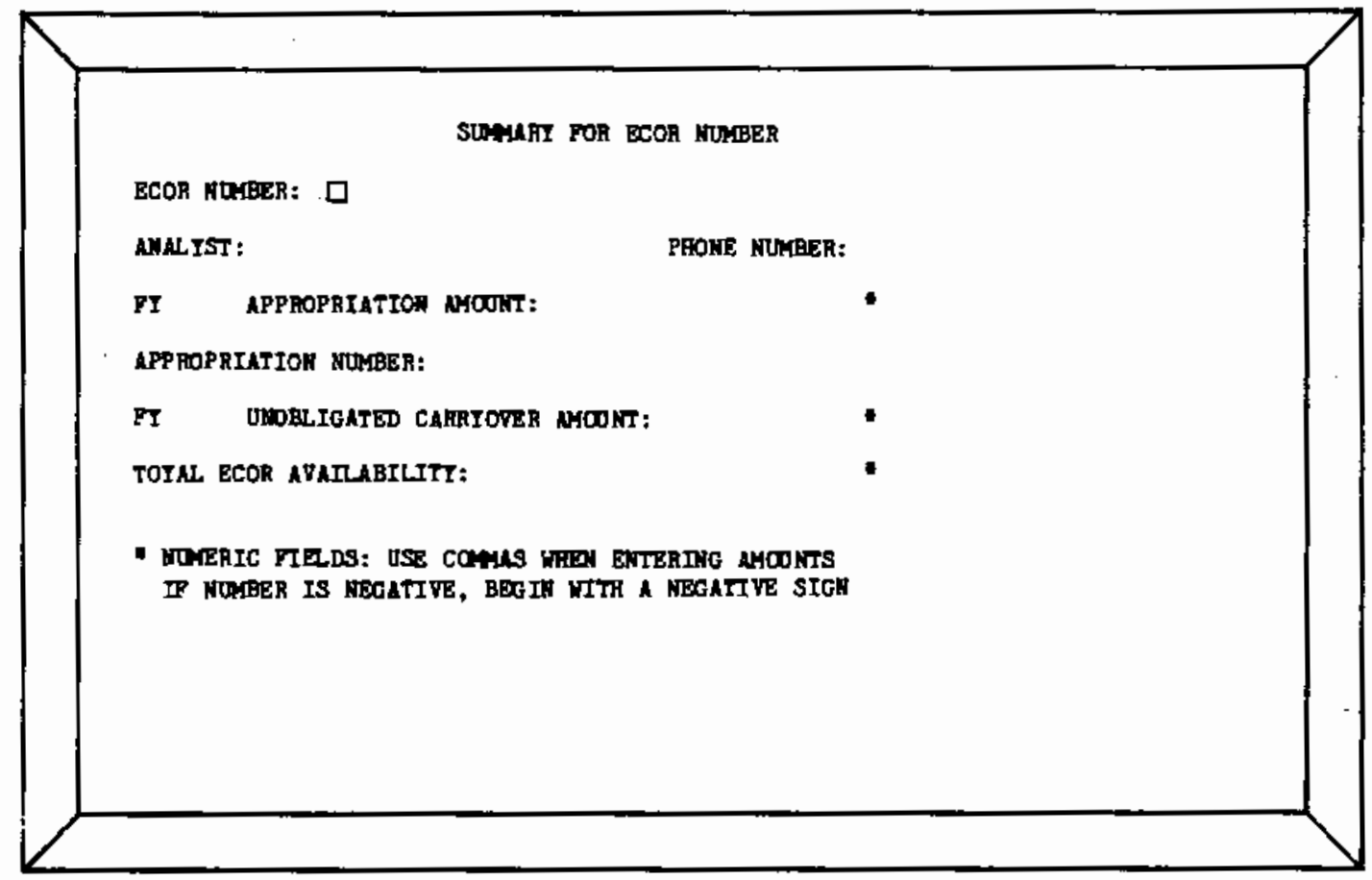


ECOR NUMBER

The ECOR NUMBER, also known as the B\&R Number, is used to categorize procurement actions. Enter the ECOR NUMBER and press FIELD REL.

EXAMPLE 2. ECOR NUMBER FIELD

a. Enter 'AK-05' for the ECOR NUMBER, and press FIELD REL.

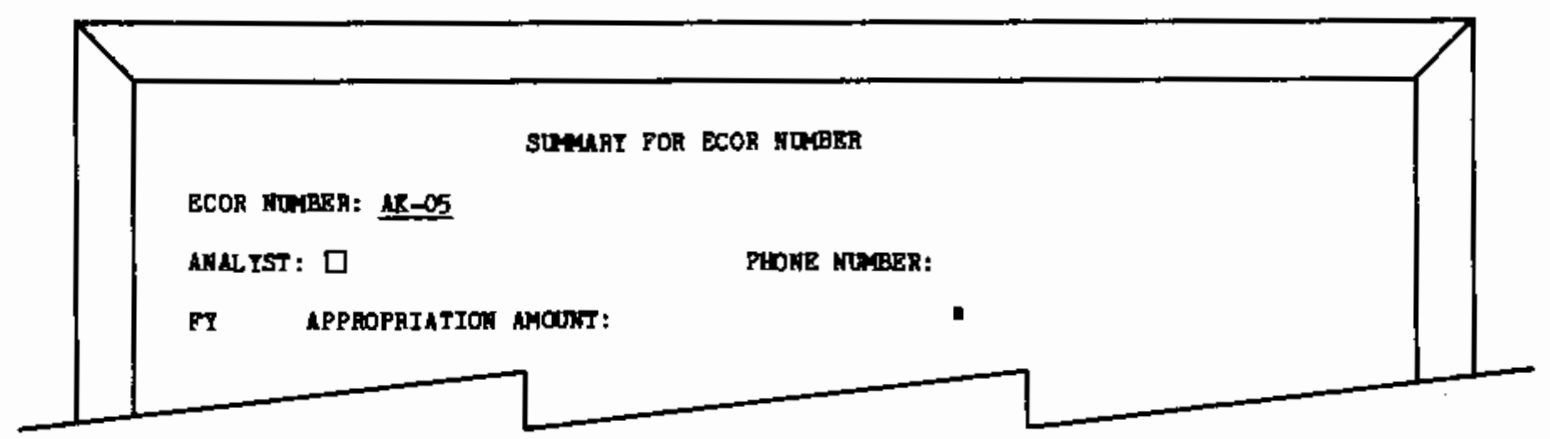

ANALYST

This field stores the name of the budget analyst in the controller's office. Enter the name of this person and press FIELD REL.

\section{EXAMPLE 3. ANALYST FIELD}

a. Enter ' $D$. KERN' as the ANALYST, and press FIELD REL.

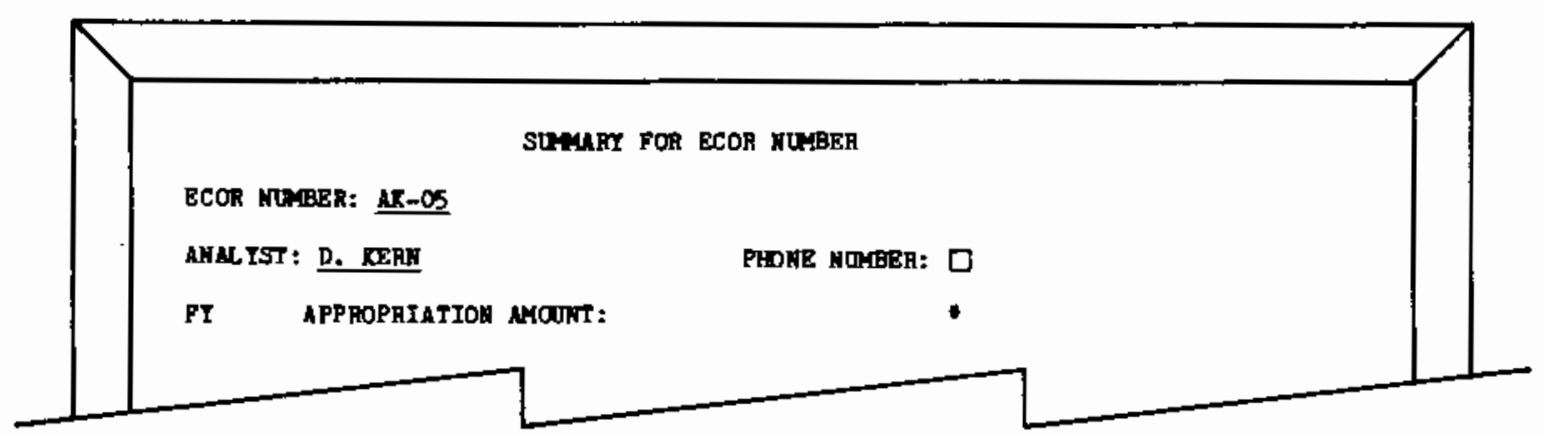




\section{PHONE NUMBER}

This field contains the Budget Analyst's phone number. Enter and press FIELD REL.

\section{EXAMPLE 4. PHONE NUMBER FIELD}

a. Enter '252-1500' as the analyst's phone number, and press FIELD REL.

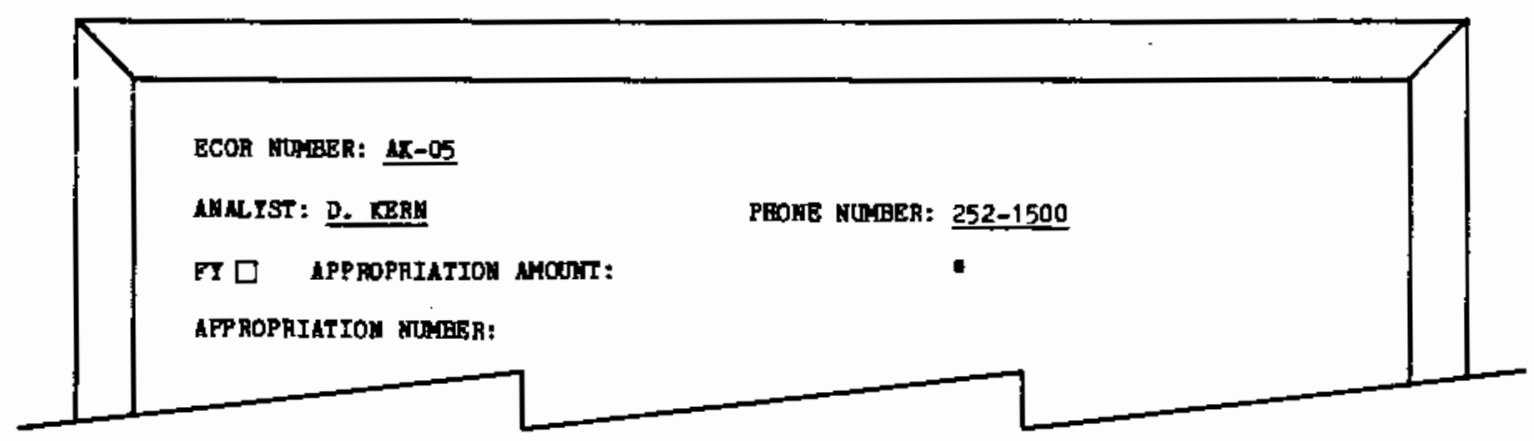


FY (FISCAL YEAR I)

The fiscal year in which the procurements are funded is entered here. All four numbers of the fiscal year must be entered. After FISCAL YEAR I is entered, the cursor will be automatically transferred to the next field.

\section{EXAMPLE 5. FISCAL YEAR I FIELD}

a. Enter ' 85 ' for the FISCAL YEAR, and press FIELD REL.

Status Line:

MUST FILL.

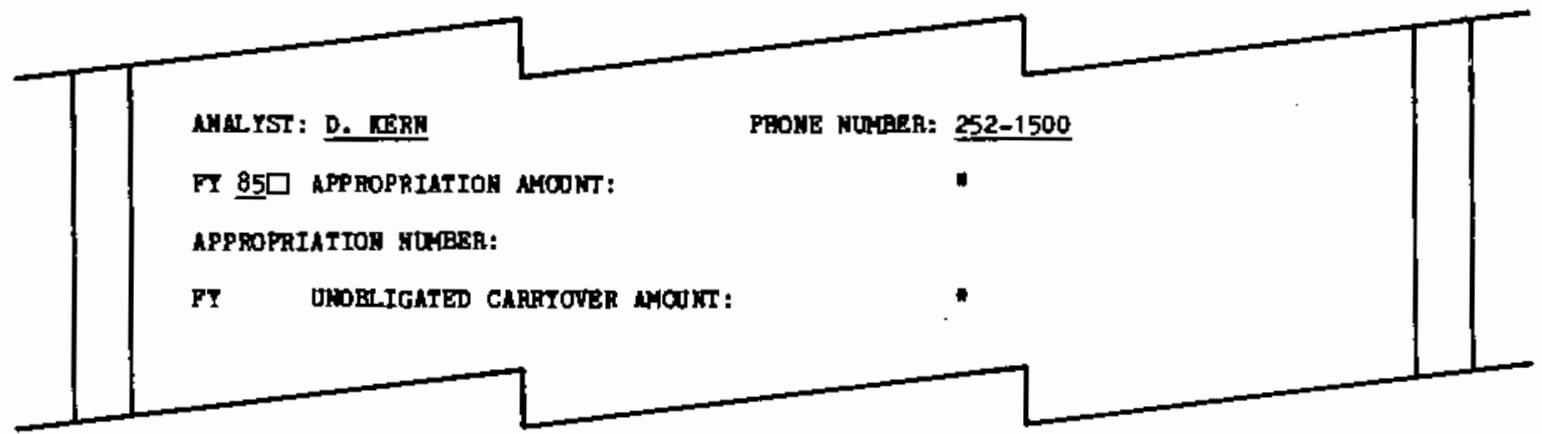

b. Press SHIFT and CORR REST simultaneously. This stops the flashing of the Status Line's error message and unlocks the keyboard.

c. Press the left arrow key twice to position the cursor at the beginning of the fiscal year field. Enter '1985'. The cursor will move to the beginning of the next field.

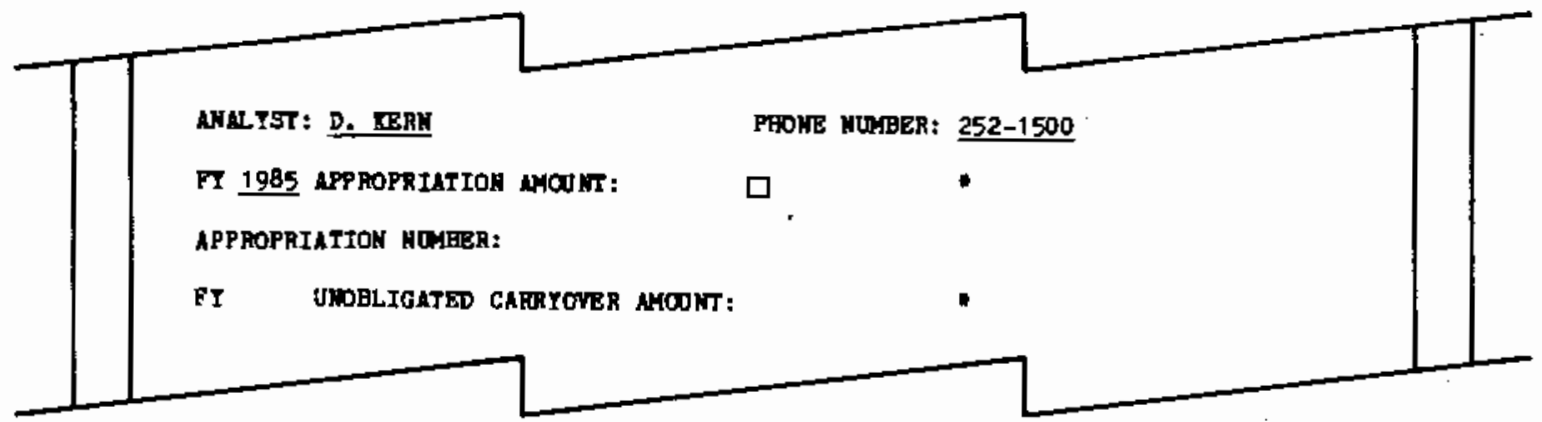


APPROPRIATION AMOUNT

This field will contain the total APPROPRIATION AMOUNT for the procurements in the fiscal year just entered. This field (along with UNOBLIGATED CARRYOVER AMOUNT and TOTAL ECOR AVAILABILITY) is a Numeric type field. The only characters which cannot be entered into numeric fields are the alphabetic characters A-Z. Thus, you can enter commas and negative signs into numeric fields such as APPROPRIATION AMOUNT. If the amount is negative, the negative sign should precede the number. Enter the figure for APPROPRIATION AMOUNT, and press FIELD REL to complete the field.

EXAMPLE 6. APPROPRIATION AMOUNT FIELD .

a. Enter ' $3,500,000$ ' for the APPROPRIATION AMOUNT, and press FIELD REL.

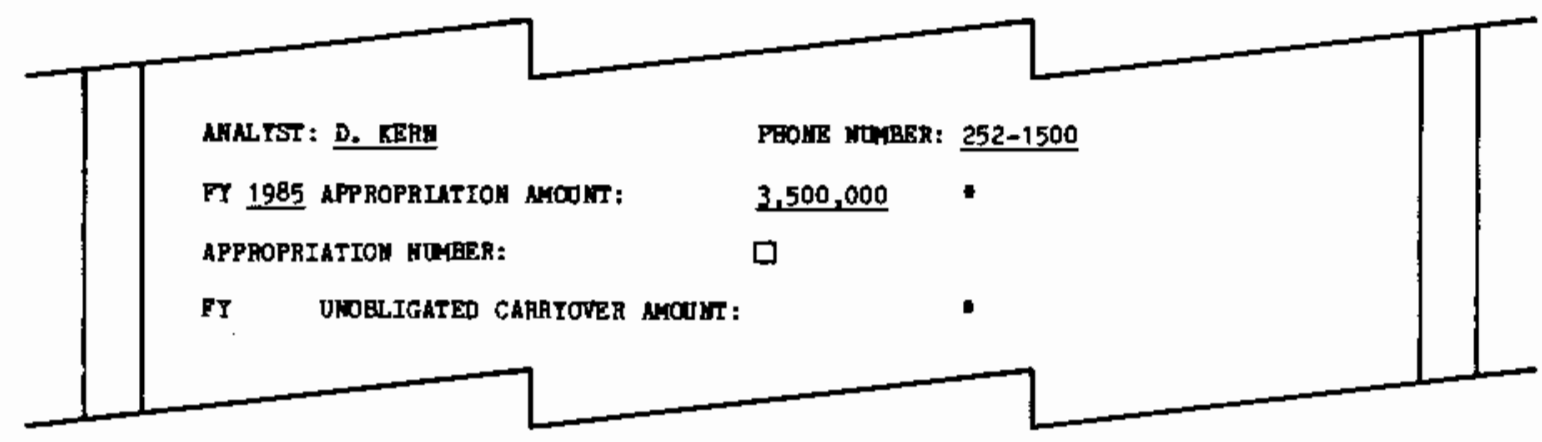

APPROPRIATION NUMBER

The APPROPRIATION NUMBER, which further identifies the appropriation, may contain letters, numbers, and punctuation. Enter the APPROPRIATION NUMBER and press FIELD REL to cont inue to the next field.

\section{EXAMPLE 7. APPROPRIATION NUMBER FIELD}

a. Enter ' $89 \times 0224.91 '$ as the APPROPRIATION NUMBER. Do not press FIELD REL yet.

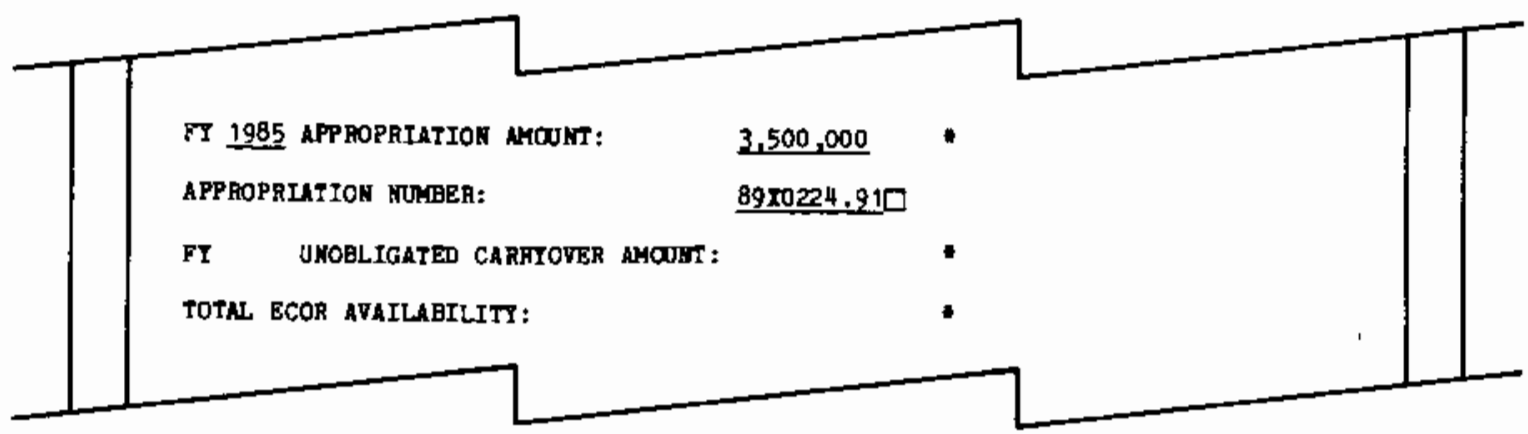


FY (FISCAL YEAR II)

This field will contain the same fiscal year as FISCAL YEAR I entered previously. However, you do not have to enter the fiscal year again yourself. Once FIELD REL is pressed af ter the APPROPRIATION NUMBER field, the computer automatically copies FISCAL YEAR I to the FISCAL YEAR II field, and moves the cursor to the beginning of the next fieid.

\section{EXAMPLE 8. FISCAL YEAR II FIELD}

a. FIELD REL was not pressed at the end of the last example. Press FIELD REL now. You can see that the fiscal year appears in the FISCAL YEAR II field, as the cursor moves to the next field.

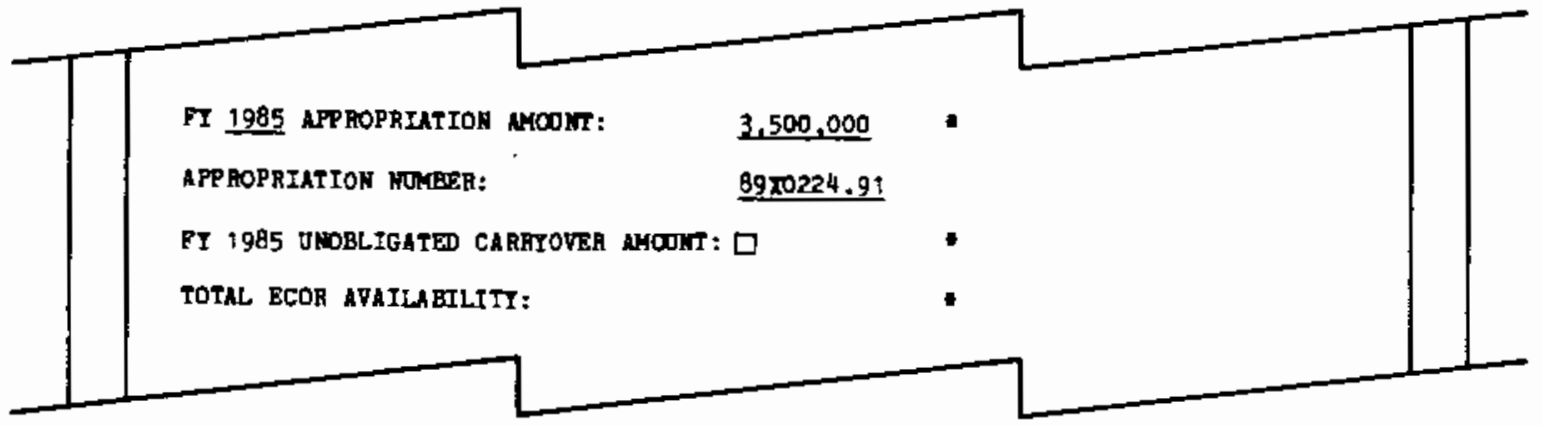

UNOBLIGATED CARRYOVER AMOUNT

This field contains the unspent funding for the ECOR NUMBER from the previous fiscal year. Like the APPROPRIATION AMOUNT field, UNOBLIGATED CARROVER AMOUNT is a Numeric type field. Enter the UNOBLIGATEO CARRYOVER AMOUNT with commas and a preceding negative sign if necessary, and press FIELD REL.

\section{EXAMPLE 9. UNOBLIGATED CARRYOVER AMOUNT FIELD}

a. Enter ' 525,060 ' as the UNOBLIGATED CARRYOVER AMOUNT, and press FIELO REL.

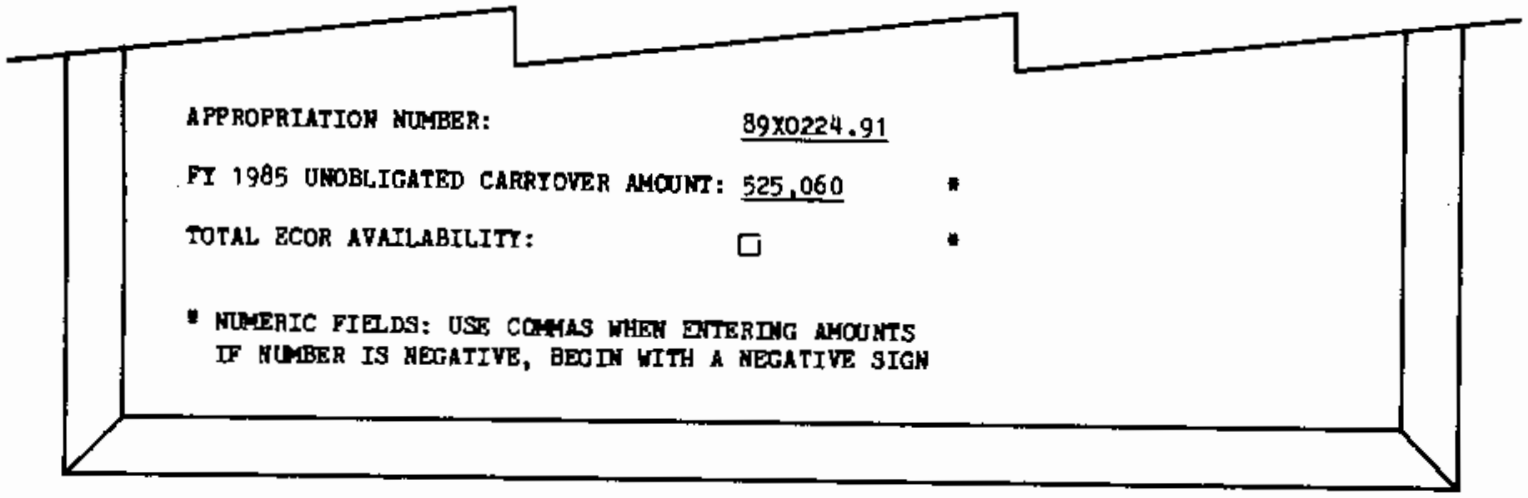


TOTAL ECOR AVAILABILITY

TOTAL ECOR AVAILABILITY, the sum of the APPROPRIATION AMOUNT and the UNOBLIGATED CARRYOVER AMOUNT fields, is another numeric fieid. Add the amounts in the APPROPRIATION AMOUNT and UNOBLIGATED CARRYOVER AMOUNT fields, and enter their sum in TOTAL ECOR AVAILABILITY (entering commas as you go). Press FIELD REL to complete both the field and the Program Level One Record; a Program Level Two Record will then be displayed.

\section{EXAMPLE 10. TOTAL ECOR AVAILABILITY FIELD}

a. Add the amounts entered in the APPROPRIATION AMOUNT and UNOBLIGATED CARRYOVER AMOUNT fields. Enter the result ' $4,025,060$ ' in the TOTAL ECOR AVAILABILITY field. Do not press FIELD REL yet.

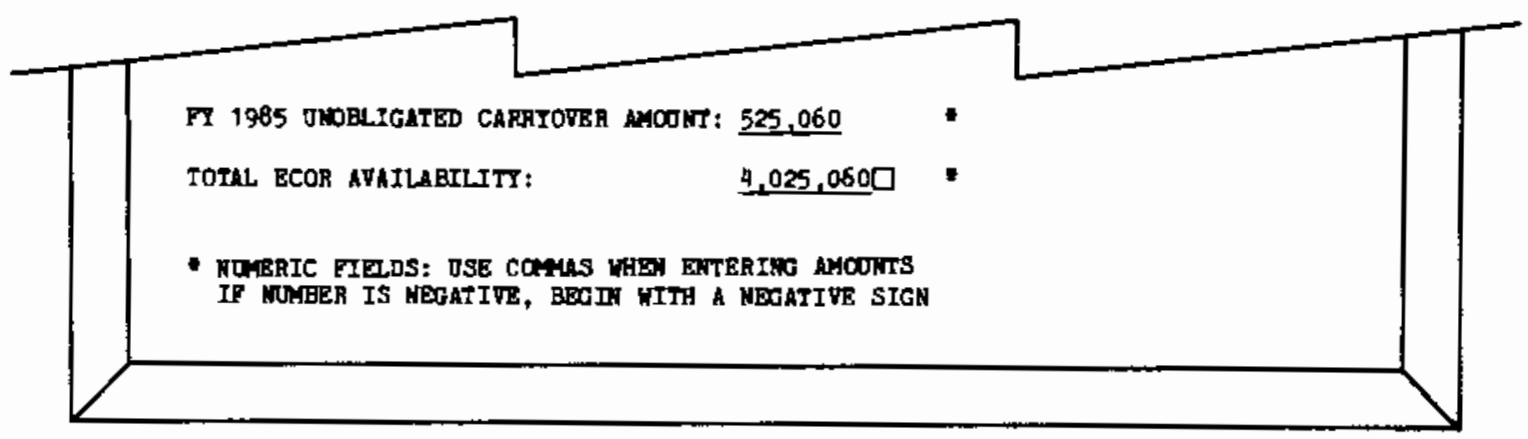

b. Press FIELD REL. You will see a Program Level Two, INDIVIDUAL CONTRACT INFORMATION screen displayed.

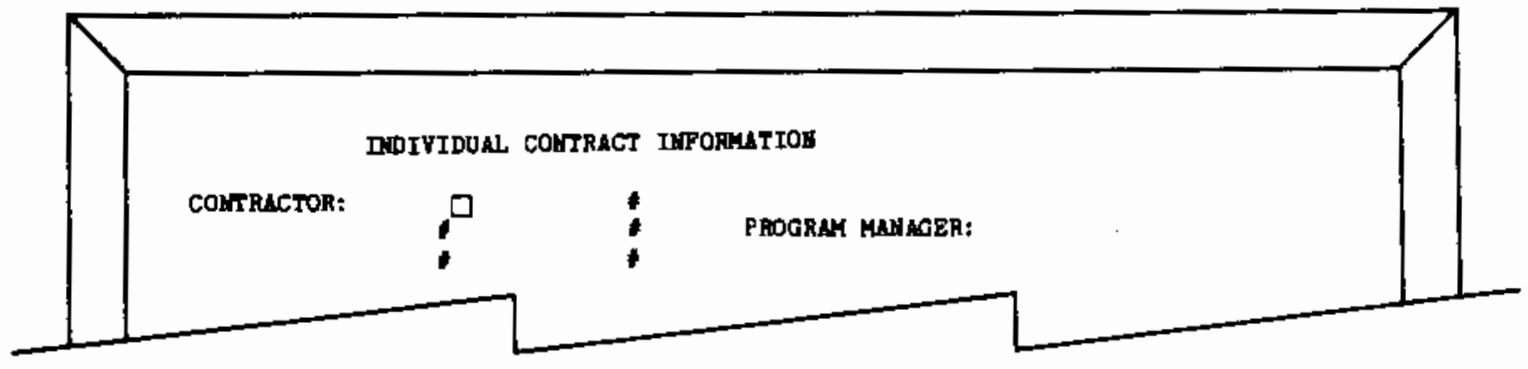


c. Press the up arrow once to view the completed SUMMARY FOR ECOR NUMBER screen.

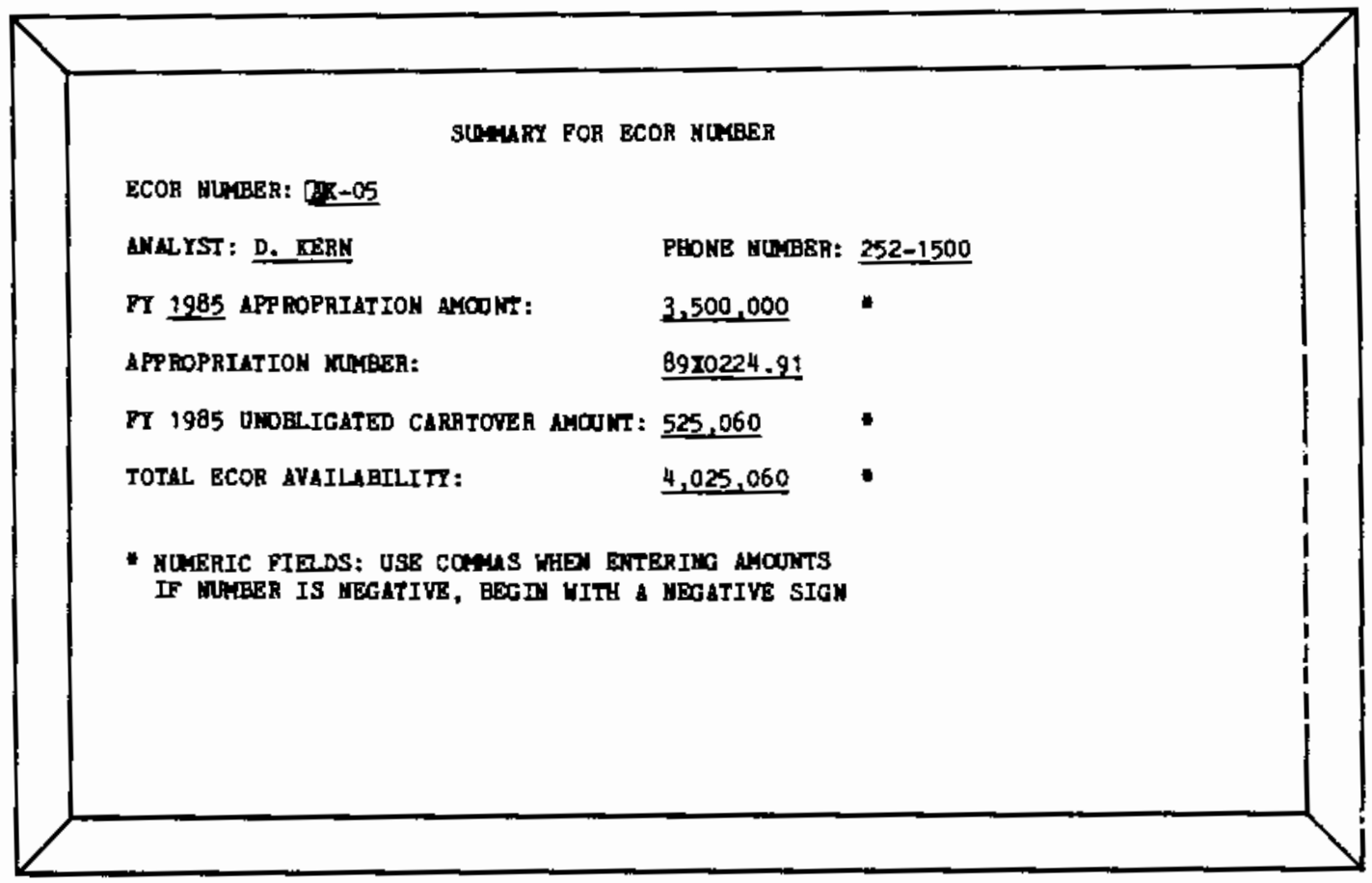

d. Press the down arrow once to return to the INDIVIDUAL CONTRACT INFORMATION screen. You are now ready to enter information on individual procurement actions; this is described in the following section.

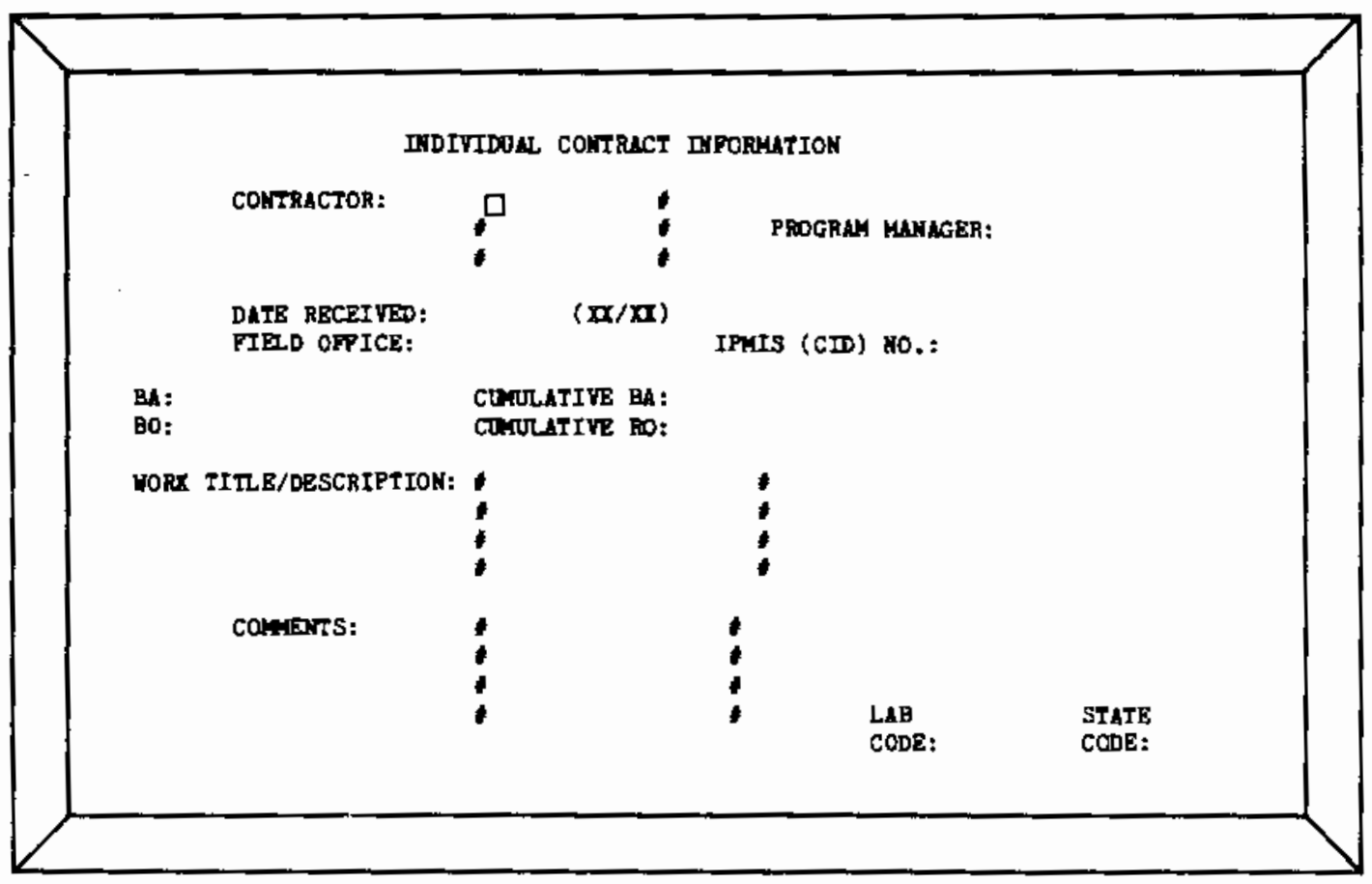




\subsection{PROGRAM LEVEL TWO: INDIVIDUAL CONTRACT INFORMATION}

Program Level Two Records provide for entry of information concerning individual procurement actions. Each Program Level Two Record contains the information on one procurement. All of the Records in a Batch of ECORLOG, after the first Record, should be Program Level Two Records. The fields in each Program Leve1 Two Record are listed in Table 2 below.

After the SUMMARY FOR ECOR NUMBER screen has been completed, all subsequent screens will be INDIVIDUAL CONTRACT INFORMATION screens. The fields entered into Program Level Two Records from these screens are described on the following pages.

TABLE 2. RECORD LAYOUT FOR PROGRAM LEVEL TWO RECOROS

\begin{tabular}{|c|c|c|c|}
\hline 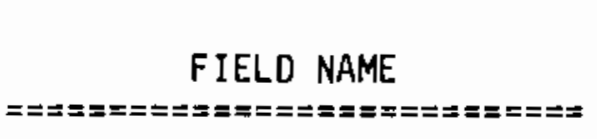 & $\begin{array}{l}\text { FIELD TYPE } \\
=========\end{array}$ & $\begin{array}{l}\text { FIELD } \\
\text { WIDTH } \\
====\end{array}$ & 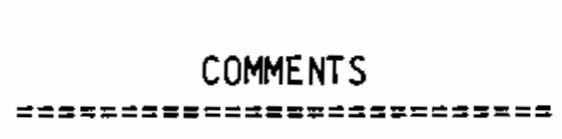 \\
\hline CONTRACTOR I & Genera 1 & 12 & $\begin{array}{l}\text { First of three fields, } \\
\text { Must Be Entered, i.e., the } \\
\text { field cannot be bypassed } \\
\text { by pressing FIELD REL. }\end{array}$ \\
\hline CONTRACTOR II & General & 12 & Second of three fields. \\
\hline CONTRACTOR III & General & 12 & Third of three fields. \\
\hline PROGRAM MANAGER & Genera 1 & 10 & Must Be Entered. \\
\hline DATE RECEIVED & $\begin{array}{l}\text { Integer } \\
\text { and Text }\end{array}$ & 5 & $\begin{array}{l}\text { Together, the first two } \\
\text { digits (the month) must be } \\
\text { greater than zero and less } \\
\text { than 13. The third digit } \\
\text { is a slash, which is gener } \\
\text { ated automatically. the } \\
\text { last two digits (the day) } \\
\text { must be greater than zero } \\
\text { and less than } 32 \text {. }\end{array}$ \\
\hline FIELD OFFICE & Gener a ? & 4 & Must Be Entered. \\
\hline PMIS (CID) NUMBER & General & 7 & \\
\hline
\end{tabular}


TABLE 2. RECORD LAYOUT FOR PROGRAM LEVEL TWO RECOROS (cont inued)

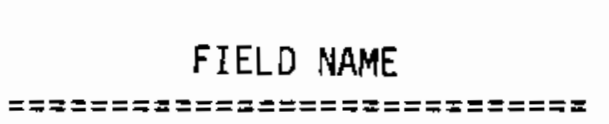

BA

CUMULATIVE BA

BO

CUMULATIVE BO

WORK TITLE/DESCRIPTION I

WORK TITLE/OESCRIPTION II

WORK TITLE/DESCRIPTION III

WORK TITLE/DESCRIPTION IV

COMMENTS I

COMMENTS II

COMMENTS III

COMMENTS IV

LAB CODE

STATE CODE
FIELD

FIELD TYPE WIOTH

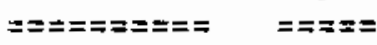

COMMENTS

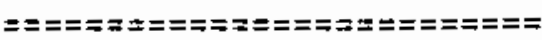

12 Must Be Entered.

12 Skipped during data entry. The contents of this field are provided by the ECORUP program.

Numer ic

12 Must Be Entered.

Numeric

12

Skipped during data entry. The contents of this field are provided by the ECORUP program.

Genera 1

19 First of four fields. Must Be Entered.

Genera 1

19 Second of four fields.

Genera T

19 Third of four fields.

Genera 1

19 Fourth of four fields.

Genera 1

17

First of four fields. Must Be Entered.

Genera?

17

Genera 1

17

Genera 1

17

Genera 1

4

Genera 1
Second of four fields.

Third of four fields.

Fourth of four fields.

2 Validated against a value set containing the postal abbreviations for the states, blanks, and ' 99 ' for foreign contracts as permitted entries. 


\section{EXAMPLE 11. BEGINNING AN INDIVIDUAL CONTRACT SCREEN}

a. You have finished entering information into the SUMMARY FOR ECOR NUMBER screen, and have pressed FIELD REL after entering TOTAL ECOR AVAILABILITY. A Program Leve? Two, INDIVIDUAL CONTRACT INFORMATION, screen is displayed.

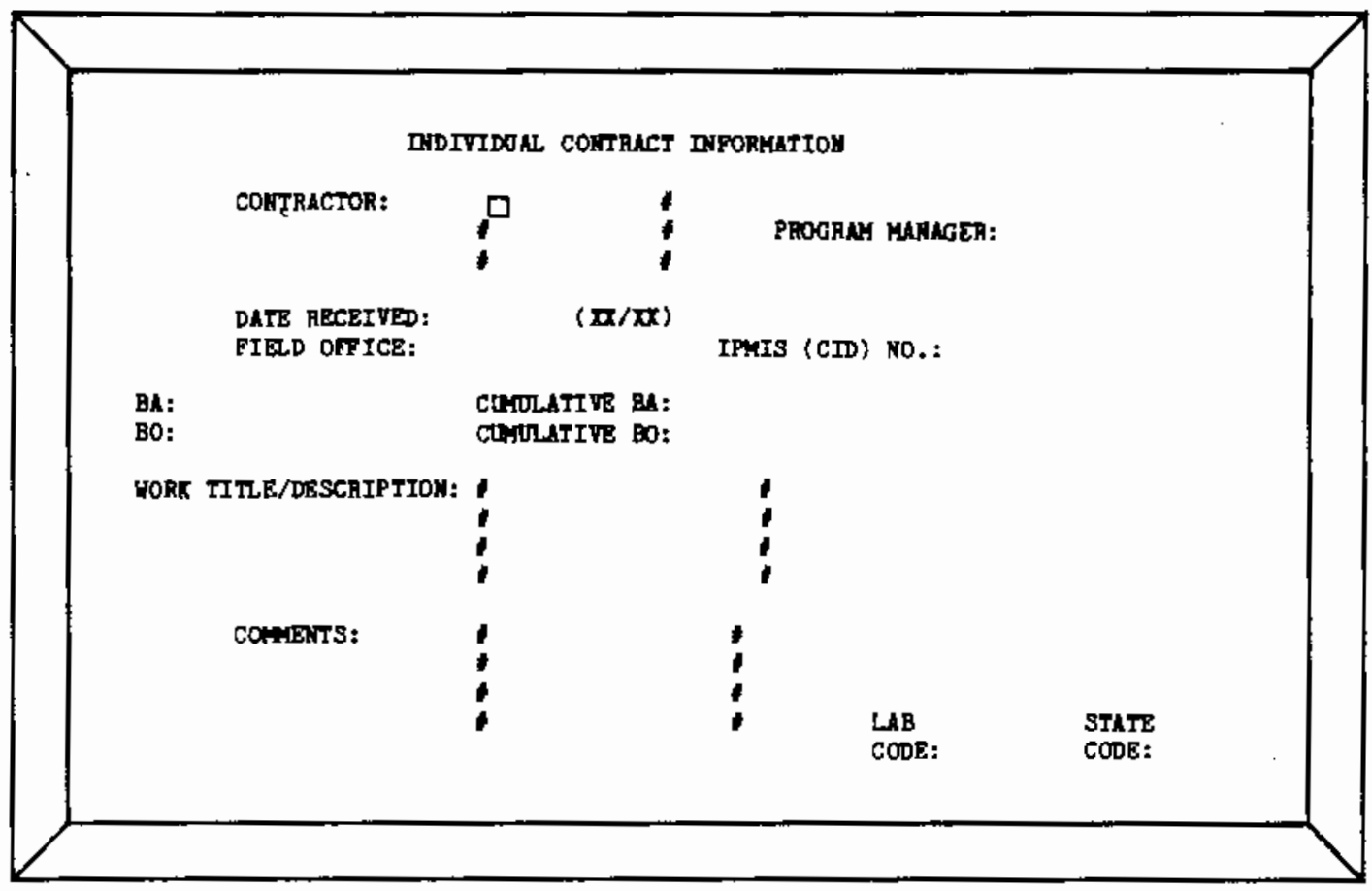

CONTRACTOR

The Contractor's name is entered in one or more of three sub-fields, which are delineated by the hash marks (\#'s) on the screen. The hash marks will disappear as the sub-fields are filled. Information entered here will appear in the same format on the ECORLOG reports, so words should not be split between lines unless they are hyphenated. Enter the name of the CONTRACTOR, pressing FIELD REL at the end of each subfieid. Note, though, that if the entire sub-field is filled, the cursor moves to the beginning of the next sub-field. Pressing FIELD REL fills unneeded sub-fields with bianks. 
a. Enter 'OAK RIDGE NATIONAL LABORATORY' in the CONTRACTOR field. Do not press FIELD REL until you are finished.

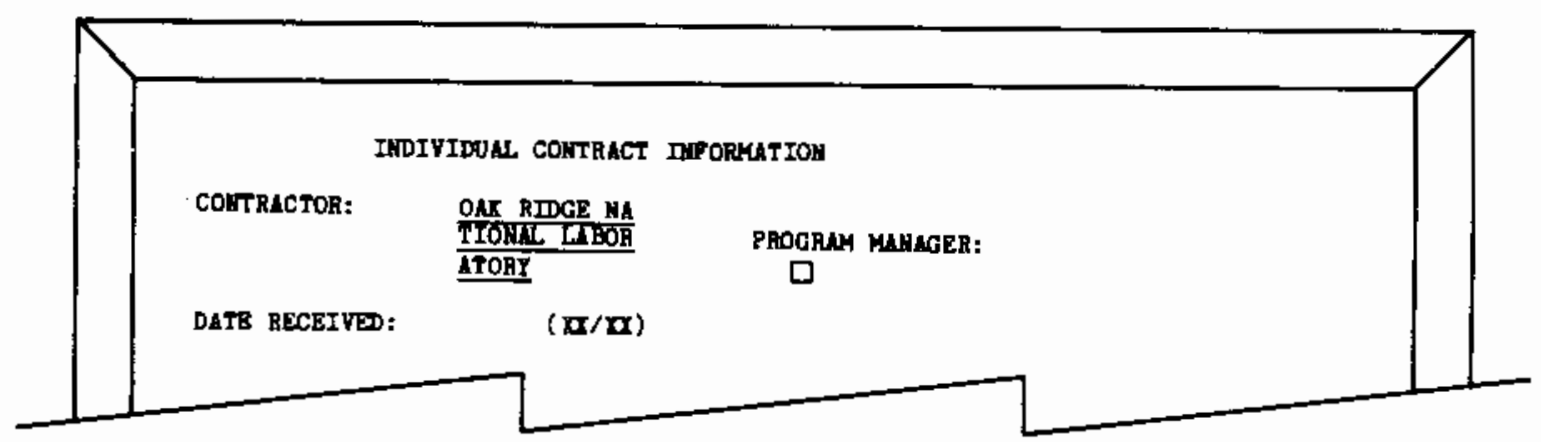

b. Since the CONTRACTDR field will print out the same way it was entered, it should be changed so that the words break at the sub-fields. Use the left arrow to move the cursor backward. Stop when the cursor is positioned between 'RIDGE' and 'NA'.

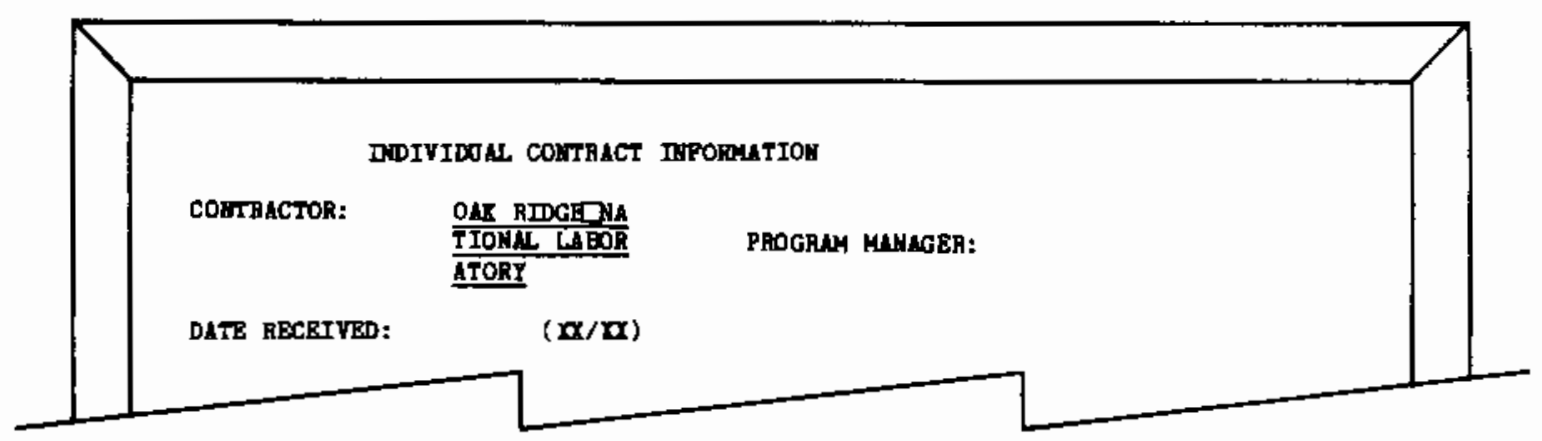

c. Press FIELD REL. Notice that the 'NA' has been erased from the first subfield, and that the cursor is now positioned at the beginning of the second sub-field.

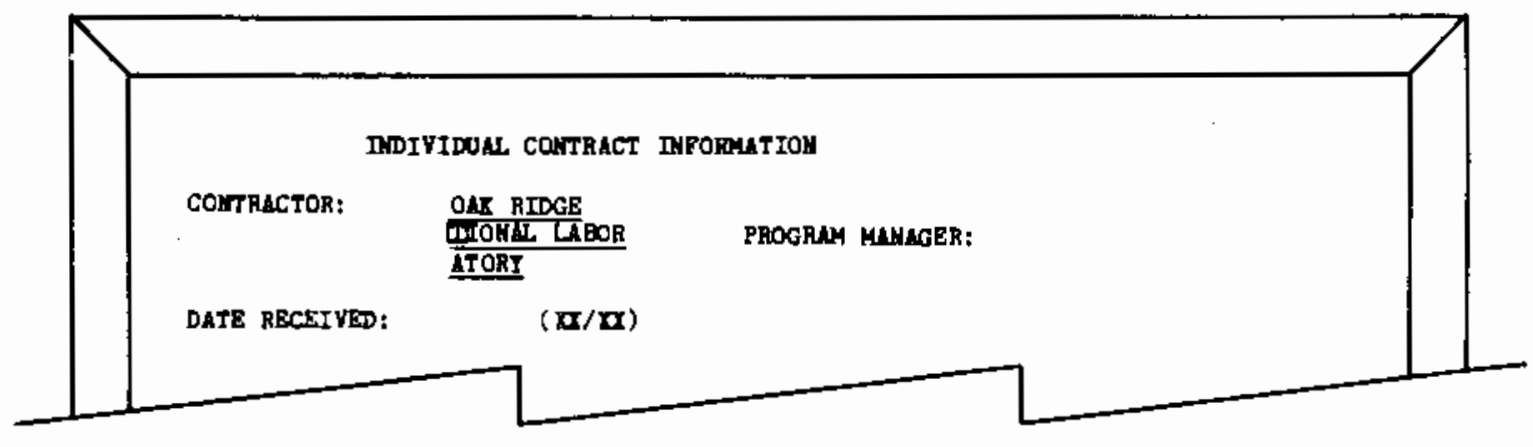


d. Enter 'NATIONAL'. The cursor is now positioned over the third 'A' in the second sub-field.

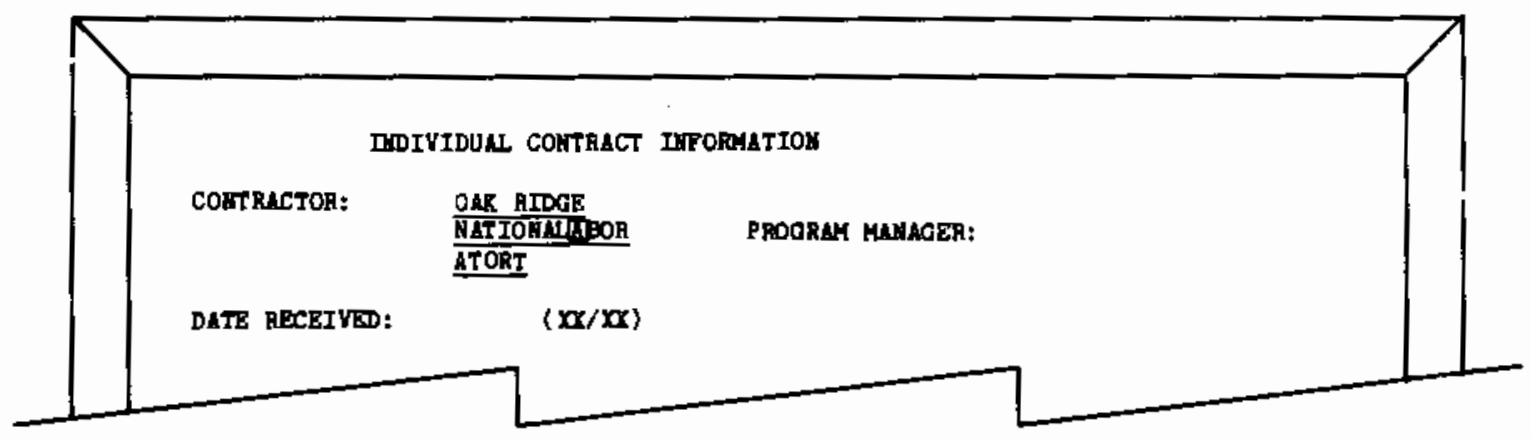

e. Press FIELD REL. 'ABOR' is erased from the screen, and the cursor is now positioned at the beginning of the third sub-field.

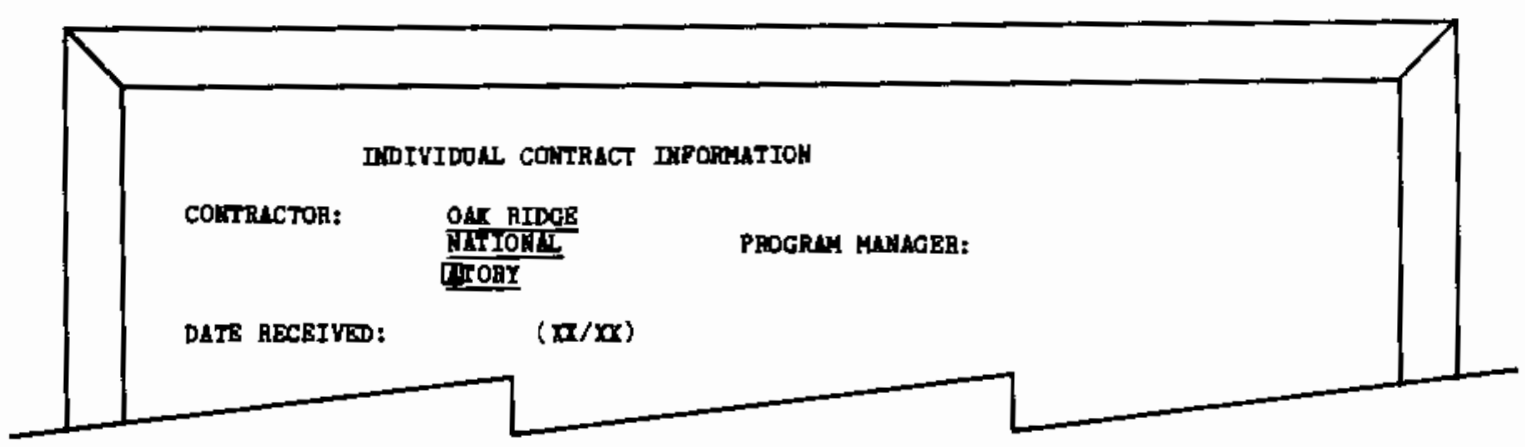

f. Enter 'LABORATORY' and press FIELD REL. The CONTRACTOR entry is now properly aligned for output in a report.

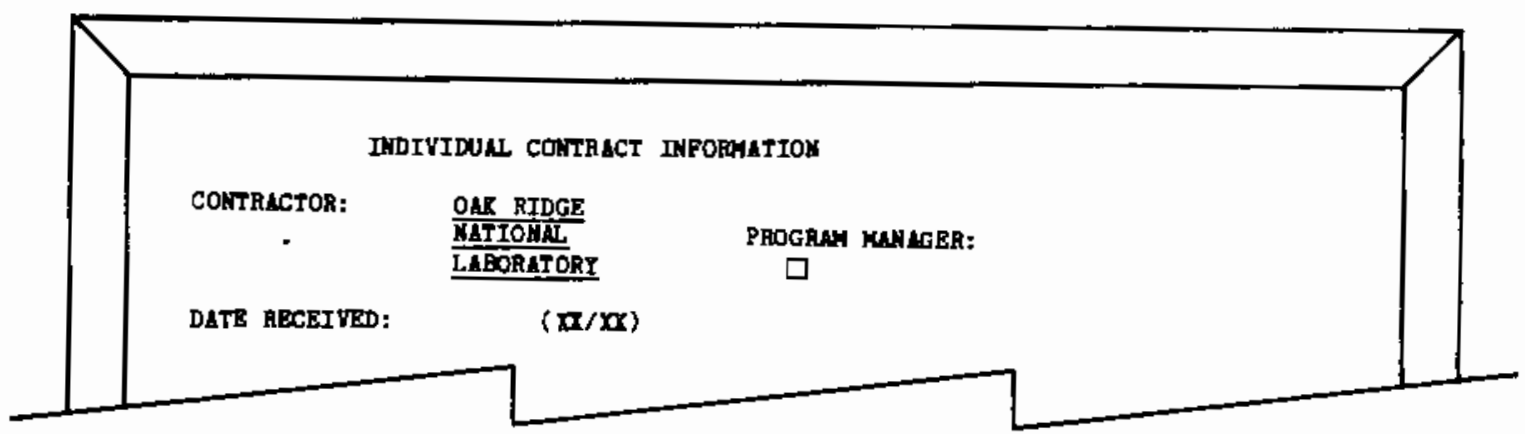


PROGRAM MANAGER

Enter the last name of the PROGRAM MANAGER for the work performed under the procurement, and press FIELD REL.

\section{EXAMPLE 13. PROGRAM MANAGER FIELD}

a. Enter 'KLEIN' in the PROGRAM MANAGER fieid, and press FIELD REL.

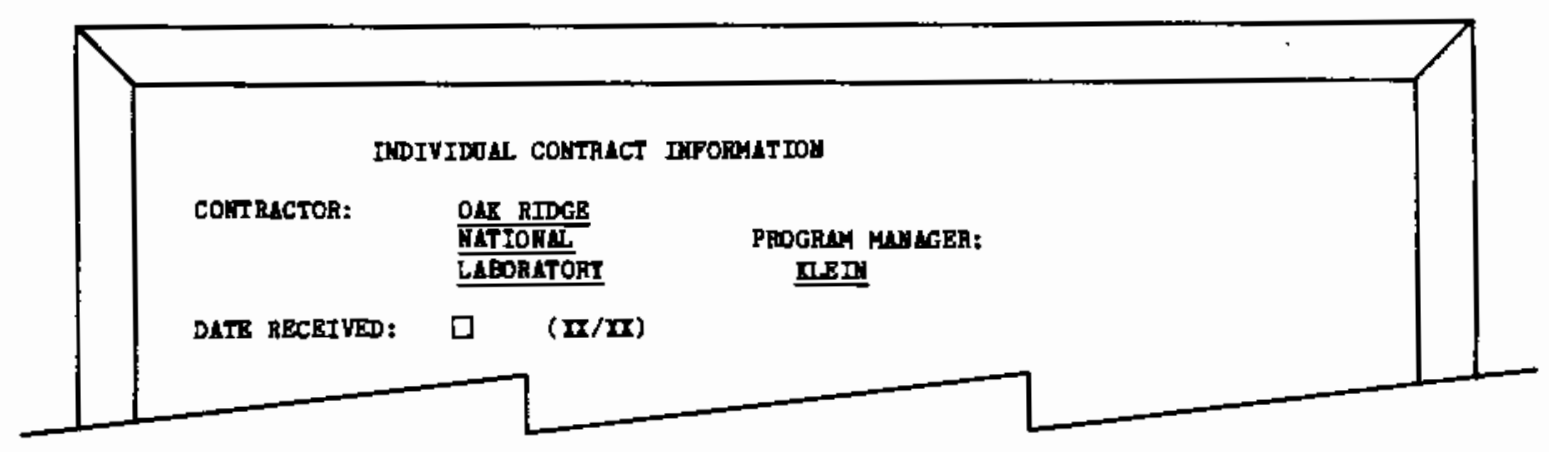

\section{DATE RECEIVED}

As indicated on the screen, the DATE RECEIVED field should be entered as $' X X / X X '$. The slash between the first two digits (the month) and the second two digits (the day) will be generated automatically after the two digits for the month are entered. Two digits must be used for the month, and two for the day; after each two digits are entered, the cursor moves to the next data entry position on the screen. If there is no date to record, hitting FIELD REL for each field will result in blanks (the slash will still be generated). Alternatively, pressing the white-lettered ? key at the top of the keyboard will fill these fields with question marks.

EXAMPLE 14. DATE RECEIVED FIELD

a. Enter ' 9 ' and press FIELD REL.

Status Line: NOT VALID DATA

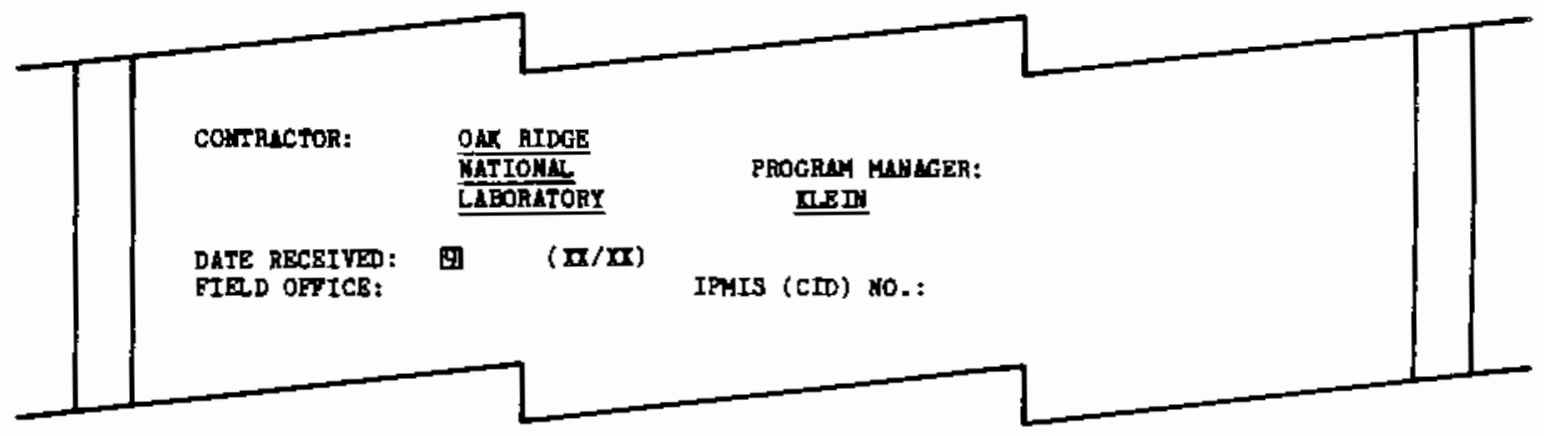


b. The error message flashes on the screen because only one digit was entered. Unlock the terminal by pressing SHIFT and CORR REST

simultaneously. Enter '09'. A slash appears to the right of ' 09 ' and the cursor is positioned in the next column.

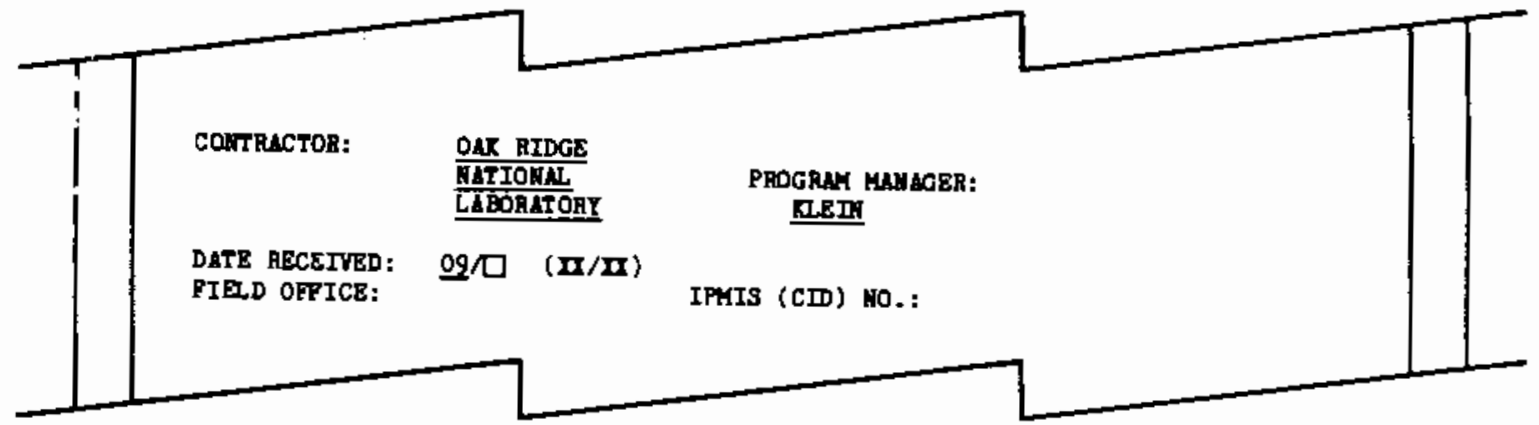

c. Enter ' 20 ' for the day. DATE RECEIVED has now been completed, and the cursor moves to the next field.

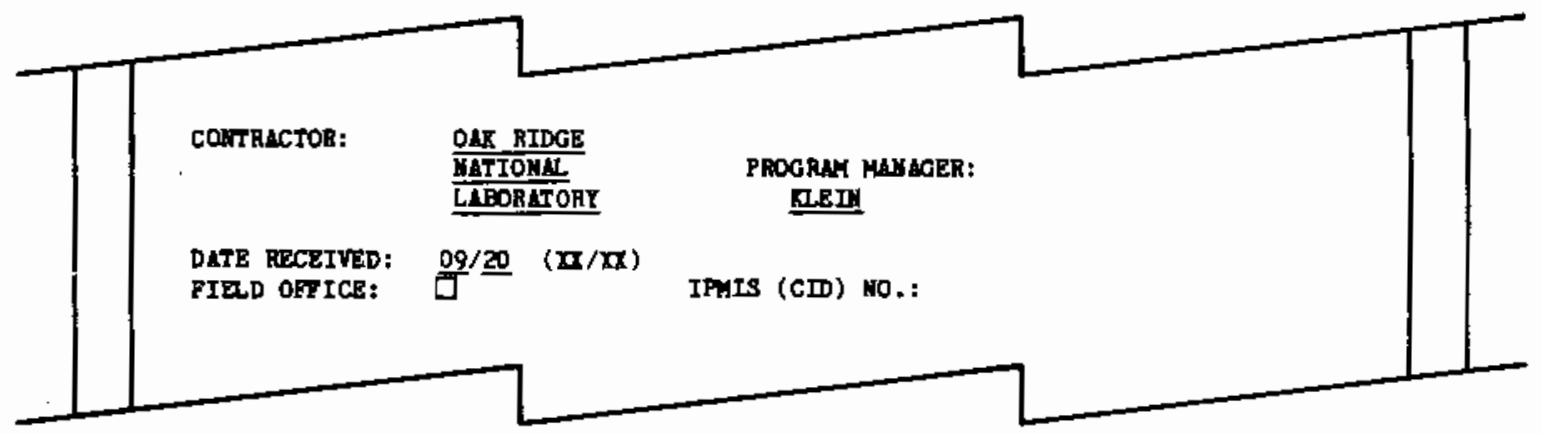

FIELD OFFICE (FO)

Here, a code is entered to indicate the Department of Energy FIELD OFFICE under which the procurement falls. If less than four characters are entered, press FIELD REL to proceed to the next field. If four characters are entered, the cursor will move to the next field automatically. Select a FIELD OFFICE code from the following list.

$\begin{array}{ll}\text { ALO } & \text { Albuquerque Operations Office } \\ \text { CHO } & \text { Chicago Operations Office } \\ \text { GJAO } & \text { Grand Junction Area Office } \\ \text { IDO } & \text { Idaho Operations Office } \\ \text { NVO } & \text { Nevada Operations Office } \\ \text { ORO } & \text { Oak Ridge Operations Office } \\ \text { RLO } & \text { Richland Operations Office } \\ \text { SFO } & \text { San Francisco Operations Office } \\ \text { WHO } & \text { DOE Headquarters/Washington Office }\end{array}$


EXAMPLE 15. FIELO DFFICE FIELD

a. Enter 'ORO' as the FIELD OFFICE, and press FIELO REL.

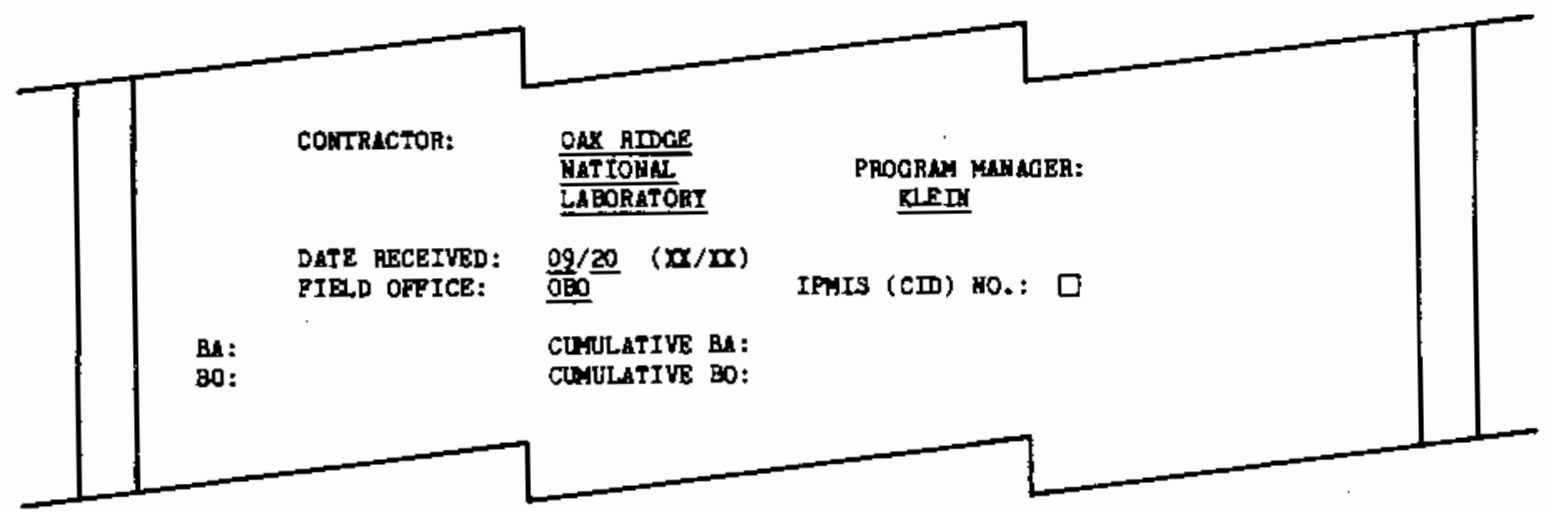

IPMIS (CIO) \#

Not all procurements have an IPMIS (CID, or CONTRACT IDENTIFICATION)

NUMBER. If there is no IPMIS NUMBER, press FIELD REL to proceed to the next field. If there is an IPMIS NUMBER associated with the procurement, enter its seven digits; the cursor will move to the next field.

\section{EXAMPLE 16. IPMIS NUMBER FIELD}

a. Enter 'OR12345' as the IPMIS NUMBER. The cursor moves to the next field.

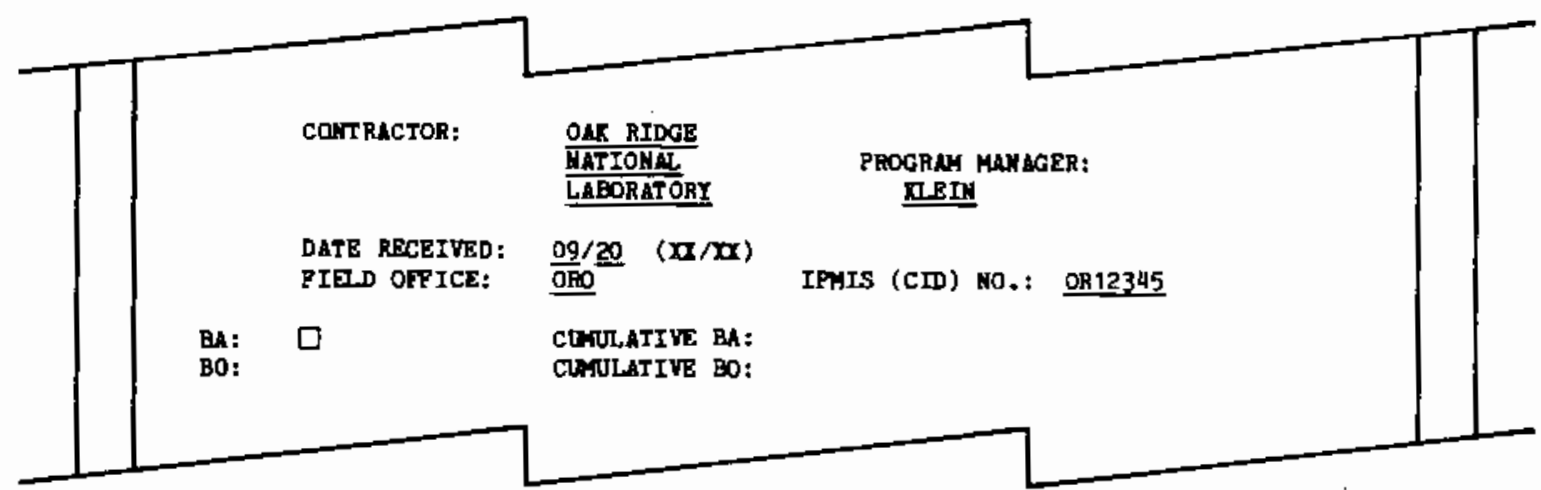


BA (BUDGET AUTHORITY)

This field will contain the BUDGET AUTHORITY (BA) amount for the procurement action. The BA field (as we 11 as CUMULATIVE BA, BO, and CUMULATIVE BO in Program Level Two Records) is a Numeric type field. The oniy characters which cannot be entered into numeric fields are the alphabetic characters $A-Z$. Thus, you can enter commas and negative signs into numeric fields such as BA (BUDGET AUTHORITY). If the amount is negative, enter the negative sign before the number. Enter the BUDGET AUTHORITY anount for the procurement, and press FIELD REL to complete the field.

\section{EXAMPLE 17. BUDGET AUTHORITY (BA) FIELD}

a. Enter ' 700 ' in the $B A$ field. Enter ' $M$ ' instead of the comma which should come next. The ' $M$ ' will not appear on the screen.

Status Line: $\quad$ A-Z NOT ALLOWED

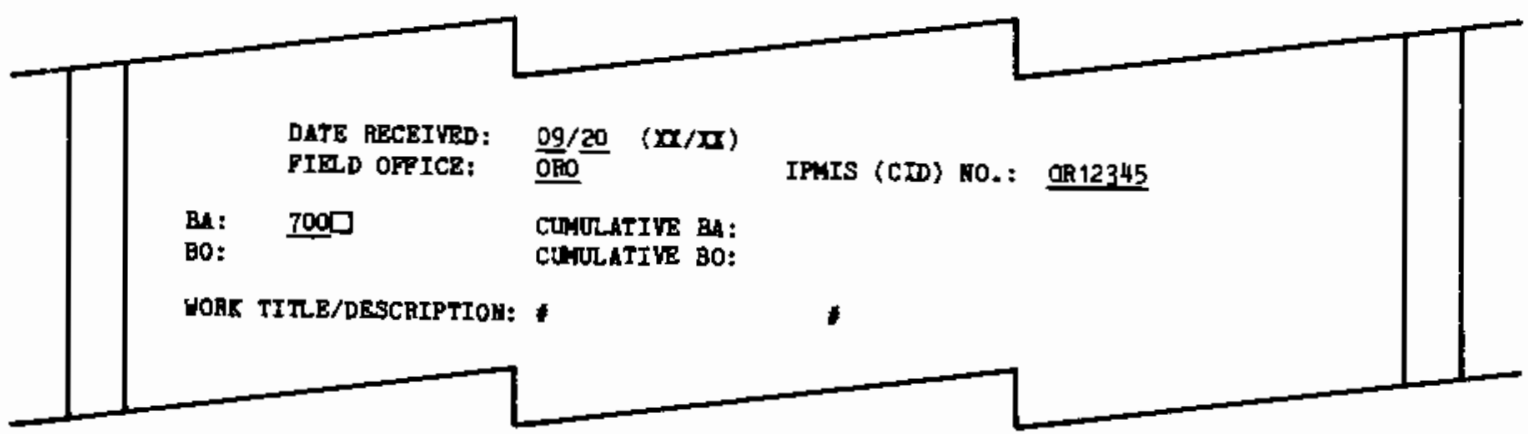

b. The error message displays on the screen because alphabetic characters cannot be entered in Numeric fields. To un lock the terminal, press SHIFT and CORR REST simultaneously. Enter ',000', but do not press FIELD REL.

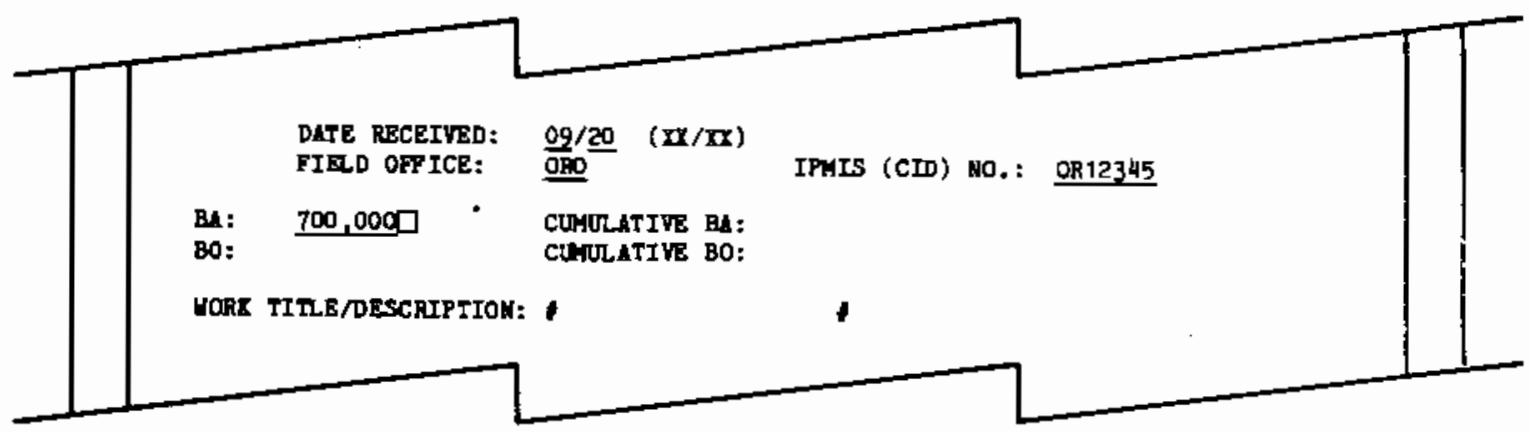


CUMULATIVE BA

CUMULATIVE $8 A$ will contain the total of all the BA amounts entered in Program Level Two Records up to and including the current Record.

CUMULATIVE BA is not entered at the terminal now, but is generated later by

the ECORUP program (Section 4.1). When FIELD REL is pressed after entering

the BA field, the cursor skips over CUMULATIVE BA and moves to the BO field.

\section{EXAMPLE 18. CUMULAT IVE BA FIELD}

a. Press FIELD REL at the end of the BA field. The cursor skips over CUMULATIVE $B A$ and moves to the $B O$ field.

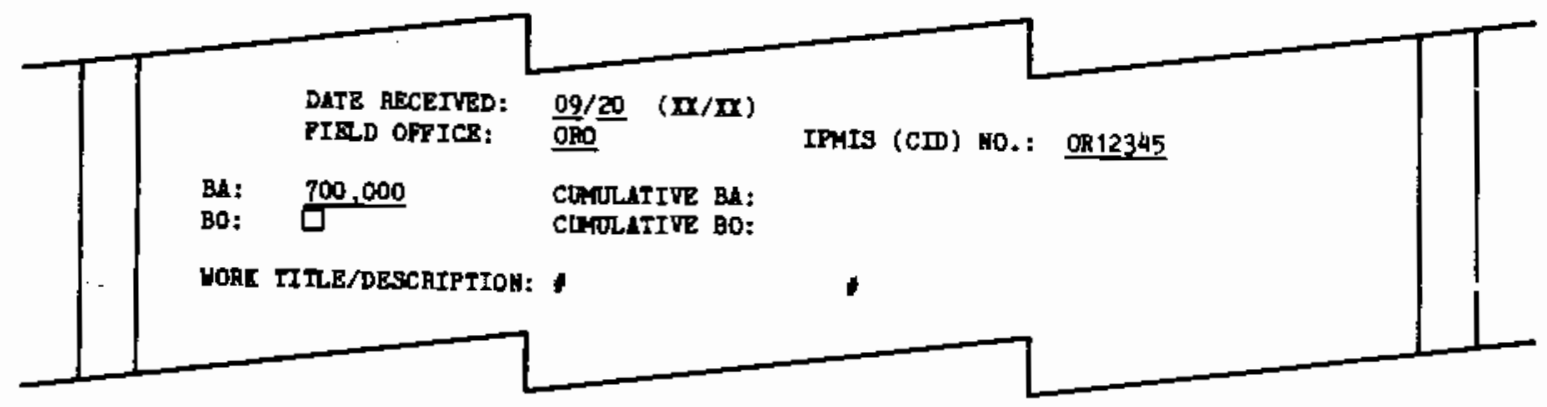

BO (BUDGET OBLIGATION)

This field will contain the BUDGET OBLIGATION (BO) amount for the procurement action. Like $B A, B O$ is a Numeric type field, in which anything except alphabetic characters can be entered. Enter the BUDGET OBLIGATION amount, using commas and a preceeding negative sign if necessary. Press FIELD REL to complete the field.

EXAMPLE 19. BUDGET OBLIGATION (BO) FIELD

a. Enter ' $700,000 '$ in the BO (BUDGET OBLIGATION) field. Do not press FIELD REL.

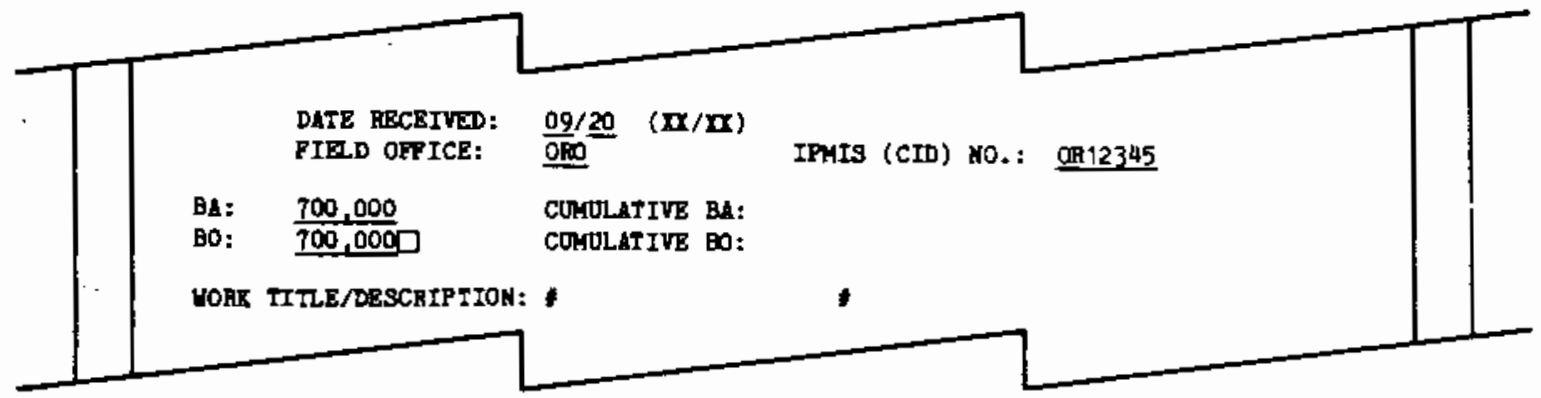




\section{CUMULATIVE BO}

CUMULATIVE BO will contain the total of all BO amounts entered in Program Leve] Two Records up to and including the current Record. Like cumulative $B A$, it is generated by the ECORUP program instead of being entered at the terminal. When FIELD REL is pressed after entering the Bo field, the cursor skips over CUMULATIVE 80 and moves to the next field.

\section{EXAMPLE 20. CUMULATIVE BO FIELD}

a. Press FIELD REL to complete the BO field. The cursor skips over CUMULATIVE $B O$ and moves to the WORK TITLE/DESCRIPTION field.

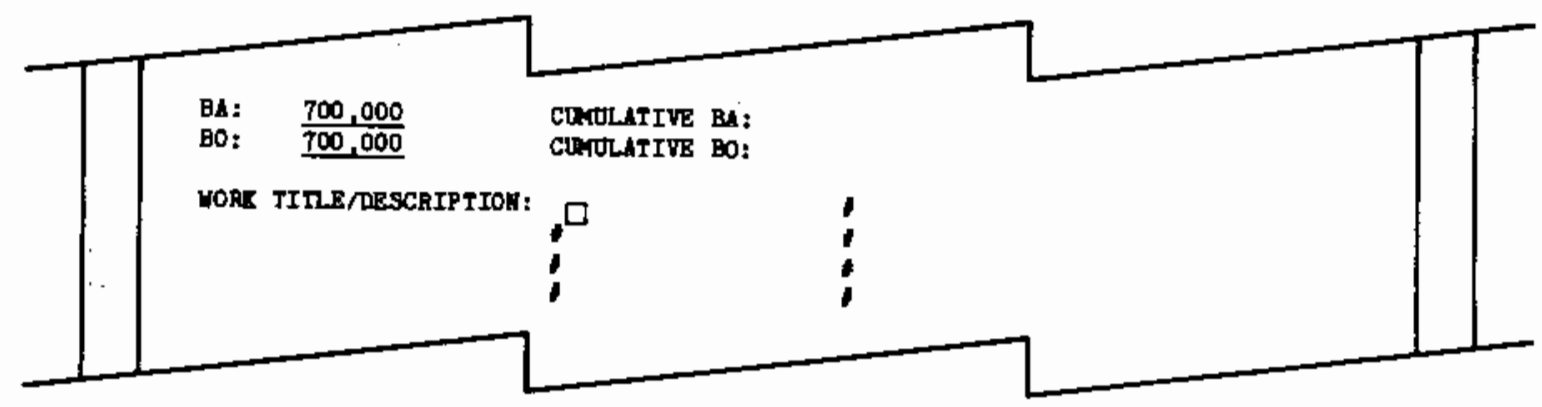

WORK TITLE/DESCRIPTION

The WORK TITLE/DESCRIPTION field is made up of four sub-fields, which are outlined by hash marks (\#'s), similar to the CONTRACTOR field. The hash marks will disappear as the sub-fields are filled. The information entered here appears in the same report format as it does on the screen. Words should not be split between lines unless they are hyphenated. Enter the WORK TITLE/DESCRIPTION information for the procurement, pressing FIELD REL at the end of each subfield. If an entire sub-field is filled, the cursor moves to the beginning of the next sub-field. Pressing FIELD REL will fill unneeded sub-fields with blanks. 


\section{EXAMPLE 21. WORK TITLE/DESCRIPTION FIELD}

a. Enter 'ELECTROMAGNETIC' in the first WORK TITLE/DESCRIPTION sub-fie id. Press FIELD REL -- the hash marks at the end of the first sub-field and at the beginning of the second sub-field are erased from the screen, and the cursor moves to the second sub-field. Enter 'PULSE'.

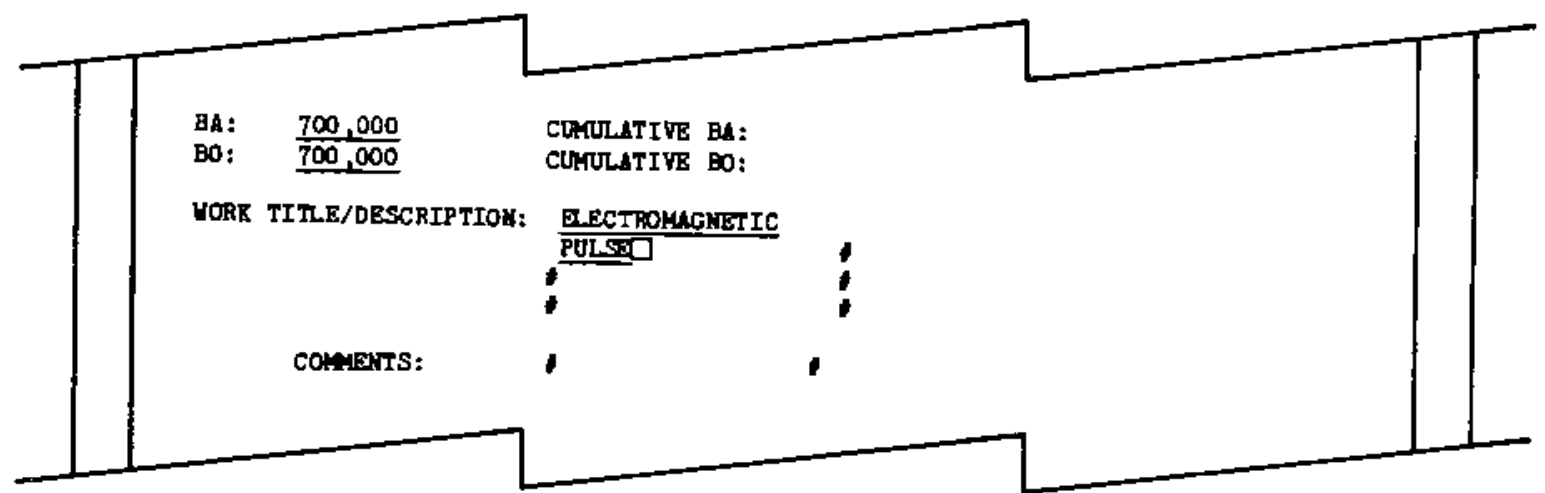

b. Press FIELD REL. The hash marks at the end of the second sub-field and the beginning of the third sub-field are erased, and the cursor moves to the third sub-field.

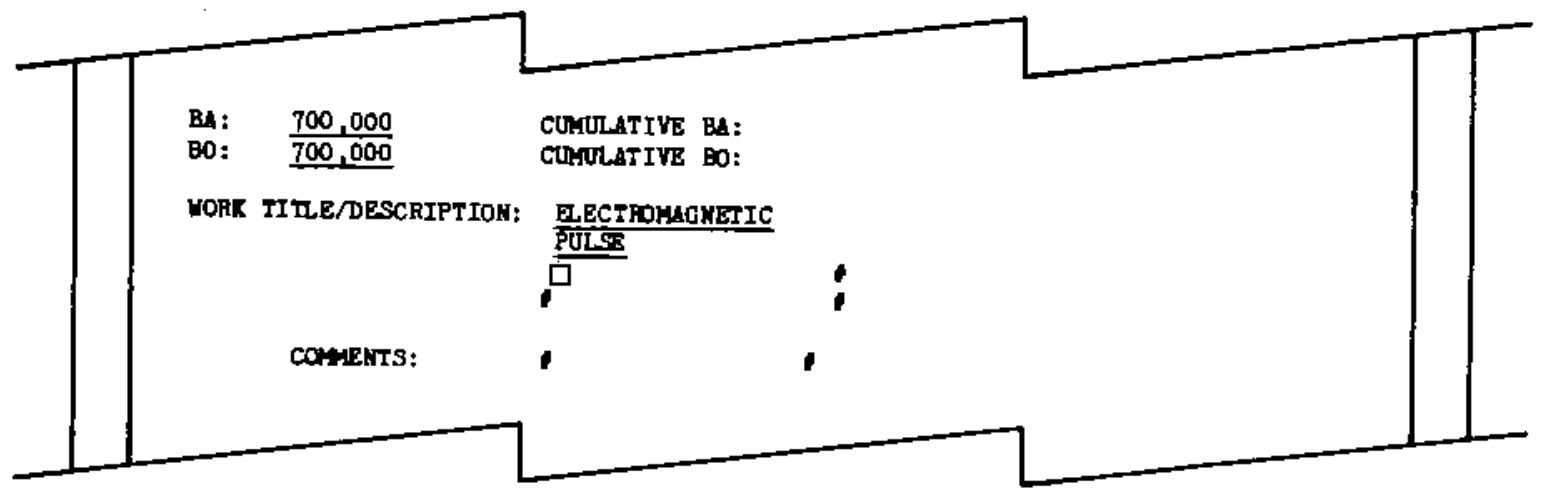


c. Press FIELD REL again to bypass the third sub-field. Two more hash marks disappear, and the cursor moves to the fourth and last sub-field.

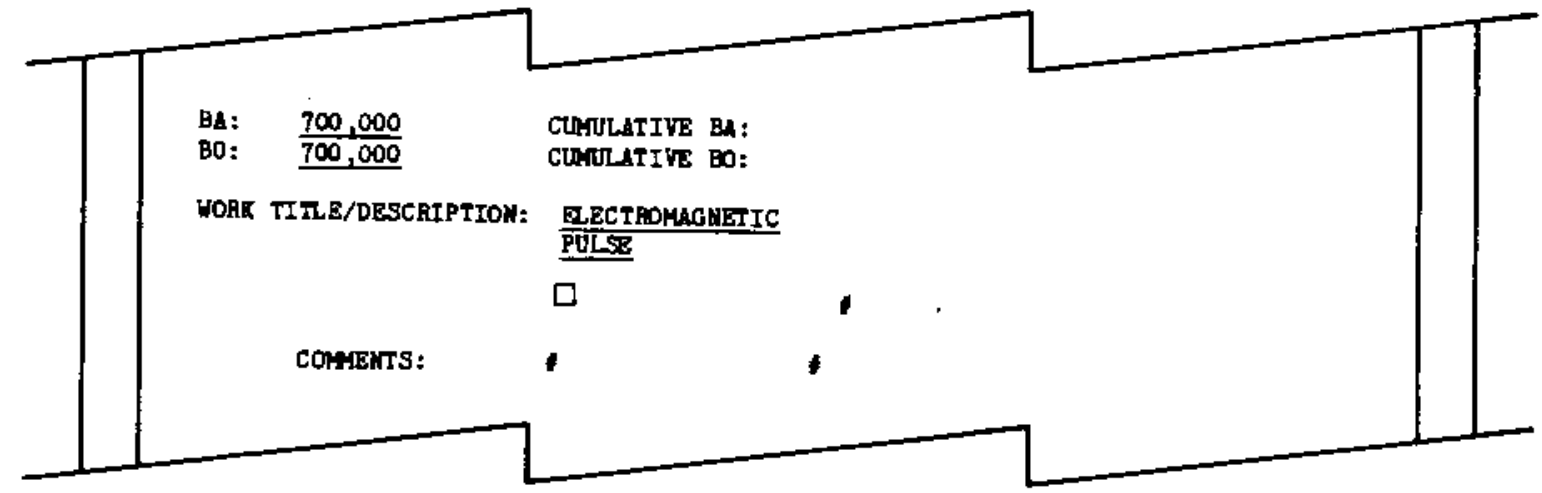

d. Press FIELD REL. The hash mark at the end of the fourth sub-field, and that at the beginning of the first COMMENTS sub-field, now disappear from the screen. The cursor moves to the first sub-field of the COMMENTS field.

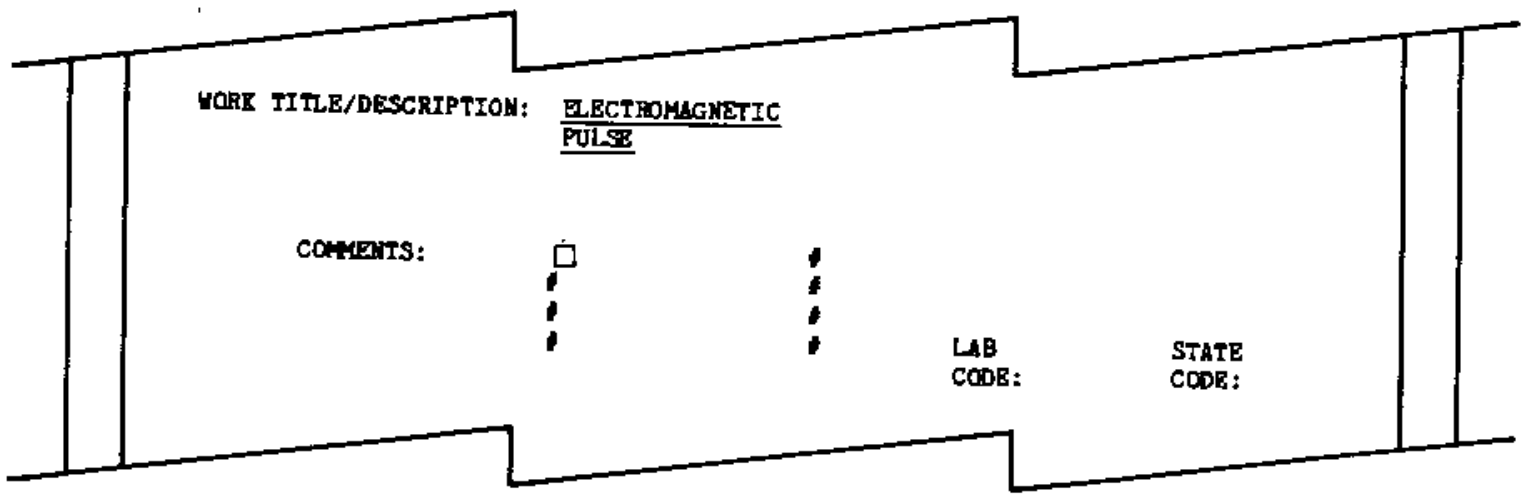

COMMENTS

Actions taken regarding the procurement are entered here. Like the WORK TITLE/DESCRIPTION field, COMMENTS contains four sub-fields outlined by hash marks (\#'s). As for WORK TITLE/DESCRIPTION, do not split words between COMMENTS sub-fields without hyphenating them, and press FIELD REL to skip sub-fields. 
a. Enter 'TO DIR 9/22' in the first COMMENTS sub-field, and press FIELD REL. Enter 'TO DASC $9 / 27^{\prime}$ in the second sub-field, and press FIELD REL again. Enter 'TO LAB $11 / 3 / 84$ ' in the third sub-field.

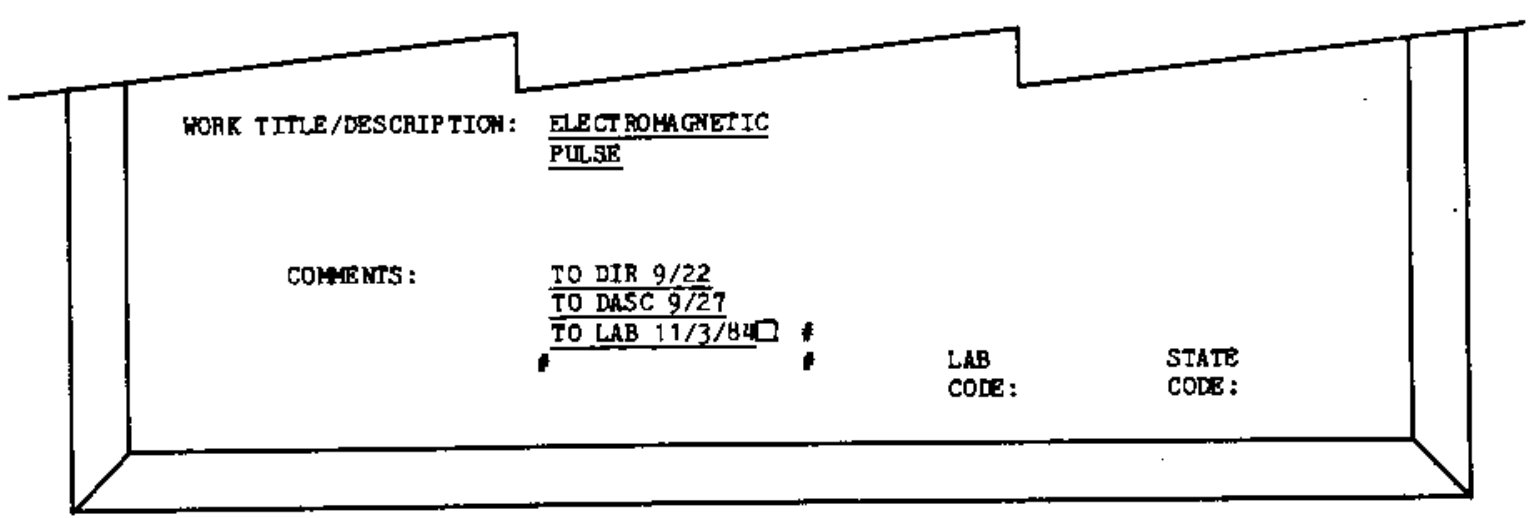

b. Press FIELD REL, and watch two of the remaining hash marks fade from the screen. Press FIELD REL a final time to complete the COMMENTS field. The cursor moves to the next field.

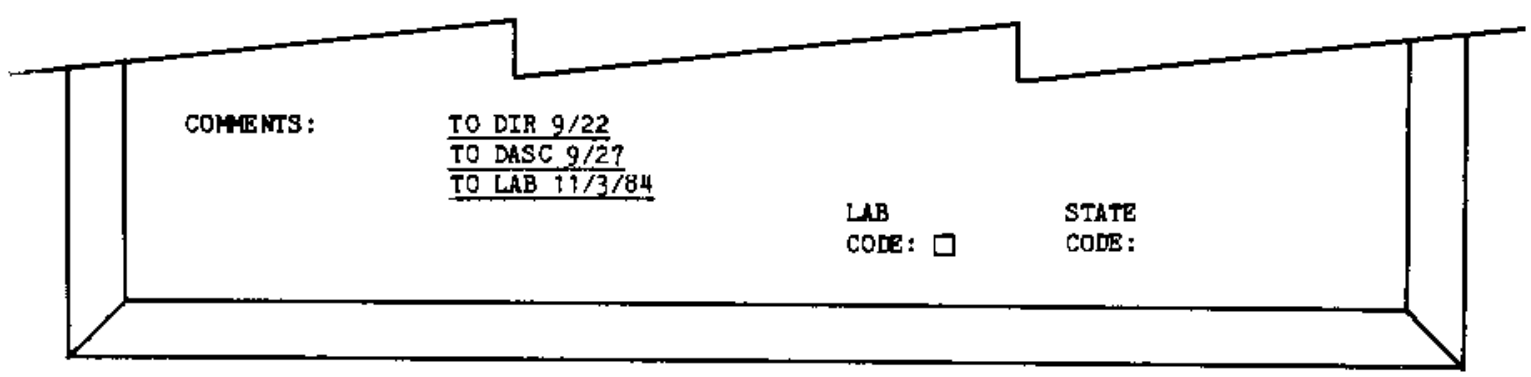

LAB CODE

A three or four digit code is entered here to indicate the Department of Energy Laboratory performing work under the procurement. If less than four characters are entered, press FIELO REL to proceed to the next field. If four characters are entered, the cursor will move to the next field automatically. Select a LAB CODE from the list below.

$\begin{array}{ll}\text { ANL } & \text { Argonne National Laboratory } \\ \text { BNL } & \text { Brookhaven National Laboratory } \\ \text { LANL } & \text { Los Alamos National Laboratory } \\ \text { ORNL } & \text { Oak Ridge National Laboratory } \\ \text { PNL } & \text { Pacific Northwest Laboratory } \\ \text { SNL } & \text { Sandia National Laboratories } \\ \text { SNLL } & \text { Sandia National Laboratories, Livermore } \\ \text { LBL } & \text { Lawrence Berkeley Laboratories } \\ \text { LLL } & \text { Lawrence Livermore Laboratories }\end{array}$


EXAMPLE 23. LAB CODE FIELD

a. Enter 'ORNL' as the LAB CODE. The cursor moves to the next field.

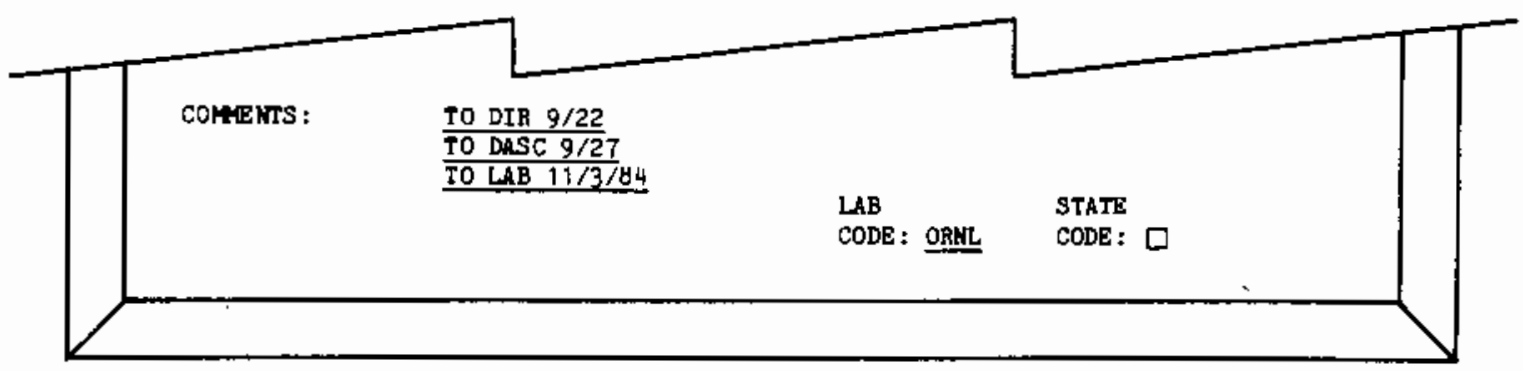

STATE CODE

This is a two-character field for entering the state in which work under the procurement is being performed. It may be left blank. If you do enter anything in this field, the computer checks your entry against a list of the standard postal abbreviations, and displays a flashing error message if the entry matches nothing in the 7 ist. ' $99^{\prime}$ 'can also be entered, and should be used if the work will be done outside of the fifty states and the District of Columbia. The standard postal abbreviations are given be low. Once the two-digit abbreviation is entered for STATE CODE (the last field in the Record), the Record is complete and a new, blank INDIVIDUAL CONTRACT INFORMATION screen will be displayed.

\begin{tabular}{|c|c|c|c|c|}
\hline Alabama & LA & Louisiana & $\mathrm{OH}$ & Ohio \\
\hline Alaska & ME & Maine & OK & Ok lahoma \\
\hline Arizona & MD & Mary 1 and & OR & Oregon \\
\hline Arkans as & MA & Massachusetts & PA & Pennsylvania \\
\hline California & MI & Michigan & RI & Rhode Is land \\
\hline Colorado & MN & Minnesota & SC & South Carolina \\
\hline Connecticut & MS & Mississippi & SD & South Dakota \\
\hline Delaware & MO & Missouri & TN & Tennessee \\
\hline Florida & MT & Montana & TX & Texas \\
\hline Georgia & NE & Nebraska & UT & Ut ah \\
\hline Hawai & NV & Nevada & VT & Vermont \\
\hline Idaho & $\mathrm{NH}$ & New Hampshire & VA & Virginia \\
\hline Illino is & NJ & New Jersey & WA & Washington \\
\hline Indiana & NM & New Mexico & WV & West Virginia \\
\hline Iowa & NY & New York & WI & Wisconsin \\
\hline Kans as & NC & North Carolina & WY & Wyoming \\
\hline Kent ucky & $\begin{array}{l}\text { ND } \\
99\end{array}$ & $\begin{array}{l}\text { North Dakota } \\
\text { Other }\end{array}$ & DC & District of Columbia \\
\hline
\end{tabular}


EXAMPLE 24. STATE CODE FIELD

a. Enter 'TE' in the STATE CODE field. Do not press FIELD REL.

Status Line: $\quad$ USE POSTAL ABBREVIATIONS - '99' FOR FOREIGN

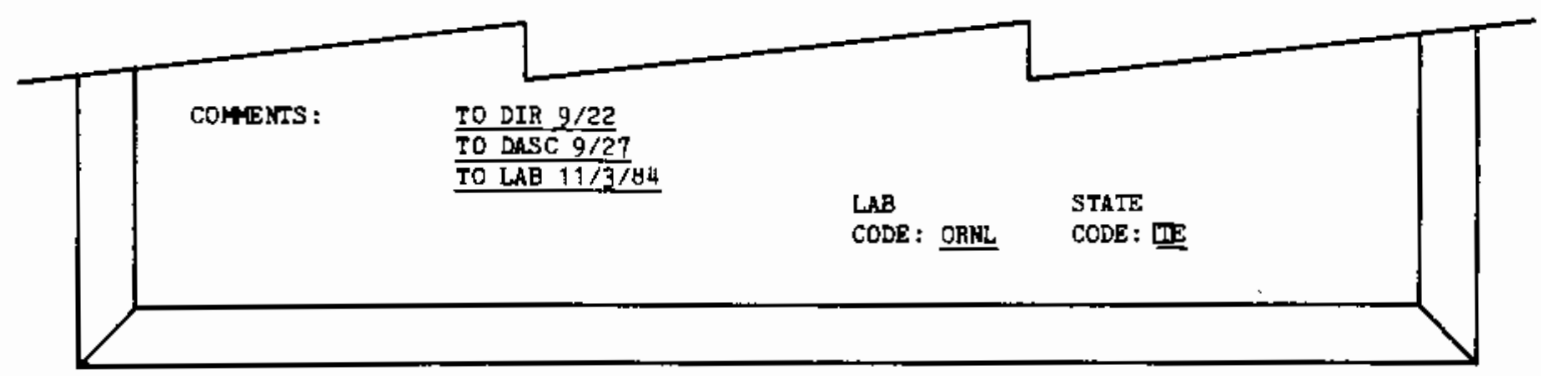

b. The Status Line message flashes on the screen because ' $T E$ ' is not a standard postal abbreviation. Press SHIFT and CORR REST together to un Tock the terminal. Enter 'TN'. The Record is now considered complete, and a blank INDIVIDUAL CONTRACT INFORMATION screen will be displayed.

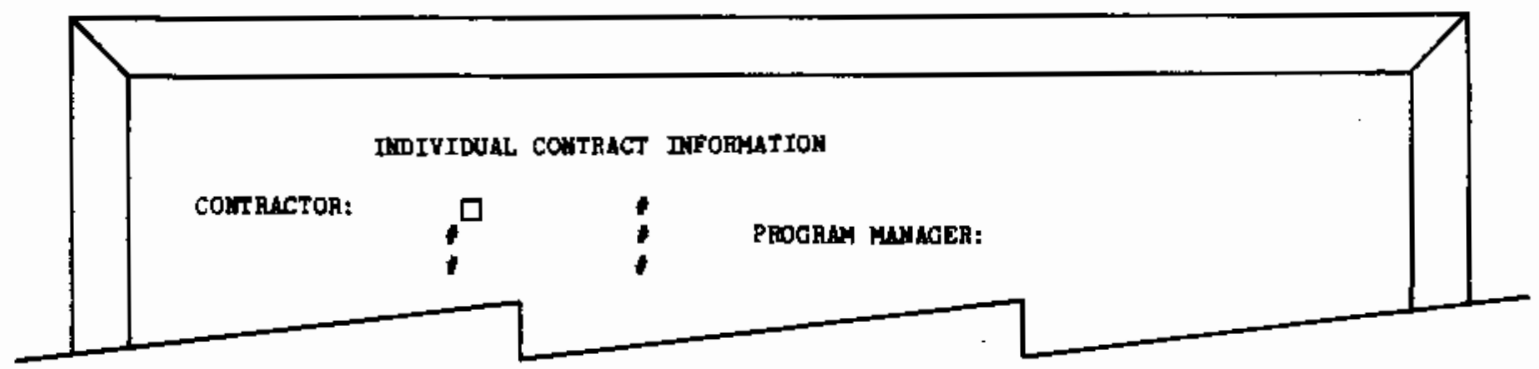


c. Press the up arrow once to review the Program Level Two Record just completed.

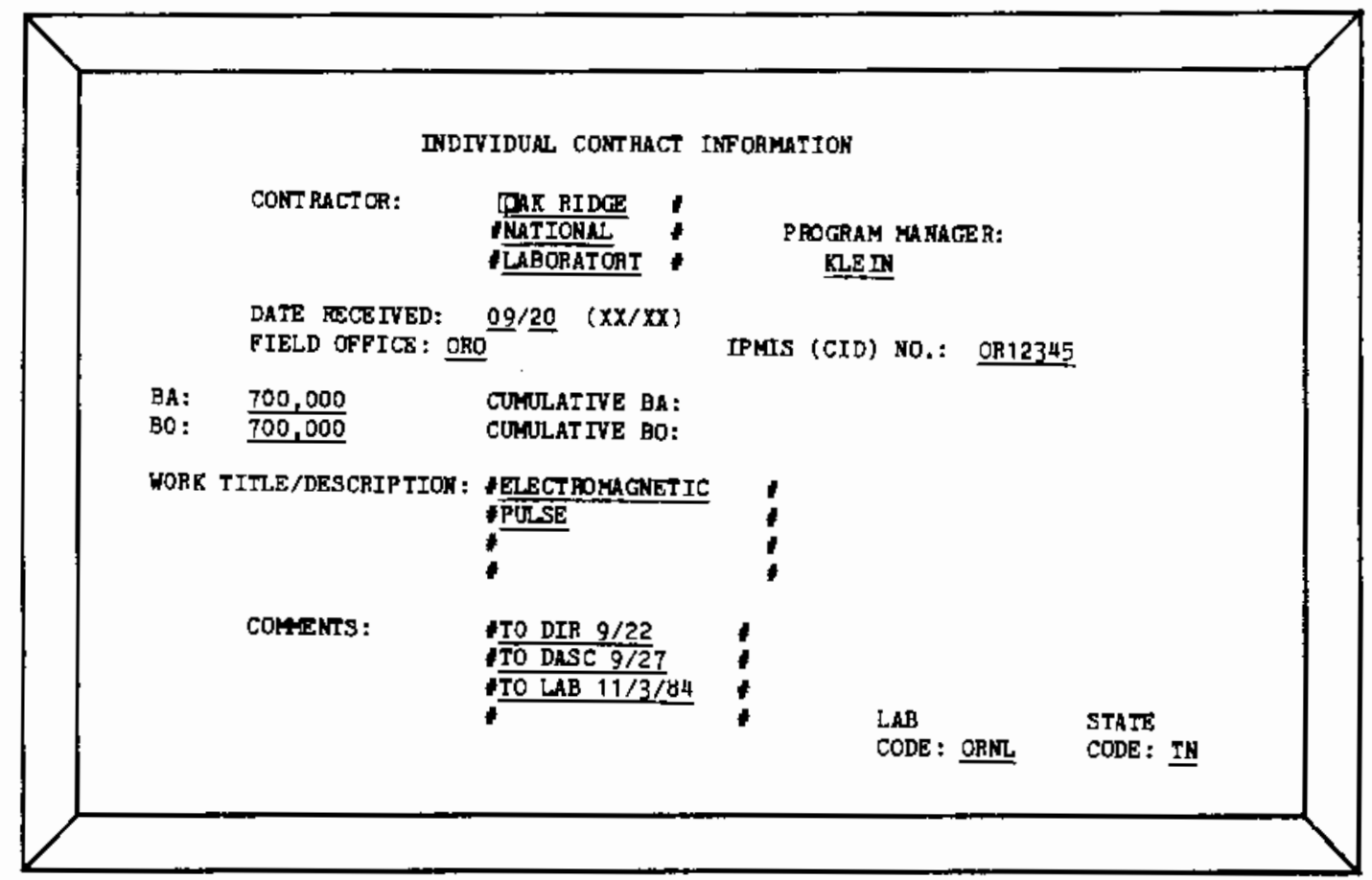

d. Press the down arrow once to return to the blank individual contract information screen.

Blank Program Level Two screens will continue to be displayed after each Record is completed. Continue entering information on indivivdual procurements as described above. When you are finished, you can review your entries by using the up and down arrow keys. The Batch can be exited by pressing the MODE key (MODE $X S$ logs the user out of VISION; following this with CTRL and FIELD REL pressed simultaneously returns the user to the "TYPE C, I, V, S OR ?" prompt, from which typing I returns the user to foreword). 



\subsection{EDITING THE DATA IN ECORLOG BATCHES}

The Records in a Batch of ECORLOG may need to be changed after they have been entered. The contents of various fields may change as the procurement is processed. Records may need to be added to or deleted from a Batch. These common editing operations -- changing, adding, and deleting Records -- are covered in the next sections.

When a Batch is reopened, a blank Program Level One SUMMARY screen, positioned at the end of the Batch, will be displayed on the screen. Before further editing, press either CTRL/up arrow (to go to the beginning of the batch), or the up arrow key (to go back one Record).

The following keys are used to move between Records in a Batch:

1. CTRL/Up arrow -to go to the beginning of a Batch;

2. CTRL/down arrow - to go to the end of a Batch;

3. up arrow - to go back one Record;

4. down arrow - to go forward one Record.

After a Batch is re-edited, the ECORUP program should be run to update the numeric fields in each Record.

\subsection{CHANGING EXISTING RECORDS}

1. Go to the Record to be changed.

2. Pressing SHIFT and CORR REST simultaneously will unlock the Record, which allows changes to be made.

3. To bypass fields without changing them, press AUX DUP. (Exception: DATE RECEIVED fields filled with blanks must be bypassed by pressing FIELD REL; pressing AUX DUP here on ly leads to an error message.)

4. When the cursor is positioned at a field to be changed, key in the new information (pressing FIELD REL if the field is not filled). When the old contents of the field are longer than the new contents, any data not written over will be erased when FIELD REL is pressed.

5. When all corrections have been made, continue to another Record by using the up or down arrow key. 
a. The Batch ' $T 1$ ' has been re-opened by typing MODE E ECORLOG, Tl, and the Record below located using the up arrow key. The WORK TITLE/DESCRIPTION field will be changed from 'MANAGE AND ASSESS TECHNOLOGY' to 'TECHNOLOGY MANAGEMENT AND ASSESSMENT' .

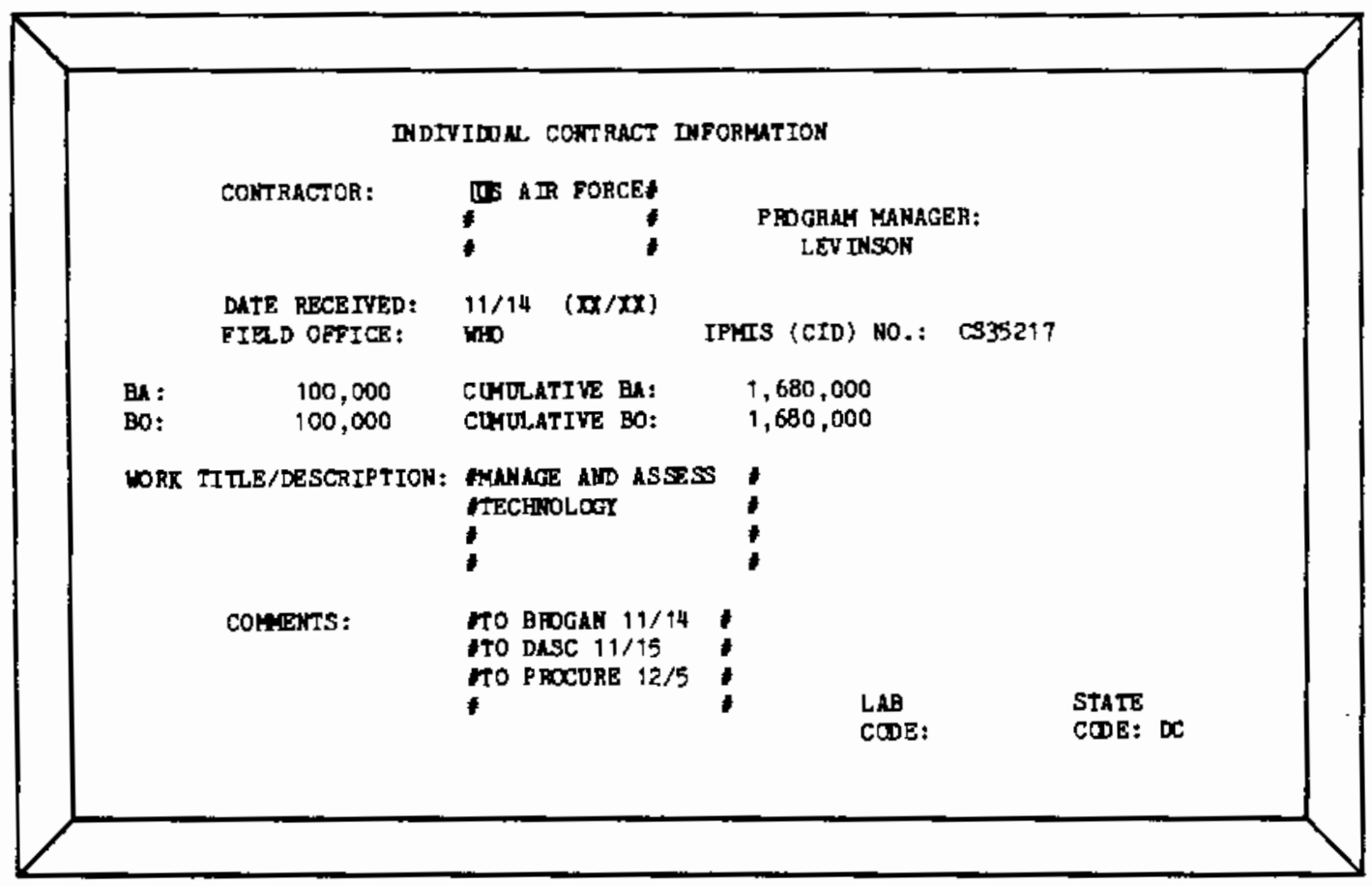


b.

Unlock the Record by pressing SHIFT and CORR REST simulataneous Iy.
Bypass fields by pressing the AUX OUP key unt il the WORK TITLE/DESCRIP.
TION field is reached. AS the BA and BO fields are bypasSed, the
CUMULATIVE BA and CUMULATIVE BO fields will be enased will be erased from the screen.

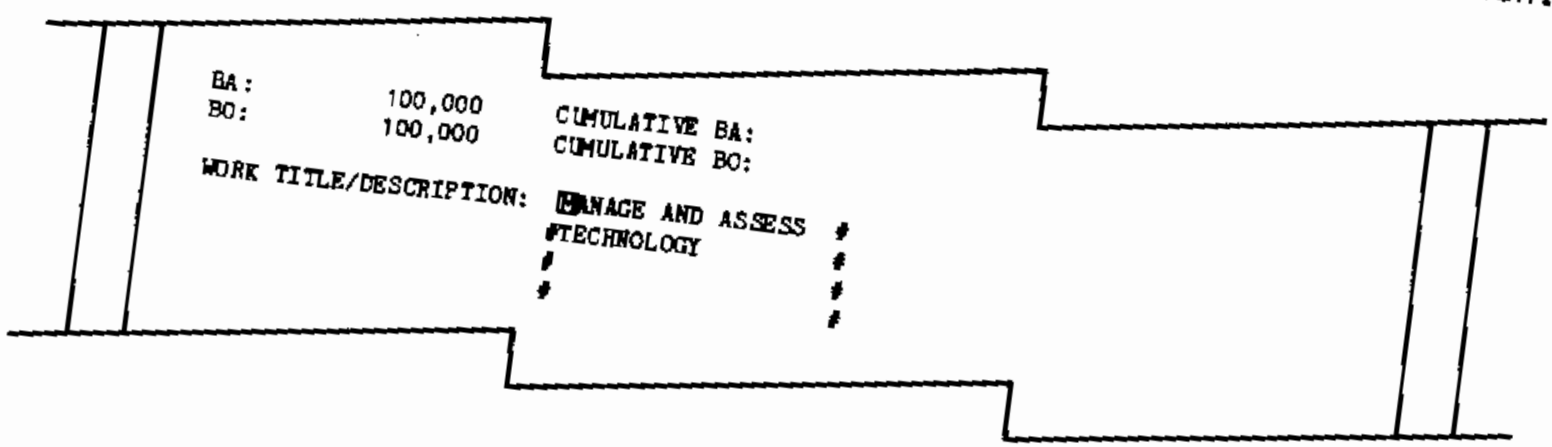

C. Enter 'TECHNOLOGY MANAGE-' as the first line of the field, and press
FIELO REL.

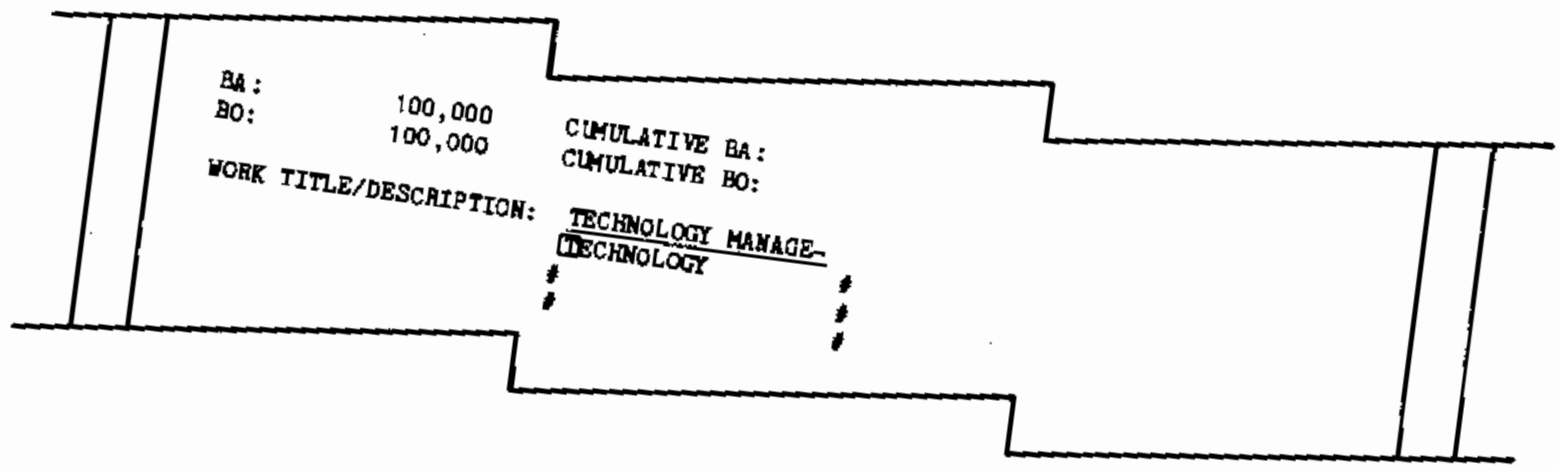

d. Enter 'MENT AND ASSESSMENT'

cursor will move to the next line automatically.

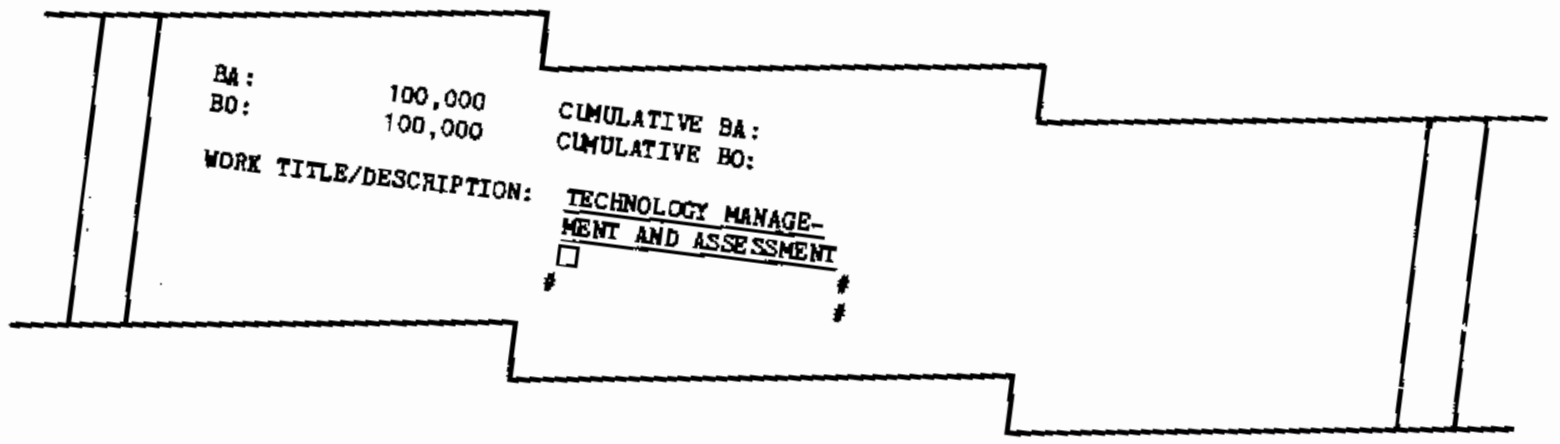


e. At this point, the change is complete. Press the down arrow to go to the next Record, then press the up arrow to go back. Notice that the contents of the COMMENTS and STATE COOE fields have been retained.

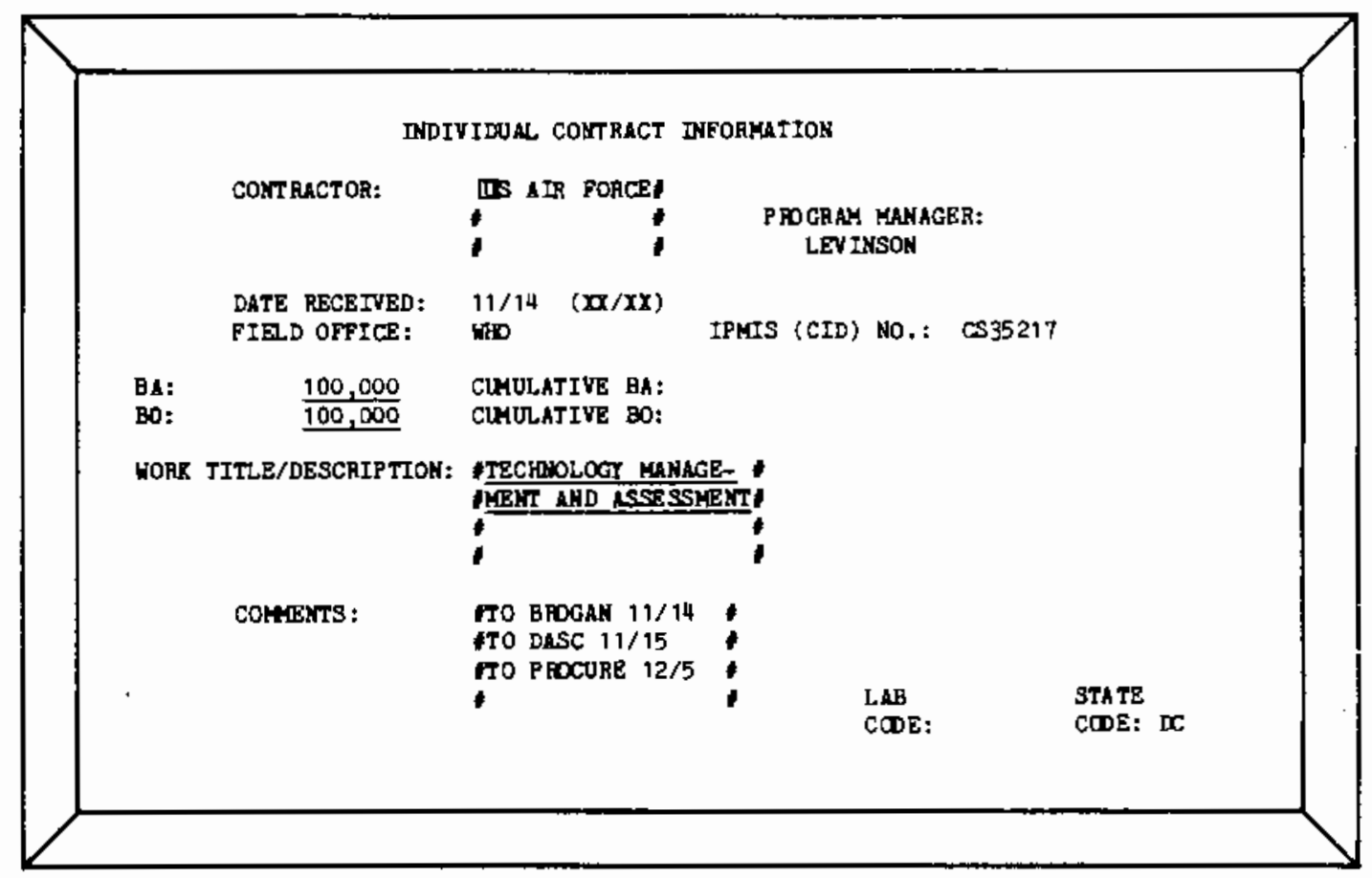

\subsection{ADDING RECORDS TO THE END OF A BATCH}

1. After reentering the Batch, press the up arrow key once and the down arrow key once.

2. A blank INDIVIDUAL CONTRACT screen will be displayed. New Records can then be added to the end of the Batch by following the data entry instructions in Section Two. 
a. The 'T1' Batch is re-entered by typing MODE E ECORLOG,T1. A blank SUMMARY FOR ECOR NUMBER screen is displayed.

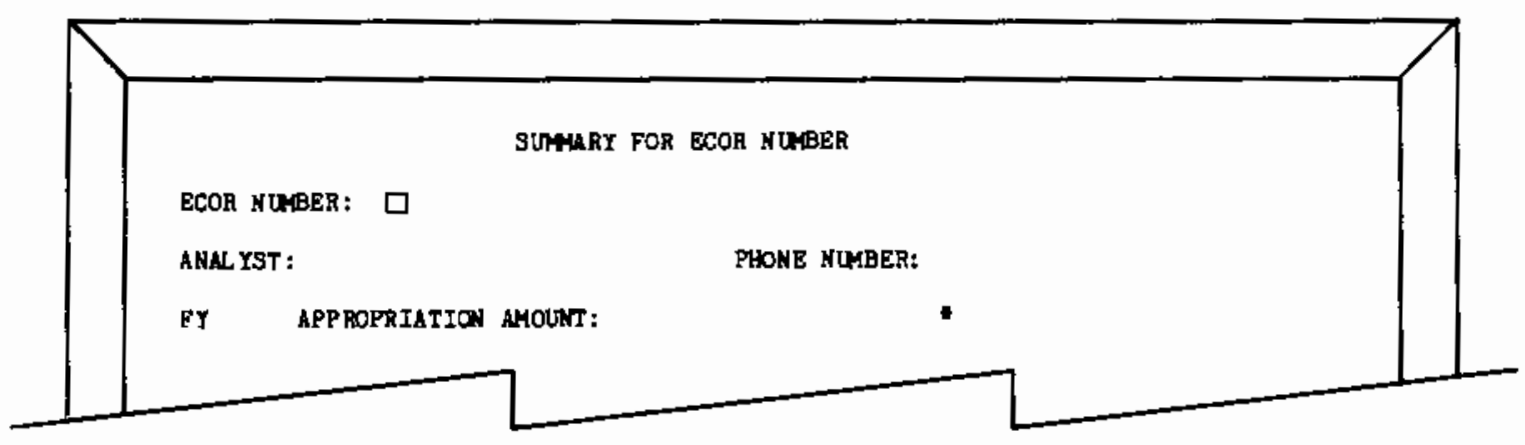

b. Press the up arrow key once to display the last INDIVIDUAL CONTRACT INFORMATION Record.

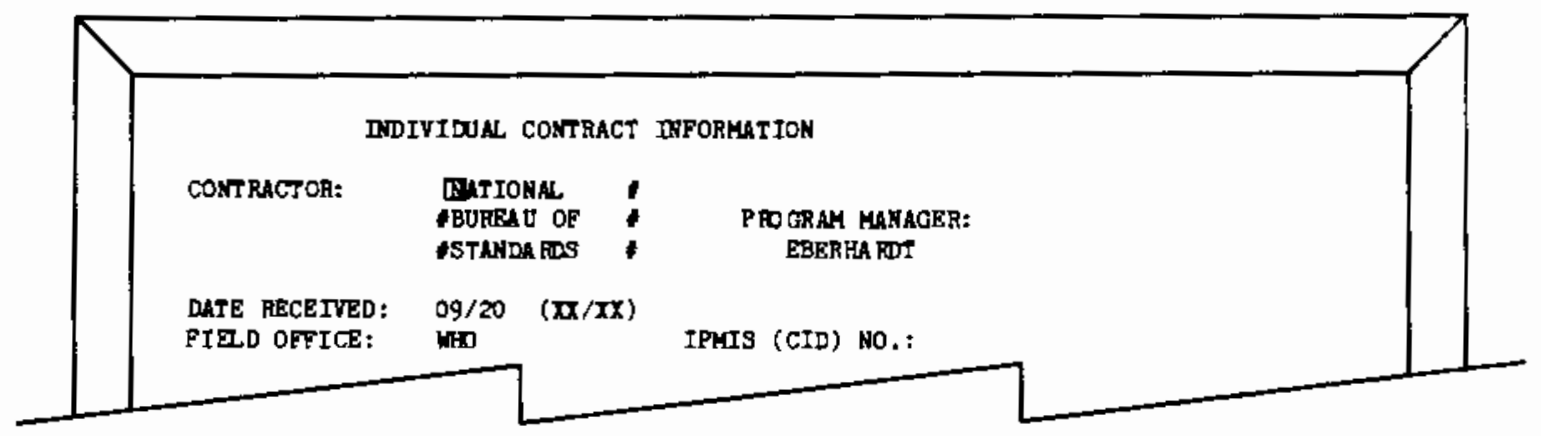

c. Press the down arrow key once to display a blank INDIVIDUAL CONTRACT INFORMATION screen.

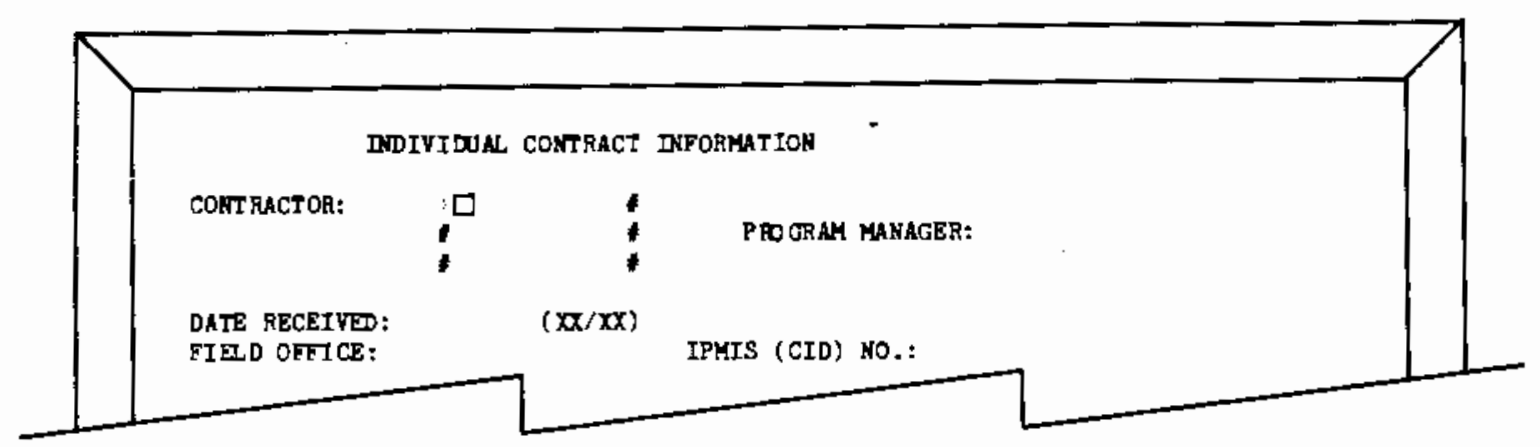


d. New data is entered into the Record. After the Record is completed, the up arrow key can be pressed to display the Record as it is shown below.

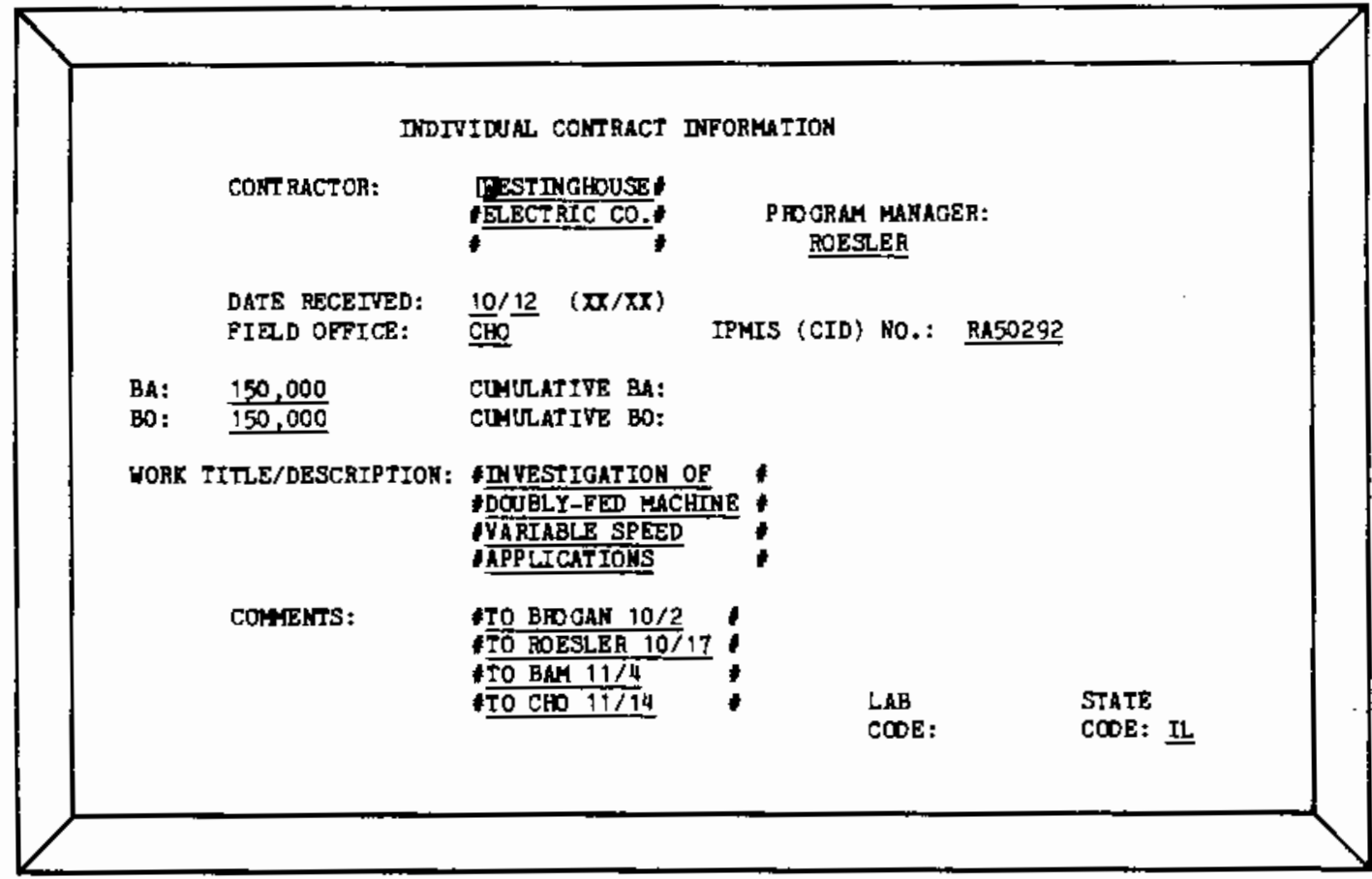

\subsection{ADOING RECOROS TO THE MIDDLE OF A BATCH}

1. Find the Record after which a new Record is to be inserted.

2. Press SHIFT and CORR REST simultaneous ly to unlock the Record and allow a copy to be made of it.

3. Press SHIFT and the down arrow simultaneously. This makes a copy of the Record (the copy is then modified to become the added Record).

4. Press the down arrow key once to display the copy of the Record.

5. Press SHIFT and CORR REST together to unlock the copy of the Record.

6. Key in the new Record, as described in the Data Entry section. To retain the contents of a field as they are displayed on the screen, press AUX DUP. When the new contents of a field are shorter than the old ones, pressing FIELD REL after entering the new contents erases anything under and to the right of the cursor. 
7. The added Record is considered complete when either FIELD REL is pressed after the final COMMENTS field, or when the up or down arrow key is pressed.

8. Steps 1 through 7 must be repeated for each Record to be added. If several Records are to be added to the middle of the Batch one after the other, multiple copies of an old Record can be made by pressing SHIFT and the down arrow key repeatediy (at Step 3); each copy can then be modified to become a new Record.

\section{EXAMPLE 27. AOOING TO THE MIDOLE OF A BATCH}

a. The Record displayed below has been located using the up arrow key. Press SHIFT and CORR REST simultaneously to unlock the Record, then SHIFT and the down arrow simultaneously to copy the Record. Press the down arrow key to display the copy, which also appears as in the screen below.

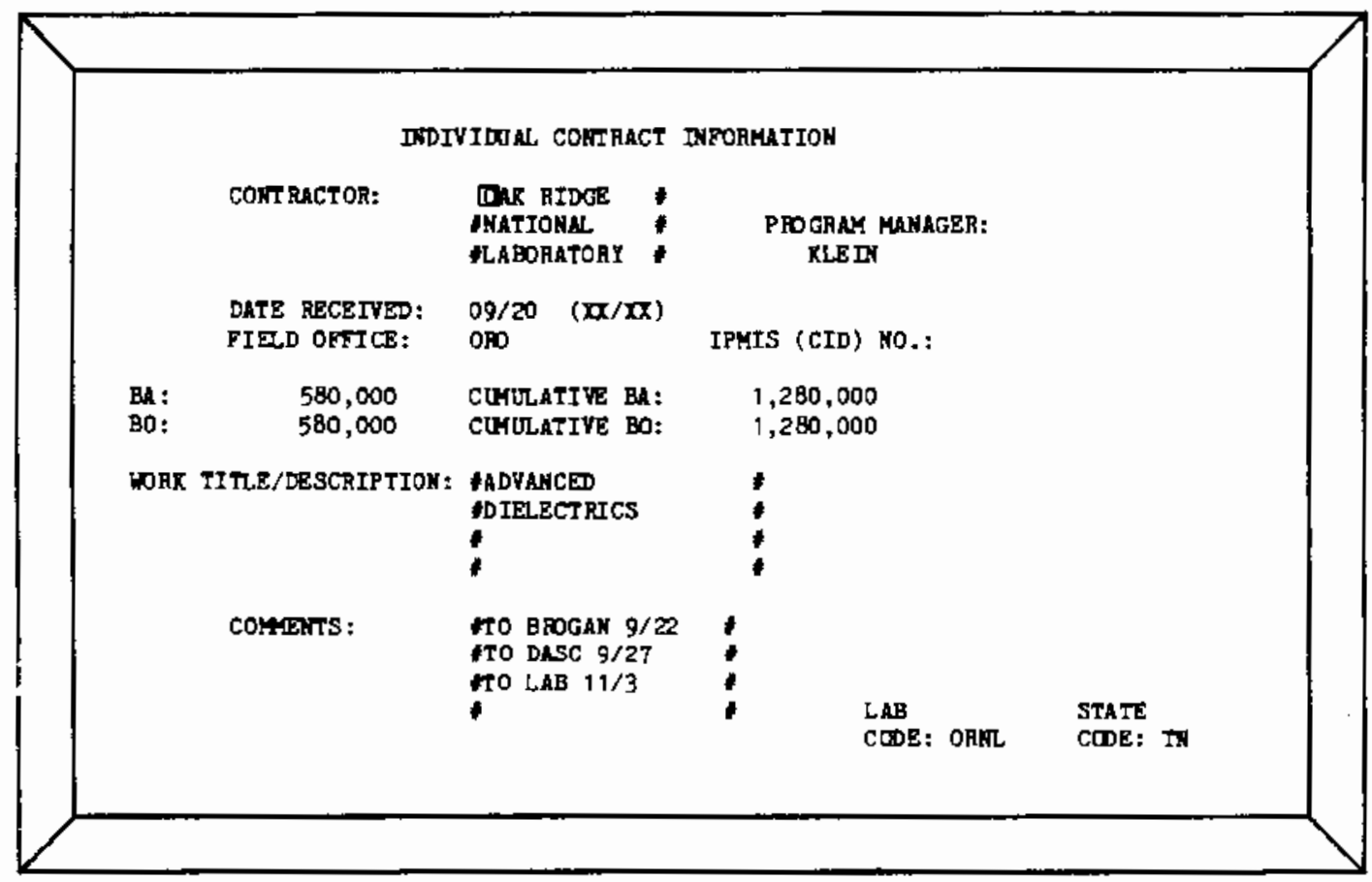


b. Oniy the BA, BO and WORK TITLE/DESCRIPTION fields need to be changed. Press SHIFT/CORR REST to unlock the Record; press AUX DUP until the cursor is at the $B A$ field. Enter $1300,000^{\prime}$ and press FIELD REL. For $B 0$, enter $1300,000^{\prime}$ again and press FIELD REL. The CUMULATIVE BA and CUMULATIVE $B O$ fields are erased from the screen. Enter 'ADAPTIVE PROTECTION' in the WORK TITLE/DESCRIPTION field. The cursor moves to the next line in this field. Press FIELD REL to erase the oid contents of the second line.

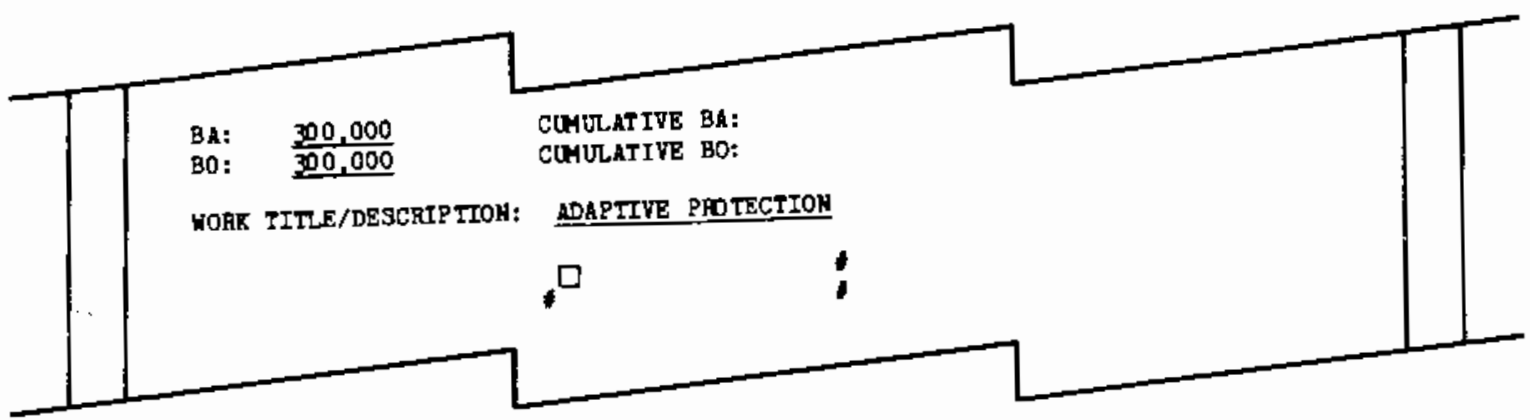

c. At this point, all necessary changes have been made. Press the down arrow key to go to the next Record, then the up arrow key to review the added Record, which appears as it does below.

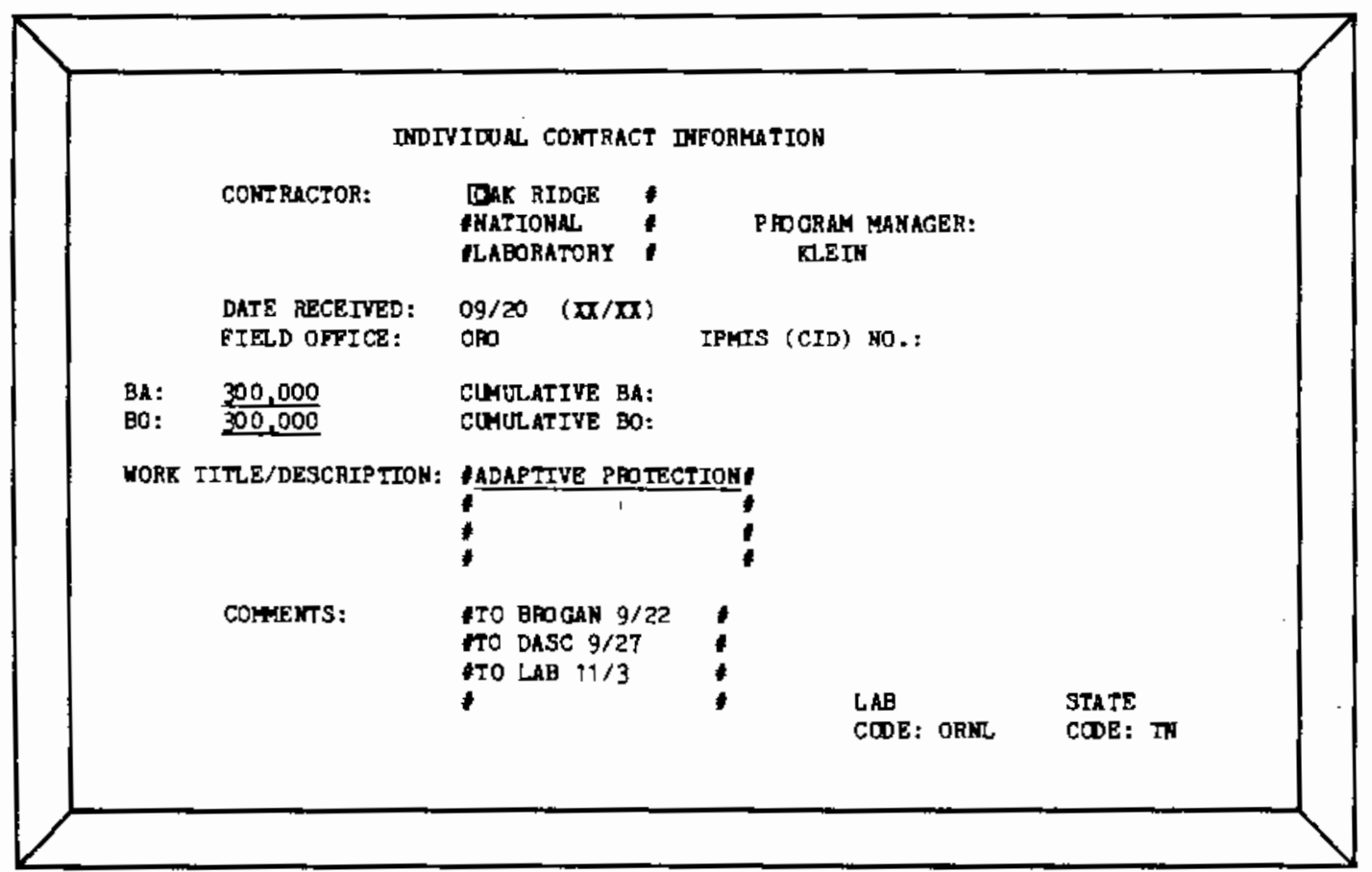




\subsection{DELETING A RECORD}

1. Display the Record that is to be deleted.

2. Press SHIFT and CORR REST simultaneously to unlock the Record.

3. Press SHIFT and the up arrow key simultaneously to delete the Record.

\section{EXAMPLE 28. DELETING A RECORD}

a. The Record below has been located with the down arrow key.

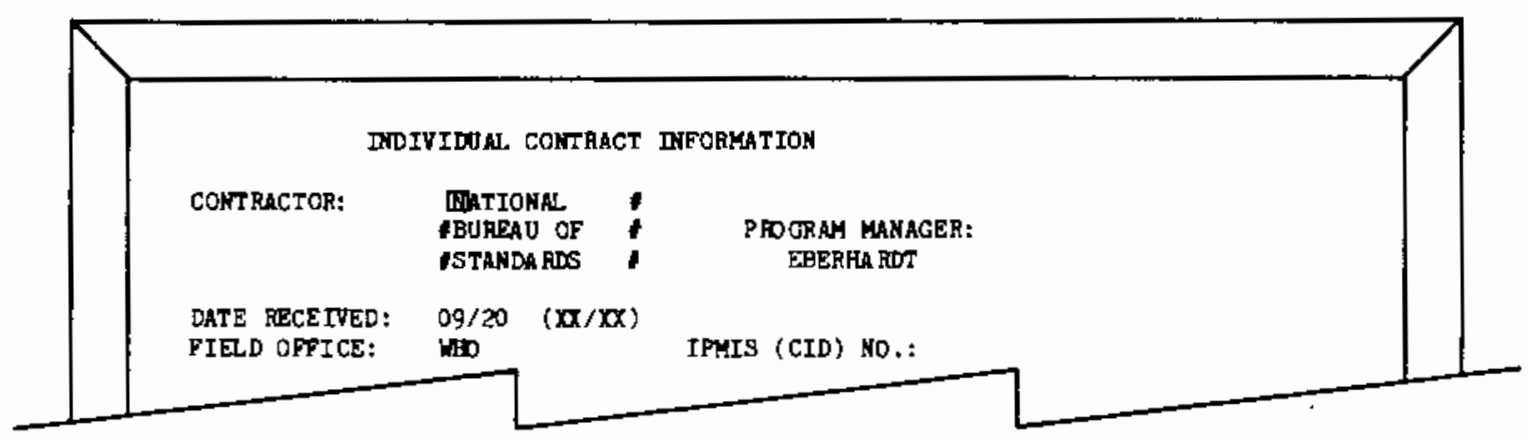

b. Press SHIFT and CORR REST simuitaneously to unlock the Record, then SHIFT and the up arrow key together to delete the Record. The Record is deleted and the next Record displayed.

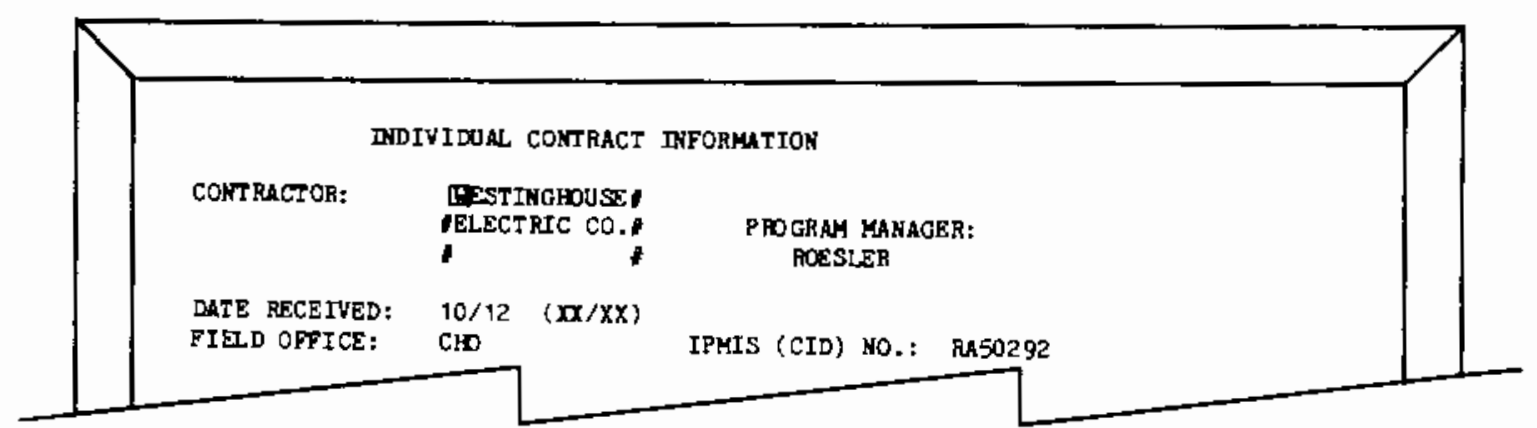





\subsection{RUNNING PROGRAMS TO PROCESS ECORLOG DATA}

There are three programs associated with the ECORLOG package. These programs -- ECORUP, ECRPT1, and ECRPT2 -- process the data which has been entered into ECORLOG Batches.

The first of these programs, ECORUP, calculates Cumulative BA and Cumulative BO amounts for each Record in one ECORLOG Batch, updates these fields in the Batch, and right justifies the Batch's other numeric fields. For the Cumulative $B A$ and Cumulative $B O$ fields of each Record in a Batch to be accurate, ECORUP should be run after the data in a Batch is first entered, and whenever any numeric fields in any Record of a Batch are changed. ECORUP will on ly process one Batch at a time, so it must be run for each Batch in which numeric fields have been modified.

The second ECORLOG program, ECRPT1, causes a standard ECORLOG report to be printed for any one Batch of ECORLOG. ECRPT1 is run whenever a printed record of the ECORLOG information in one Batch is needed. During an ECRPT1 run, prompts on the screen request the current date and the name of the user. These items are incorporated in an end-of-report entry, which appears on the printed output but is not stored in the ECORLOG Batch.

The third program, ECRPT2, produces a standard ECORLOG report for more than one ECORLOG Batch. The ECRPT2 report includes, for each Batch, all the information printed by the ECRPT1 report. In addition, a Report Summary gives the Total BA and Total BO amounts for each Batch included in the report, and a grand total of these amounts. During an ECRPT2 run, a list of the Batches to process is requested by screen prompts, the data in the Bathces is formatted and printed, and the date and user's name are requested for the Report Summary.

The ECORUP, ECRPT1 and ECRPT2 programs are stored in the ECORLG Batch of Job Master. (Note that MASTER,ECORLG is a storage area for these programs, while ECORLOG is the Job which stores ECORLOG information.) The three programs can be run separateiy or together. Whenever substantial changes have been made to a Batch of ECORLOG, it is advisable to run the ECORUP program so that the Cumulative $B A$ and $B O$ fields contain current information, whether or not a report is needed at the time. Instructions follow for running each progran by itself, and for running the three programs in succession. Section 4.5 gives examples of ECRPT and ECRPT2 reports. 


\subsection{UPDATING A BATCH'S NUMERIC FIELDS: THE ECORUP PROGRAM}

1. After all entries or changes have been made for a Batch of ECORLOG, make a note of the Batch ID.

2. Press the MOOE key, then type F. The F represents Find Mode, which allows the user to locate the first ECORUP program statement.

3. When the prompt TYPE JOBNAME, BATCH\# appears, enter MASTER,ECORLG and press FIELD REL.

4. When the prompt TYPE SEARCH INFORMATION appears, type '\#1' (without the quotes), and press FIELD REL. This will locate Record 1 in MASTER,ECORLG, which is the first statement of the ECORUP program.

EXAMPLE 29. ECORUP

a. Steps 1 through 3 have been followed. At the TYPE SEARCH INFORMATION prompt (Step 4), ' 1 ' ' is entered. Before FIELD REL is pressed, the screen looks like the example below.

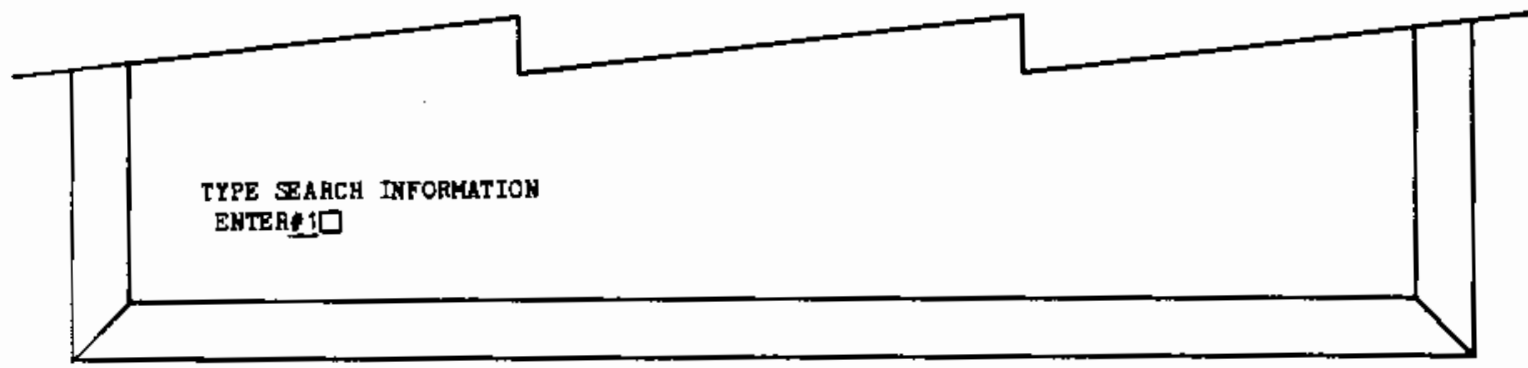

5. Press the MOOE key, then type T. Mode $T$ allows for execution of ECORUP (or any other VISION program).

6. When prompted for a password, type in the word PASSWORO (pressing FIELD REL is unnecessary).

7. At the prompt beginning TYPE S=SINGLE, M=MULTI..., type $M$. At this point, an ECORUP run begins. 
8. The jobname, ECORLOG, appears near the top of the screen, and the prompt ENTER BATCH IO TO UPDATE appears near the bottom. Type in the ID of the Batch for which totals are being updated, and press FIELD REL. The Batch ID will appear next to ECORLOG on the screen.

\section{EXAMPLE 30. ECORUP}

a. The ECORUP program has been initiated (Steps 5 through 7 ), and the ENTER BATCH IO TO UPDATE prompt (Step 8) appears on the screen. The Batch ID ' $T 1$ ' is entered; the screen is shown as it appears before FIELD REL is pressed.

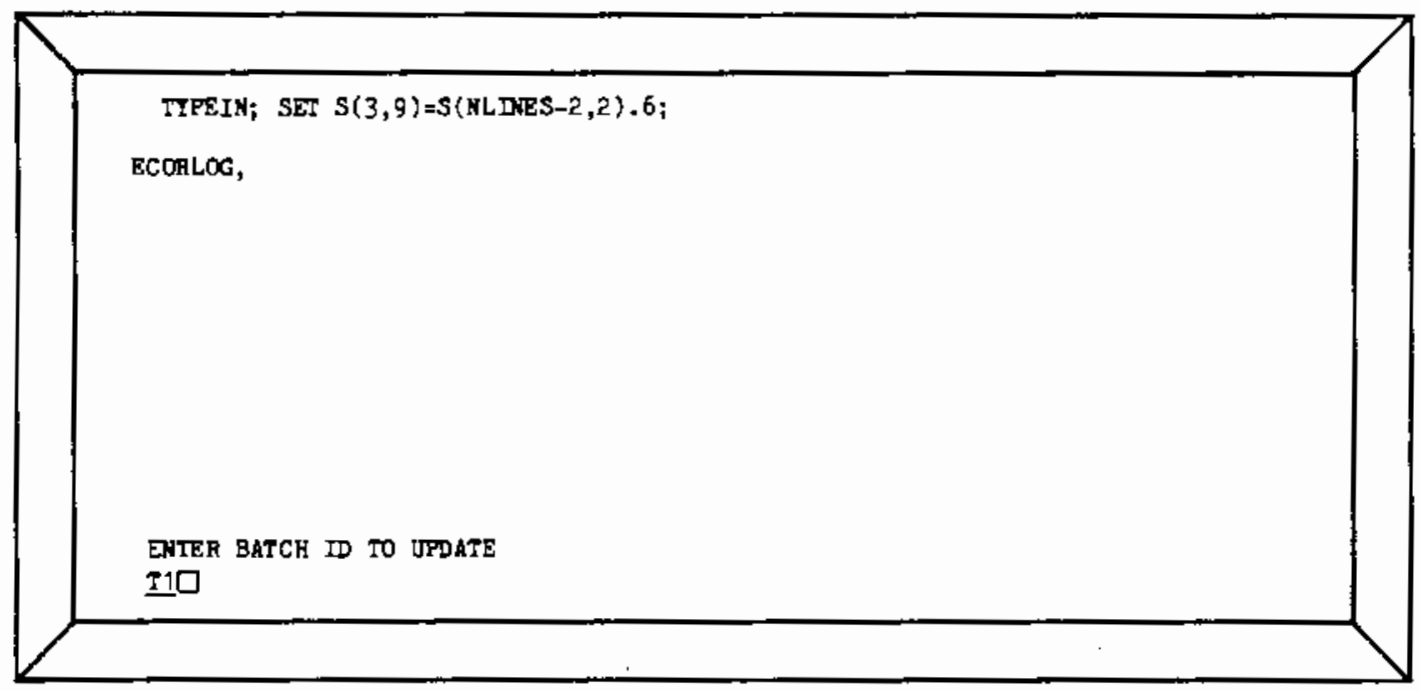

9. If the Batch entered in Step 8 does not exist, the ECORUP program halts. Press the MODE key to exit the program, recheck the Batch ID, and go back to Step 2. 
10. If the Batch does exist, the next prompt to appear will be: IS THIS THE CORRECT BATCH? ENTER YES OR NO. If the wrong batch has been chosen, type the word NO. Otherwise, type YES. Press FIELD REL.

\section{EXAMPLE 31. ECORUP}

a. The 'Tl' Batch is a valid ECORLOG Batch, so the IS THIS THE CORRECT BATCH?... prompt is displayed on the screen (Step 10). Since it is also the correct Batch, 'YES' is entered as the response.

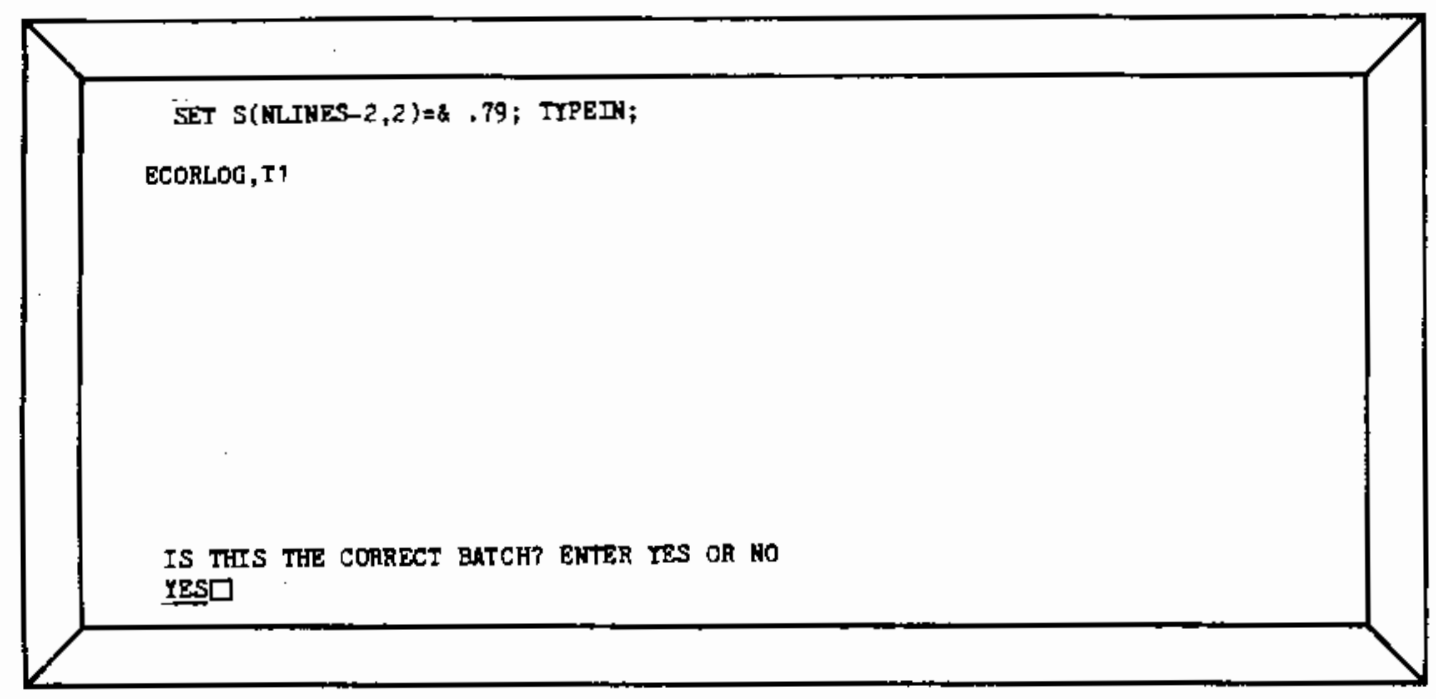

11. If NO was entered at Step 10 , or if the Batch specified does not contain any data, the Batch ID will be erased from the top of the screen and a prompt is set to TRY AGAIN. Either go back to Step 8, or exit the program by pressing the MODE key, recheck the Batch ID and begin again at Step 2. 
12. If YES was entered at Step 10, a message is written next to ECORLOG and the Batch ID indicating that TOTALS ARE BEING UPDATED. As program statements are executed, they flash rapidly at the top of the screen. Depending on the size of the Batch, ECORUP will take approximately one to three minutes to run.

EXAMPLE 32. ECORUP

a. FIELD REL has been pressed to complete Step 11, and the numeric fields in the ' $\mathrm{T1}$ ' Batch are being updated. While the statements to update the Batch are being executed (Step 12), the screen displays the message below.

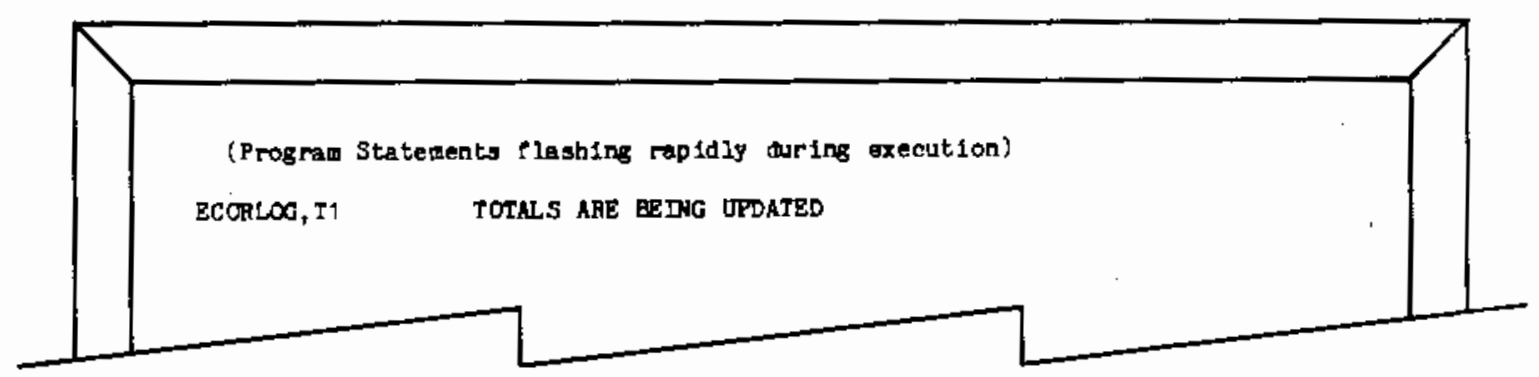


13. When ECORUP is completed, the top line of the screen reads:

SPAUSE PRESS SPACE BAR TO PRINT REPORT ON ONE BATCH, MODE KEY TO EXIT. The prompt near the bottom of the screen reads:

HIT SPACE BAR TO CONT INUE MULTI-MODE. Press the MODE key. To exit VISION, continue by typing $X S$; to go back to a Batch, type $E$, then ECORLOG and the Batch ID.

\section{EXAMPLE 33. ECORUP}

a. Updating of the 'T1' Batch is now complete, and the screen now gives the option of continuing on to the ECRPTl program (see Section 4.4) or exiting (Step 13). To exit, the MODE Key would be pressed, and the next task selected.

\$PAUSE PRESS SPACE BAR TO PRIIT REPORT ON ONE BATCH, MODE KEY TO EXIT 


\subsection{PRINTING A REPORT ON ONE BATCH: THE ECRPTI PROGRAM}

1. Enter the Batch for which a report will be printed, and ascertain that the Cumulative BA and Cumulative BO fields in each Record contain the correct totals, and that other numeric fields in the Batch are rightjustified. If you find inaccurate Cumulative $B A / B O$ fields or leftjustified numeric fields, run ECORUP before printing the ECRPTI report (see the previous section for information on running ECORUP).

2. Press the MODE key, then type $F$ to enter Find Mode.

3. At the TYPE JOBNAME, BATCH\# prompt, enter MASTER,ECORLG and presS FIELD REL.

4. At the TYPE SEARCH INFORMATION prompt, type '\#148' (without the quotes) and press FIELD REL. This will locate Record 148 in MASTER,ECORLG, the first statement of the ECRPTl program.

5. Press the MODE key, then type $T$ to enter Mode $T$.

6. When prompted for a password, type in the word PASSWORD (pressing FIELD REL is not necessary).

7. At the prompt beginning TYPE $S=S I N G L E, M=M U L T I . .$. , type $M$. At this point, an ECRPTI run begins.

8. By default, VISION reports (including ECRPTI and ECRPT2) are printed on the system printer in the computer room. (See Section 5.1 for information on changing the default printer.) Make sure the printer is loaded with 14-inch wide paper, line up the edge of the paper with the metal guide behind the printer ribbon, and press the RESET button on the printer. 
9. The jobname, ECORLOG, appears near the top of the screen, and the prompt ENTER BATCH ID TO FORMAT FOR REPORT appears near the bottom. Type in the ID of the Batch for which a report is to be printed, and press FIELD REL. The Batch ID will appear next to ECORLOG on the screen.

\section{EXAMPLE $34 . \quad$ ECRPT1}

a. The ECRPT1 program has been initiated, and the printer has been set up (Steps 1 through 8). A Batch ID is requested for the ECRPT1 report, as shown be low (Step 9). The Batch ID 'T2' is entered, but it is not the correct Batch.

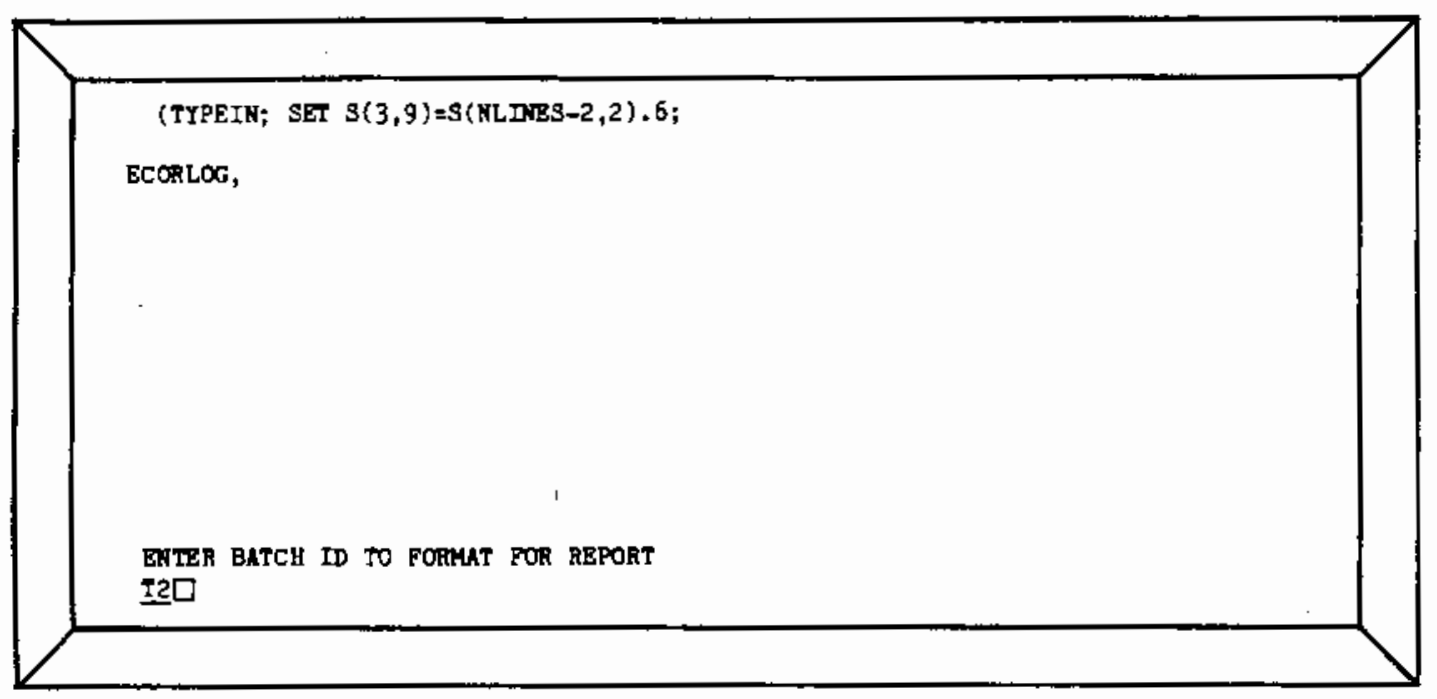

10. If the Batch entered in Step 9 does not exist, the ECORUP progran halts. Press the MODE key to exit the program, recheck the Batch ID, and go back to Step 2 . 
11. If the Batch does exist, the next prompt to appear will be: IS THIS THE CORRECT BATCH? ENTER YES OR NO. If the wrong batch has been chosen, type the word NO. Otherwise, type YES. PresS FIELD REL.

\section{EXAMPLE 35. ECRPT1}

a. Although 'T2' is not the Batch for which the report is run, it does exist. At Step 11, the IS THIS THE CORRECT BATCH?... prompt gives the chance to correct the Batch ID. As shown below, 'NO' is entered.

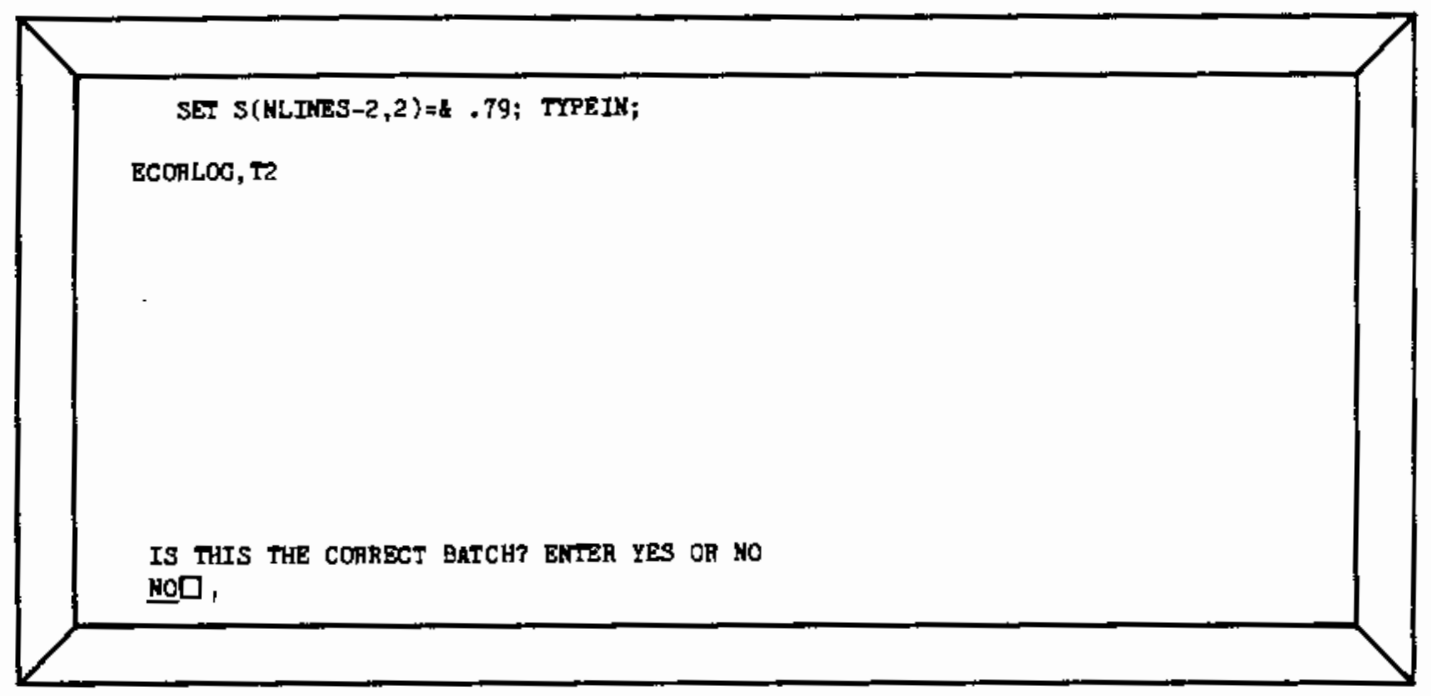


12. If N0 was entered at Step 11, or if the Batch specified does not contain any data, the Batch ID will be erased from the top of the screen and the prompt is set to TRY AGAIN. Either go back to Step 9, or exit the program by pressing the MODE key, recheck the Batch ID and begin again at Step 2 .

\section{EXAMPLE 36. ECRPT1}

a. In Step 12, the Batch ID ' $T 2$ ' is erased from the top of the screen, and the TRY AGAIN prompt is displayed near the bottom of the screen. 'TI' is now entered as the correct Batch ID.

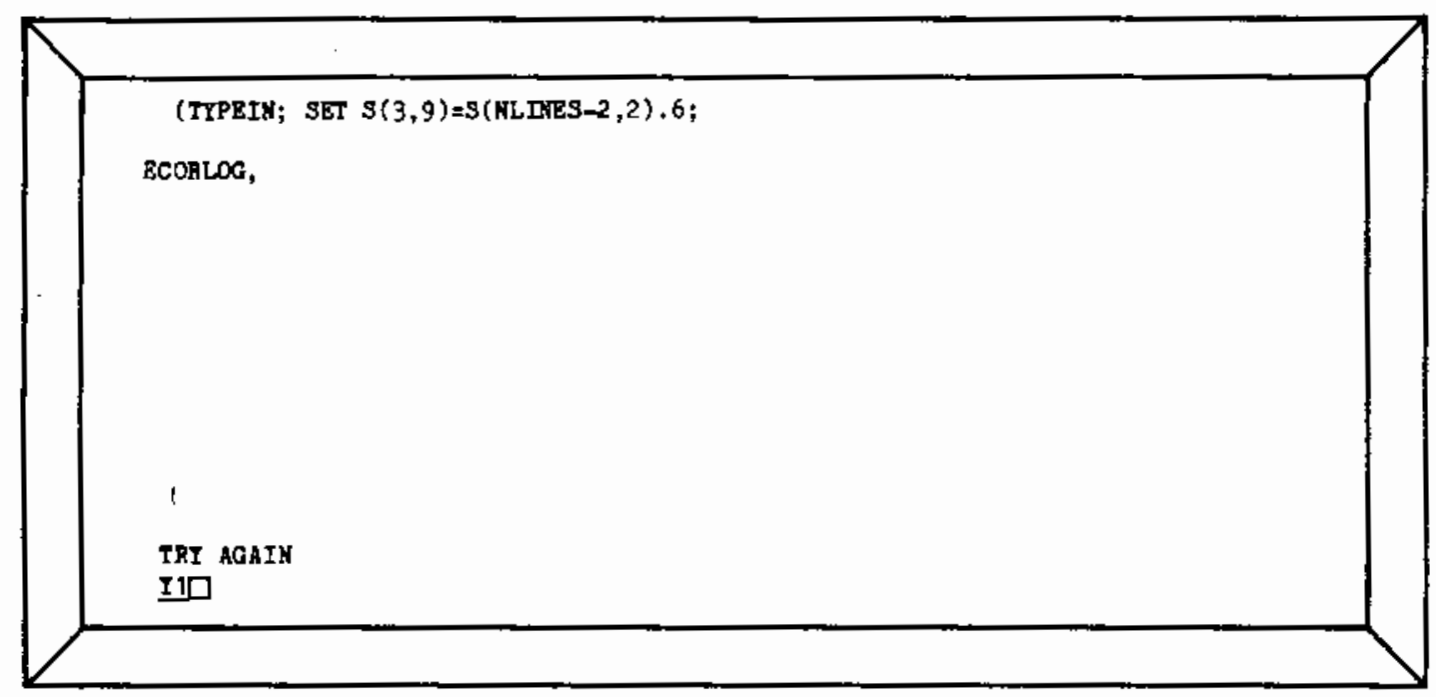

13. If YES was entered at Step 11, a message is written next to ECORLOG and the Batch ID indicating that the Batch IS BEING FORMATTED FOR REPORT.

14. A message flashes at the bottom of the screen to READY 8121 PRINTER UNIT NUMBER $x$ (where ' $x$ ' is the number of the system printer (zero) or the reassigned printer). Go to the printer, check again to make sure the printer is loaded with 14" wide paper, and push the READY button. The paper will advance and the first line of the heading (which prints NATIONAL ECOR LOG at the center of the page and the page number on the right) begins printing. If the heading is not at the top of a page, push the RESET button while the first line is printing. Reposition the paper at the top of a page, push the READY button, and the first Tine of the heading will print in the proper place. Once the beginning of the report is lined up correctly, the rest of the report will position properly. 
15. At the terminal, two lines have been written underneath ECORLOG,Batch IS BEING FORMATTEO FOR REPORT. They read: REPORT DATE : PREPARED BY:

TOTAL BA: TOTAL BO:

The prompt at the bottom of the screen reads ENTER TODAY'S DATE. Type in the date (MONTH DAY, YEAR) and presS FIELD REL. The date entered will appear next to REPORT DATE.

\section{EXAMPLE 37. ECRPT1}

a. When the Records from Batch 'Tl' have been processed for the ECRPTI report (Steps 13 and 14), the screen is set to request the date and the user's name (Step 15). The next prompt asks you to ENTER TOOAY'S DATE. 'JUNE 33, 1984 ' is entered, as shown below.

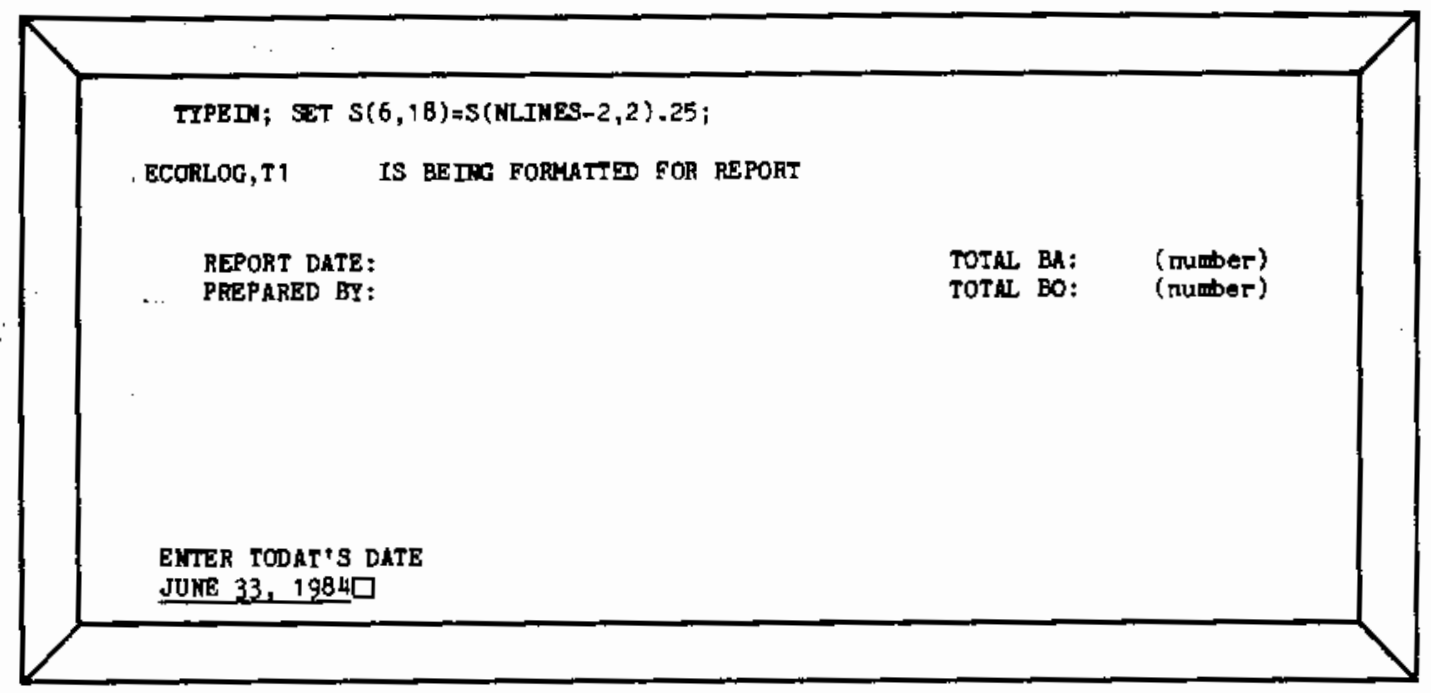

16. The next prompt at the bottom of the screen is ENTER YOUR NAME. Type in your name and press FIELO REL. The name entered wi Tl appear next to PREPARED BY at the top of the screen. 
17. The prompt at the bottom asks ARE NAME AND DATE CORRECT? ENTER YES OR NO. Type in the word YES or the word NO and press FIELD REL.

\section{EXAMPLE $38 . \quad$ ECRPT1}

a. The user's name has been entered (Step 16), and the prompt in Step 17 asks for validation of the name and date. Since the date (JUNE 33 ) needs to be corrected, 'NO' is entered here.

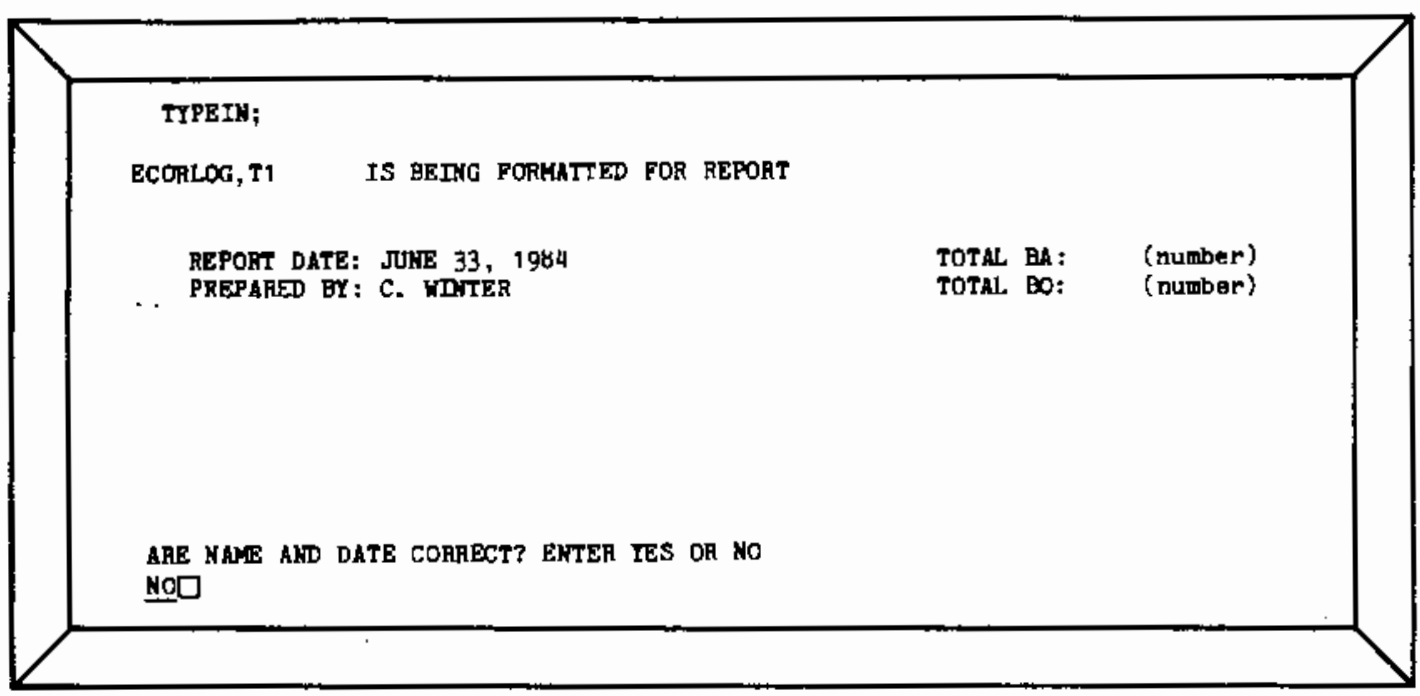


18. If NO was entered at Step 17, the name and date last entered will be erased from the top of the screen, and the prompt at the botton of the screen becomes TRY AGAIN - ENTER TODAY'S DATE. Go back to Step 15 to reenter the date and name.

\section{EXAMPLE 39. ECRPT1}

a. In Step 18, the previously entered name and date are erased from the middle of the screen, and the prompt requests a corrected date.

'JUNE 3, 1984' is entered. Next, a corrected name will be requested.

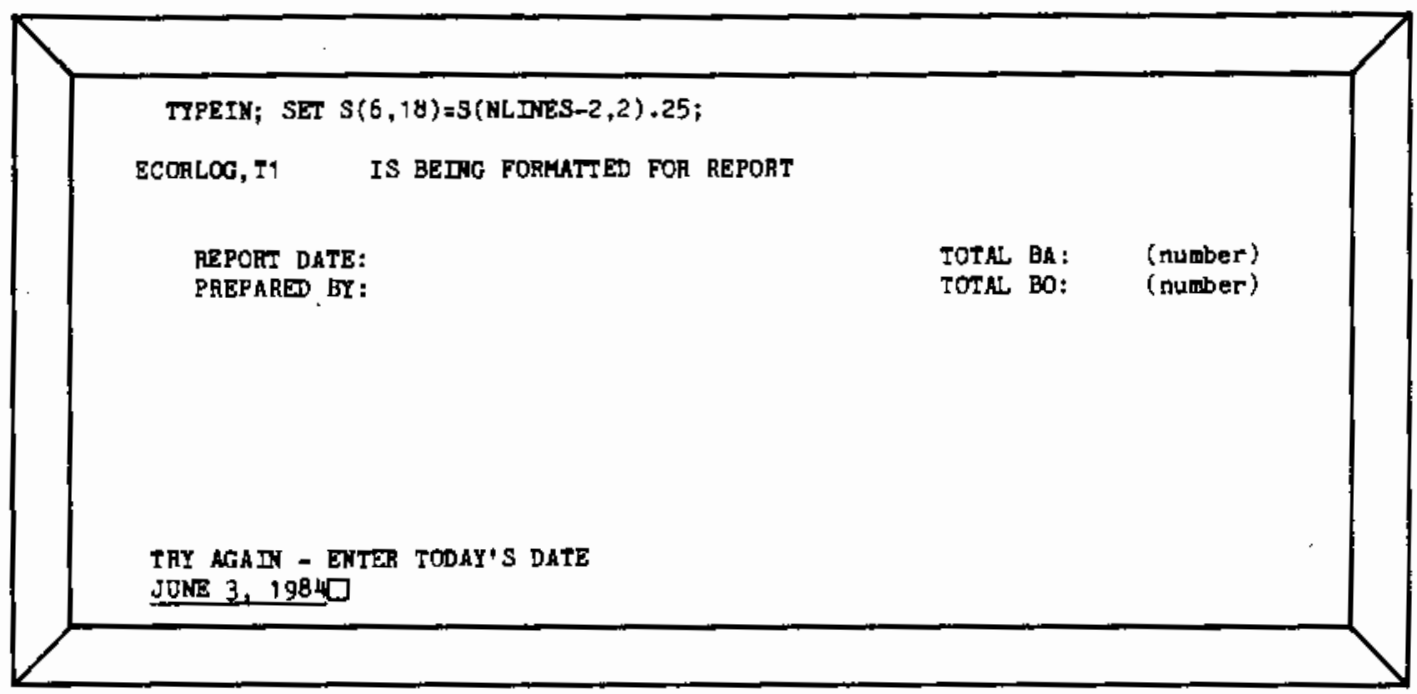


19. If YES was entered at Step 17, the report continues to print until finished. After the entire ECRPTI program has executed, the prompt near the botton of the screen reads:

HIT SPACE BAR TO CONTINUE MULTI-MODE

The top line of the screen displays:

\$PAUSE PRESS SPACE BAR TO PRINT MULTI-BATCH REPORT, MODE KEY TO EXIT

At this point, press the MODE key (MODE $X S$ signs the user out of VISION, MODE E ECORLOG,Batch allows another Batch to be viewed or edited). Pressing the MODE key will not interrupt a report still being printed.

\section{EXAMPLE 40. ECRPT1}

a. After the report summary has been sent to the printer, the option is given in Step 19 of continuing on to the ECRPT2 program (see Section 4.4 for details) or exiting. At this point, the MODE Key should be pressed to continue on to the next VISION task.

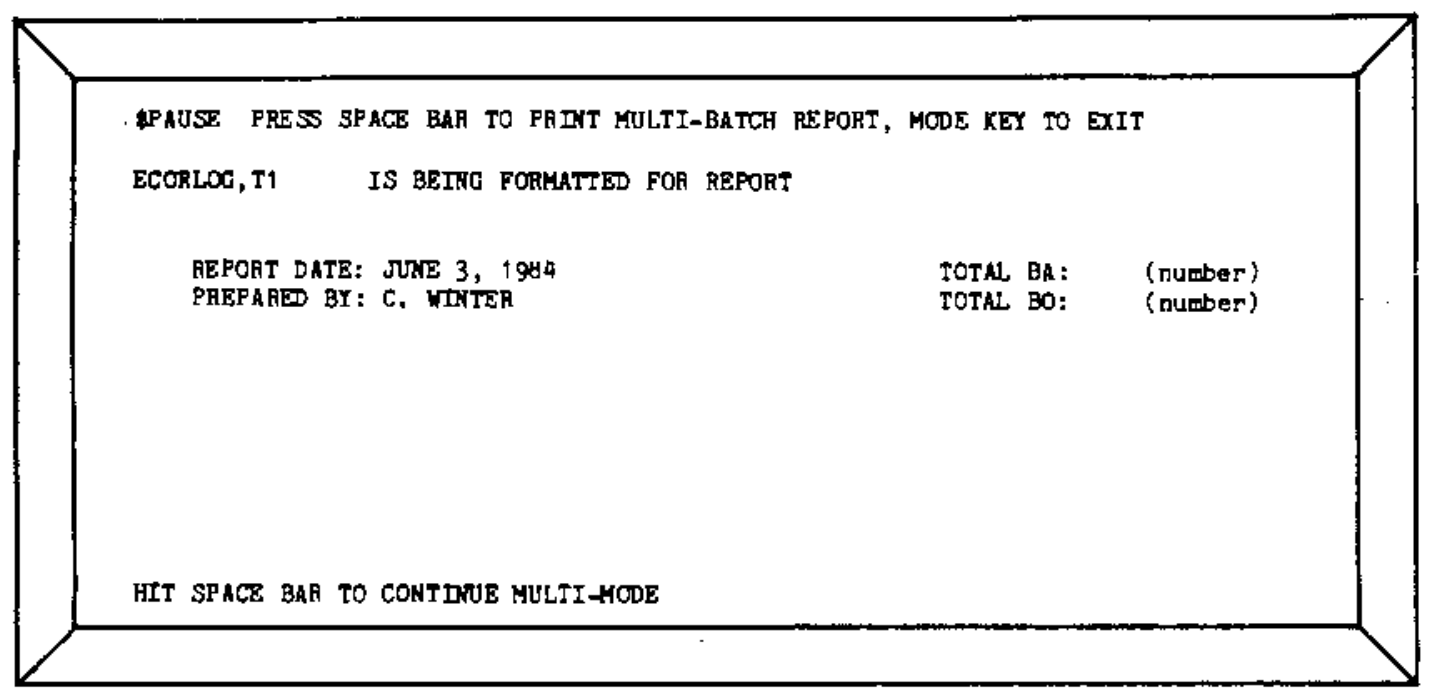




\subsection{PRINTING A REPORT ON MULTIPLE BATCHES: THE ECRPT2 PROGRAM}

1. Enter the Batches for which the report will be printed, and ascertain that the Cumulative BA and Cumulative BO fields in each Record contain the correct totals, and that all numeric fields are right-justified. If any numeric fields are incorrect, run ECORUP on the Batch(es) before printing the ECRPT2 report (see Section 4.1 for information on running ECORUP). Make a note of the Batch ID's for which the report is to be printed, and the order in which they should appear.

2. Press the MODE key, then type $F$ to enter Find Mode.

3. At the TYPE JOBNAME, BATCH\# prompt, enter MASTER, ECORLG and press FIELD REL.

4. At the TYPE SEARCH INFORMATION prompt, type '\#248' (without the quotes) and press FIELD REL. This will locate Record 248 in MASTER,ECORLG, the first statement of the ECRPT2 program, and the message FOUND 248 will be displayed.

5. Press the MODE key, then type $T$ to enter Mode $T$ and run the program.

6. When prompted for a password, type in the word PASSWORD (pressing FIELD REL is not necessary).

7. At the prompt beginning TYPE S=SINGLE, M=MULTI...., type $M$. At this point, an ECRPT2 run begins.

8. By default, the ECRPT2 report is printed on the system printer in the computer room. (Section 5.1 gives instructions for changing the default printer.) Make sure the printer is loaded with 14-inch wide paper, line up the edge of the paper with the metal guide behind the printer ribbon, and press the RESET button on the printer.

9. Near the top of the terminal screen, a message appears reading ECORLOG BATCHES AVAILABLE FOR PROCESSING. Be low this, a list of the Batches which have been entered into the ECORLOG Job will appear. If there are forty or fewer ECORLOG Batches in the system, a line near the bottom of the screen will read ALL AVAILABLE BATCHES ARE DISPLAYED. If there are more than forty ECORLOG Batches in the system, the bottom of the screen will read: JOB HAS MORE BATCHES THAN CAN BE DISPLAYEO ABORT PROGRAM WITH MODE KEY TO SEE OTHERS IN JOB MODE If these messages appear and there are undispiayed Batches (to include in the ECRPT2 report) whose ID's you cannot recall, abort the ECRPT2 program with the MODE key. Use Mode $J$ to find the names of all ECORLOG Batches, then begin ECRPT2 again at Step 2. 
10. Below the list of available Batches, another message appears on the screen, reading:

ECORLOG BATCHES TO BE INCLUDED IN REPORT (ORDERED FROM LEFT TO RIGHT) The prompt ENTER FIRST BATCH ID TO INCLUDE IN REPORT appears near the bottom. Type in the ID of the first Batch to appear in the report, and press FIELD REL. The Batch ID will be written to the middle of the screen.

\section{EXAMPLE 41. ECRPT2}

a. The ECRPT2 program has been initiated, and printer set for output, and a list of the available ECORLOG Batches written on the screen (Steps 1 through 9). In Step 10, a new prompt requests that the first Batch ID for the report be entered. ' $T 2$ ' is entered for the first Batch ID.

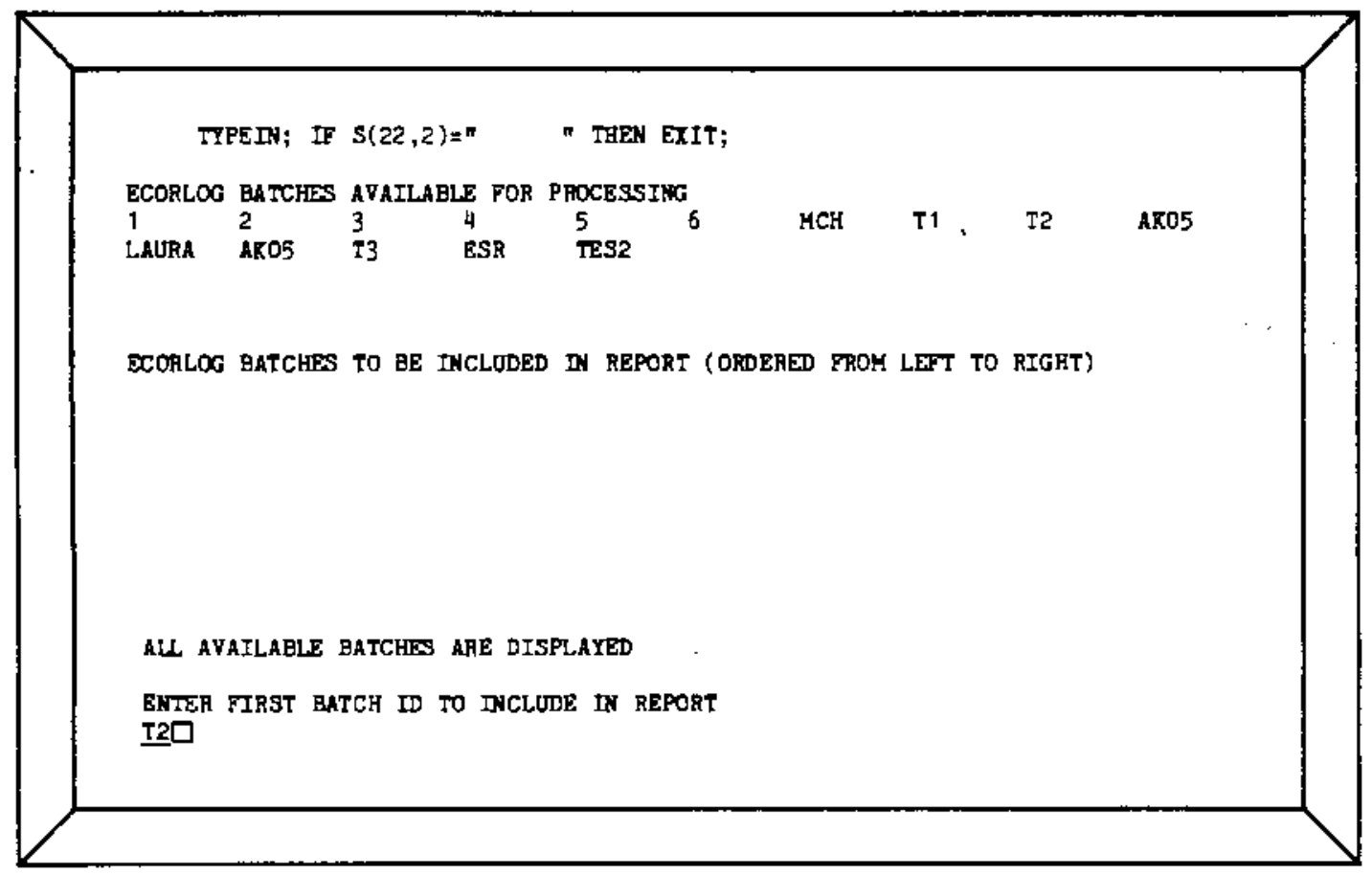


11. The next prompt to appear will be: IS BATCH ABOVE CORRECT? ENTER YES OR NO. If the wrong batch has been chosen, type the word NO. Otherwise, type YES. Press FIELD REL.

\section{EXAMPLE 42, ECRPT2}

a. In Step 11, 'T2' is placed in the list of ECORLOG BATCHES TO BE INCLUDED IN REPORT, and the IS THIS THE CORRECT BATCH?... requests that it be validated. 'YES' has been entered to validate the Batch, and will be followed by pressing FIELD REL.

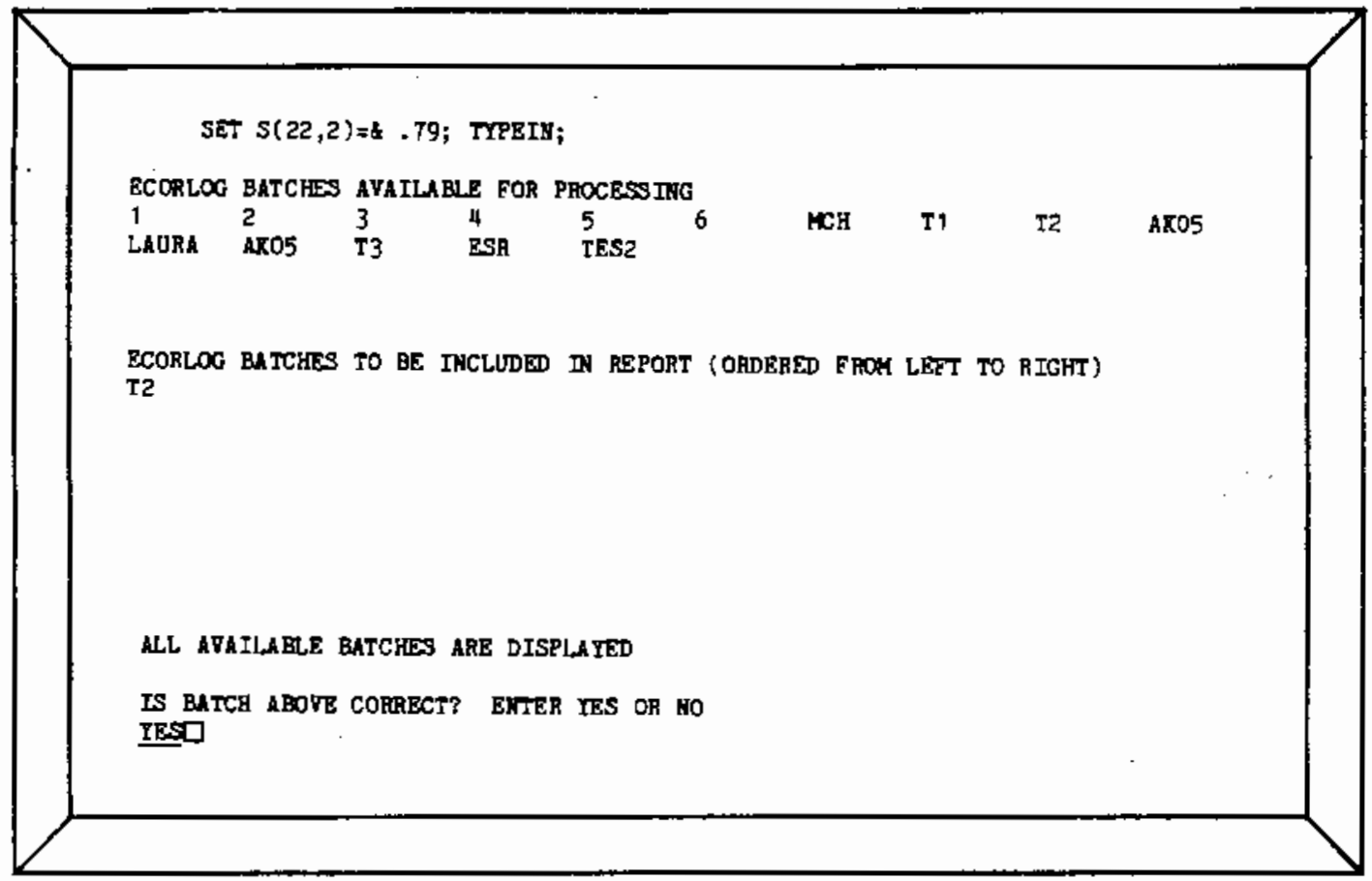

12. If NO was entered at Step 11, the Batch ID will be erased from the middle of the screen and the prompt is set to ENTER CORRECT BATCH ID. Go back to Step 9 to reenter the Batch ID.

13. If YES was entered at Step 11, the prompt will become ENTER NEXT BATCH ID, OR FIELD REL WHEN DONE. If more Batches are to be included in the report, enter the ID of the next to include, press FIELD REL and go back to Step 11. If a 11 Batch ID's for the report have been entered (and appear on the middle of the screen), press FIELD REL without entering anything. The ECRPT2 program will process a maximum of twenty Batches per report. 
14. The screen prompt now reads IS LIST OF BATCHES CORRECT?

ENTER YES OR NO. Check the Batch list at the middle of the screen to see if it contains valid Batch ID's and is in the correct order. Type in YES or NO and press FIELD REL.

\section{EXAMPLE 43. ECRPT2}

a. Another Batch has been entered in the list of Batches for the report; FIELD REL was pressed to complete the Tist (Steps 11 through 13). In Step 14, a prompt requests validation of the entire list of Batches. In this case, the order of ' $T 1^{\prime}$ ' and ' $T 2$ ' should be reversed, so 'NO' is entered in answer to the prompt.

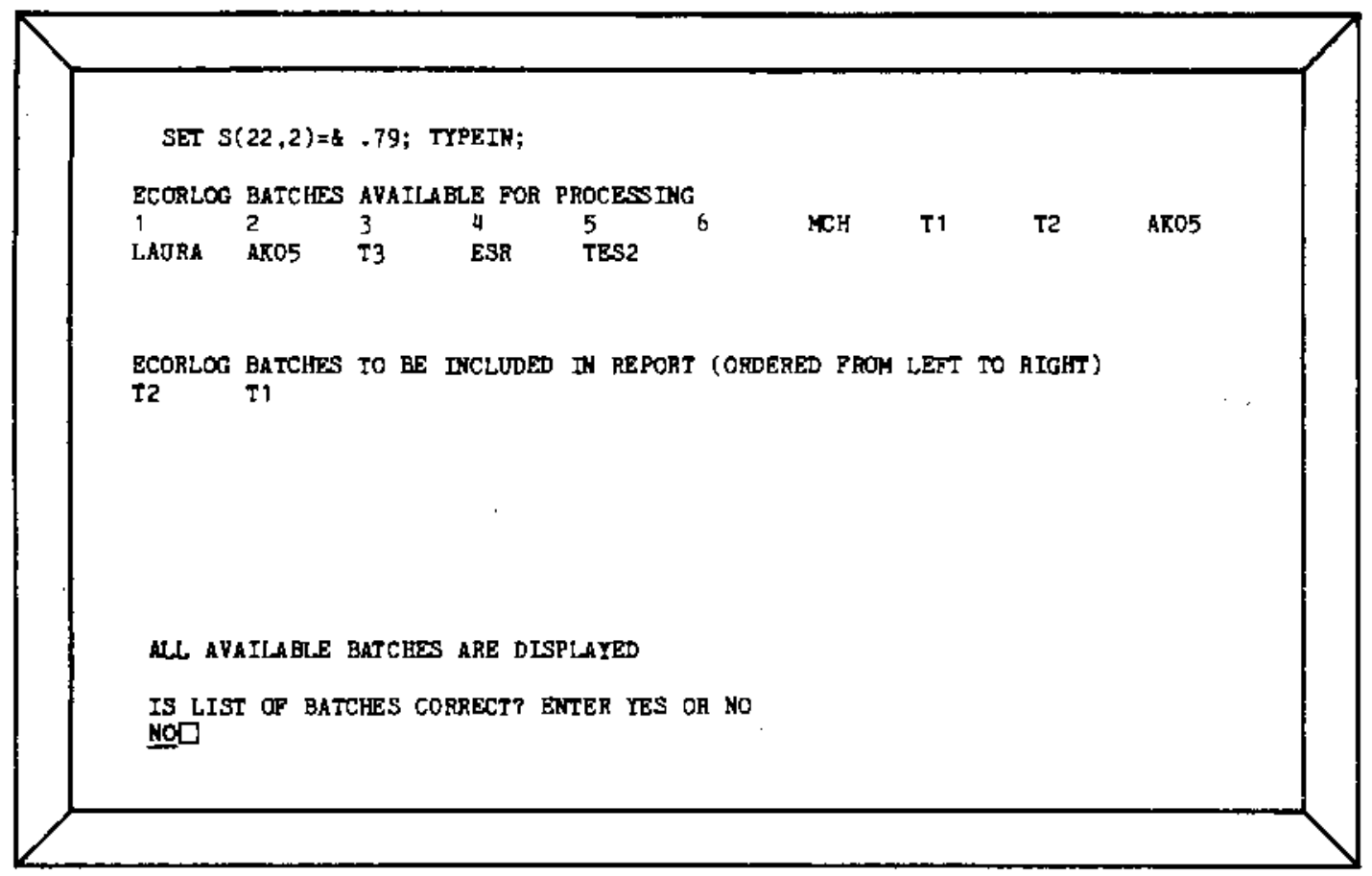


15. If NO was entered in Step 14, the iist below ECORLOG BATCHES TO BE INCLUDED IN REPORT $W$ ill be erased from the screen, and the prompt near the bottom becomes TRY AGAIN - ENTER FIRST BATCH TO PROCESS. Go back to Step 10 and enter the first Batch ID for the report.

\section{EXAMPLE 44. ECRPT2}

a. In Step 15, the 1ist of Batches for the ECRPT2 report is erased, with a new prompt at the bottom of the screen to request a corrected $f$ irst Batch ID. 'T1' is entered as the correct first Batch.

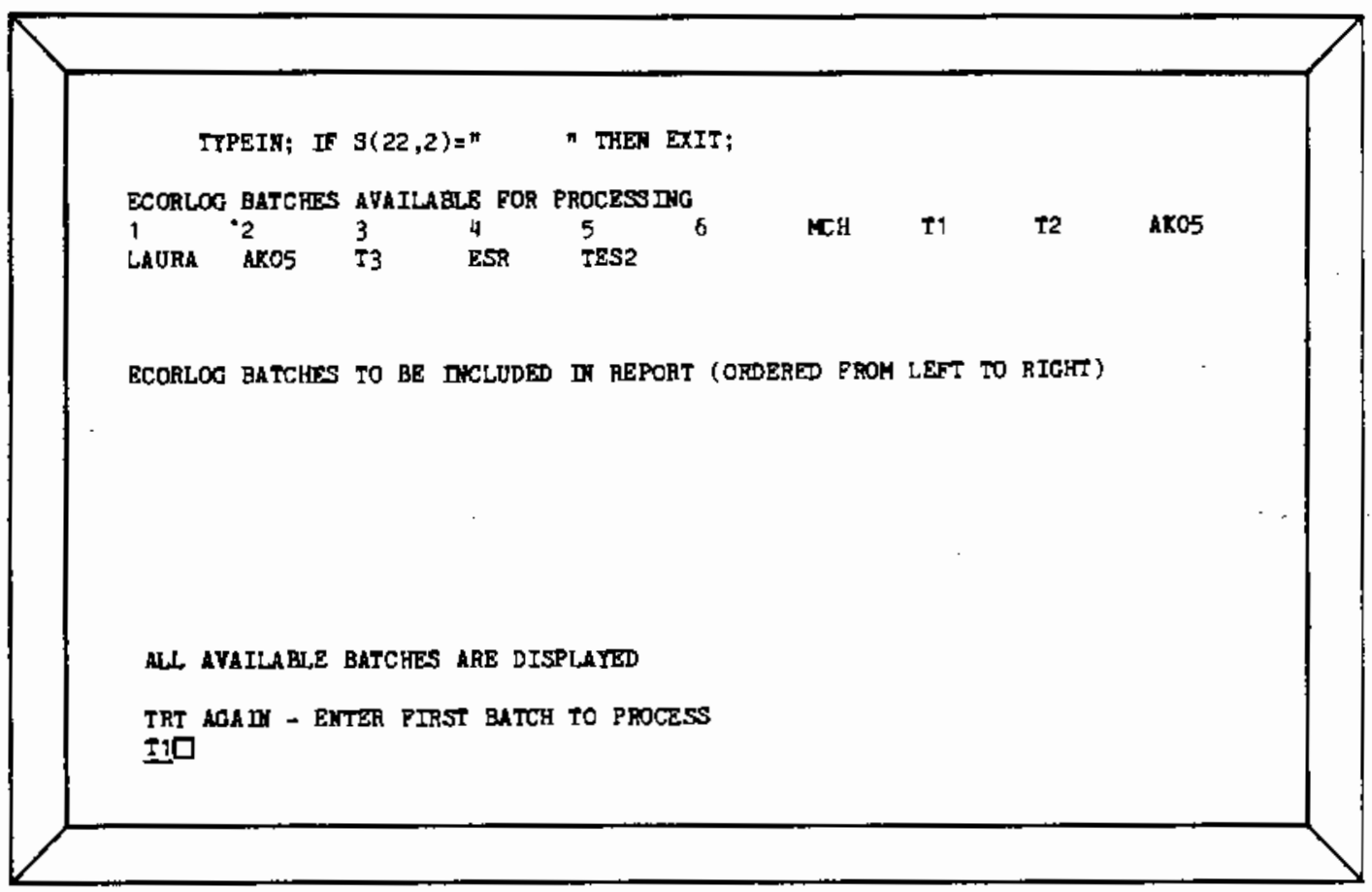


16. If YES was entered at Step 14, all messages will be erased from the screen except the list of Batches chosen for ECRPT2. Be low this list, another message will read BATCH NOW BEING PROCESSED: ECORLOG,. The ECRPT2 program now begins to process each selected Batch in turn. As a Batch is processed, its ID will be written to the right of this mess age line. The ECOR Number, Total BA and Total BO amounts for each Batch are also displayed on the screen in turn.

\section{EXAMPLE 45. ECRPT2}

a. The 1ist of Batches for the ECRPT2 report has been entered and validated (Steps 11 through 15), and the processing the each Batch's contents has begun. While the Batches are being processed, the screen appears as it does belaw.

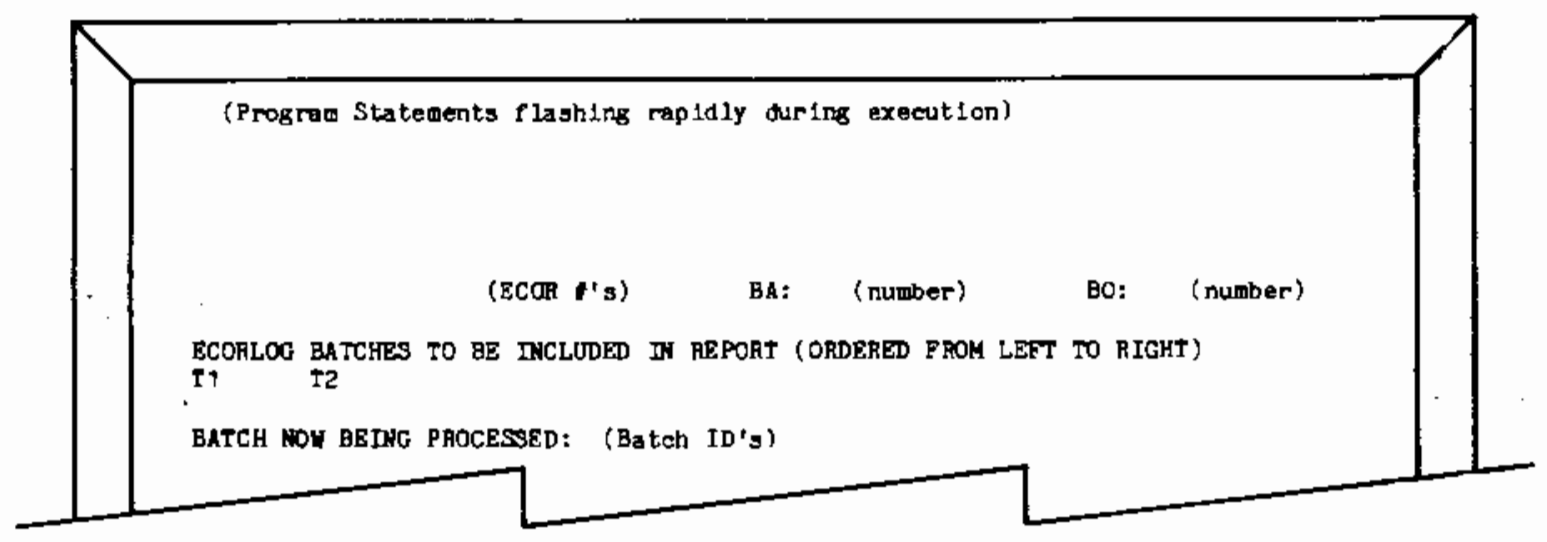

17. A message flashes at the bottom of the screen to READY 8121 PRINTER UNIT NUMBER $x$ (' $x$ ' being the number of the printer you are using). Go to the printer, check again to make sure the printer is loaded with 14" wide paper, and push the READY button. The paper will advance and the first line of the heading (which prints NATIONAL ECOR LOG at the center of the page and the page number on the right) begins printing. If the heading is not at the top of a page, push the RESET button while the first line is printing. Reposition the paper at the top of a page, push the READY button, and the first line of the heading will print in the proper place. Once the beginning of the report is lined up correctly, the rest of the report will position properly.

18. When all Batches have been formatted for ECRPT2, several additional lines appear on the screen. Near the top of the screen, they read:

ECOR NUMBER

REPORT TOTAL:
REPORT SUMMARY

TOTAL BA

(number)
TOTAL BO (number) 
Also, two new lines have appeared near the bottom of the screen: REPORT DATE : PREPARED BY:

The prompt at the bottom of the screen reads ENTER TODAY'S DATE. Type in the date (MONTH DAY, YEAR) and press FIELD REL. The date entered will appear next to REPORT DATE.

19. The next prompt at the bottom of the screen is ENTER YOUR NAME. Type in your name and press FIELD REL. The name entered will appear next to PREPARED BY in the middle of the screen.

20. The prompt at the bottom asks ARE NAME AND DATE CORRECT? ENTER YES OR NO. Type in the word YES or the word NO and presS FIELD REL.

\section{EXAMPLE 46. ECRPT2}

a. The ECORLOG Batches for the ECRPT2 report have been processed, and a name and date requested and entered for the report summary (Steps 17 through 19). In Step 20, the name and date are validated by the ARE NAME AND DATE CORRECT?... prompt. Since the name and date were entered correct 1y, 'YES' is entered.

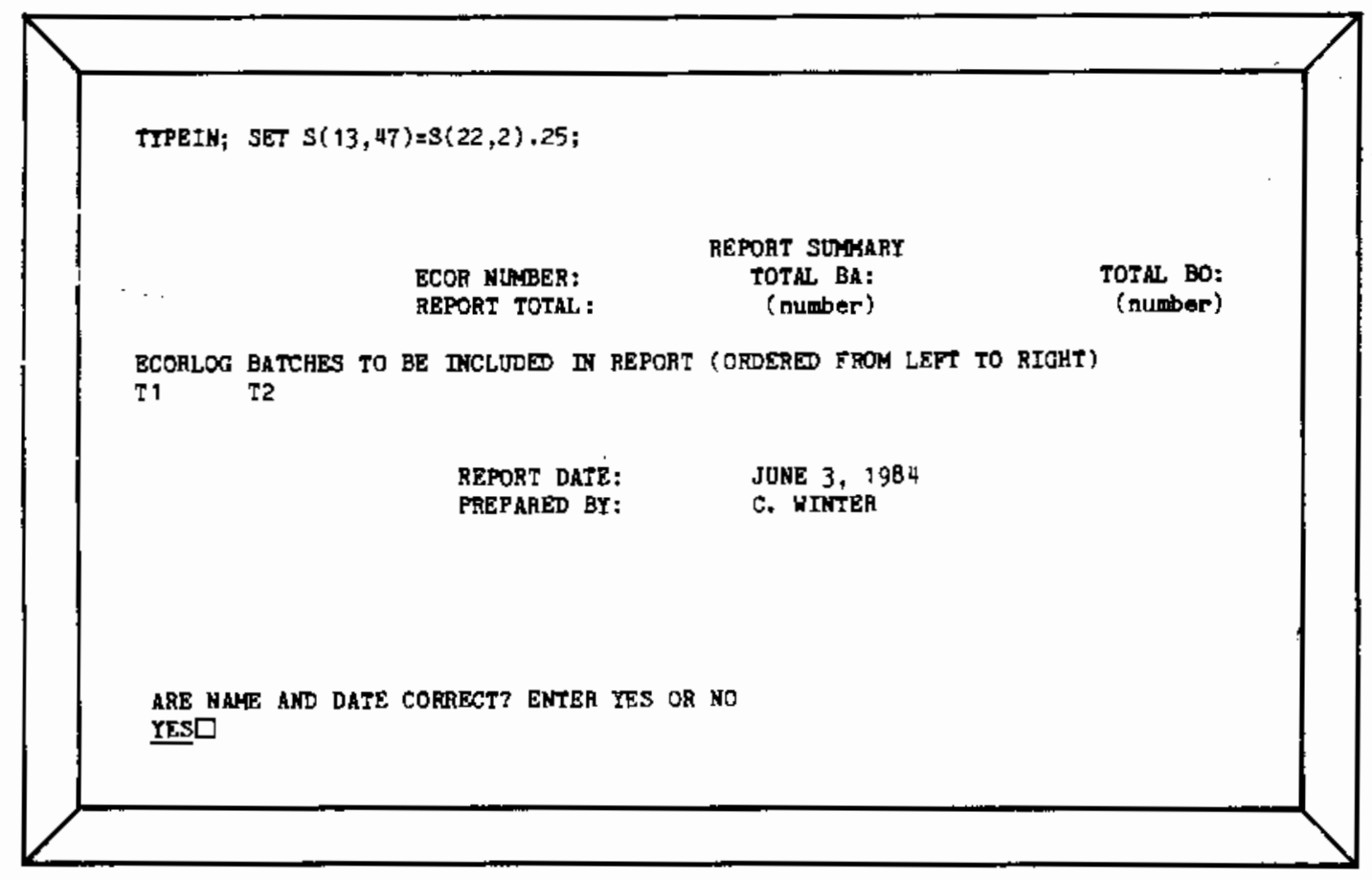


21. If NO was entered at Step 20, the name and date last entered will be erased from the top of the screen, and the prompt at the bottom of the screen becomes TRY AGAIN - ENTER TODAY'S DATE. Go back to Step 18 to reenter the date and name.

22. If YES was entered at Step 20 , the report continues to print unt $i 1$ finished. After al1 ECRPT2 program statements have been executed, the prompt near the bottom of the screen reads:

HIT MODE KEY TO EXIT WHEN 'SEND ENCOUNTERED' APPEARS BELOW

Almost immediately, the bottom line of the screen displays

\$END ENCOUNTERED. At this point, press the MODE Key (MODE $\times \mathrm{S}$ signs the user out of VISION, MODE E ECORLOG,Batch allows another Batch to be viewed or edited). As long as \$END ENCOUNTERED is displayed, pressing the MODE Key will not interrupt a report still being printed.

\section{EXAMPLE 47. ECRPT2}

a. In Step 22, the report summary is sent to the printer, and the ECRPT2 program finishes. As the prompt on the screen indicates, the MODE Key should be pressed to proceed to the next VISION task.

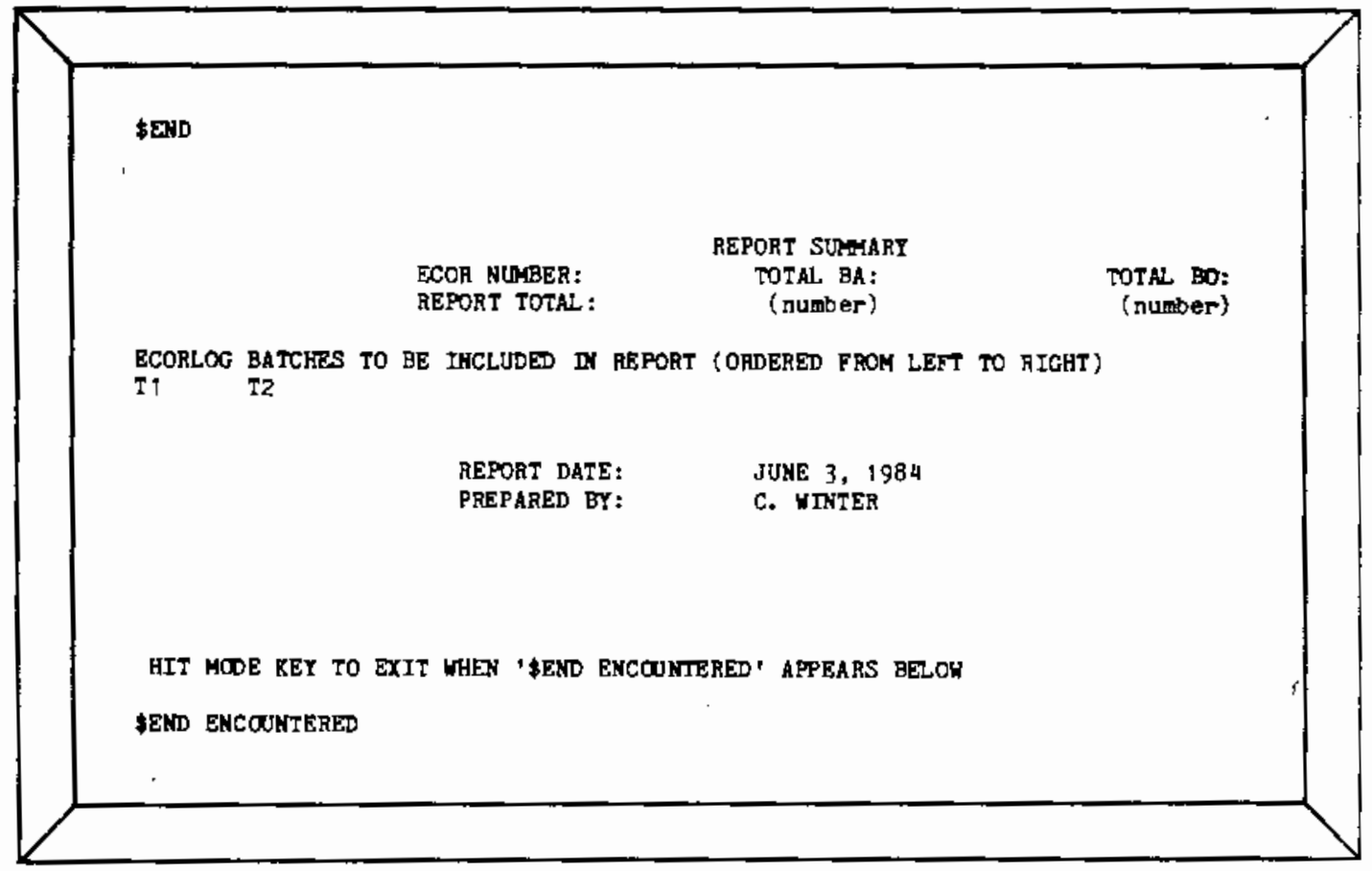




\subsection{RUNNING ECORUP, ECRPT1 AND ECRPT2 IN ONE OPERATION}

1. Follow Steps 1 through 12 in the section on running ECORUP.

2. When ECORUP is completed, the top line of the screen reads: \$PAUSE PRESS SPACE BAR TO PRINT REPORT ON ONE BATCH, MODE KEY TO EXIT The prompt near the bottom of the screen reads:

HIT SPACE BAR TO CONTINUE MULTI-MODE. Press the space bar.

3. At this point ECRPTl will begin to execute (Steps 1 through 7 of the section on running ECRPT1 have been bypassed). Continue by following Steps 8 through 18 in the ECRPT1 section.

4. The ECRPTl report will finish printing out; when it is completed, the top line of the screen reads:

\$PAUSE PRESS SPACE BAR TO PRINT MULTI BATCH REPORT, MODE KEY TO EXIT The prompt near the bottom of the screen reads: HIT SPACE BAR TO CONTINUE MULTI-MODE. Press the space bar again. Do not remove the ECRPT1 report from the printer or reposition the paper.

5. ECRPT2 wil1 begin to execute (Steps 1 through 8 of the ECRPT2 section have been bypassed). Follow Steps 9 through 22 for ECRPT2, omitting Step 17 . When the program is complete and \$END ENCOUNTERED appears at the bottom of the screen, press the MOOE key to go to other VISIDN tasks or exit VISION. 


\subsection{SAMPLE ECORLOG REPORTS}

This section contains samples of the ECORLOG reports. These sample reports were produced from the Batches ' $T 1$ ' and ' $T 2$ ' which have been used in the Examples throughout the Users' Guide. Figure 1 shows a sample ECRPTI report; Figure 2 shows a sample ECRPT2 report. 


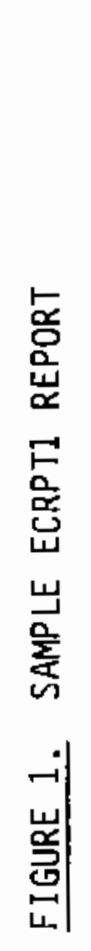

FY 1984 APPROPRIATION AMOUNT:

FY 1984 UNOBLIGATEO CARR YOVER AMT:

$3,500,000$

525,060

\section{ECOR \#: AK OS}

APPROPRIATION NLMBER: $89 \times 0224.91$

TOTAL ECOR AVAILABILITY: $\quad 4,025,060$

ARALYST: D. KERN

PHONE $\boldsymbol{f}$ :

\begin{tabular}{|c|c|c|c|c|c|c|c|c|c|c|}
\hline $\begin{array}{l}\text { DATE } \\
\text { REC'D. }\end{array}$ & CONTRACTOR & Fo & $\operatorname{IPMIS}_{(\mathrm{C}[0)}$ & BA & CUM. BA & Bo & CUM. Bо & $\begin{array}{l}\text { PROGRAM } \\
\text { MANAGER }\end{array}$ & $\begin{array}{l}\text { WORK } \\
\text { DESCRIPTION/TITLE. }\end{array}$ & COHENTS \\
\hline $09 / 20$ & $\begin{array}{l}\text { OAK RIDGE } \\
\text { NAI IONAL } \\
\text { LABORATORY }\end{array}$ & ORO & & 700,000 & 700,000 & 700,000 & 700,000 & KLEIN & $\begin{array}{l}\text { ELECTRONAGNETIC } \\
\text { PULSE }\end{array}$ & $\begin{array}{l}\text { to BROGAN } 9 / 22 \\
\text { to DASC } 9 / 27 \\
\text { To LAB } 11 / 3\end{array}$ \\
\hline $09 / 20$ & $\begin{array}{l}\text { OAK RIGGE } \\
\text { NAT IONAL } \\
\text { LABORATORY }\end{array}$ & $\propto R 0$ & & 580,000 & $1,290,000$ & 580,000 & $1,280,000$ & KLEIN & $\begin{array}{l}\text { ADVANCEO } \\
\text { DIELECTRICS }\end{array}$ & $\begin{array}{l}\text { TO BROGAN } 9 / 22 \\
\text { TO DASC } 9 / 27 \\
\text { TO LAB } 11 / 3\end{array}$ \\
\hline $09 / 20$ & $\begin{array}{l}\text { OAK RIDGE } \\
\text { MAI 1ONAL } \\
\text { LABORATORY }\end{array}$ & ORO & & 300,000 & $1,580,000$ & 300,000 & $1,580,000$ & KLE IN & $\begin{array}{l}\text { AOAPTIVE PROTECTION } \\
\text { OIELECTRICS }\end{array}$ & $\begin{array}{l}\text { TO BROGAN } 9 / 22 \\
\text { TO DASC } 9 / 27 \\
\text { To LAB } 11 / 3\end{array}$ \\
\hline $11 / 14$ & US AIR FORCE & 10 & C535217 & 100,000 & $1,680,000$ & 100,000 & $1,680,000$ & LEVINSON & $\begin{array}{l}\text { TECHNOLOGY MANAGE- } \\
\text { MENT AND ASSESSMENT }\end{array}$ & $\begin{array}{l}\text { TO BROGAN } 11 / 14 \\
\text { TO DASC } 11 / 15 \\
\text { TO PROCURE } 12 / 5\end{array}$ \\
\hline $11 / 04$ & $\begin{array}{l}\text { GENERAL } \\
\text { ELECTRIC CO. }\end{array}$ & WhO & ET29040 & 9,000 & $1,689,000$ & 9,000 & $1,689,000$ & ROESLER & $\begin{array}{l}\text { COOROINATED DECEN- } \\
\text { TRAL IZED EMERGENCY } \\
\text { STATE CONIROL - } \\
\text { HO COST EXTENSION }\end{array}$ & $\begin{array}{l}\text { To BROGAN } 11 / 4 \\
\text { To BAM } 11 / 4\end{array}$ \\
\hline $10 / 12$ & $\begin{array}{l}\text { WEST INGHONSE } \\
\text { ELECTRIC CO. }\end{array}$ & CHIO & RA50292 & 150,000 & $1,839,000$ & 150,000 & $1,839,000$ & ROESLER & $\begin{array}{l}\text { INVESTIGAT ION OF } \\
\text { DOUBLY-FED MACHINE } \\
\text { YAR IABLE SPEED } \\
\text { APPLICATIONS }\end{array}$ & $\begin{array}{l}\text { TO BROGAN } 10 / 2 \\
\text { TO ROESLER } 10 / 17 \\
\text { TO BAM } 11 / 4 \\
\text { To CHO } 11 / 14\end{array}$ \\
\hline
\end{tabular}

REPORT DATE: JUNE 3, 1984

PREPAREO BY: C. WINTER $\begin{array}{ll}\text { TOTAL BA: } & 1,839,000 \\ \text { TOTAL B0: } & 1,839,000\end{array}$ 


\section{ECOR 1: AK 05}

$3,500,000$

APPROPRIATION NUMBER: $89 \times 0224.91$

FY 1984 UNOBLIGATED CARRYOVER AMT: $\quad 525,060$

TOTAL ECOR AVAILABILITY: $\quad 4,025,060$

\section{ANALYST: D. KERM}

PHONE : :

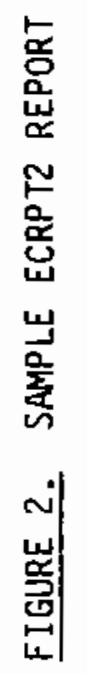

\begin{tabular}{|c|c|c|c|c|c|c|c|c|c|c|}
\hline $\begin{array}{l}\text { OAIE } \\
\text { REC'0. }\end{array}$ & CONTRACTOR & Fo & $\begin{array}{l}\text { IPMIS } \\
\text { (CID) }\end{array}$ & $\mathrm{BA}$ & $\begin{array}{l}\text { ECOR\# } \\
\text { CUM. BA }\end{array}$ & 80 & $\begin{array}{l}\text { ECOR: } \\
\text { CUM. BO }\end{array}$ & $\begin{array}{l}\text { PROGRAM } \\
\text { MANAGER }\end{array}$ & $\begin{array}{l}\text { WORK } \\
\text { DESCRIPT ION/TITLE }\end{array}$ & COMENTS \\
\hline $09 / 20$ & $\begin{array}{l}\text { OAK RIDGE } \\
\text { NAI IONAL } \\
\text { LABORATORY }\end{array}$ & ORO & & 700,000 & 700,000 & 700,000 & 700,000 & KLEIN & $\begin{array}{l}\text { ELECTROMAGMETIC } \\
\text { PULSE }\end{array}$ & $\begin{array}{l}\text { TO BROGAN } 9 / 22 \\
\text { TO DASE } 9 / 27 \\
\text { to LAB } 11 / 3\end{array}$ \\
\hline $09 / 20$ & $\begin{array}{l}\text { OAK RIDGE } \\
\text { HAT IONAL } \\
\text { LABORATORY }\end{array}$ & ORO & & 580,000 & $1,280,000$ & 580,000 & $1,280,000$ & KLE IN & $\begin{array}{l}\text { ADVANCED } \\
\text { DIELECTRICS }\end{array}$ & $\begin{array}{l}\text { To BROGAN } 9 / 22 \\
\text { To DASC } 9 / 27 \\
\text { To LAB } 11 / 3\end{array}$ \\
\hline $09 / 20$ & $\begin{array}{l}\text { OAK RIOGE } \\
\text { NAT IONAL } \\
\text { LABORATORY }\end{array}$ & ORO & & 300,000 & $1,580,000$ & 300,000 & $1,580,000$ & KLEIN & $\begin{array}{l}\text { ADAPTIVE PROTECTION } \\
\text { DIELECTRICS }\end{array}$ & $\begin{array}{l}\text { TO BROGAN } 9 / 22 \\
\text { TO OASC } 9 / 27 \\
\text { TO LAB } 11 / 3\end{array}$ \\
\hline $11 / 14$ & US AIR FORCE & in & $\operatorname{cs} 35217$ & 100,000 & $1,680,000$ & 100,000 & $1,680,000$ & LFYINSON & $\begin{array}{l}\text { TECHNOL OGY MANAGE- } \\
\text { MENT ANO ASSESSMENT }\end{array}$ & $\begin{array}{l}\text { To BROGAN } 11 / 14 \\
\text { T0 DASC } 11 / 15 \\
\text { TO PROCURE } 12 / 5\end{array}$ \\
\hline $11 / 04$ & $\begin{array}{l}\text { GENERAL } \\
\text { ELECTR1C CO. }\end{array}$ & WHO & ET29040 & 9,000 & $1,689,000$ & 9,000 & $1,6 \mathrm{Bg}, 000$ & ROESLER & $\begin{array}{l}\text { COORDIMATED DECEN- } \\
\text { TRALIZEO EMERGENCY } \\
\text { STATE CONTROL- } \\
\text { NO COST EXTEMSION }\end{array}$ & $\begin{array}{l}\text { TO BROGAN } 11 / 4 \\
\text { To BAM } 11 / 4\end{array}$ \\
\hline $10 / 12$ & $\begin{array}{l}\text { WESTIMGHOUSE } \\
\text { ELECTRIC CO. }\end{array}$ & CHO & RA50292 & 150,000 & $1,839,000$ & 150,000 & $1,839,000$ & ROESLER & $\begin{array}{l}\text { INVESTIGATION OF } \\
\text { OOUBLY-FED MACHINE } \\
\text { VAR LABLE SPEEO } \\
\text { APPLICATIONS }\end{array}$ & $\begin{array}{l}\text { TO BROGAN } 10 / 2 \\
\text { TO ROESLER } 10 / 17 \\
\text { TO BAH } 11 / 4 \\
\text { TO CHO } 11 / 14\end{array}$ \\
\hline
\end{tabular}

SUMARY FCA ECOR NUMBER AK 05

BA: $\quad 1,839,000$

B0: $\quad 1,839,000$ 


\section{ECOR H: AK 06}

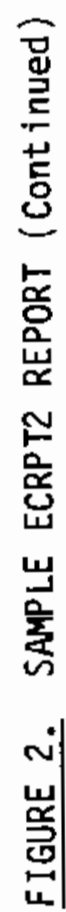

FY 1984 APPROPRIAT ION AMOUNT:

$11,500,000$

APPROPRIATION NUMBER: $89 \times 224.91$

FY 1984 UNOBLIGATED CARRYOVER AMT:

0

TOTAL ECOR AVAILABILITY:

$10,614,000$

AMALYST: D. KERN

DATE
REC'D.

CONTRACTOR Fo IPMIS

11/04 OAK RIDGE ORN

NAT IONAL LABORATORY

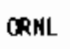

(ID)

sa

ECOR:

80

ECOR

PROGRAM

HORK

PHONE :

10/12 CORNELI

CORNELL
UNIVERSITY

CHO RA50664

855,000

555,000

555,000 KLE IN

TECHNICAL CONCEPTS TO BAM $11 / 15$ AND MANAGEMENT TO ORO $11 / 28$
$10 / 2$

11/22 DHR, INC.

HO CS10097

09/25 BROOKHAVEH

MATIONAL

LABORATORY

CHO

$1 / 12 \quad \mathrm{NASA} / \mathrm{JPL}$

(RO
$74,000 \quad 929,000$

74,000

629,000 ROESLER

$35,000 \quad 964,000$

35,000

564,000 KLEIN

$97,000 \quad 1,061,000$

$1,500,000 \quad 2,561,000 \quad 1,500,000 \quad 2,261,000$ EATON

$500,000 \quad 3,061,000$

500,000
INTEGRATION METHOD-
OLOGY FOR LARGE
WINO ENERGY

CONYERSION SYSTEMS

TO BROGAN $10 / 12$

TO ROESLER $10 / 18$

TO BAH $11 / 4$

TECHNICAL SUPPORT TO BROGAN 10/21

TO BAM $11 / 4$

STUDY FOR POSSIBLE TO BAM $11 / 26$

$\begin{array}{ll}\text { STUDY FOR POSSIELE } & \text { TO BAM 11/26 } \\ \text { TRANSFER OF } & \text { TO PROCURE } 12 / 5\end{array}$

ACHIEVEMENTS TO DOD

AC SUPERCONOUCTING TO OASC 9/?7

POWER CABLE TO DAS $10 / 11$

RESEARCH

TO LAB $11 / 3$

FIBER OPTICS

COMHUN I CATIONS

TO DASC $1 / 16$
TO LAB $2 / 2$

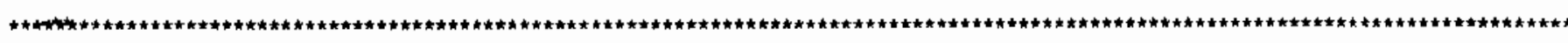




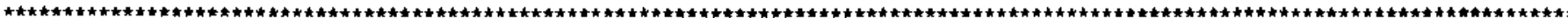

REPORT SUMARY

$\begin{array}{lrr}\text { ECOR NUMBER } & \text { TOTAL BA } & \text { TOTAL BO } \\ \text { AK O5 } & 1,839,000 & 1,839,000 \\ \text { AK O6 } & 3,061,000 & 2,761,000 \\ \text { REPORT TOTAL: } & 4,900,000 & 4,600,000 \\ & & \\ \text { REPORT DATE: } & \text { JUNE 3,1984 } & \\ \text { PREPARED BY: } & \text { C. HINTER } & \end{array}$




\subsection{UTILITY FUNCTIONS FOR THE ECORLOG APPLICATION}

This section contains instructions for two utility operations used by the ECORLOG application. Section 5.1 describes two alternate procedures for resetting the VISION system printer with the \$SETPRINT command. Section 5.2 gives details on storing oId ECORLOG Batches in archival storage, and retrieving those Batches when necessary.

\subsection{RESETTING THE VISION SYSTEM PRINTER}

By default, all printed output from VISION Jobs and programs is sent to the system printer in the computer room. It is often desirable to redirect that output to another printer in a more convenient location. Output can by redirected with the VISION \$SETPRINT command. The \$SETPRINT command can be issued directly from the terminal; alternately, \$SETPRINT commands can be accessed and executed in the MASTER, SETPRT Batch. Procedures for both methods are given below.

\subsubsection{Resetting the VISION Printer Directly}

1. Press the MOOE key, type E, and press FIELD REL.

2. The prompt at the bottom of the screen asks you to TYPE COMMAND. Enter:

\$SETPRINT SYSPRINT TO P8121 n

where ' $n$ ' is the number of the printer to which VISION output should be sent.

3. Press the MOOE key, and type T. When prompted to TYPE PASSWORD, type in the word PASSWORD. Type $S$ to execute the command. If the command is executed successfully, the bottom of the screen will display: REQUEST COMPLETE.

\subsubsection{Resetting the VISION Printer with MASTER, SETPRT}

1. Press the MODE key and type $F$ to access Find Mode. When you are prompted to TYPE JOBNAME,BATCH\#, type MASTER, SETPRT and presS FIELD REL.

2. The next prompt asks you to TYPE SEARCH INFORMATION. To redirect output to the printer in the computer room, type \#3. To redirect output to printer\#2, enter \#1. Conclude ejther entry by pressing FIELD REL.

3. Press the MOOE key, and type T. When prompted to TYPE PASSWORO, type in the word PASSWORD. Type $S$ to execute the command. If the command is executed successfully, the bottom of the screen will display: REQUEST COMPLETE. 


\subsection{YEAR-END PROCEDURES FOR STORING ECORLOG BATCHES}

Procurements are issued under the sane ECOR Number in successive fiscal years. Each Batch of ECORLOG, however, should cover only those procurements issued under one ECOR Number in one fiscal year. If Batches continued to be stored in the ECORLOG Job year after year, it would become difficult to find unique Batch ID's for the same ECOR Number. For this reason, a procedure has been developed for transferring ECORLOG Batches to archival (compressed) storage in computer memory. These procedures, described in the sections which follow, should be followed at the end of each fiscal year.

The commands which transfer ECORLOG Batches to archival storage are stored in Batch ECPURG of the MASTER Job. Each year, these commands are edited so that the ID's of all Batches created during the past fiscal year are included. After the editing is completed, the set of commands is executed to transfer ECORLDG Batches to storage, then to delete the Batches from the ECORLOG Job. In addition, MASTER,ECPURG contains commands to retrieve old Batches from archival storage. These commands can be modified and executed whenever there is a need to access ECORLOG data from prior fiscal years.

The three operations - storage, deletion, and retrieval - each use a different VISION command. All three types of commands are stored in MASTER,ECPURG. The storage commands at the beginning of the the Batch make up a \$TODOS command string. The deletion commands which follow the storage commands are \$PURGE command strings. The last commands in MASTER,ECPURG - the retrieval commands are a \$FRODOS command string.

In Section 5.2.1, the VISION commands and their parameters are discussed in greater detail. The editing of the MASTER, ECPURG commands is covered in Section 5.2.2. The next section (Section 5.2.3) gives instructions for storing and deleting ECORLOG Batches; Section 5.2.4 contains instructions for retrieving ECORLOG Batches from archival storage.

A second set of storage and retrieval commands has been created in MASTER, ECPG84. These commands should be used on ly for the Fiscal Year 1984 Batches stored in the ECLOG84 Job. The instructions on the following pages are also valid for ECPG84, with one exception: 'ECPG84' should be substituted for 'ECPURG' when the commands are being edited and executed. 


\subsubsection{The VISION Commands for Storage, Deletion and Retrieval}

The Batch containing the ECORLOG storage, deletion, and retrieval commands is MASTER, ECPURG. This Batch has been created with templates of the \$TOOOS, \$PURGE and \$FRODOS commands used, respectively, for storing, deleting, and retrieving ECORLOG Batches. The contents of the original MASTER, ECPURG Batch are shown in Figure 3. Since these contents are modified before execution, the MASTER,ECPURG Batch stored in the computer will not be identical to Figure 3. The following paragraphs describe the setup and parameters for each of the three comands.

FIGURE 3. ORIGINAL CONTENTS OF MASTER,ECPURG

\$COMMENT COMMANDS TO ARCHIVE ECORLOG BATCHES

$\$$ TODOS

$10=B C H 184 @ 0, J=E C O R L O, K=K G, B=B B A T C H, C=C 1, P$

$10=B C H 28400, J=E C O R L O, K=K G, B=B B A T C H, C=C 2, P$

\$PAUSE COMMANDS TO DELETE ECORLOG BATCHES

\$PURGE ECORLOG,BATCH1

\$PURGE ECORLOG, BATCH2

\$PAUSE COMANDS TO RETRIEVE ECORLOG BATCHES

\$FRODOS

$/ \mathrm{I}=\mathrm{BCH} 184 @ 0, \mathrm{~J}=\mathrm{ECORLO}, \mathrm{K}=\mathrm{KG}, \mathrm{B}=\mathrm{BBATCH}, \mathrm{C}=\mathrm{Cl}, \mathrm{P}$

$/ \mathrm{I}=\mathrm{BCH} 284 \mathrm{CO}, \mathrm{J}=\mathrm{ECORLO}, \mathrm{K}=\mathrm{KG}, \mathrm{B}=\mathrm{BBATCH}, \mathrm{C}=\mathrm{C} 2, \mathrm{P}$

\$END 
$\$ T O D O S$ Commands. The first command string in MASTER,ECPURG is the \$TODOS comand string to transfer ECORLOG Batches to archival storage. A copy of the $\$$ TODOS command string appears below.

$$
\begin{aligned}
& \$ T O D O S \\
& / 0=B C H 18400, J=E C O R L O, K=K G, B=B B A T C H, C=C 1, P \\
& / 0=B C H 28400, J=E C O R L O, K=K G, B=B B A T C H, C=C 2, P \\
& \$ P A U S E
\end{aligned}
$$

The command string begins with the keyword \$TODOS, which is followed by parameter lines for one or more Batches. Each parameter line, except the last, is followed by a blank line. The last parameter line is followed by a \$PAUSE (or a \$END) keyword. Each parameter line consists of the parameters described be low.

$10=\mathrm{BCH} 18400$,

The $/ 0=$ parameter indicates the name of the output file, and that the file is to be created on Drive\#0. The underlined characters are the output file name - this should be changed for each transfer operation. The output file name's last two characters should indicate the fiscal year.

$J=E C O R L O, K=K G$,

The $J=/ J=K$ parameter indicates that the data to be transferred is currently stored in the ECORLOG Job. This parameter should not be changed.

$\mathrm{B}=\mathrm{BBATCH}, \mathrm{C}=\mathrm{C} \underline{\mathrm{T}}$,

The $B=B / C=C$ parameter indicates the Batch ID where the data is current $1 y$ stored. The underlined characters are the Batch IO (in this case, 'BATCHI'). The Batch ID should be changed for each Batch to be transferred. If the Batch $I D$ is five characters or less in length, the $C=C$ parameter and the comma which follows it shouid be deleted from the parameter line.

$P$

The P parameter, which sets the program level for the data transfer, concludes all \$TODOS command strings used in transferring ECORLOG Batches. It should never be deleted or modified.

\$PURGE comands. The next command strings in MASTER,ECPURG are SPURGE command strings, each of which deletes one ECORLOG Batch after it has been copied to archival storage. Two SPURGE command strings are shown below.

SPURGE ECORLOG,BATCHI

\$PURGE ECORLOG,BATCH2

\$PAUSE

For each ECORLOG Batch to be deleted, there is a comand string beginning with the SPURGE keyword. This is followed by the Job name (ECORLOG) and the ID of the Batch to be deleted (here, the Batches are BATCH1 and BATCH2). The Batch ID should be modified for each Batch which is to be deleted. The set of command strings - one for each Batch - is concluded by a SPAUSE (or SEND) keyword. 
\$FRODOS Commands. The last command string in MASTER,ECPURG is the \$FRODOS command string, wich retrieves ECORLOG Batches from archival storage. A copy of the \$FRODOS command string appears below.

$$
\begin{aligned}
& \text { \$FRODOS } \\
& \text { / I =BCH1 } 8400, J=E C O R L O, K=K G, B=B B A T C H, C=C 1, P \\
& \text { /I }=B C H 28400, J=E C O R L O, K=K G, B=B 8 A T C H, C=C 2, P \\
& \text { \$END }
\end{aligned}
$$

The command string begins with the keyword \$FRODOS, which is followed by parameter lines for one or more Batches. Each parameter line, except the last, is followed by a blank line. The last parameter line is followed by a \$END (or a SPAUSE) keyword. The parameter lines consist of the following parameters.

$/ 1=\mathrm{BCH} 18400$,

The $\bar{I} I=$ parameter indicates the name of the input file in archival storage, and that the $f i l e$ is stored on Drive\#0. The underlined characters are the input file name - this should be changed for each retrieval operation. The names of files in archival storage $c$ an be viewed in the IDOS Index from Foreword.

$J=E C O R L O, K=K G$,

The $J=/ J=K$ parameter indicates that the data is to be retrieved into the ECORLOG Job. This parameter should not be changed.

$\mathrm{B}=\mathrm{BBATCH}, \mathrm{C}=\mathrm{C} 1$,

The $B=B / \bar{C}=C$ parameter indicates the Batch ID of the destination ECORLOG Batch. The underlined characters are the Batch ID (here, it is 'BATCH1'). The Batch ID should be changed for each Batch to be retrieved. If the Batch ID is five characters or less in length, the $C=C$ parameter and the comma which follows it should be deleted from the parameter line.

$P$

The $P$ parameter, which sets the program level for the data retrieval, concludes all \$FRODOS command strings used in transferring ECORLOG Batches. It should never be deleted or modified.

\subsubsection{Editing the Commands in MASTER, ECPURG}

Before the storage or retrieval command strings in MASTER,ECPURG can be executed, the Batch must be edited to change the parameters to the command $(s)$. This editing is done in data Entry mode (MODE E). To begin editing the MASTER, ECPURG commands, type MODE E MASTER,ECPURG. Details on changing, adding and deleting MASTER,ECPURG Records are given below. 
Changing Records.

1. Find and display the Record that is to be changed by using the up or down arrow key.

2. Press SHIFT and CORR REST simultaneously. This unlocks the Record and allows changes to be made.

3. Move the cursor to the first character of an item which needs changing. The right arrow key moves the cursor to the right; the left arrow key moves the cursor to the left.

4. Type the new parameter over the old one. The CTRL and right arrow keys, when pressed together, will open up one space (use this when the new parameter is longer than the old one). The CTRL and left arrow keys pressed simultaneously will delete one space (used if the new parameter is shorter than the old one).

5. Repeat Steps 3 and 4 until a 11 needed changes have been made.

6. If you want to retain that portion of the Record which is under and to the right of the cursor, press the AUX DUP key to finish editing the Record. If you want to erase the portion of the Record underneath and to the right of the cursor, press FIELD REL to complete the edit.

\section{Adding Records.}

1. Display the Record after which the new Record is to be added.

2. Press SHIFT/CORR REST to un lock the Record.

3. Press SHIFT and the down arrow together to make a copy of the Record.

4. Press the down arrow key once to display the copy of the Record. This copy will be changed to become the added Record.

5. If you are adding a blank Record, press SHIFT/CORR REST to unlock the Record, then press FIELD REL to erase its contents and store it as a blank Record.

6. If you are adding a non-blank Record, refer to the instructions in the previous section on Changing Records.

\section{Deleting Records.}

1. Display the Record which is to be deleted, using the up or down arrow key.

2. Press SHIFT/CORR REST to un lock the Record.

3. Press SHIFT and the up arrow simultaneously to delete the Record. 


\subsubsection{Storing and Deleting ECORLOG Batches}

1. When you are ready to store and delete ECORLOG Batches at the end of the fiscal year, make a list of the Batches you want to store and delete. Next to each Batch ID, write the name of the output file (maximum six characters) to which it will be copied in archival storage. The name of each output file should end in two numbers signifying the fiscal year.

2. Edit the \$TODOS and \$PURGE commands in MASTER,ECPURG, following the instructions given in Section 5.2.3. You should include one \$TODOS parameter line for each Batch; the $0=$ (output file name) and $B=8 / C=C$ (Batch ID) parameters need to be edited in each of the \$TODOS parameter lines. Do not forget to include a blank line after each \$TOOOS parameter line except the last. You also need to create one \$PURGE command string for each Batch. The Batch ID parameter will need to be changed in each of the \$PURGE command strings.

3. When the editing is finished, press CTRL and the up arrow together to display the first Record of MASTER,ECPURG, which reads:

\section{\$COMMENT COMMANOS TO ARCHIVE ECORLOG BATCHES}

4. Press the MODE key, and type T. At the TYPE PASSWORD prompt, type the word PASSWORD. At the prompt beginning TYPE $S=S I N G L E, M=M U L T I . . .$, type $M$. The transfer of ECORLOG Batches to archival storage wili' begin.

5. When all selected ECORLOG Batches have been copied to archiva? storage, the top and bottom lines of the screen will display, respectively:

\section{SPAUSE COMMANDS TO DELETE ECORLOG BATCHES}

HIT SPACE BAR TO CONTINUE MULTI-MODE

Press the space bar. The selected Batches will now be deleted from the ECORLOG Job.

6. When all of the selected Batches have been deleted, the top and bottom lines of the screen will display:

\$PAUSE COMMANDS TO RETRIEVE ECORLOG BATCHES HIT SPACE BAR TO CONTINUE MULTI-MODE

Presis the MODE key to exit VISION or proceed to another VISION task. 


\subsubsection{Retrieving ECORLOG Batches}

1. When you need to retrieve ECORLOG Batches from archival storage, make a list of the file names under which the Batches are stored. A list of the files in archival storage can be viewed by accessing the IDOS Index from Foreword. Next to each file name, write the name of the Batch ID (maximum six characters) to which it will be copied in the ECORLOG Job.

2. Edit the $\$ F R 000 S$ command string in MASTER, ECPURG, following the instructions given in Section 5.2.3. You should include one $\$ F R O 00 S$ parameter line for each Batch; the $I=$ (input file name) and $B=B / C=C$ (Batch ID) parameters need to be edited in each of the \$FRODOS parameter lines. Do not forget to include a blank line after each \$FRODOS parameter line except the last.

3. When the editing is finished, use the up arrow to display that Record of MASTER,ECPURG which reads:

\$FRODOS

4. Press the MODE key, and type T. At the TYPE PASSWORD prompt, type the word PASSWORD. At the prompt beginning TYPE S=SINGLE, M=MULTI..., type $M$. The transfer of Batches from archival storage to the ECORLOG Job will begin.

5. When all selected ECORLOG Batches have been retrieved from archival storage, the top and bottom lines of the screen will read, respectively:

\section{SEND}

\section{SEND ENCOUNTERED}

Press the MODE key. The Batches have been stored in the ECORLOG Job. They can now be viewed and edited (see Section Three) or used in the ECORLOG programs (Section Four). 
APPENDIX

ECORLOG COMPUTER APPLICATION PROGRAMMERS' GUIDE 


\section{APPENDIX}

\section{ECORLOG COMPUTER APPLICATION PROGRAMMERS' GUIDE}

This Appendix describes the structure and logic of the ECORLOG Job (database) and programs. The information here will be useful for programers who are maintaining or enhancing the ECORLOG application.

Section A.1 contains a description of the ECORLOG Job; Sections A.2 through A.4 outline each of the three ECORLOG programs. The outline for each program includes a description of the steps followed by the progran, a list of uses made of the system resources (Buffers, Variables and Scratch Accumulators), and print layouts for the two report programs. Finally, Section A.5 contains listings of all pertinent ECORLOG source code. 


\section{A.1 THE ECORLOG JOB}

The ECORLOG Job embodies the database structure used in this application. It was created by the source code stored on the system in the MASTER,ECORJB Batch. Essentially, the Job provides for two different kinds of Records (sumary and detail Records) and a screen display for entering data into each Record type. Figure A.1 summarizes the fields contained in the Program Level One summary Records, while Figure A.2 shows a data entry screen for these Records. Figure A.3 shows the fields contained in the Progran Level Two detail Records and Figure A.4 is a data entry screen layout for these detail Records. 
FIGURE A.1. RECORD LAYOUT FOR PROGRAM LEVEL ONE RECORDS

\begin{tabular}{|c|c|c|c|c|c|c|}
\hline 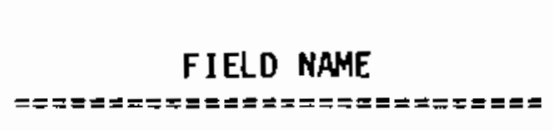 & $\begin{array}{l}\text { FIELD TYPE } \\
=========\end{array}$ & $\begin{array}{l}\text { FIELD } \\
\text { HIDTH } \\
=== \pm=\end{array}$ & $\begin{array}{l}S C R \\
====\end{array}$ & $\begin{array}{l}\text { 3EGINNING } \\
\text { EEN POSITION } \\
============\end{array}$ & $\begin{array}{l}\text { RECORD } \\
\text { POSITIOH } \\
=======\end{array}$ & 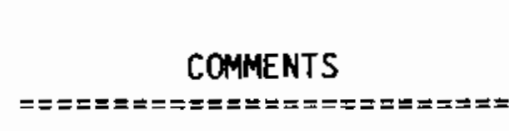 \\
\hline ECOR NUMBER & General & 15 & Line & 3, Column 15 & $1-15$ & \\
\hline ANALYST & Genera 1 & 20 & Line & 5, Column 11 & $16-35$ & \\
\hline PHONE NUMBER & General & 15 & Line & 5, Column 54 & $36-50$ & \\
\hline FISCAL YEAR 1 & Integer & 4 & line & 7, Column 5 & $51-54$ & $\begin{array}{l}\text { Must be filled, i.e., all } \\
\text { four digits of the year } \\
\text { must be entered. }\end{array}$ \\
\hline APPROPRIATION AMOUNT & Numeric & 12 & Line & 7, Column 40 & $55-66$ & \\
\hline APPROPRIATION NUMBER & Genera 1 & 15 & Line & 9 , Column 40 & $67-81$ & \\
\hline FISCAL YEAR II & Integer & 4 & Line & 11, Column 5 & $82-85$ & $\begin{array}{l}\text { The contents of FISCAL } \\
\text { YEAR I are used to fill } \\
\text { this fie ld automatically. }\end{array}$ \\
\hline UNOBLIGATED CARRYOVER AMOUNT & Numer ic & 12 & Line & 11, Column 40 & $86-97$ & \\
\hline TOTAL ECOR AVAILABILITY & Numer ic & 12 & Line & 13, Column 40 & $98-109$ & \\
\hline
\end{tabular}


FIGURE A.3. RECORD LAYOUT FOR PROGRAM LEVEL TWO RECOROS

\begin{tabular}{|c|}
\hline 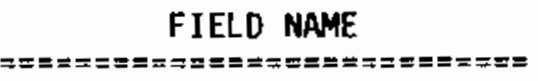 \\
\hline
\end{tabular}

CONTRACTOR I

CONTRACTOR II

CONTRACTOR III

PROGRAM MANAGER

DATE RECEIVED

FIELD OFFICE

IPMIS (CIO) NUMBER

BA

CUMULATIYE BA

FIELD TYPE
$== \pm===== \pm$

FIELD
WIDTH
$== \pm==\quad$ SCREEN POSITION
$=== \pm==== \pm== \pm=== \pm$

Genera 1

12

Line

3. Column 27

\section{General}

Genera 1

Genera 1

Integer and Text
RECORO

POSITION

$1-12$

First of three fields. Must be entered, i.e., the field cannot be bypassed by pressing FIELD REL.

second of three fields.

Third of three fields.

Must be entered.

Together, the first two digits (the month) must be greater than zero and less than 13. The third digit is a slash, which is gener ated automatically. the last two digits (the day) must be greater than zero and less than 32 .

$\begin{array}{lrlll}\text { General } & 4 & \text { Line } 8, \text { Column } 26 & 52-55 \\ \text { General } & 7 & \text { Line } 8 \text {, Column } 61 & 56-62 \\ \text { Numer ic } & 12 & \text { Line } 10, \text { column } 9 & 63-74 \\ \text { Numeric } & 12 & \text { Line } 10, \text { Column } 43 & 75-86\end{array}$

\section{Must be entered.}

Must be entered.

Skipped during data entry. The contents of this field are provided by the ECORUP program. 
FIGURE A.3.- RECORD LAYOUT FOR PROGRAM LEVEL THO RECOROS (cont inued)

\begin{tabular}{|c|c|c|c|c|c|c|}
\hline 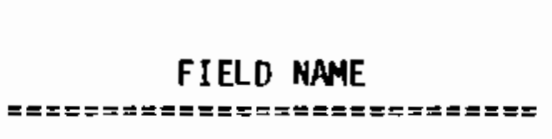 & $\begin{array}{l}\text { FIELD TYPE } \\
===== \pm====\end{array}$ & $\begin{array}{l}\text { FIELD } \\
\text { WIDTH } \\
== \pm==\end{array}$ & $\begin{array}{c}\text { BEGINNING } \\
\text { SCREEN POSITIDN } \\
=============0\end{array}$ & & $\begin{array}{l}\text { RECORD } \\
\text { POSITION } \\
======= \pm\end{array}$ & 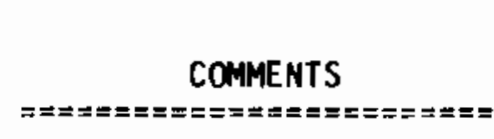 \\
\hline BO & Numer ic & 12 & Line 11 , Column & 9 & $87-98$ & Must be entered. \\
\hline CUMULATIVE BO & Numer ic & 12 & Line 11 , Column & 43 & $99-110$ & $\begin{array}{l}\text { Skipped during data entry } \\
\text { The contents of this fiel } \\
\text { are provided by the ECORU } \\
\text { program. }\end{array}$ \\
\hline WORK TITLE/DESCRIPTION I & General & 19 & Line 13, Column & 27 & $111-129$ & $\begin{array}{l}\text { First of four fields. } \\
\text { Must be entered. }\end{array}$ \\
\hline WORK TITLE/OESCRIPTION II & General & 19 & Line 14 , Column & 27 & $130-148$ & Second of four fields. \\
\hline HORK TITLE/DESCRIPTION III & General & 19 & Line 15, Colımn & 27 & $149-167$ & Third of four fields. \\
\hline WORK TITLE/DESCRIPTION IV & Genera 1 & 19 & Line 16, Column & 27 & $168-186$ & Fourth of four fields. \\
\hline COMMENTS I & General & 17 & Line 18 , Column & 27 & $187-203$ & $\begin{array}{l}\text { First of four fields. } \\
\text { Must be entered. }\end{array}$ \\
\hline COMMENTS II & General & 17 & Line 19, Column & 27 & $204-220$ & Second of four fields. \\
\hline COMMENTS III & General & 17 & Line 20, Column & 27 & $221-237$ & Third of four fields. \\
\hline COMAENTS IV & Genera 1 & 17 & Line 21, Column & 27 & $238-254$ & Fourth of four fields. \\
\hline LAB CODE & Genera 1 & 4 & Line 22, column & 60 & $255-258$ & \\
\hline STATE COOE & General & 2 & Line 22, Column & 75 & $259-260$ & $\begin{array}{l}\text { Validated against Value } \\
\text { Set oll, which contains } \\
\text { the postal abbreviations } \\
\text { for the states, blanks, } \\
\text { and ' } 991 \text { for foreign } \\
\text { contracts. }\end{array}$ \\
\hline
\end{tabular}




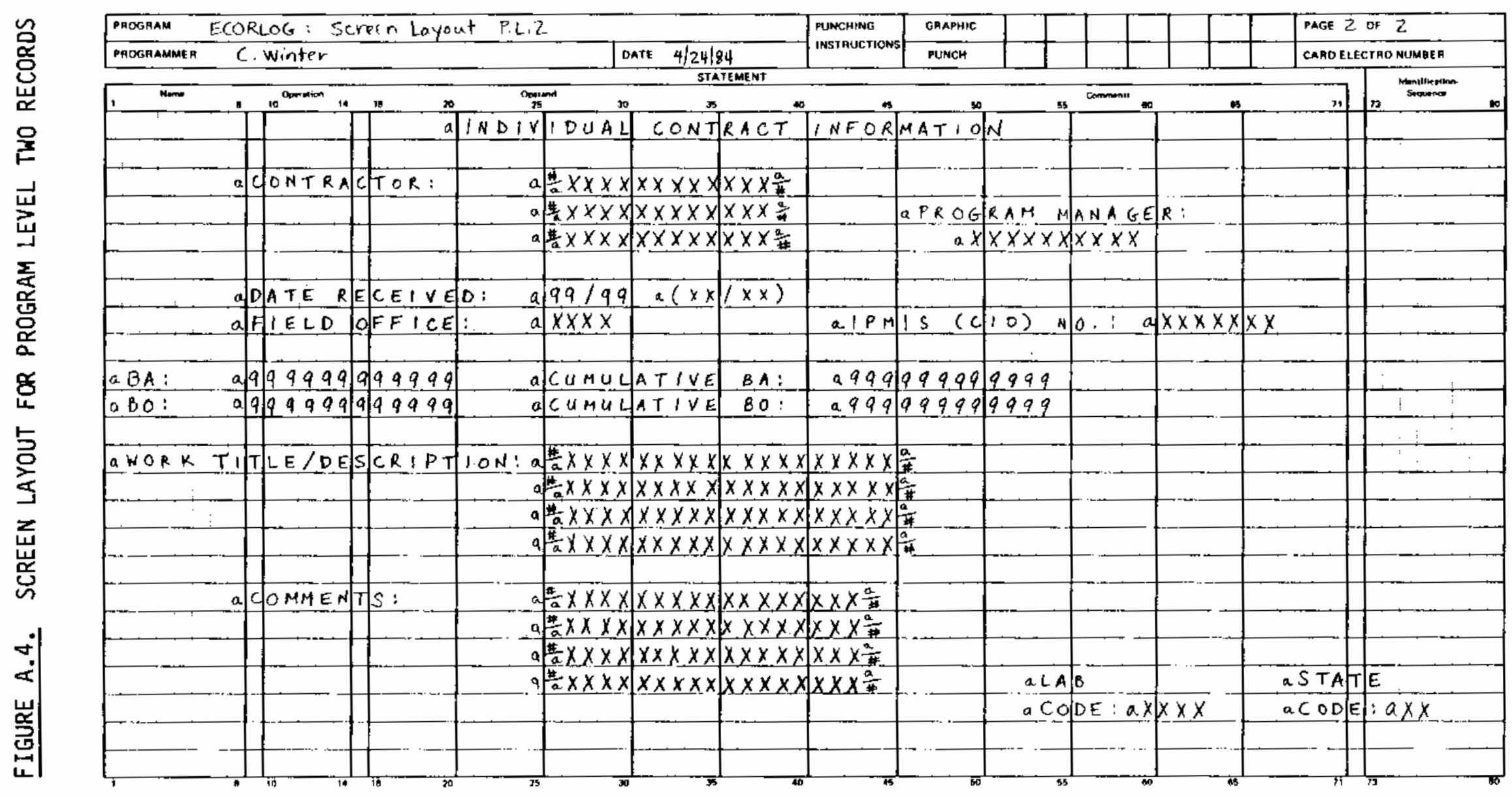




\section{A.2 THE ECORUP PROGRAM}

The ECORUP program serves to update the numeric fields in all Records contained in one Batch of the ECORLOG Job. It is stored at the beginning of the MASTER, ECORLG Batch, in Statements 1-147. Each step that the program follows is listed below. The numbers in parentheses following the name of each step correspond to Statement numbers in the source code. Figure A.5 shows the use of system resources by the ECORUP program.

A brief description of the ECRJST subroutine called by the ECORUP program is also included in this section. This subroutine is stored in MASTER,ECRJST. Figure A.6 shows how the ECRJST subroutine uses system resources.

\section{DESCRIPTION OF THE ECORUP PROGRAM}

1. RETRIEVE A VALID BATCH ID TO UPDATE (2-18) Use the screen buffer to request and validate the Batch ID of the Batch to be updated. In testing the 8atch, it is opened and the first (header) Record read into Buffertl.

2. RIGHT-JUSTIFY HEADER REC'S NUMERIC FIELDS IF NECESSARY (19-25) The header Record now in 8uffer $\$ 1$ contains three numeric fields. For each field, the last position is checked. If it contains a blank, the field needs to be right-justified. The field is then copied to SAC1, a call to the ECRJST subroutine copies the field to SAC2 during the justification, and the field is copied back to Buffer \#1 from SAC2.

3. OPEN BATCH 'TEMP', WRITE HEADER RECORD TO IT (26-31)

The Batch 'TEMP' will temporarily hold an updated copy of the ECORLOG Batch. This Batch is created (and opened), and the header Record written to it.

4. BEGIN MAIN PROGRAM LOOP TO PROCESS DETAIL RECS (32-35)

The main program loop, which processes one detail Record per iteration, begins here. A Record is read, and the loop exited if the end of the Batch has been reached.

5. PROCESS BA (36-83)

Process the $B A$ and CUMLATIVE $B A$ fields of the detail Record. This operation is consists of the four tasks that follow.

5A. RIGHT-JUSTIFY BA IF NECESSARY (37-42)

The BA field is copied from positions 63-74 of Buffer\#l to SACl. If the last position of SACl is blank, a call to ECRJST will rightjustify the field and copy it to SAC2. If the field is already justified, SAC1 is copied to SAC2.

5B. EDIT BA TO USE IT IN ARITHMETIC (43-54)

This task involves removing any commas and/or negative signs from the BA amount. This is done using a position-by-position copy from SAC2 to SAC3, with only numerals being copied. Variable I controls the WHILE statement which does this, and also serves as pointer to each position in SAC2. Variable $J$ is a pointer to the rightmost available position in SAC3 (the edited version), while $K$ serves as a flag which 
is set to the value of one if a negative sign is found in the number. If the number is negative, SAC3 is copied to SAC4, which is then subtracted from SAC3 twice so that SAC3 contains a negative number. Now SAC 3 can be added to SAC11, which accumulates the BA amounts from the CUMULATIVE BA field of each detail Record.

5C. EDIT CUM. BA TO REMOVE LEADING ZEROES (55-69)

The CUMLATIVE BA figure now stored in SAC11 must be edited twice; the first edit removes leading zeroes and adds a negative sign if necessary. SAC11 is copied twice: once to SAC5, where the rightmost poistion contains the sign (positive or negative) of the number, once to SAC6 without the sign. SAC6 is then scanned from left to right to remove leading zeroes. Variable I controls the WHILE statement that accomplishes this, and points to each position of SAC6 in turn. If the position contains a zero and the preceeding position contains a blank, the position is a leading zero which is blanked out. Variable $J$ is set to mark the last leading zero/blank position and that position marked with a ' - ' when the first non-zero number is encountered. When the scan is complete, SAC5's twelth position is checked. If the number is not negative, the ' - ' at SAC6(J) is blanked out; if the number is negative, the overpunched letter in the last position of SAC6 is replaced by the appropriate number (from SAC5(11)).

5D. INSERT COMMAS IN CUM. BA (70-83)

Commas are inserted in the number representing CUMLATIVE BA by another copy between SAC's, this time from SAC6 to SAC7. The copy proceeds from right to left. Three positions are copied. The next position (to the left) in SAC6 is checked: if it is blank, the number has been copied in its entirety; if it is a negative sign, this is copied to SAC7 to complete the edit; if it is a number, the copy is not complete, so a comma and the next three positions of SAC6 are copied to SAC7 to continue the edit. When the edit is complete, SAC7 is uritten to positions 75-86 of Buffer $\# 1$, where CUMLATIVE BA is stored. This completes the processing of BA.

6. PROCESS BO ( $84-131)$

The same logic is used to process $B O$ as for the previous operations on $B A$. The following descriptions of the four subtasks contain only the different storage locations used in handling $B 0$.

6A. RIGHT-JUSTIFY BO IF NECESSARY ( 85-90)

$B O$ is copied to SACl from positions $87-98$ of Buffer\#l.

6B. EDIT BO TO USE IT IN ARITHMETIC (91-102)

CUMLATIVE BO is aCcumulated in SAC12.

6C. EDIT CUM. BO TO REMOVE LEAOING ZEROES (103-117)

SAC5 and SAC6 are copied from SAC12.

6D. INSERT COMMAS IN CUM. BO (118-131)

CUMLATIVE BO is stored in positions 99-110 of Buffer \#1.

7. WRITE UPDATED RECORD TO BATCH (132-133)

The Record is copied from Buffer $\$ 1$ to the Batch 'TEMP' in the last statement of the main program loop. 
8. TRANSFER BATCH 'TEMP' BACK INTO ORIGINAL BATCH (134-147)

Both the original Batch and 'TEMP' are closed. The original Batch is recreated, which erases $i$ ts former contents, and 'TEMP' is reopened. Each record in 'TEMP' is then read into Buffer $\# 1$ and copied to the original Batch. After all Records have been copied, both Batches are closed, and 'TEMP' is deleted. The last (\$PAUSE) statement allows the user a choice of exiting or running the ECRPT1 program.

FIGURE A.5. USE OF SYSTEM RESOURCES BY THE ECORUP PROGRAM

\section{BUFFERS}

Buffer\#1 - Used to read both header and detail Records from the Batch, and to write to the updated Batch. During most of the program (Steps 1-7), Records are read from the Batch chosen for updating and written to Batch 'TEMP'. At the end of the program (Step 8), Records are read from 'TEMP' and written back to the original Batch. Columns 1-109 of the buffer are used to process the header Record; columns 1-260 are used to process detail Records.

\section{VARIABLES}

$I, J, K$ (Steps 5B,6B): Used in removing commas from each detail Record's $B A$ field (Step 5B) and BO field (Step 6B).

$I, J$ (Steps $5 C, 6 C$ ): Used in removing leading zeroes from the number representing each detail Record's CUMULATIVE BA (Step 5C) and CUMULATIVE BO (Step 6C) fields.

\section{SCRATCH ACCUMULATORS (SAC's)}

SACl through SAC7: Used sequentially in the four edits performed on $B A$ (Step 5) and BO (Step 6) amounts.

SAC11: ACCumulates CUMULATIVE BA for the duration of the program.

SAC12: Accumulates CUMULATIVE BO for the duration of the program. 
DESCRIPTION OF THE ECRJST SUBROUT INE

This subroutine, which is called by the ECORUP program, right-justifies any one of the numeric fields in a Batch of ECORLOG. It is called after the last position of a numeric field is checked; if this position contains a blank the field needs justifying and so ECRJST is called.

ECRJST uses a position-by-position copy from SAC1 (the unjustified version) to SAC2, which is initialized with blanks. The copy proceeds from right to left, with Variable I pointing to positions in SACl, J to positions in SAC2. If SAC1(I) is not blank, it is copied to $S A C 2(J)$ and $J$ is decremented. Then $I$ is decremented and the next position checked. If SACl contained nothing, the number is assumed to be zero, and $S A C 2(12)$ set to zero.

FIGURE A.6. USE OF SYSTEM RESOURCES BY THE ECRJST SUBROUTINE

\section{BUFFERS}

No Buffers are used in this subroutine.

\section{VARIABLES}

$1, \mathrm{~J}: \quad$ Used in right-justifying numeric fields.

\section{SCRATCH ACCUMULATORS (SAC's)}

SAC1, SAC2: Used in right-justifying numeric fields. 


\section{A.3 THE ECRPT1 PROGRAM}

The ECRPT1 program outputs a report on the information contained in one ECORLOG Batch. The source code for this program is stored in Statements 148-247 of MASTER,ECORLG. The steps followed by the ECRPT1 program are described below. The numbers in parentheses after the name of each ECRPT1 step indicate the location of the step in the source code. Figure A.7 lists the use of system resources by ECRPT1. Figure A.8 shows the print layout for the report produced by the ECRPTI program.

\section{DESCRIPTION OF THE ECRPTI PROGRAM}

1. RETRIEVE A VALID BATCH ID TO PROCESS (149-166)

Use the screen to request and validate a Batch ID entered by the user. The Batch is tested by opening it and reading the first (header) Record into Buffer $\$ 2$.

2. FORMAT THE REPORT HEADER IN BUFFER\#1 (167-183)

The report header is set up in Buffer $\# 1$. Some of the information consists of text strings which do not change from Batch to Batch, so are treated as literals. The rest of the header information is contained in the Batch's header Record; these fields are copied from Buffer $\$ 2$ to the correct positions in Buffer\#1.

3. PREPARE FOR, BEGIN MAIN PROGRAM LOOP TO PROCESS DETAIL RECORDS (184-197) The main program loop processes one detail Record per iteration. Before the loop begins, Variable $I$ is set for use as a line counter, $J$ for use as a page counter. As the loop begins, the value of $I$ is checked; if necessary, the value of $\mathrm{J}$ (the page number) is set into the report header, the header printed, and $I$ and $J$ incremented. Next, a detail Record is read. If the end of the Batch has been reached, the loop is exited. Otherwise, processing continues by clearing Buffer \#3, into which the Record will be formatted for printing.

4. FORMAT A DETAIL RECORD INTO BUFFER\#3 (198-210)

The contents of the detail Record are copied from Buffer $\# 2$ (into which they have been read) to Buffer\#3 in the proper format for printing.

5. PRINT THE FORMATTED DETAIL RECORD (210-214)

The contents of Buffer $\$ 3$ are printed, followed by a blank line from the screen. Line counter $I$ is incremented, Buffer $\# 2$ cleared to read the next Record, and the main program loop ends, with control returning to Step 3 (Statement 188).

6. PRINT FINAL HEADER IF NECESSARY, SET UP FINAL ENTRY (215-223) Only the first four lines of the header $w i 11$ be printed if a header is needed, since column headings are not used for the report summary. The report sumbry lines are formatted on the screen. Total BA and Total 80 are the numbers in the CUMULATIVE BA and CUMLATIVE BO fields of the last detail Record. These are copied from Buffer \#3 (which, in the main program loop, is cleared after the EXIT statement). 
7. GET DATE AND NAME FROM USER (224-241)

The screen buffer is used to request and validate the user's name and the date. These are copied to lines six and seven of the screen, which are being used to format the final entry.

8. PRINT FINAL ENTRY (242-247)

The final entry is transferred from the screen to Buffer\#4 to align it

properly on the page, and then printed. The Batch processed for the report is closed and a \$PAUSE message displayed on the screen. 
FIGURE A.7. USE OF SYSTEM RESOURCES BY THE ECRPTI PROGRAM

\section{BUFFERS}

Buffer\#1 - Used to hold a formatted header Record for printing. Columns 1-135 contain Line One of the Batch header. Columns 136-216 contain Line Two of the Batch header. Columns 217-351 contain Line Three of the Batch header. Columns 352-486 contain Line Four of the Batch header. Columns 487-594 contain Line Five of the Batch header. Columns 595-723 contain Line Six of the Batch header.

Buffer\#2 - Used to read both header and detail Records from the Batch. Columns $1-109$ are used in reading header Record.

Columns 1-260 are used in reading detail Records.

Buffer \#3 - Used to hold formatted detail Records for printing.

Columns 1-135 contain Line One of the detail Record.

Columns 136-270 contain Line Two of the detail Record.

Columns 271-405 contain Line Three of the detail Record.

Columns 406-540 contain Line Four of the detail Record.

Buffer \#4 - Columns 1-84 are used to temporarily hold the report summary entries before printing. These entries are copied from the screen to the buffer so that they will be properly aligned when printed.

\section{VARIABLES}

I (entire program): Print line counter.

J (entire progran): Print page counter.

\section{SCRATCH ACCUMULATORS (SAC's)}

No Scratch Accumulators are used in this program. 
Print Chart for ECRPTI program (single Batch report) artput

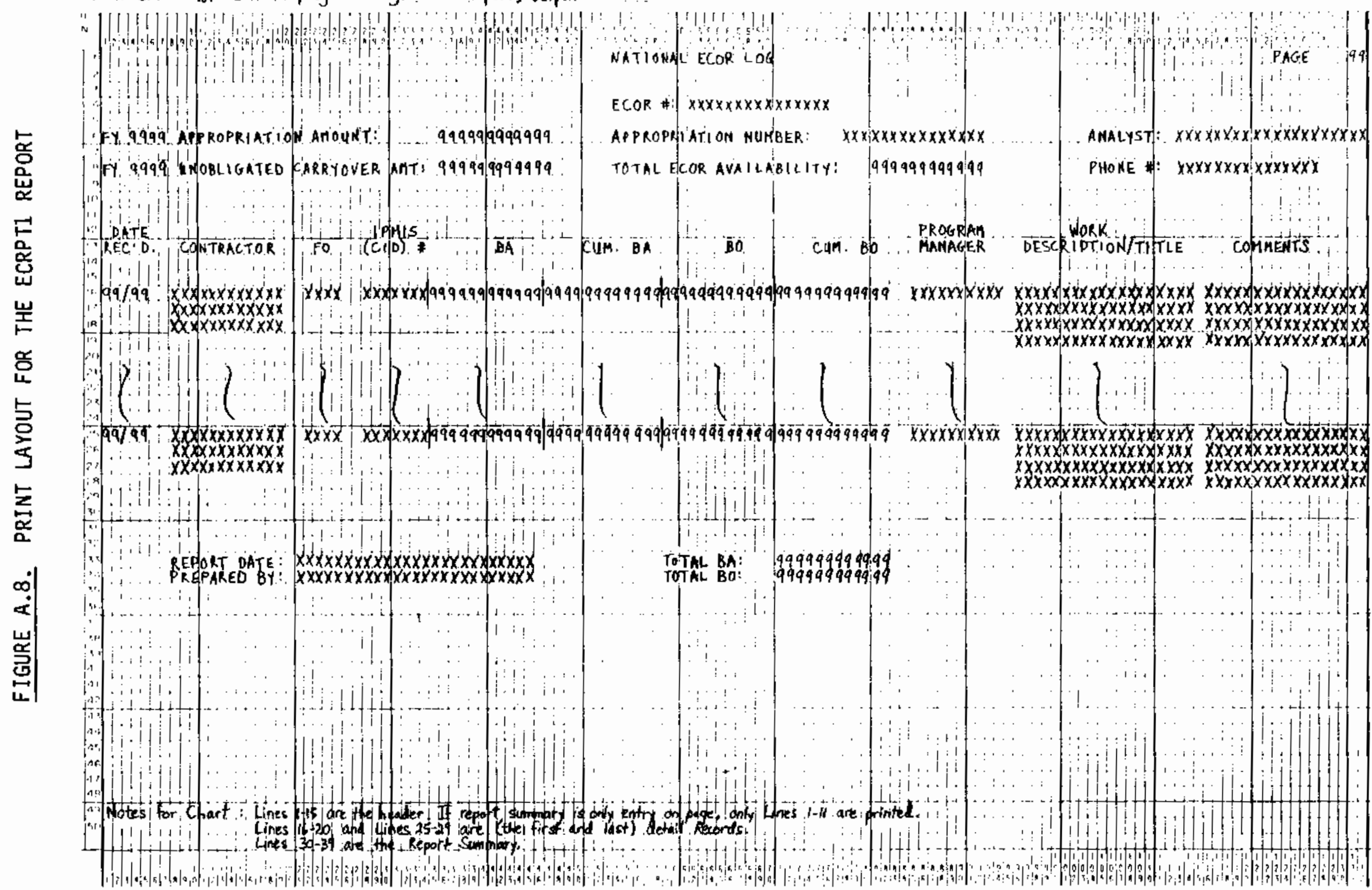




\section{A.4 THE ECRPT2 PROGRAM}

The ECRPT2 program produces a report on the information in more than one Batch of the ECORLOG Job. The source code for this program is stored in Statements 248-537 of MASTER,ECORLG. A description of the steps followed by the ECRPT2 program is given below, with the statement numbers corresponding to each step given in parentheses after its name. Figure A.9 shows the system resources used by the program. Figure A.10 gives a print layout for the ECRPT2 report.

\section{DESCRIPTION OF THE ECRPT2 PROGRAM}

1. DISPLAY LIST OF ALL BATCHES ONSCREEN (249-264)

The Batch ID's of all ECORLOG Batches are displayed on the screen so that Batches can be selected for the report. In this and subsequent tasks, Variable $I$ is used to point to lines on the screen, while $J$ points to screen columns. A loop is used to open each Batch in turn and write its ID at the next slot on the screen. A maximum of 40 Batch ID's will be displayed on the screen.

2. SELECT THOSE BATCHES TO BE PROCESSED (265-298)

The user's selection of a list of Batches for the report is accomplished by a set of three nested loops. The innermost loop (Statements 272-281) is executed separately for each Batch ID selected, and iterates unt $i 1$ the user verifies that Batch ID. The middle loop (Statements 271-291) is executed separately for each list of Batches selected, iterating once for each Batch ID. Variable $K$ tallies the number of Batches in the list as they are entered. A maximum of 20 Batches can be selected for one report. When the user presses FIELD REL to signify that there are no more Batches to enter, this loop is exited, with control passing to the outermost loop (Statements 270-298). The outermost loop validates the entire list of Batches. If the user verifies the list, the loop is exited; if not, the list is erased and control passes back to the top of the loop to obtain another list.

3. SET UP SCREEN TO BEGIN PROCESSING BATCHES (299-304)

The screen is cleared of all messages except the list of batches chosen for the report. Another message written to the screen allows Batches to be opened from the screen and informs the user of the program's progress.

4. FORMAT REPORT HEADER RECORD IN BUFFER 4 (305-322)

The report header consists of a few text strings, the page number, and a list of the ECOR Numbers of the Batches included in the report. The text strings are set into Buffer $\$ 4$, along with constant information for the Batch summary entry (also stored in Buffer 4 , beginning at position 541). A WHILE statement iterates once for each of the $K$ Batches selected for the report. Variable L controls the execution of the WHILE statement. I and $\mathrm{J}$ point to the screen position of each Batch ID in turn. The Batch is opened, and the header Record read into Buffer \#2. The ECOR NUMBER field is copied to Buffer\#4, at the position indicated by Variabie M (used as a buffer position pointer).

5. FORMAT CONSTANT PORTIONS OF BATCH HEADER IN BUFFER\#1 (323-341)

The Batch header (stored in Buffer \#1) consists of fields from the Batch's header Record, text strings describing those fields, and column headers. 
Items in the last two categories do not change from Batch to Batch, so they are formatted into Buffer\#1 here, before the main program loop. In addition, text strings are written to the screen for the Batch summary entry, and variables set for the main program loop. Variables I and $J$ still point to screen lines and columns, and $L$ will control the main program loop. Variable M will now be used to point to positions in Buffer $\#$, where each Batch summary is stored for the report sumary. Variable 0 is used as a print line counter, $P$ as a page counter.

6. BEGIN MAIN PROGRAM LOOP TO PROCESS BATCHES (342-351)

The main program loop (Steps 6-11) is a WHILE statement which iterates once for each of the $K$ Batches. At the top of the loop, a Batch is opened and its header record read into Buffer \#2. The ECOR NUMBER field is copied to the screen for the Batch sumary entry. The fields from this Record are copied to the Batch header for the report in Buffer\$1. Buffer $\# 2$ is cleared and the first detail Record read into it.

7. BEGIN INNER LOOP TO PROCESS DETAIL RECORDS (352-362) The inner WHILE loop (Steps 7-9), executed unt it the end of the Batch is encountered, processes one detai) Record per iteration. If the printer is at the end of a page of output, the printer is advanced to the next page, and the page number is set into the report header. The report header (from Buffer\#4) and the Batch header (from Buffer \#1) are printed; line counter 0 and page counter $P$ are incremented.

8. FORMAT A DETAIL RECORD INTO BUFFER\#3 (363-375)

The most recently read detail Record (read in Step 6 or Step 9) is formatted for printing by copying its fields from Buffer \#2 to Buffer \#3.

9. PRINT A DETAIL RECORD (376-381)

The formatted detail Record in Buffer $\# 3$ is printed, along with a blank line from the screen. Line counter 0 is incremented, and the next detail Record read into Buffer $\# 2$ in the last statement enclosed by the inner (detail Record) WHILE statement beginning in Step 7.

10. COMPLETE PROCESSING FOR ONE BATCH (382-398)

The Batch is closed, and the CUMULATIVE BA and CUMULATIVE BO fields from the last detail Record are copied from Buffer $\$ 3$ to the screen for the Batch sumnary. The report header and Batch header are printed if necessary, but column headings are not printed since they are not needed for the Batch summary. The Batch summary is transferred to Buffer $\# 4$ for proper alignment and printed. The ECOR Number, $B A$ and $B O$ amounts are then transferred to the Buffer $\$ 5$ positions pointed to by Variable $M$. Note that if 20 Batches are included in the report, the BO amount for the last Batch is stored in SAC13 due to the buffer size limit of 768 characters.

11. PREPARE TO PROCESS NEXT BATCH (399-405)

The Batch sumary is cleared from the screen. Variables I and $J$ are incremented to point to the next Batch ID on the screen. $L$ is incremented by one to signal to the WHILE statement that a Batch has been completed. $M$ is incremented to point to the next available positions in Buffer\#5, and 0 is set to ensure that the next Batch will begin to print on a new page. The main program loop begun at Step 6 ends here, with control returning to Step 6. 
12. PREPARE FOR REPORT SUMMARY PROCESSING (406-415)

At this point, detailed information from all of the Batches included in the report has been printed. 0ld screen messages are cleared and new ones set for the report summary. The report header and the summary title and column headings are printed on a new page.

13. GET EACH BATCH SUMMARY BACK FROM BUFFER\#5 (416-423)

A WHILE statement (encompassing Steps 13-15) is used for this task, with Variable $L$ looping over Batches and $M$ pointing to positions in Buffer $\$ 5$. For each Batch, the ECOR Number, Total BA and Total BO are copied from Buffer $\$ 5$ to the screen. If 20 Batches were included in the report, the $B O$ amount for the last Batch is retrieved from SAC13. The sumary information for the Batch is then copied from the screen to Buffer \#4 and printed.

14. EDIT BATCH TOTAL BA, ADD TO SAC11 FOR RPT TOTAL BA (424-436)

The Total BA figure from each Batch will be added to SAC11 to obtain a report Total $B A$ anount. Before it can be added, however, it must be edited to remove commas and/or negative signs. This is accomplished by copying Total BA from the screen to SAC2, then using a position-by-position copy from SAC2 to SAC3, with only numerals being copied. Variable I controls the WHILE statement which does this, and also serves as pointer to each position in SAC2. Variable $J$ is a pointer to the rightmost available position in SAC3 (the edited version), while $N$ serves as a flag which is set to the value of one if a negative sign is found in the number. If the number is negative, SAC 3 is copied to SAC4, which is then subtracted from SAC 3 twice so that SAC3 contains a negative number. Now SAC3 can be added to SAC11 for the report Total $B A$.

15. EDIT BATCH TOTAL BO, ADD TO SAC12 FOR RPT TOTAL BO (437-450)

Report Total BO is accumulated in SAC12. The current Batch's Total B0 is copied from the screen to SAC2, and edited the same way that BA was in the previous step. The result is added to SAC12. Variables $L$ and $M$ are incremented for the next iteration of the WHILE statement, and control returns to Step 13 .

16. EDIT REPORT TOTAL BO (451-481)

All Batch summaries have now been processed and printed - totals for the report will now be formatted and printed. The report Total BA stored in SACll must be edited twice before printing: first to remove leading zeroes, then to add commas and a negative sign if necessary. These two subtasks are described next.

16A. EDIT BA TO REMOVE LEADING ZEROES (452-467)

The report Total BA in SAC11 is copied twice: once to SAC5, where the rightmost position contains the sign (positive or negative) of the number, once to SAC6 without the sign. SAC6 is then scanned from left to right to remove leading zeroes. Variable I controls the WHILE statement that accomplishes this, and points to each position of SAC6 in turn. If the position contains a zero and the preceeding position contains a blank, the position is a leading zero which is blanked out. Variable $J$ is set to mark the rightmost leading zero/blank position and that position marked with a ' -1 when the first non-zero number is encountered. When the scan is complete, SAC5's twelth 
position is checked. If the number is not negative, the ' - ' at SAC6(J) is blanked out; if the number is negative, the overpunched letter in the last position of SAC6 is replaced by the appropriate number (from SAC5(11)).

16B. INSERT COMMAS IN REPORT TOTAL BA (468-481)

Commas are inserted in the number representing report Total BA by another copy between SAC'S, this time from SAC6 to SAC7. The copy proceeds from right to left. Three positions are copied. The next position (to the left) in SAC6 is checked: if it is blank, the number has been copied in its entirety; if it is a negative sign, this is copied to SAC7 to complete the edit; if it is a number, the copy is not complete, so a confla and the next three positions of SAC6 are copied to SAC7 to continue the edit. When the edit is complete, SAC7 is written to the screen for the report summary.

17. EDIT REPORT TOTAL BO (482-513)

Now the report Total $B 0$ must be edited for the final report entry. The logic of this step mirrors that of Step 16 - only the differences between the two are described below.

17A. EDIT BO TO REMOVE LEADING ZEROES (483-497)

The copies to SACS and SAC6 are made from SAC12, where the report Total BO amount has been accumulated.

17B. INSERT COMMAS IN REPORT TOTAL BO (498-513)

After the editing operation is complete and SAC7 has been copied to the screen, the report total line on the screen is complete. It is transferred to Buffer $\$ 4$ and printed.

18. GET NAME AND DATE FROM USER (514-531)

The screen is used to request and validate the user's name and the date. These are copied to lines 13 and 14 of the screen, which are being used to format the final entry.

19. PRINT FINAL ENTRY (532-537)

The final entry is transferred from the screen to Buffer $\$ 4$ to align it properly for printing. A message for the user is written on the screen. The final report entry is printed in the last statements. 
FIGURE A.9. USE OF SYSTEM RESOURCES BY THE ECRPT2 PROGRAM

\section{BUFFERS}

Buffer\#1 - Used to hold a line of asterisks for printing in various parts of the ECRPT2 report, as well as a formatted Batch header constructed from each Batch's header Record. Columns 1-135 contain a line of asterisks. Columns 136-216 contain Line One of the Batch header. Columns 217-351 contain Line Two of the Batch header. Columns 352-486 contain Line Three of the Batch header. Columns 487-594 contain Line Four of the Batch header. Columns 595-723 contain Line Five of the Batch header.

Buffer $\$ 2$ - Used to read both header and detail Records from Batches. Columns 1-109 are used in reading header Records. Columns 1-260 are used in reading detail Records.

Buffer\#3 - Used to hold formatted detail Records for printing. Columns 1-135 contain Line One of the detail Record. Columns 136-270 contain Line Two of the detail Record. Columns 271-405 contain Line Three of the detajl Record. Columns 406-540 contain Line Four of the detail Record.

Buffer \#4 - Used to hold a formatted report header for printing, and to align Batch and report summary entries before printing. Columns 1-135 contain Line One of the report header. Columns 136-270 contain Line Two of the report header. Columns 271-405 contain Line Three of the report header. Columns 406-540 contain Line Four of the report header. Columns 541-624 are used to align sumary entries.

Buffer \#5 - Used to store the information from each Batch summary entry for use in the report summary. The information from each Batch fills 39 columns of the buffer: fifteen for the ECOR Number, twelve for Batch Total BA, and twelve for Batch Total BO. If twenty Batches are included in the report, only the ECOR Number and Total BA for the last Batch are stored here - Total BO is stored in SAC13. 
FIGURE A.9. USE OF SYSTEM RESOURCES BY THE ECRPT2 PROGRAM (continued)

\section{VARIABLES}

$K$ (entire program): Set to the number of Batches in the report at Step 2.

$L$ (entire program): Used to iterate looping statements from zero to $(K-1)$.

0 (entire program): Print line counter.

P (entire program): Print page counter.

I (Steps 1-13): Pointer to screen lines.

$J$ (Steps 1-13): Pointer to screen columns.

I,J,N (Steps 14-15): Used in removing commas from each Batch's Tota1 BA (Step 14) and Total BO (Step 15) amounts.

$I, J$ (Steps 16-17): Used in removing leading zeroes from the report Total BA (Step 16) and Total BO (Step 17) amounts.

M (Step 4): Points to positions in Buffer $\# 4$ while the report header is being formatted.

M(Steps 5-15): Points to positions in Buffer 45 for storing and retrieving each Batch sumary.

\section{SCRATCH ACCUMULATORS (SAC'S)}

SAC2, SAC3, SAC4: Used in removing commas from each Batch's Total BA and Total Bo amounts (Steps 14-15).

SAC5, SAC6, SAC7: Used to remove leading zeroes and add commas to the report Total BA and Total BO amounts (Steps 16-17).

SAC11: Accumulates report Total BA for the duration of the program.

SAC12: Accumulates report Total BO for the duration of the program.

SAC13: If twenty Batches (the maximum) are included in the report, the Total 80 amount for the last Batch summary is stored here. 
Chart for ECRPT2 program (multiple-batch report)output: Batch details

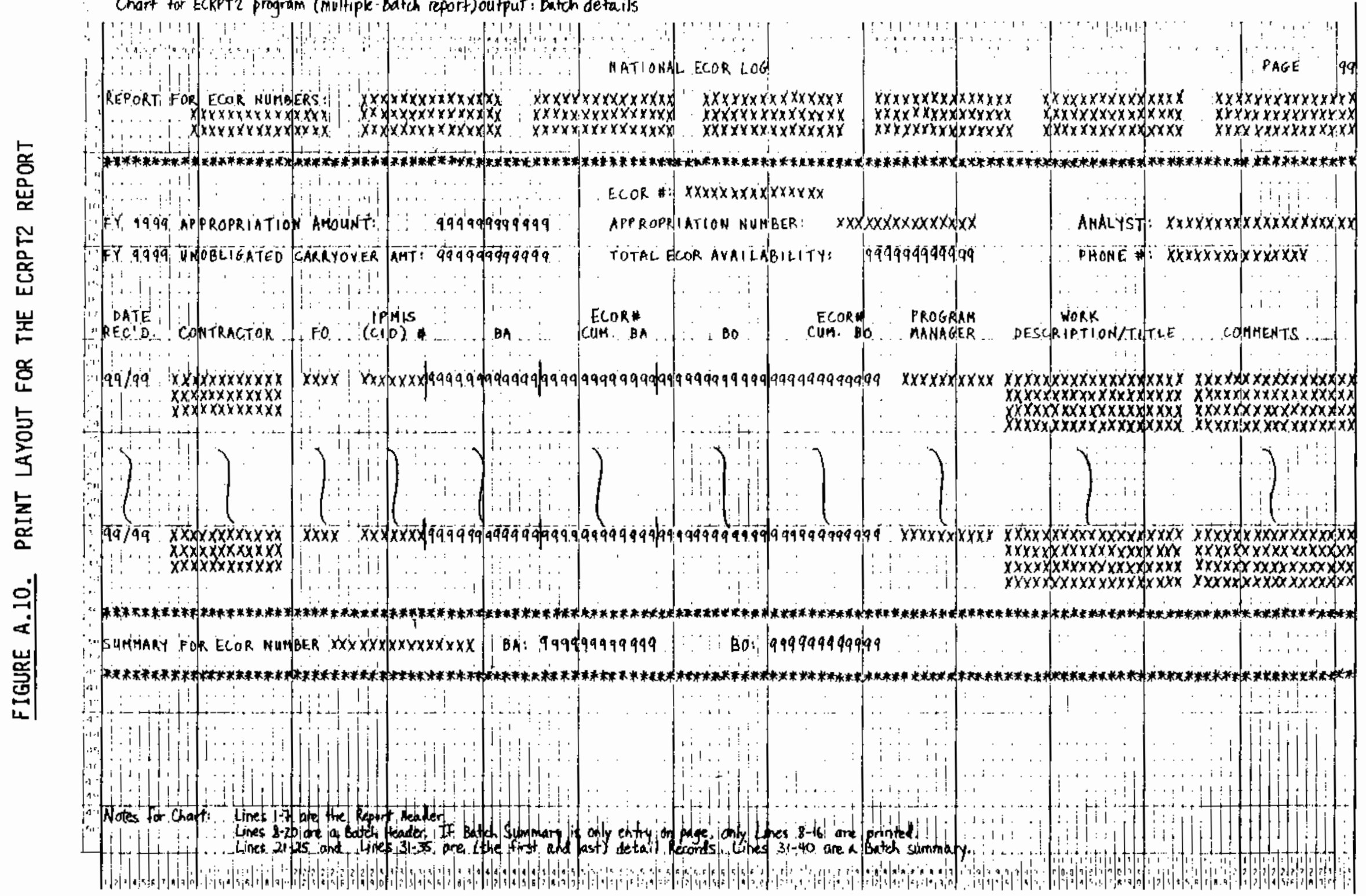


Chart for ECRPT2 program (multiple-Batch report) output: Report Surmary

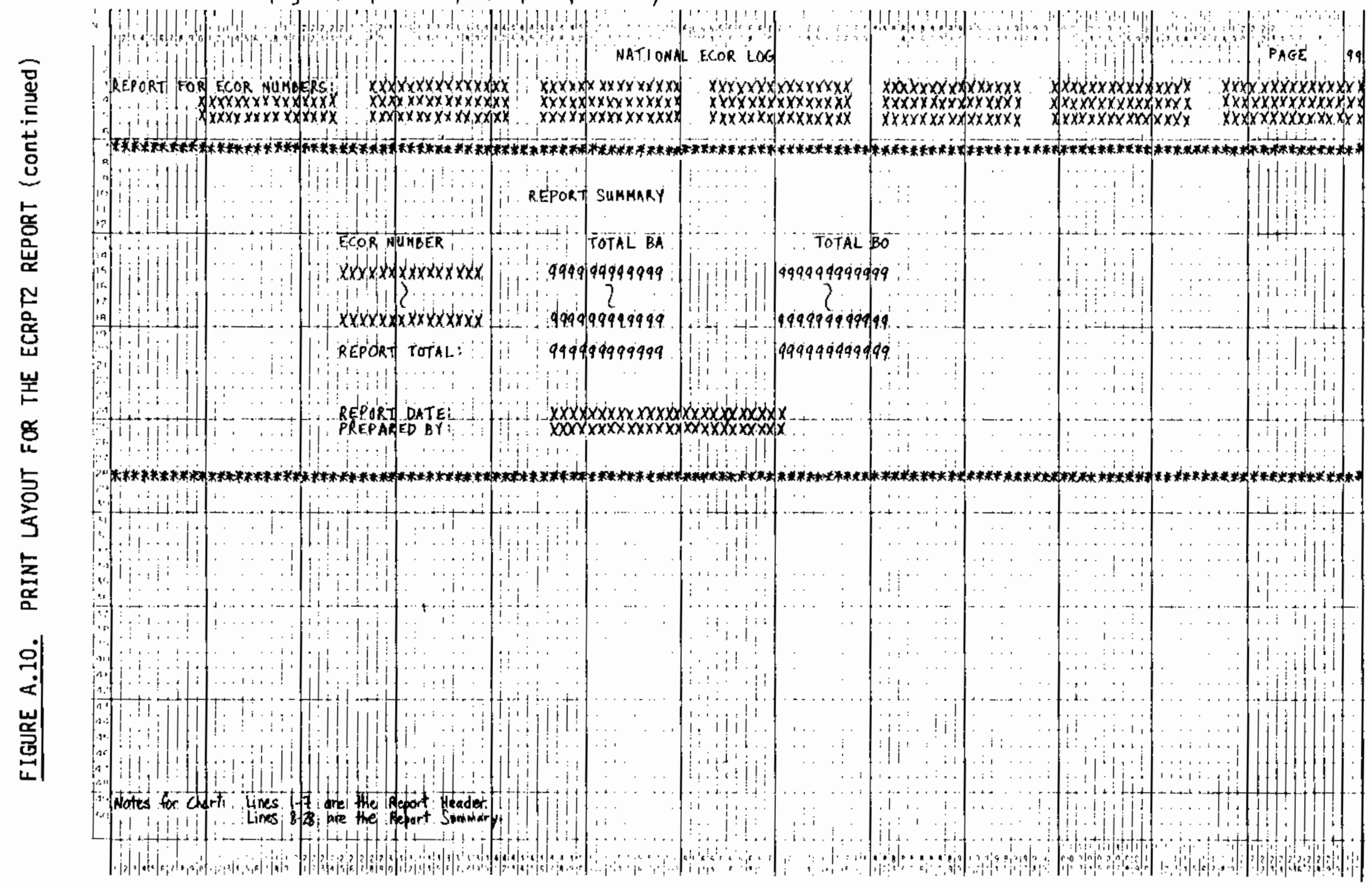




\section{A.5 SOURCE CODE FOR THE ECORLOG APPLICATION}

This section contains source code printouts for all code used in the ECORLOG application. The different pieces of source code are identified by the Job (a 11 MASTER) and Batch in which each is stored. An indication of the contents of each Batch is given below, followed by the printouts of these Batches.

MASTER, ECORLG

The three ECORLOG programs are stored in this Batch. The ECORUP progran constitutes Statements 1-147 in the ECORLG Batch. ECRPTI is stored in Statements 148-247, ECRPT2 in Statements 248-537.

MASTER, ECRUST

This Batch contains the short ECRJST subroutine, which is called by the ECORUP progran from MASTER,ECORLG.

MASTER, ECPURG

Templates of the commands to store and retrieve ECORLOG Batches after the end of a fiscal year are stored in this Batch.

MASTER,ECORJB

The statements defining the ECORLOG Job are stored in this Batch. The statements stored here were used to define formats C21 (Program Leve] One) and C22 (Program Leve] Two) and value set 011 to validate postal abbreviations for the STATE CODE field.

\section{MASTER,ECLG84}

This Batch is used to store old versions of the ECORLOG prograns, which should be used to process data only in Batches of the ECLOG84 Job. The older version of the ECORUP progran is stored in Statements I-74 of MASTER,ECLG84. Statements 75-200 make up the old ECRPT1 progran, Statements 201-486 the old ECRPT2 program.

MASTER, ECPG84

Examples of the commands used to store and retrieve ECLOG84 Batches at the end of a fiscal year are stored in this Batch.

MASTER,ECJB84

The code in this Batch was used to create the ECLOG84 Job, which uses formats C11 and C12 and value set 011 . 
\$EDIT !PROGRAM NAME: ECORUP -- UPDATES TOTALS IN A BATCH OF ECORLOG;

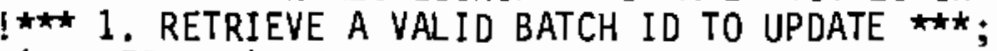

SET S(NLINES-3,2)="ENTER BATCH ID TO UPDATE";

SET $S(3,1)=" E C O R L O G, "$;

LOOP(

TYPEIN; SET $S(3,9)=S($ NLINES-2,2).6;

OPEN1 $S(3,1)$; READ1 B1;

SET S(NLINES-3,2)="IS THIS THE CORRECT BATCH? ENTER YES OR NO";

SET $S($ NLINES $-2,2)=8.79 ;$ TYPEIN;

IF 7 EOF AND $S$ (NLINES-2,2)="YES"

THEN (SET $S(3,18)="$ TOTALS ARE BEING UPDATED"; EXIT)

ELSE SET S(NLINES-3,2)=\& .79;

IF $S($ NL INES $-2,2)=$ "YES"

THEN SET S(NLINES-3,2)="NO DATA IN THIS BATCH...TRY AGAIN"

ELSE SET S(NLINES-3,2)= "TRY AGAIN";

CLOSE1; SET S(NLINES-2,2)=\& .79;

SET $S(3,9)=\& .71)$;

.79; SET S(NLINES-2, 2)=\& .79;

IF $B i(66)="$ "THEN(

SET SACI=B1(55).12; CALL "MASTER,ECRJST"; SET B1(55)=SAC2.12; );

IF $B 1(97)="$ " THEN(

SET $S A C 1=B 1(86) .12 ;$ CALL "MASTER,ECRJST"; SET B1(86)=SAC2.12;);

IF $B 1(109)="$ " THEN(

SET SAC1=B1 (98).12; CALL "MASTER,ECRJST"; SET B1(98)=SAC2.12;);

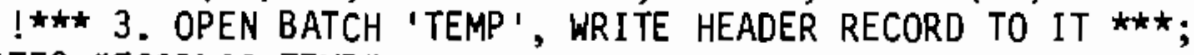

CREATE2 "ECORLOG, TEMP" ;

SET PLEVEL2=1; SET RECSIZ2=109;

WRITE2 B1;

ISET PROG.LEVEL, REC.SIZE TO PROCESS DETAIL RECS;

SET PLEVEL2=2; SET RECSIZ2 $=260$; LOOP

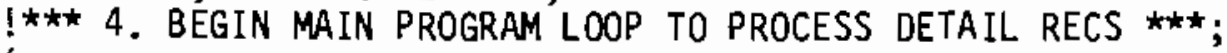

READ1 B1;

IF EOF THEN EXIT;

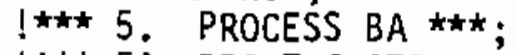

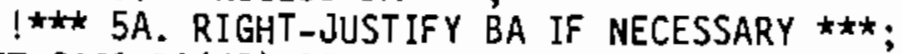

SET $S A C 1=B 1(63) .12$;

IF $\operatorname{SACl}(12)="$ "THEN(

ELSE

CALL "MASTER, ECRJST"; SET B1(63)=SAC2.12; )

SET SAC2=SAC1.12;

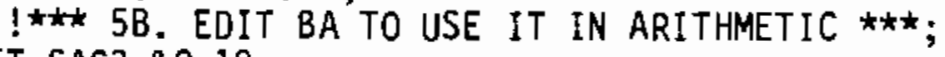

SET $S A C 3=\& 0.12$

SET I=12; SET $J=12$; SET $K=0$;

WHILE I $>0($

IF (SAC2 (I) $\rangle=" 0 "$ AND SAC2(I) $=" g ")$ THEN(

$\operatorname{SET} \operatorname{SAC} 3(\mathrm{~J})=\operatorname{SAC2}(\mathrm{I}) .1$; SET $\mathrm{J}=\mathrm{J}-1$; );

IF $\operatorname{SAC2}(\mathrm{I})="-"$ THEN SET $K=1$;

SET $I=I-1 ;)$;

IF $\mathrm{K}=1$ THEN(

SET SAC4=SAC3.12; SUB SAC4.12 FROM SAC3;

SUB SAC4.12 FROM SAC3; SET $K=0$;);

ADD SAC3.12 TO SAC11;

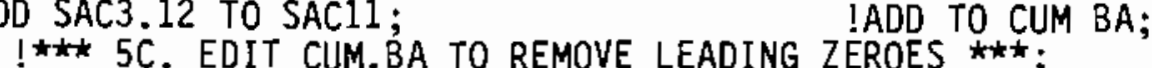

IFLAG K SET IF ' -' ENCOUNTERED;

!END WHILE STMT;

!RESOLVE NEGATIVE NUMBERS;

!EXIT LOOP IF NO MORE RECORDS; 


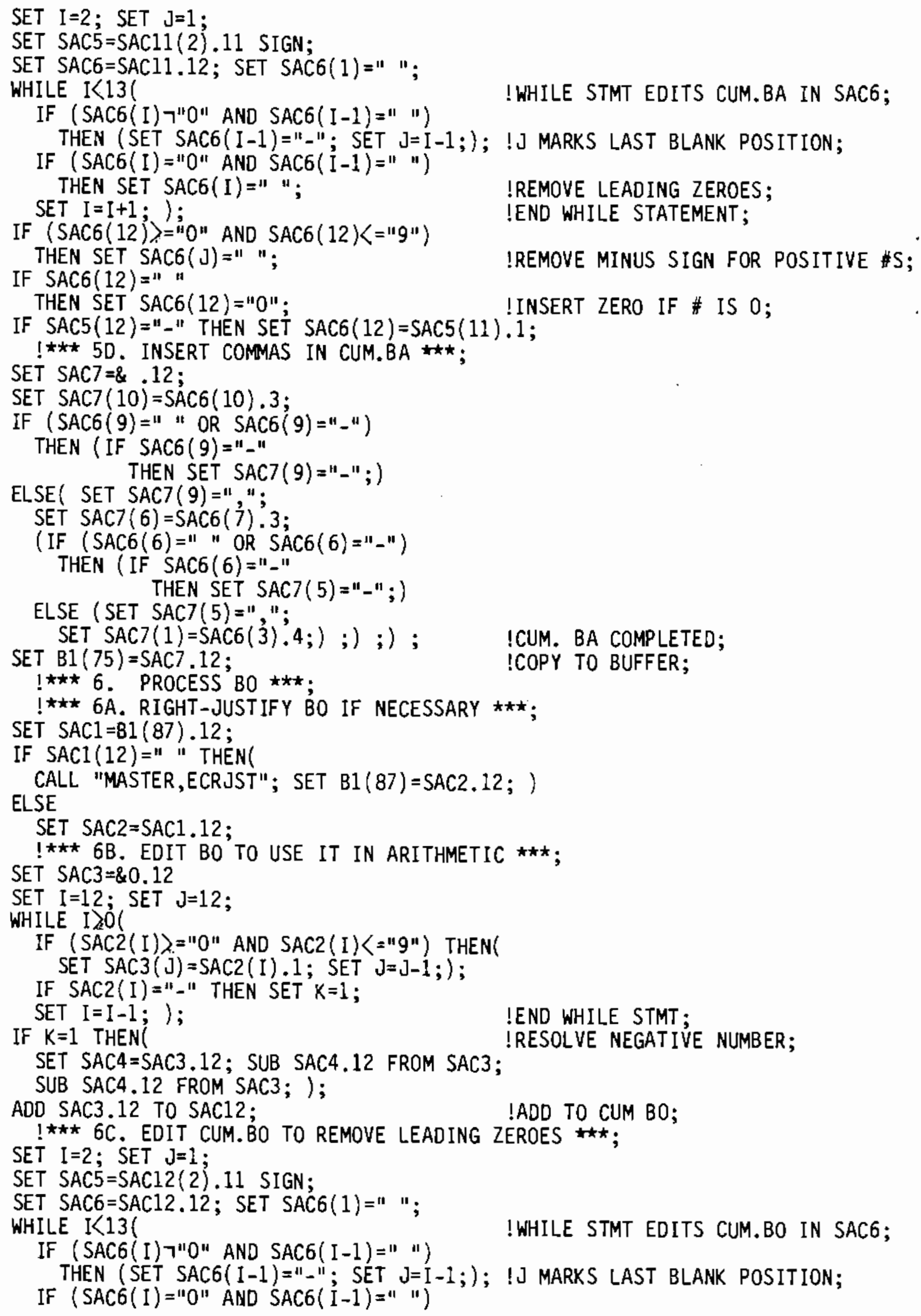


SOURCE CODE FROM MASTER,ECORLG

111

112

113

114

115

116

117

118

119

120

121

122

123

124

125

126

127

128

129

130

131

132

133

134

135

136

137

138

139

140

141

142

143

144

145

146

147

148

149

150

151

152

153

154

155

156

157

158

159

160

161

162

163

164

165
THEN SET SAC6(I) =" "; SET $\mathrm{I}=\mathrm{I}+1 ;$;);

IF ( SAC6 (12) $\rangle=" 0 "$ AND SAC6(12)〈" $=" 9 ")$

THEN SET SAC6 $(J)="$ ";

IF $\operatorname{SAC6}(12)="$ "

THEN SET SAC6(12)="0";

IF SAC5(12) $="$ " " THEN SET SAC6(12) $=\operatorname{SAC5}(11) .1$;

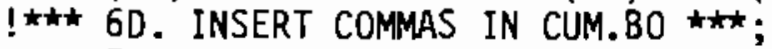

SET $S A C 7=\& .12$;

SET $\operatorname{SAC7}(10)=\operatorname{SAC6}(10) .3$;

IF $(\operatorname{SAC6}(9)=$ " " OR SAC6 $(9)="$ "-" )

THEN (IF SAC6 (9) =" -"

THEN SET $\operatorname{SAC7}(9)="-"$;)

ELSE( $\operatorname{SET} \operatorname{SAC7}(9)="$ ", ;

SET SAC7 (6) $=\operatorname{SAC6}(7) .3$;

(IF (SAC6(6) =" "OR SACG(6)=" -")

THEN (IF SAC6(6) $="-"$

THEN SET $\operatorname{SAC7}(5)="-"$;)

ELSE (SET SAC7(5)=",";

SET SAC7 (1)=SACG (3).4;) ;) ;) ; ICUM.BO COMPLETED;

SET B1 (99) = SAC7.12;

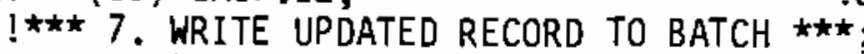

WRITE2 B1;)

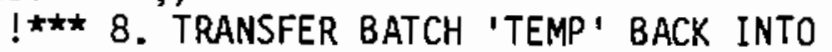
CLOSE1; CLOSE2;

OPEN1 "ECORLOG, TEMP";

CREATE2 S(3,1);

SET PLEVEL2=1; SET RECSIZ2=109;

READ1 B1; WRITE2 B1;

SET PLEVEL2=2; SET RECSIZ2=260;

LOOP(

READ1 B1;

IF EOF THEN EXIT;

WRITE2 B1;)

CLOSE1; CLOSE2;

\$PURGE ECORLOG, TEMP

\$PAUSE PRESS SPACE BAR TO PRINT REPORT ON ONE BATCH, MODE KEY TO EXIT

\$EDIT !PROGRAM NAME: ECRPT1 -- PRINTS AN ECORLOG REPORT FOR ONE BATCH;

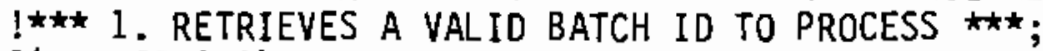

SET S(NLINES-3,2) ="ENTER BATCH ID TO FORMAT FOR REPORT";

SET $S(3,1)=" E C O R L O G, "$;

LOOP

(TYPEIN; SET $S(3,9)=S($ NLINES-2,2).6;

OPEN1 S( 3,1$)$; READ1 B2;

SET S(NLINES-3,2)="IS THIS THE CORRECT BATCH? ENTER YES OR NO";

SET S(NLINES-2,2) $=\& .79$; TYPEIN;

IF 7 EOF AND S(NLINES-2,2) = "YES"

THEN (SET $S(3,17)=" I S$ BEING FORMATTED FOR REPORT"; EXIT)

ELSE SET S(NLINES-3,2)=\& .79;

IF $S($ NLINES $-2,2)=$ "YES"

THEN SET S(NLINES-3,2)="NO OATA IN THIS BATCH... TRY AGAIN"

ELSE SET S(NLINES-3,2)="TRY AGAIN";

CLOSE1;

SET S(NLINES $-2,2)=\& .79$;

$\operatorname{SET} S(3,9)=\& .71)$
!END LOOP; 
166

167

168

169

170

171

172

173

174

175

176

177

178

179

180

181

182

183

184

185

186

187

188

189

190

191

192

193

194

195

196

197

198

199

200

201

202

203

204

205

206

207

208

209

210

211

212

213

214

215

216

217

218

219

220

SET S(NL INES $-3,2)=\& .79 ;$ SET $S($ NL INES $-2,2)=\& .79 ;$

$! \star \star \star 2$ 2. FORMAT THE REPORT HEADER IN BUFFER SET B1 (54)="NAT IONAL ECOR LOG"; SET B1(123)="PAGE"; SET B1 (189) ="ECOR \#:"; SET B1(197)=B2(1).15; SET B1(217)="FY APPROPRIATION AMOUNT:"; SET $B 1(220)=B 2(51) .4$; SET B1 (252) =B2(55).12;

SET B1 (270)="APPROPRIATION NUMBER:"; SET B1(294)=B2(67).15;

SET B1 (320)="ANALYST:"; SET B1 (329) =B2(16) . 20;

SET B1 (352) ="FY UNOBLIGATED CARRYOVER AMT:";

SET B1 (355) =B2(82).4; SET B1(387)=B2(86).12;

SET B1 (405)="TOTAL ECOR AVAILABILITY:"; SET B1(432)=B2(98) .12;

SET B1 (455) = "PHONE \#:"; SET B1 (464)=B2(36).15;

SET B1 (488)="DATE"; SET B1 (515) = "IPMIS" ;

SET B1 (572)="PROGRAM"; SET B1(588)="WORK" ;

SET B1(595) ="REC'D. CONTRACTOR FO";

SET B1 $(622)="(C I D) \# \quad B A$

SET B1 $(660)=" B 0$

CUM. BA";

SET B1 $(691)=$ "DESCRIPTION/TITLE COMMENTS";

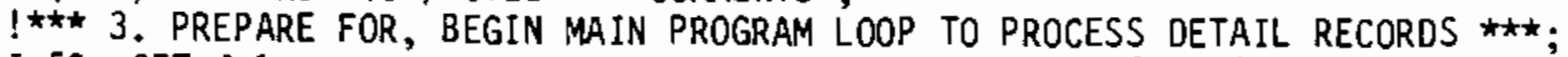

SET I $=52$; SET $\mathrm{J}=1$;

SET B2=\& .109;

LOOP(

IF I $>51$ THEN(

TFORM; SET B1 (127) $=0.6$; SET B1 (127) ="

PRINT B1(1).132; PRINT S(4,1).1;

PRINT B1(136).78; PRINT S(4,1).1;

PRINT B1(352).132; PRINT S 4,1$) .1$;

SET I $=16$; SET $\mathrm{J}=\mathrm{J}+1 ;$; ;

READ1 B2;

IF EOF THEN EXIT;

SET $B 3=\& .540$;

!*** 4. FORMAT A DETAIL RECORD INTO BUFFER\#3 $3 \star \star *$;

SET B3 (1) =B2 (47).5; $\quad$ SET B3 $(8)=B 2(1) .12$;

SET B3(22) $=\mathrm{B} 2(52) .4 ; \quad$ SET $B 3(28)=B 2(56) .7$;

SET B3(35) =B2(63).12; $\quad$ SET $B 3(47)=B 2(75) .12$;

SET B3 $(59)=B 2(87) .12$; $\quad$ SET B3 $(71)=B 2(99) .12$;

SET B3 $(85)=\mathrm{B} 2(37) .10 ; \quad$ SET B3(96) $=\mathrm{B} 2(111) .19$;

SET B3(116)=B2(187).17;

SET B3 $(143)=B 2(13) .12 ;$ SET B3(231) $=B 2(130) .19$;

SET B3 (251)=B2 (204).17;

SET B3 (278) =B2 (25) .12; SET B3 $(366)=B 2(149) .19$;

$\mathrm{SET} \mathrm{B} 3(386)=\mathrm{B} 2(221) .17$;

SET B3 $(501)=B 2(168) .19$; SET B3 $(521)=B 2(238) .17$;

! $\star \star \star ~ 5$. PRINTS THE FORMATTED DETAIL RECORD $\star \star \star * ;$

PRINT B3(1).132; PRINT B3(136).132;

PRINT B3(271).132; PRINT B3(406).132; PRINT S $(4,1) .1$;

SET I $=\mathrm{I}+5$;

SET B2 $=\& .260 ;)$; IINCREMENT LINE COUNTER;

!END MAIN PROGRAM LOOP;

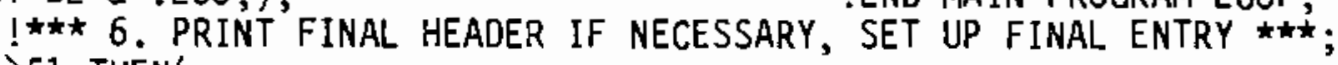

IF I $>51$ THEN(

TFORM; SET $B 1(127)=0.6$; SET $B 1(127)=" \quad "$;

PRINT 81(1).132; PRINT S(4,1).1; PRINT Ś $(4,1) .1$;

PRINT B1(136).78; PRINT S(4,1).1; PRINT B1(217).132; PRINT S(4,1).1;

PRINT B1(352).132; PRINT S(4,1).1; PRINT S(4,1).i; PRINT S(4,1).1;); 
221 SET $S(6,5)=$ "REPORT DATE:" ; SET $S(6,56)="$ TOTAL BA:" ;

222

223

224

225

226

227

228

229

230

231

232

233

234

235

236

237

238

239

240

241

242

243

244

245

246

247

248

249

250

251

252

253

254

255

256

257

258

259

260

261

SET $S(7,5)=$ "PREPARED BY:"; SET $S(7,56)="$ TOTAL BO:";

SET $S(6,68)=B 3(47) .12$; SET $S(7,68)=B 3(71) .12$;

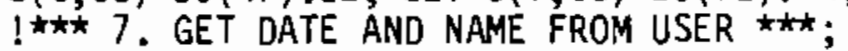

SET S(NLINES-3,2)="ENTER TODAY'S DATE";

LOOP(

TYPEIN; SET $S(6,18)=S(N L I N E S-2,2) .25$;

SET S(NLINES-3,2) $\& .79 ;$ SET S(NLINES-2,2) $=\& .79$;

SET S(NLINES-3,2)= "ENTER YOUR NAME";

TYPEIN; SET $S(7,18)=S($ NLINES-2,2).25;

SET S(NLINES-3,2) =\& .79; SET S(NLINES-2,2)=\& .79;

SET S(NLINES-3,2)= "ARE NAME AND OATE CORRECT? ENTER YES OR NO";

TYPEIN;

IF $S($ NLINES $-2,2)=$ "YES" THEN

EXIT

ELSE (

SET $S(6,18)=\& \quad .25$; SET $S(7,18)=\& \quad .25$;

SET $S($ NLINES $-3,2)=\& .79$; SET $S($ NLINES $-2,2)=\& \quad .79$;

SET S(NLINES-3,2)="TRY AGAIN - ENTER TOOAY'S OATE";);); !END LOOP;

SET $S($ NLINES-2,2) $=\& .79$;

SET $S(N L I N E S-3,2)=\& \quad .79$;

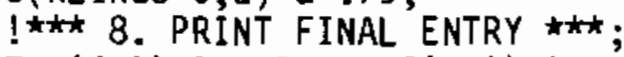

PRINT $S(4,1) .1 ;$ PRINT $S(4,1) .1 ;$ PRINT $S(4,1) .1$;

SET $B 4=\& .84 ; \quad$ SET $B 4(4)=S(6,1) .80 ; \quad$ PRINT $84(1) .84$;

SET $B 4(4)=S(7,1) .80$; PRINT B4(1).84;

CLOSE

\$PAUSE PRESS SPACE BAR TO PRINT MULTI-BATCH REPORT, MODE KEY TO EXIT

SEDIT !PROGRAM ECRPT2 -- PRODUCES MULTI-BATCH REPORT;

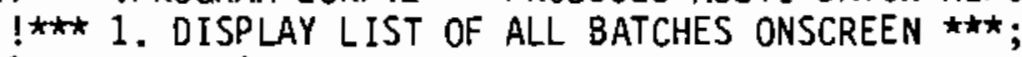

OPEN1 "ECORLOG, \$";

SET I $=4$; SET $J=2$; II COUNTS SCREEN LINE\#, J COLUMN\#;

SET $S(3,2)=$ "ECORLOG BATCHES AVAILABLE FOR PROCESSING":

SET $S(I, J)=$ BATCH1 .6;

LOOP(

!WRITE 1STं BATCH IO ONSCREEN;

NEXTBI;

IF ᄀOPENI THEN (SET $S(19,2)=" A L L$ AVAILABLE BATCHES ARE DISPLAYED"; EXIT); IF $\mathrm{J}<74$

THEN SET $J=\mathrm{J}+8$

ELSE (SET I $=I+1$; SET $\mathrm{J}=2 ;$ );

IF $I=8$

THEN (SET S(19,2)="JOB HAS MORE BATCHES THAN CAN BE OISPLAYED"; !MAX 40;

SET $S(20,2)=$ "ABORT PROGRAM WITH MODE KEY TO SEE OTHERS IN JOB MODE"; EXIT;);

SET $S(I, J)=B A T C H 1.6 ;)$; IEND LOOP;

CLOSE1;

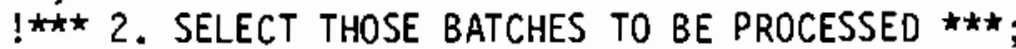

SET $S(9,2)=$ "ECORLOG BATCHES TO BE INCLUDED IN REPORT";

SET $S(9,44)="$ (ORDERED FROM LEFT TO RIGHT)";

SET I $=10$; SET $J=2$; SET $K=0$;

IK COUNTS \# OF BATCHES SELECTED;

SET $S(21,2)=" E N T E R$ FIRST BATCH ID TO INCLUDE IN REPORT"; LOOP( LOOP(

LOOP(

TYPEIN; IF $S(22,2)="$

SET $S(I, J)=S(22,2) .6$;

" THEN EXIT;

!LOOP ONE VALIOATES ENTIRE LIST;

!LOOP TWO SELECTS LIST OF BATCHES;

!LOOP THREE SELECTS ONE VALID BATCH;

!COPY ID ENTERED TO $S(1, \mathrm{~J})$;

SET $S(21,2)="$ IS BATCH ABOVE CORRECT? ENTER YES OR NO "; 


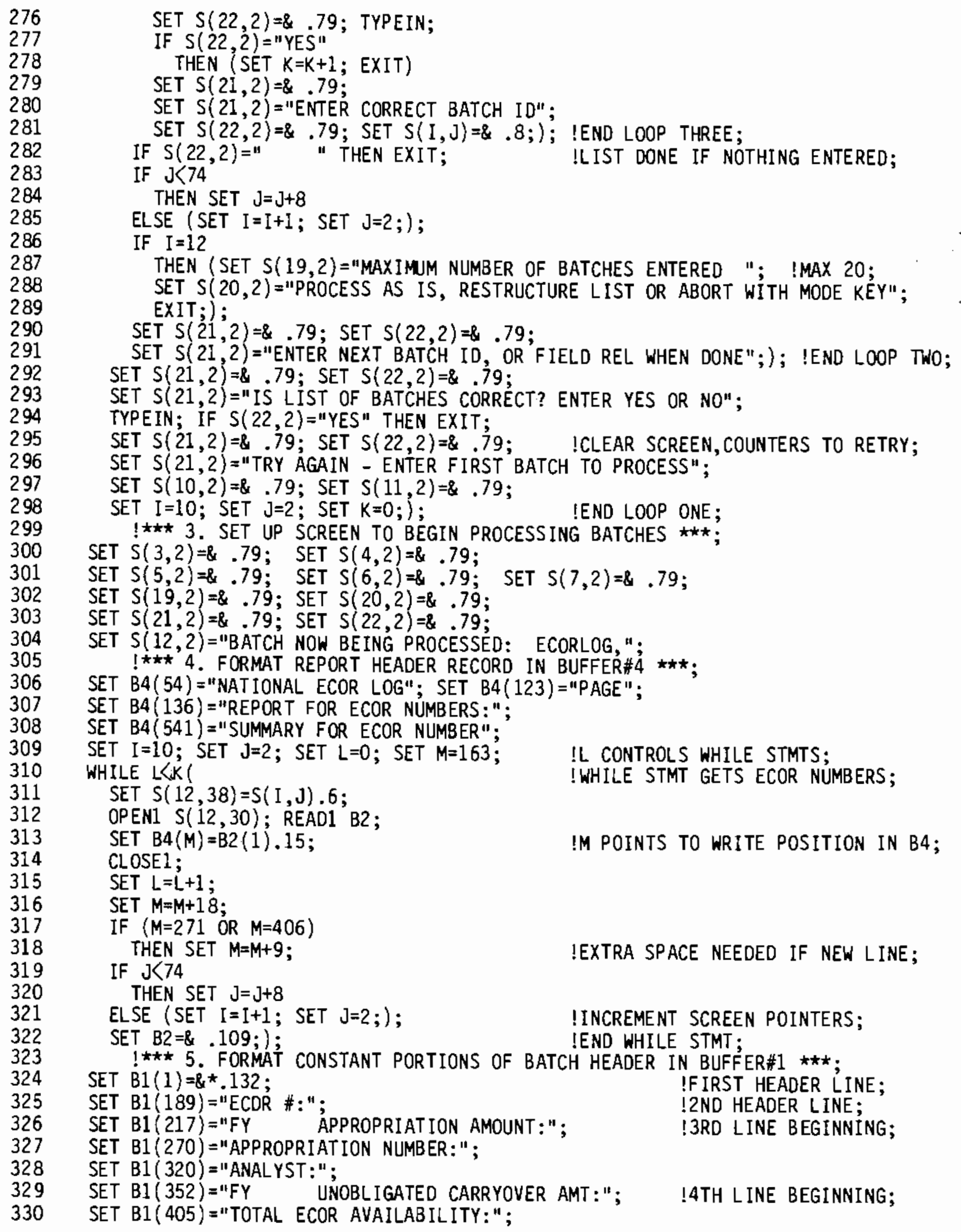


331

332

333

334

335

336

337

338

339

340

341

342

343

344

345

346

347

348

349

350

351

352

353

354

355

356

357

358

359

360

361

362

363

364

365

366

367

368

369

370

371

372

373

374

375

376

377

378

379

380

381

382

383

384

385

SET B1(455)="PHONE \#:" ;

SET B1 (488)="DATE"; SET B1(515)="IPMIS";

SET B1 (538) = "ECOR\#"; SET B1(562)="ECOR\#";

SET B1 (572) ="PROGRAM"; SET B1 (588)="WORK";

SET B1 (595) ="REC'D. CONTRACTOR FO";

SET B1 $(622)="(C I D) \# \quad B A$ CUM. BA";

SET $B 1(660)=" B 0 \quad$ CUM. BO MANAGER" ;

SET B1 $(691)=$ "DESCRIPTION/TITLE COMMENTS";

SET $S(7,40)=" B A: "$; SET $S(7,64)=" B 0: "$; !SET UP BATCH SUMMARY ENTRY LINE;

SET I $=10$; SET $J=2$; SET $L=0 ;$ SET $M=1 ; \operatorname{SET} 0=52$; SET $P=1$;

!O IS PRINT LINE COUNTER, P PAGE COUNTER;

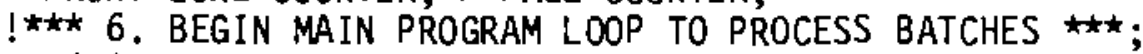

WHILE L $\langle X($

SET $S(12,38)=S(1, J) .6$; OPEN1 $S(12,30)$;

READ1 B2; SET $S(7,22)=B 2(1) .15$;

SET B1 $(197)=B 2(1) .15$;

SET $B 1(220)=B 2(51) .4 ; \quad \operatorname{SET} B 1(252)=B 2(55) .12$;

SET B1 (294) $=B 2(67) .15 ; \quad \operatorname{SET} B 1(329)=B 2(16) .20 ; \quad$ SET B1 $(355)=B 2(82) .4$;

SET B1 $(387)=B 2(86) .12$; SET B1 $(432)=B 2(98) .12 ; \quad$ SET B1 $(464)=B 2(36) .15$;

SET B2=\& .109;

READ1 B2;

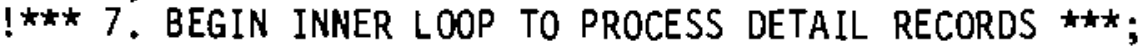

WHILE $\neg$ EOF

IF $0>51$ THEN(

TFORM; SET B4(127)=P.6; SET B4(127) $="$

PRINT B4(1).132; PRINT S $(4,1) .1 ;$

PRINT B4(271).132; PRINT B4(406).i132;
PRINT B1(1).132; PRINT S $(4,1) .1 ;$

PRINT B1(136).78; PRINT S(4,1).1;

PRINT B1(352).132; PRINT S(4,1).1;

PRINT B1 (487).105; PRINT B1(595).126;

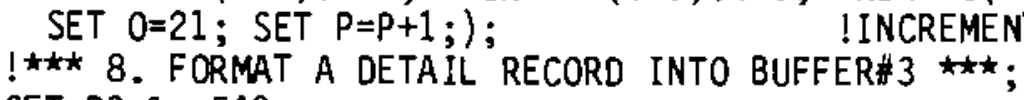

SET B3=\& .540;

SET B3(1)=B2(47).5; $\quad \operatorname{SET~} 83(8)=B 2(1) .12$;

SET B3 (22) $=\mathrm{B} 2(52) .4 ; \quad$ SET B $3(28)=B 2(56) .7$;

SET B3 $(35)=B 2(63) .12 ; \quad$ SET B3 $(47)=B 2(75) .12$;

SET $B 3(59)=B 2(87) .12 ; \quad$ SET B3 $(71)=B 2(99) .12$;

SET $B 3(85)=B 2(37) .10 ; \quad \operatorname{SET} B 3(96)=B 2(111) .19$;

SET $B 3(116)=B 2(187)$.17;

SET $B 3(143)=B 2(13) .12 ; \quad S E T \quad B 3(231)=B 2(130) .19$;

SET B3 $(251)=B 2(204) .17$;

SET B3 $(278)=B 2(25) .12 ;$ SET B3(366) =B2(149) .19;

SET $B 3(386)=B 2(221) .17$;

SET B3 $(501)=B 2(168) .19 ;$ SET B3 $(521)=B 2(238) .17 ; \quad$ IFOURTH LINE;

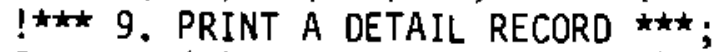

PRINT B3(1).132; PRINT B3(136).132;

PRINT B3(271).132; PRINT B3(406).132; PRINT S(4,1).1;

SET $0=0+5$;

!INCREMENT LINE COUNTER;

SET $B 2=8,260$;

READ1 B2;);

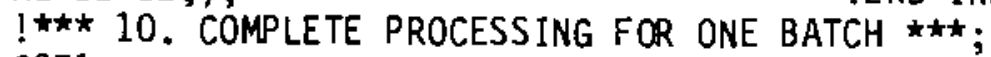

CLOSE1;

SET $S(7,44)=B 3(47) .12 ; \operatorname{SET} S(7,68)=B 3(71) .12$;

IF $0>51$ THEN(

IPRINT HEADER IF NECESSARY; 
386

387

388

389

390

391

392

393

394

395

396

397

398

399

400

401

402

403

404

405

406

407

408

409

410

411

412

413

414

415

416

417

418

419

420

421

422

423

424

425

426

427

428

429

430

431

432

433

434

435

436

437

438

439

440

TFORM; SET B4(127)=P.6; SET B4(127)="

PRINT B4(1).132; PRINT $S(4,1) .1$;

PRINT B4(271).132; PRINT B4(406).132;

PRINT B1(1).132; PRINT S(4,1).1;

PRINT S $(4,1) .1 \quad$ PRINT BI(217).132;

PRINT B1(352).132; PRINT $S(4,1) .1$;

PRINT S $(4,1) .1$;

PRINT B1(1).132;

SET $P=P+1 ;$;

PRINT $S(4,1) .1$; !PRINT BATCH SUMMARY RECORD;

SET $B 4(565)=S(7,22) .59$; PRINT B4(541).84; PRINT $S(4,1) .1$; PRINT B1(1).132;

SET $B 5(M)=S(7,22) .15$; SET $B 5(M+15)=S(7,44) .12$; !STORE BATCH SUMMARY IN B5;

IF $L<19$

THEN SET $B 5(M+27)=S(7,68) .12$

$\operatorname{ELSE~SET~} \operatorname{SAC} 13(1)=S(7,68) .12$

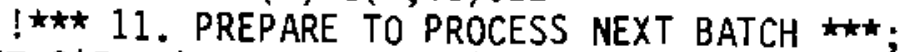

SET $S(7,22)=\& .15 ; \operatorname{SET} S(7,44)=\& .12 ; \operatorname{SET} S(7,68)=\& .12$; IF $\mathcal{3}<74$

THEN SET $\mathrm{J}=\mathrm{J}+8$

ELSE (SET I $=1+1$; SET $\mathrm{J}=2$;);

SET $L=L+1 ;$ SET $M=M+39$; SET $0=52$;

SET $B 3=\& .540$; );

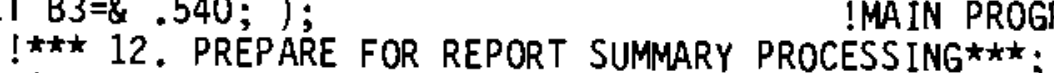

SET $S(12,1)=\& .80 ;$ SET $S(7,1)=\& .80 ;$ SET $B 4(541)=\& .84$;

SET $S(5,45)=$ "REPORT SUMMARY"; SET $S(6,22)=" E C O R$ NUMBER";

SET $S(6,48)=$ "TOTAL BA"; SET $S(6,72)="$ TOTAL BO";

TFORM; SET $B 4(127)=P .6$; SET B4(127)=" "; !PRINT HEADING FOR SUMMARY;

PRINT B4(1).132;

PRINT B4(271).132;

PRINT B1(1).132;

PRINT S(5,1).80;

PRINT $S(4,1) .1$;

PRINT B4(136).132;

PRINT B4(406).132; PRINT S $(4,1) .1$;

PRINT $S(4,1) .1$;

PRINT $S(4,1) .1$;

PRINT S $(4,1) .1$;

PRINT $S(4,1) .1$;

SET $B 4(544)=S(6,1) .80 ;$ PRINT B4(541).84; PRINT $S(4,1) .1$;

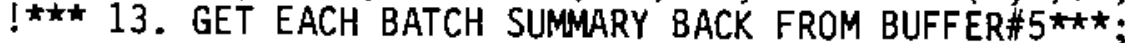

SET L $=0 ;$ SET $M=1$;

WHILE L'K(

IM POINTERS TO BUFFER\#5 COLUMN;

SET $S(7,22)=B 5(M) .15$; SET $S(7,44)=85(M+15) .12$;

IF $L<19$

THEN SET $S(7,68)=B 5(M+27) .12$

ELSE SET $S(7,68)=S A C 13(1) .12$;

SET $B 4(544)=S(7,1) .80$; PRINT $B 4(541) .84$; !PRINT BATCH SUMMARY ENTRY;

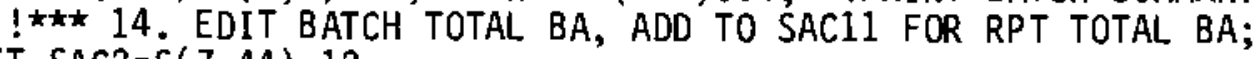

SET SAC2 $=S(7,44) .12$;

SET SAC3 $=\& 0.12$

SET I $12 ;$ SET J=12; SET $N=0$;

WHILE I $>0$ (

IF (SAC2(I) $\rangle=" 0 "$ AND SAC2(I) $\langle=" g ")$ THEN(

SET $\operatorname{SAC} 3(\mathrm{~J})=\operatorname{SAC2}(\mathrm{I}) .1$; SET $\mathrm{J}=\mathrm{J}-1$; );

IF $\operatorname{SAC2}(\mathrm{I})="-"$ THEN SET $\mathrm{N}=1$;

SET I $=I-1 ;$ );

IF $N=1$ THEN?

SET SAC4=SAC3.12; SUB SAC4.12 FROM SAC3;

SUB SAC4 .12 FROM SAC3; SET $\mathrm{N}=0$; );

ADD SAC3.12 TO SAC11;

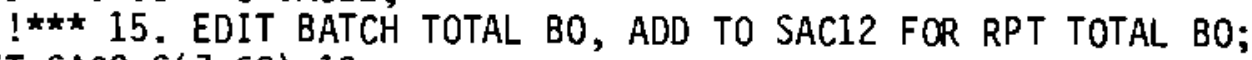

SET $S A C 2=S(7,68) .12$;

SET $S A C 3=\& 0.12$

SET I $=12 ; \operatorname{SET} J=12$;

!FLAG N SET IF '-' ENCOUNTERED;

!END WHILE STMT;

!RESOLVE NEGATIVE NUMBER; 
441

442

443

444

445

446

447

448

449

. 450

451

452

453

454

455

456

457

458

459

460

461

462

463

464

465

466

467

468

469

470

471

472

473

474

475

476

477

478

479

480

481

482

483

484

485

486

487

488

489

490

491

492

493

494

495

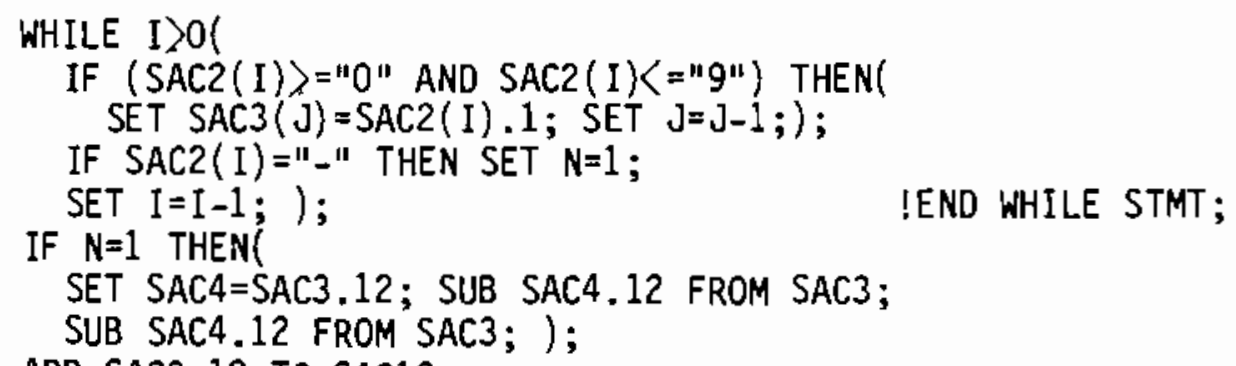

IEND WHILE STMT;

!REMOVE MINUS SIGN FOR POSITIVE \#S; !INSERT ZERO IF \# IS 0;

IEND WHILE STARTED AT STEP 14; 
496 THEN SET SAC6(12)="0" :

497 IF SAC5(12)="-" THEN SETं $\operatorname{SAC6}(12)=\operatorname{SAC5}(11) .1$;

498

499

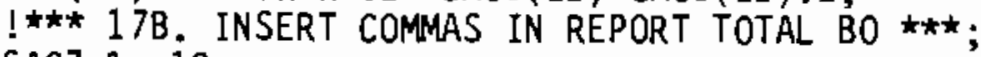

SET $S A C 7=\& .12$;

500 SET SAC7 $(10)=\operatorname{SAC6}(10) .3$;

501 IF $(\operatorname{SAC6}(9)="$ " OR SAC6 $(9)="-")$

502

503

504

505

506

507

508

509

510

511

512

513

514

515

516

517

518

519

520

521

522

523

THEN (IF SAC6(9)=" -" THEN SET $\operatorname{SAC7}(9)="-"$;)

ELSE( SET SAC7 (9) ="," ;

SET $\operatorname{SAC} 7(6)=\operatorname{SAC} 6(7) .3$;

(IF (SAC6(6) =" "OR SAC6(6) ="-")

THEN (IF SAC6(6) =" -" THEN SET $\operatorname{SAC7}(5)="-" ;)$

ELSE (SET $\operatorname{SAC7}(5)=", "$; $\operatorname{SET} \operatorname{SAC7}(1)=\operatorname{SAC6}(3) .4$;) ;) ;) ;

SET $S(7,68)=$ SAC7.12;

PRINT $S(4,1) .1$;

SET $B 4(544)=S(7,1) .80 ;$ PRINT B4(541).84;

!TOTAL BO COMPLETED; !PRINT REPORT TOTALS;

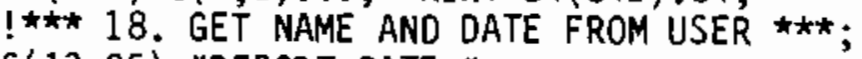

SET $S(13,25)=$ "REPORT DATE:" ;

SET $S(14,25)=$ "PREPARED BY:";

SET $S(21,2)=$ "ENTER TODAY'S DATE" ; LOOP(

TYPEIN; SET $S(13,47)=S(22,2) .25$;

!REQUESTS DATE/NAME UNTIL VALID;

SET $S(21,2)=\& \quad .79 ;$ SET $S(22,2)=\& .79$;

SET $S(21,2)=" E N T E R$ YOUR NAME";

TYPEIN; SET $S(14,47)=S(22,2) .25$;

SET $S(21,2)=\& \quad .79 ; \operatorname{SET} S(22,2)=\& \quad .79$;

SET $S(21,2)=" A R E$ NAME AND DATE CORRECT? ENTER YES OR NO";

TYPEIN;

IF $S(22,2)=$ "YES" THEN

EXIT

ELSE(

SET $S(13,47)=\& .25 ;$ SET $S(14,47)=\& \quad .25$;

SET $S(21,2)=\& .79 ;$ SET $S(22,2)=\& .79$;

SET $S(21,2)=$ "TRY AGAIN - ENTER TODAY'S DATE";) ;) ; IEND LOOP;

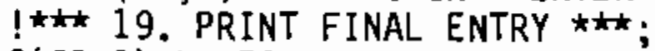

SET $S(22,2)=\& \quad: 79$;

SET $S(21,2)=$ "HIT MODE KEY TO EXIT WHEN '\$END ENCOUNTERED' APPEARS BELOW";

PRINT S(4,1).1; PRINT $S(4,1) .1$; PRINT $S(4,1) .1$; PRINT $S(13,1) .80$;

PRINT S(14,1).80; PRINT S(4,1).1; PRINT S(4,1).1; PRINT BI(1).132;

\$END 
SOURCE CODE FROM MASTER, ECRJST

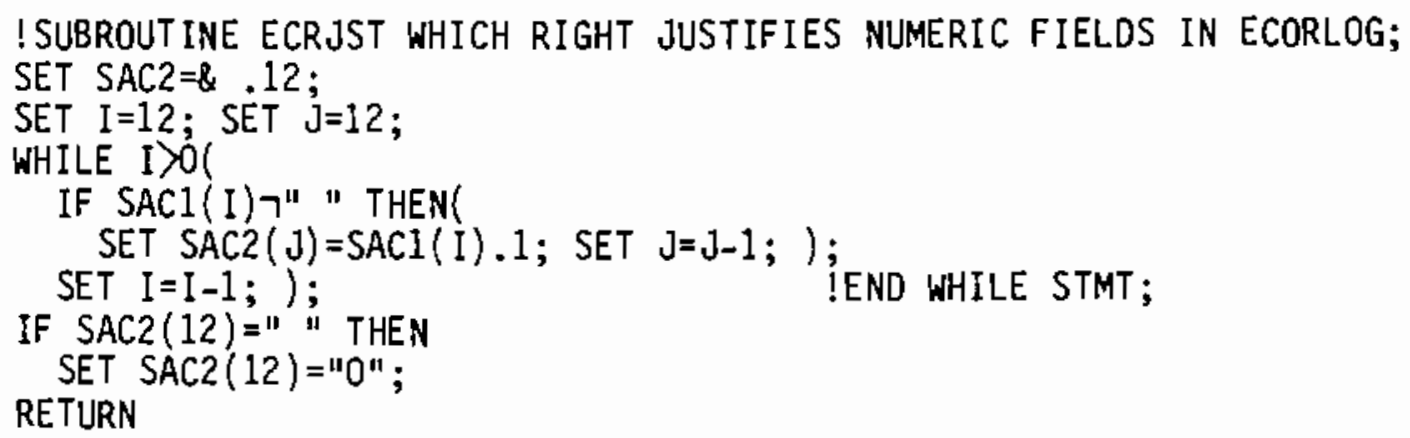


SOURCE CODE FROM MASTER, ECPURG

$\begin{array}{ll}1 & \text { \$COMMENT COMMANDS TO ARCHIVE ECORLOG BATCHES } \\ 2 & \text { \$TODOS } \\ 3 & / 0=B C H 18400, \mathrm{~J}=E C O R L O, K=K G, B=B B A T C H, C=C 1, P \\ 4 & \text { /O=BCH28400, J=ECORLO, } K=K G, B=B B A T C H, C=C 2, P \\ 5 & \text { \$PAUSE COMMANDS TO DELETE ECORLOG BATCHES } \\ 6 & \text { \$PURGE ECORLOG, BATCH1 } \\ 7 & \text { \$PURGE ECORLOG, BATCH2 } \\ 8 & \text { \$PAUSE COMMANDS TO RETRIEVE ECORLOG BATCHES } \\ 9 & \text { \$FRODOS } \\ 10 & / I=B C H 18400, J=E C O R L O, K=K G, B=B B A T C H, C=C 1, P \\ 11 & / I=B C H 28400, J=E C O R L O, K=K G, B=B B A T C H, C=C 2, P \\ 12 & \text { \$END }\end{array}$




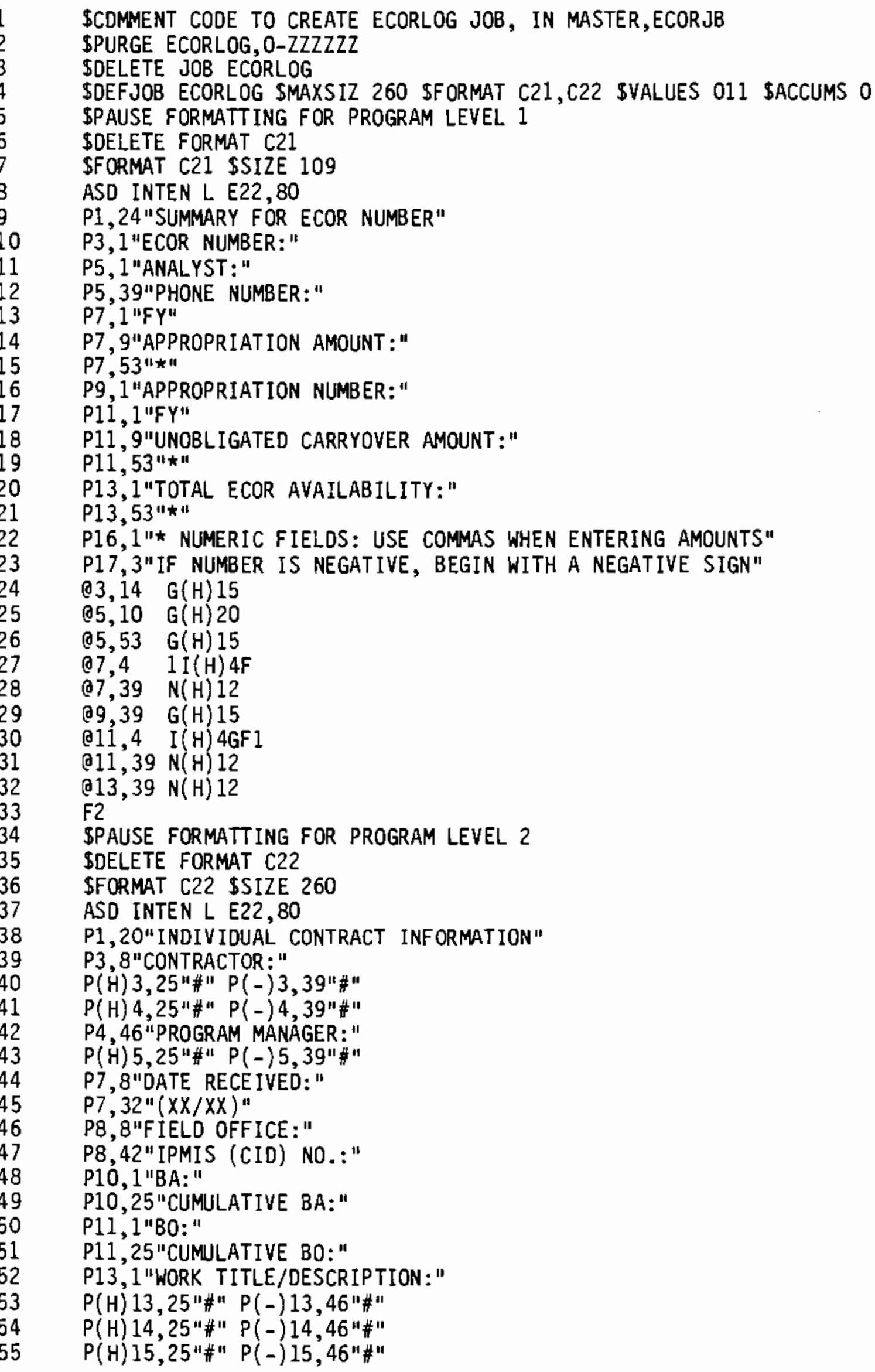




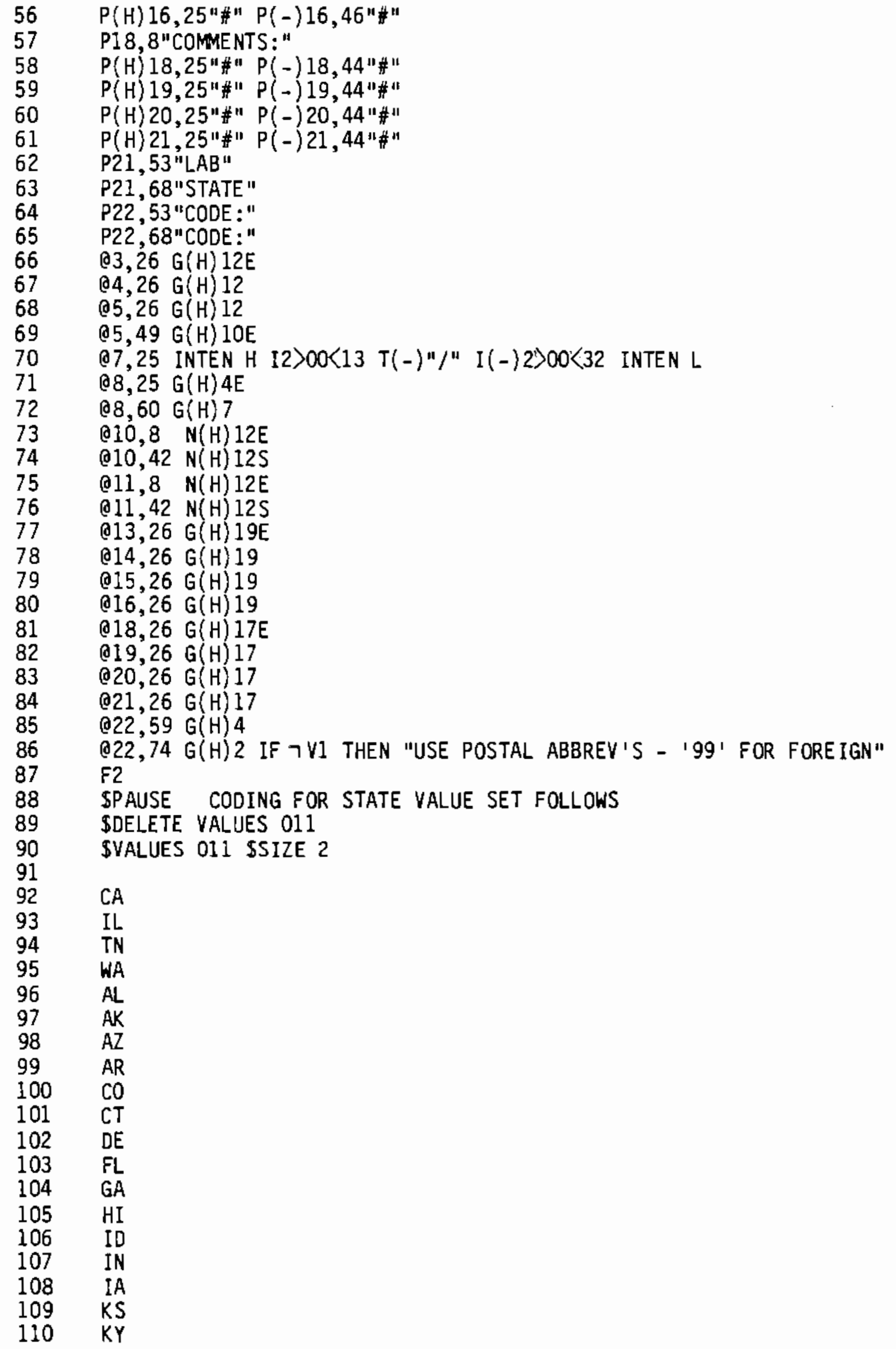


SOURCE CODE FROM MASTER,ECORJB

$\begin{array}{ll}111 & \text { LA } \\ 112 & M E \\ 113 & M D \\ 114 & M A \\ 115 & M I \\ 116 & M N \\ 117 & M S \\ 118 & M O \\ 119 & M T \\ 120 & \text { NE } \\ 121 & \text { NV } \\ 122 & \text { NH } \\ 123 & N J \\ 124 & \text { NM } \\ 125 & \text { NY } \\ 126 & \text { NC } \\ 127 & \text { ND } \\ 128 & O H \\ 129 & O K \\ 130 & O R \\ 131 & P A \\ 132 & \text { RI } \\ 133 & \text { SC } \\ 134 & \text { SD } \\ 135 & \text { TX } \\ 136 & \text { UT } \\ 137 & V T \\ 138 & \text { VA } \\ 139 & \text { WV } \\ 140 & W I \\ 141 & \text { WY } \\ 142 & \text { DC } \\ 143 & 99 \\ 144 & \text { \$END } \\ & \end{array}$


1 SEDIT !PROGRAM NAME: ECORUP -- UPDATES TOTALS IN A BATCH OF ECLOG84;

!THIS SECTION RETRIEVES A VALID BATCH TO UPDATE;

SET S(NLINES -3,2) ="ENTER BATCH ID TO UPDATE";

SET $S(3,1)=" E C L O G 84, "$; LOOP(

!LOOP REQUESTS BATCH ID UNTIL VALID BATCH ENTERED;

TYPEIN; SET $S(3,9)=S($ NLINES-2,2) .6;

DPEN1 S(3,1); READ1 B1;

SET S(NLINES-3,2)="IS THIS THE CORRECT BATCH? ENTER YES OR NO";

SET $S($ NLINES $-2,2)=\& .79 ;$ TYPEIN;

IF ᄀEOF AND $S($ NLINES-2,2) = YES"

THEN (SET $S(3,18)="$ TOTALS ARE BEING UPDATED"; EXIT)

ELSE SET S(NLINES-3,2)=\& .79;

IF $S($ NL INES $-2,2)=$ "YES"

THEN SET S(NLINES-3,2)="NO DATA IN THIS BATCH... TRY AGAIN"

ELSE SET S(NLINES-3,2)="TRY AGAIN";

CLOSE1;

SET $S($ NLINES-2,2) $=\& .79 ;$ SET $S(3,9)=\& .71) ; \quad$ !END LOOP;

SET $S(N L I N E S-3,2)=\& \quad .79 ;$ SET $S($ NLINES $-2,2)=\& .79$;

!THIS SECTION OPENS BATCH 'TEMP', WRITES HEADER RECORD TO IT;

CREATE2 "ECLOG84, TEMP";

SET PLEVEL2=1 ; SET RECSIZ2=139;

WRITE2 B1;

ISET PROG.LEVEL, REC.SIZE TO PROCESS OETAIL RECS;

SET PLEVEL2=2; SET RECSIZ2=281; LOOP(

IMAIN PROGRAM LOOP TO PROCESS DETAIL RECS STARTS HERE;

READ1 B1;

IF EOF THEN EXIT;

!FOLLOWING SECTION UPDATES CUM BA;

AOD B1(66) . 8 TO SAC1;

SET $S A C 2=S A C 1.12$;

SET $K=2$; SET $L=1$;

SET $\operatorname{SAC} 2(1)="$ ";

WHILE Kく 13(

IF ( SAC2 (K) ᄀ"O" AND SAC2(K-1)=" ")

THEN (SET SAC2 $(K-1)="-"$; SET $L=K-1$;);

IF $(\operatorname{SAC2}(K)=" 0$ " AND $\operatorname{SAC2}(K-1)="$ ") THEN SET SAC2 $(K)="$ ";

SET $K=K+1 ;)$;

If $(\operatorname{SAC2}(12)\rangle=" 0 "$ AND $S A C 2(12)<=" 9 ")$

THEN SET SAC2 $(\mathrm{L})="$ ";

IF $\operatorname{SAC2}(12)="$ "

THEN SET SAC2(12)="0";

SET $B 1(74)=\operatorname{SAC2}(3) .10$;

!FOLLOWING SECTION UPDATES CUM BO;

IEXIT LOOP IF NO MORE RECORDS;

ADD B1(84). 8 TO SAC3;

SET $S A C 4=S A C 3.12$;

SET $K=2$; SET $L=1$;

SET $\operatorname{SAC} 4(1)="$ ";

WHILE $K<13($

IF ( $\operatorname{SAC4}(K) \neg " 0 "$ AND SAC4$(K-1)="$ ")

IK ITERATES WHILE STMT,L IS A MARKER;

!WHILE STMT EDITS CUM BA IN SAC2;

THEN (SET SAC4 $(K-1)="-"$; SET L=K-1;);

IF ( $\operatorname{SAC4}(K)=" 0$ " AND SAC4 $(K-1)="$ ")

THEN SET SAC4(K)=" ";

SET $K=K+1 ;)$;

IF $(\operatorname{SAC} 4(12)\rangle=" 0 "$ AND $\operatorname{SAC4}(12 K=" 9 ")$

!END WHILE STMT;

IUPDATED CUM BA (SAC2) WRITTEN TO BUFFER;

IL MARKS LAST BLANK POSITION; 
THEN SET SAC4(L)=" ";

IF $\operatorname{SAC4}(12)=" 1 "$

THEN SET SAC4(12) = "0"; SET $81(92)=\operatorname{SAC} 4(3) .10$;

IUPDATED CUM BO (SAC4) WRITTEN TO BUFFER; WRITE2 81 ;) !WRITE UPDATED RECORD TO BATCH TEMP, CLOSE MAIN PROG. LOOP; CLOSE1; CLOSE2; !CLOSE ORIGINAL AND UPDATED BATCHES; !THIS SECTION TRANSFERS TEMP BACK INTO ORIGINAL BATCH; OPEN1 "ECLOG84, TEMP"; CREATE2 $S(3,1)$; SET PLEVEL2 $=1$; SET RECSIZ2=139; READ1 B1; WRITE2 B1; SET PLEVEL2=2; SET RECSIZ2=281; LOOP(

!REOPEN TEMP;

!CLEAR OUT ORIGINAL BATCH;

ITRANSFER HEADER RECORD; !SET FOR DETAIL RECORDS; READ1 B1;

IF EOF THEN EXIT;

WRITE2 B1;) !LOOP TO TRANSFER DETAIL RECORDS;

CLOSE1; CLOSE2;

SPURGE ECLOG84, TEMP

SPAUSE PRESS SPACE BAR TO PRINT REPORT ON ONE BATCH, MODE KEY TO EXIT

SEDIT !PROGRAM NAME: ECRPTI -- PRINTS AN ECORLOG REPORT FOR ONE BATCH;

!THIS SECTION RETRIEVES A VALID BATCH TO PROCESS;

SET S(NLINES-3,2)="ENTER BATCH ID TO FORMAT FOR REPORT";

$\operatorname{SET} S(3,1)=" E C L O G 84, "$;

LOOP

(TYPEIN; SET $S(3,9)=S($ NLINES-2,2).6;

OPEN1 $S(3,1)$; READI B2;

SET S(NLINES-3,2)="IS THIS THE CORRECT BATCH? ENTER YES OR NO";

SET S(NLINES-2,2) $=8.79$; TYPEIN;

IF רEOF AND S( NLINES $-2,2)=$ "YES"

THEN (SET $S(3,17)=" I S$ BEING FORMATTED FOR REPORT"; EXIT)

ELSE SET S(NLINES-3,2) = \& .79;

IF $S($ NLINES-2,2) = Y YES"

THEN SET S(NLINES-3,2)="NO DATA IN THIS BATCH... TRY AGAIN"

ELSE SET S(NLINES-3,2) ="TRY AGAIN";

CLOSE1;

SET $S(N L I N E S-2,2)=\& \quad .79 ;$ SET $S(3,9)=\& .71)$;

SET $S($ NLINES-3,2) $=8.79$; SET S(NLINES-2, 2$)=8.79$;

!THIS SECTION FORMATS THE REPORT HEADER IN BUFFER 1;

SET B1 $(54)=$ "NATIONAL ECOR LOG"; SET 81 (123)= "PAGE";

SET B1 (189)="ECOR \#:"; SET B1(197)=B2(1).15;

SET B1 (217)="FY APPROPRIATION AMOUNT:";

SET $B 1(219)=B 2(51) .4$; $\operatorname{SET} B 1(251)=B 2(102)$. 12;

SET B1(270)="APPROPRIAT ION NUMBER:"; SET B1 (295)=B2(64).15;

SET B1 (319)="ANALYST:"; SET B1 (328)=B2(16) .20;

SET B1 (352) ="FY UNOBLIGATED CARR YOVER AMT:";

!END LOOP;

SET B1 (354)=B2(79) .4; SET B1 (386) =B2(114).12;

SET B1(405)="TOTAL ECOR AVAILABILITY:"; SET B1(431)=B2(126) .14;

SET B1 $(454)=$ "PHONE \#:"; SET B1 $(463)=B 2(36) .15$;

SET B1 (489)= "DATE"; SET B1 (518)="IPMIS";

SET B1 (569)="PROGRAM"; SET B1(586)="WORK" ;

SET B1 (595)= "RECEIVED CONTRACTOR FO";

SET B1 (625) =" (CID) \# BA CUM. BA";

SET B1 $(658)=" B O$ CUM. BO MANAGER";

SET B1 $(688)=$ "DESCRIPTION/TITLE COMMENTS";

SET $[=52 ;$ SET $]=1$;

!1ST HEADER LINE;

!2ND HEADER LINE;

!3RD LINE BEGINNING;

II IS A LINE COUNTER, I A PAGE COUNTER; 
111

112

113

114

115

116

117

118

119

120

121

122

123

124

125

126

127

128

129

130

131

132

133

134

135

136

137

138

139

140

141

142

143

144

145

146

147

148

149

150

151

152

153

154

155

156

157

158

159

160

161

162

163

164

165
SET B2 = \& .139;

LOOP(

IF I $>51$ THEN(

TFORM; SET $B 1(127)=0.6$; SET $B 1(127)=1 "$

PRINT B1 (1).132; PRINT $S(4,1) .1 ;$ PRINT' $S(4,1) .1$;

PRINT B1(136).78; PRINT S(4,1).1; PRINT B1(217).132; PRINT S(4,1).1;

PRINT B1(352).132; PRINT $S(4,1) 1$; PRINT $S(4,1) \cdot 1$; PRINT $S(4,1) .1 ;$ PRINT B1 (487).105; PRINT B1 $(595) .123$; PRINT S 4,1$) .1$; PRINT S $(4,1): 1$; SET I $=16$; SET $\mathrm{J}=\mathrm{J}+1 ;$; ;

READ1 B2;

IF EOF THEN EXIT;

SET B3=\&.540;

! INCREMENT COUNTERS, END IF;

ICLEAR BUFFER TWO FOR INDIVIDUAL RECORDS;

!BEGINNING OF MAIN PROGRAM LOOP;

IPRINT HEADER AT TOP OF EACH PAGE;

!THIS SECTION FORMATS A DETAIL RECORD INTO BUFFER3;

SET B3 $(1)=B 2(47) .8 ; \quad$ SET B3(11)=B2(1).12;

SET B3(25)=B2 (55). 4; SET B3 $(31)=B 2(59) .7$;

SET B3 $(39)=B 2(258) .9 ; \quad$ SET B3 $(49)=B 2(74) .10 ;$

SET $B 3(60)=B 2(267) .9$; $\quad$ SET B3 $(70)=B 2(92) .10$;

SET B3 $(82)=B 2(37) .10 ; \quad$ SET B3 $(93)=B 2(102) .19$;

SET $B 3(113)=B 2(178) .20$;

SET B3(146)=B2(13).12; SET B3(228)=B2(121).19;

SET $B 3(248)=B 2(198) .20$;

SET B3(281)=B2(25).12; SET B3(363)=B2(140).19;

SET B3 (383) $=B 2(218) .20$;

SET B3(498)=B2(159).19; SET B3(518) =B2(238) .20;

!THIS SECTION PRINTS THE DETAIL LINE;

PRINT B3(1).132; PRINT B3(136).132;

PRINT B3(271).132; PRINT B3(406).132; PRINT S(4,1).1;

SET $I=I+5$;

I INCREMENT LINE COUNTER;

SET $B 2=\& .281$;); ICLEAR BUFFER2 FOR NEW RECORD, END MAIN PROGRAM LOOP;

ITHIS SECTION FORMATS AND PRINTS CLOSING INFORMATION;

!PRINT OUT FINAL HEADER BELOW IF NECESSARY;

IF I $>51$ THEN(

TFORM; SET $B 1(127)=J .6$; SET $B 1(127)=" \quad "$;

PRINT BI(1).132; PRINT S(4,1).1;

PRINT B1(136).78; PRINT S(4,1).1; PRINT B1(217).132; PRINT S(4,1).1;

PRINT B1(352).132; PRINT S(4,1).1; PRINT S(4,1).1; PRINT S(4,1).1;);

SET S $(6,11)=$ "REPORT DATE:"; SET S(6,54)="TOTAL BA:"; IUSE SCREEN BUFFER;

SET $S(7,11)=" P R E P A R E D$ BY:"; SET $S(7,54)=$ "TOTAL BO:"; IFOR CLOSING ENTRY;

!BEGIN EDITING TOTAL BA USING SACI AND SCREEN;

SET $\operatorname{SAC1}(1)="$ "; $\operatorname{SET} \operatorname{SACl}(3)=B 3(49) .10$;

SET $S(6,77)=\operatorname{SACl}(10) .3$;

IF $(\operatorname{SAC1}(9)="$ ") OR $(\operatorname{SAC1}(9)="-")$ THEN

(IF SAC1 (9) =" $-"$ THEN

ELSE

SET $S(6,76)="-" ;)$

SET $S(6,76)=", "$;

SET $S(6,73)=\operatorname{SACI}(7) \cdot 3$;

(IF ( $\operatorname{SAC1}(6)="$ ") OR (SAC1(6)="-") THEN

(IF SAC1(6) $="$-" THEN

ELSE

$\operatorname{SET} S(6,72)="-" ;)$

(SET $S(6,72)=", "$;

SET $S(6,6 B)=S A C 1(3) .4 ;)$;) ;);

! BEGIN EDITING TOTAL BO US ING SAC2 AND SCREEN;

SET $\operatorname{SAC2}(1)="$ "; $\operatorname{SET} \operatorname{SAC2}(3)=B 3(70) .10$;
!TOTAL BA COMPLETED; 
166

167

168

169

170

171

172

173

174

175

176

177

178

179

180

181

182

183

184

185

186

187

188

189

190

191

192

193

194

195

196

197

198

199

200

201

202

203

204

205

206

207

208

209

210

211

$\cdot 212$

213

214

215

216

217

218

219

220

SET $S(7,77)=\operatorname{SAC2}(10) \cdot 3$;

IF (SAC2(9)=" ") OR (SAC2(9)="-") THEN

(IF SAC2 (9) =" -" THEN

ELSE(

SET $S(7,76)="-. " ;)$

SET $S(7,76)="$ ",

SET $5(7,73)=\operatorname{SABC} 2(7) .3$;

(IF (SAC2(6) =" ") OR (SAC2(6)="-") THEN

(IF SAC2 (6) $="-"$ THEN

ELSE

$$
\text { SET } S(7,72)="-" ;)
$$

(SET $S(7,72)=", "$;

SET $S(7,68)=\operatorname{SẢC2}(3) .4$;) ;) ;) ; ITOTAL BO COMPLETED;

!GET DATE AND NAME FROM USER;

SET S(NLINES-3,2)="ENTER TODAY'S DATE";

LOOP(

TYPEIN; SET $S(6,25)=S($ NLINES $-2,2) .25$;

SET S(NLINES $-3,2)=8 \quad .79$; SET S(NLINES-2,2) $=\& .79$;

SET S(NLINES-3,2)="ENTER YOUR NAME";

TYPEIN; SET $S(7,25)=S$ (NLINES-2,2).25;

SET S(NLINES-3,2) $=\& .79 ;$ SET S(NL. INES $-2,2)=\& .79$;

SET S(NLINES-3,2)="ARE NAME AND DATE CORRECT? ENTER YES OR NO";

TYPEIN;

IF S(NLINES-2,2) ="YES" THEN EXIT

ELSE

SET $S(6,25)=8 \quad .25 ;$ SET $S(7,25)=2.25$;

SET S(NLINES-3,2) $=\$ .79$; SET S(NLINES $-2,2)=\& .79$;

SET S(NLINES-3,2)="TRY AGAIN - ENTER TODAY'S DATE";) ;) ; !END LOOP;

SET S(NLINES-2,2) $=$ \& .79;

SET S(NLINES-3,2) $=8, .79$;

PRINT S(4,1).1; PRINT S(4,1).1;

PRINT S(4,1).1; PRINT S(6,1).80; PRINT S(7,1).80;

CLOSE1;

SPAUSE PRESS SPACE BAR TO PRINT MULTI-BATCH REPORT, MODE KEY TO EXIT

\$EDIT !PROGRAM ECRPT2 -- PRODUCES OFFICE SUMMARY REPORT;

OPEN1 "ECLOG84,\$";

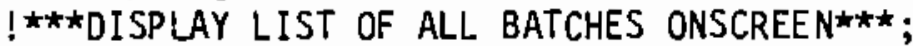

SET I=4; SET $J=2$; II COUNTS SCREEN LINE\#, J COLUMN\#;

SET $S(3,2)=$ "ECORLOG BATCHES AVAILABLE FOR PROCESSINǴ";

SET $S(1, J)=B A T C H 1.6$;

LOOP(

!WRITE 1ST BATCH ID ONSCREEN;

NEXTB1;

IF 7OPEN1 THEN (SET S(19,2)="ALL AVAILABLE BATCHES ARE DISPLAYED"; EXIT);

IF $]<74$

THEN SET $\mathrm{J}=\mathrm{j}+8$

ELSE (SET I $=\mathrm{I}+1$; SET $\mathrm{J}=2 ;$ ); $\quad$ !INCREMENT LINE, COL COUNTERS I, $\mathrm{J}$;

IF $I=8$

THEN (SET $S(19,2)=" J O B$ HAS MORE BATCHES THAN CAN 8E DISPLAYED"; !MAX 40;

SET $S(20,2)=$ "ABORT PROGRAM WITH MODE KEY TO SEE OTHERS IN JOB MODE"; EXIT;);

SET $S(I, J)=B A T C H 1.6 ;)$;

CLOSEl;

! LOOP DISPLAYS ONE BATCH ID ONSCREEN;

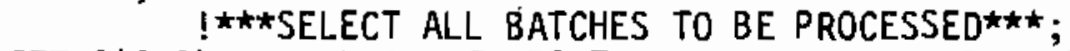

SET $S(9,2)=" E C O R L O G$ BATCHES TO BE INCLUDED IN REPORT";

SET $S(9,44)="$ (ORDERED FROM LEFT TO RIGHT)"; 
221 SET I=10; SET $\mathrm{J}=2$; SET $\mathrm{K}=0$; $\quad$ !RESET I, $\mathrm{J}-\mathrm{K}$ COUNTS \# OF BATCHES SELECTED;

222

223

224

225

226

227

228

229

230

231

232

233

234

235

236

237

238

239

240

241

242

243

244

245

246

247

248

249

250

251

252

253

254

255

256

257

258

259

260

261

262

263

264

265

266

267

268

269

270

271

272

273

274

275

SET $S(21,2)=$ "ENTER FIRST BATCH ID TO INCLUDE IN REPORT"; LOOP( LOOP !LOOP ONE VALIDATES ENTIRE LIST AFTER SELECTION; !LOOP TWO SELECTS LIST OF BATCHES; !LOOP THREE SELECTS ONE VALID BATCH;

TYPEIN; IF $S(22,2)="$ "THEN EXIT; SET $S(I, J)=S(22,2) .6$; $\quad$ !COPY ID ENTERED TO $S(I, J)$;

SET $S(21,2)=" I S$ BATCH ABOVE CORRECT? ENTER YES OR NO ";

SET $S(22,2)=\& .79$; TYPEIN;

IF $S(22,2)=" Y E S "$

THEN (SET $K=K+1 ; E X I T)$

SET $S(21,2)=\& \quad .79$;

SET $S(21,2)=$ "ENTER CORRECT BATCH ID";

$\operatorname{SET} S(22,2)=\& .79 ; \operatorname{SET} S(I, J)=\& .8 ;) ; \quad$ !END LOOP THREE;

IF $S(22,2)="$ "THEN EXIT; !LIST COMPLETE IF NOTHING ENTERED;

IF $3<74$

THEN SET $\mathrm{J}=\mathrm{J}+8$

ELSE (SET $I=I+1$; SET $\mathrm{J}=2 ;$ ); IINCREMENT $\mathrm{I}, \mathrm{J}$;

IF $I=12$

THEN (SET S(19,2)="MAXIMUM NUMBER OF BATCHES ENTERED "; !MAX 20 BATCHES;

SET S(20,2)="PROCESS AS IS, RESTRUCTURE LIST OR ABORT WITH MODE KEY"; EXIT; ;

SET $S(21,2)=\& \quad .79 ; \operatorname{SET} S(22,2)=\& \quad .79 ;$

SET $5(21,2)=$ "ENTER NEXT BATCH ID, OR FIELD REL WHEN DONE";); !END LOOP TWO; SET $S(21,2)=\& \quad .79 ;$ SET $S(22,2)=\& .79$;

SET $S(21,2)=" I S$ LIST OF BATCHES CORRECT? ENTER YES OR NO";

TYPEIN; IF $S(22,2)=$ "YES" THEN EXIT;

SET $S(21,2)=\& .79 ; \operatorname{SET} S(22,2)=\& .79 ; \quad$ !CLEAR SCREEN, COUNTERS TO RETRY;

SET $S(21,2)=" T R Y$ AGAIN - ENTER FIRST BATCH TO PROCESS";

SET $S(10,2)=\& \quad .79$; SET $S(11,2)=\& \quad .79$;

SET $[=10 ;$ SET $\mathrm{J}=2$; SET $K=0$; ; $! * \star \star$ SET UP SCREEN TO BEGIN PROCESSING BATCHES $* \star \star ;$

SET $S(3,2)=\& .79 ;$ SET $S(4,2)=\& .79 ; \quad$ !CLEAR AVAILABLE BATCH LIST, MESSAGES;

SET $S(5,2)=\& .79 ; \quad$ SET $S(6,2)=\& .79 ; \quad$ SET $S(7,2)=\& .79$;

SET $S(19,2)=\& \quad .79 ;$ SET $S(20,2)=\& \quad .79 ;$

SET $S(21,2)=\& .79$; SET $S(22,2)=\& \quad 79$;

SET $S(12,2)=$ "BATCH NOW BEING PROCESSED: ECLOG84,";

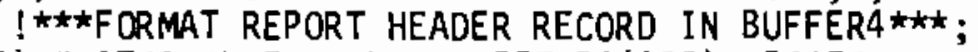

SET $B 4(54)=$ "NATIONAL ECOR LOG"; SET B4(123)="PAGE";

SET B4(136) = "REPORT FOR ECOR NUMBERS:";

SET I $=10$; SET $J=2$; SET $L=0$; SET $M=163$; !L CONTROLS WHILE LOOPS;

WHILE LKX(

SET $S(12,38)=S(I, J) .6$;

OPEN1 $S(12,30)$; READI 82 ;

SET $B 4(M)=B 2(1) .15$;

CLOSEI;

SET $L=L+1$

SET $M=M+18$;

IF ( $M=271$ OR $M=406)$

THEN SET $M=M+9$;

IF $J<74$

!WHILE LOOP GETS ECOR NUMBERS;

THEN SET $\mathrm{J}=\mathrm{J}+8$

ELSE (SET I $=I+1$; SET $\mathrm{J}=2 ;$ ); IINCREMENT SCREEN LINE, COL POINTERS;

SET B2 $=\& .139 ;$;

!END WHILE, ALL ECOR \#'S READ;

IM POINTS TO WRITE POSITION IN B5;

!EXTRA SPACE NEEDED IF NEW LINE;

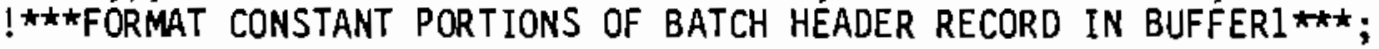




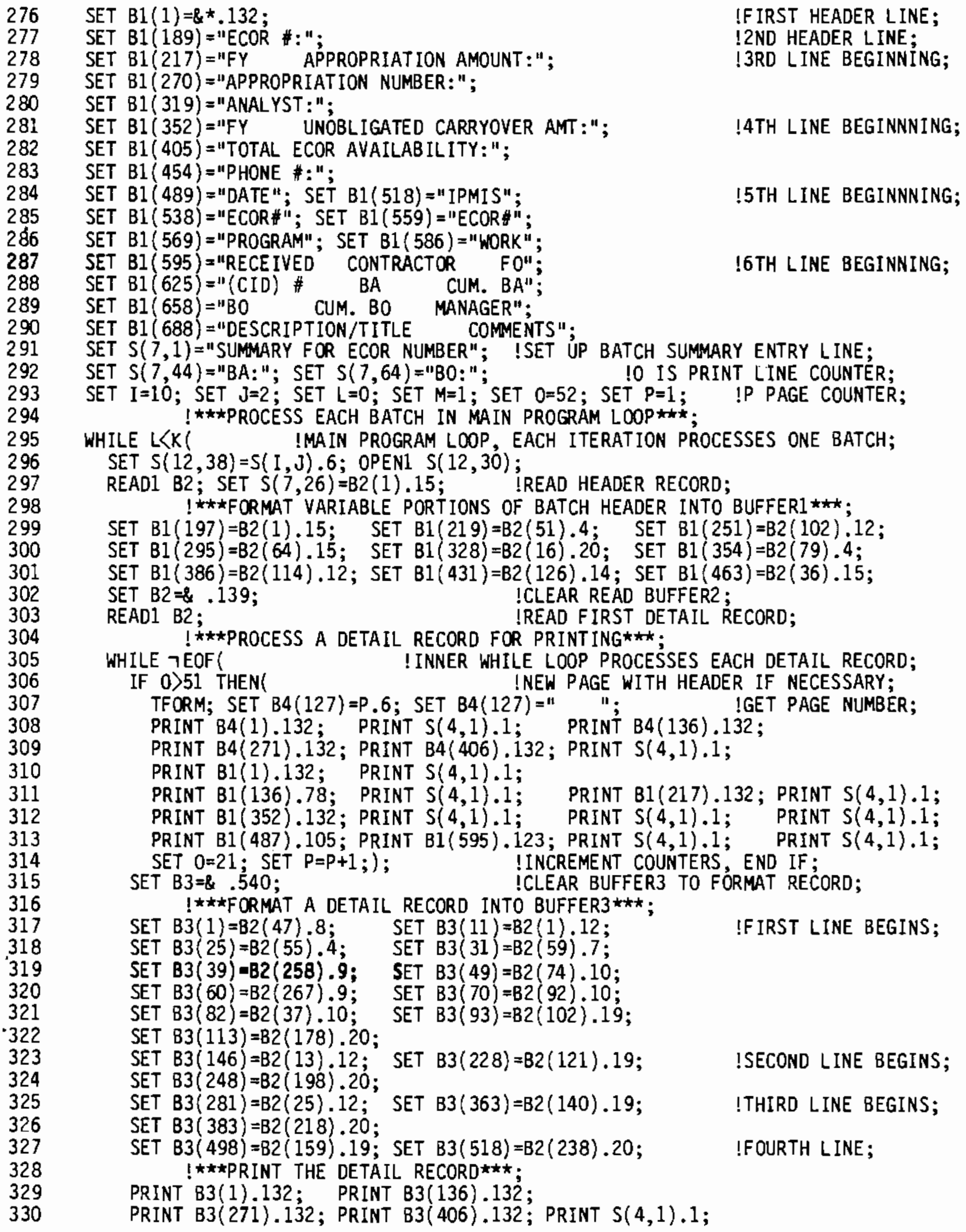


331
SET $0=0+5$;

SET B2 $=\& \quad 281$;

READ1 B2;);

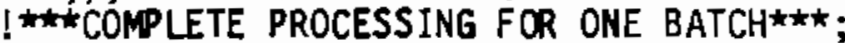

CLOSE1;

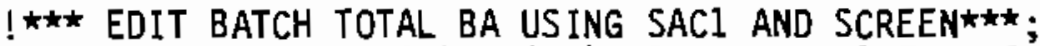
SET SAC1 $(1)="$ "; SET SAC1(3)=B3(49).10; !PUT BA IN SAC1; ADD B3(49).10 TO SAC3; !WRITE TO SCREEN, INSERT COMMAS WHERE NEEDED; SET $S(7,57)=\operatorname{SAC} 1(10) .3$; IF ( $\operatorname{SACl}(9)="$ ") OR (SACl(9)="-") THEN

(IF SAC1(9)="-" THEN SET $S(7,56)="-" ;)$

ELSE(

SET $S(7,56)=", "$;

SET $S(7,53)=\operatorname{SACI}(7) .3$;

(IF (SACI $(6)="$ ") OR (SAC1(6)="-") THEN

(IF $\operatorname{SACl}(6)="-"$ THEN SET $S(7,52)="-" ;)$

ELSE

(SET $S(7,52)=", "$;

SET $S(7,48)=\operatorname{SAC}(3) .4 ;) ;) ;)$;

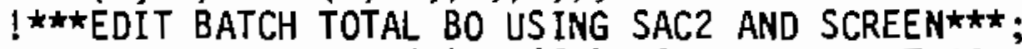

$\operatorname{SET} \operatorname{SAC} 2(1)="$ "; $\operatorname{SET} \operatorname{SAC} 2(3)=B 3(70) .10$;

ADD B3(70).10 TO SAC4;

SET $S(7,77)=\operatorname{SAC} 2(10) .3$;

IF (SAC2(9)=" ") OR (SAC2(9)=" -") THEN

(IF $\operatorname{SAC2}(9)="-"$ THEN

ELSE(

SET $S(7,76)="-" ;)$

SET $S(7,76)="$ " ;

SET $S(7,73)=\operatorname{SAC} 2(7) .3$;

(IF (SAC2(6)=" ") OR (SAC2(6)="-") THEN

(IF SAC2 (6) $="-"$ THEN

$\operatorname{SET} S(7,72)="{ }_{-}$; )

\section{ELSE}

(SET $S(7,72)="$ "

SET $S(7,68)=\operatorname{SAC} 2(3\rangle .4 ;) ;)$;) ; !TOTAL BO COMPLETED;

IF $0>51$ THEN(

TFORM; SET $B 4(127)=P .6 ;$ SET $B 4(127)=1$

PRINT $B 4(1) .132 ; \quad$ PRINT $S(4,1), 1$;

PRINT B4(271).132; PRINT B4(406).132; PRINT S(4,1).1;

PRINT BI(1).132; PRINT S(4,1).1;

PRINT S(4,1).1 PRINT B1(217). 132;

PRINT BI(352).132; PRINT $S(4,1) .1$;

PRINT $S(4,1) .1$; $\quad$ SET $P=P+1 ;)$;

PRINT B1(1).132; PRINT S $(4,1) .1$;

PRINT $S(7,1) .80 ; \quad$ PRINT $S(4,1) .1$;

!PUT BO IN SAC2;

!EDIT TO SCREEN AS FOR BA;

SET $B 5(M)=S(7,26) .15$; SET $B 5(M+15)=S(7,48) .12$; ISTORE BATCH SUMMARY IN B5; IF $L<19$

THEN SET $B 5(M+27)=S(7,68) .12$

ELSE SET $\operatorname{SAC5}(1)=S(7,68) .12$

SET $S(7,26)=\& \quad .15 ;$ SET $S(7,48)=\& .12 ; \operatorname{SET} S(7,68)=\& .12 ; \quad$ !CLEAR SCREEN; IF $1<74$

THEN SET $J=J+8$ 
386

387

388

389

390

391

392

393

394

395

396

397

398

399

400

401

402

403

404

405

406

407

408

409

410

411

412

413

414

415

416

417

418

419

420

421

422

423

424

425

426

427

428

429

430

431

432

433

434

435

436

437

438

439

440

ELSE (SET I $=\mathrm{I}+1$; SET J=2;);

SET $L=L+1 ;$ SET $M=M+39$; SET $0=52$;

SET $B 3=\&$. 540;); ! $\star \star \star$ SET UP SCREEN FOR REPORT SUMMARY PROCESSING ${ }^{\star \star \star}$;

$\operatorname{SET} S(7,1)=\& .25 ; \operatorname{SET} S(7,44)=" \quad$ "; $\operatorname{SET} S(7,64)="$ ";

SET $S(12,1)=\& .80$;

SET $S(5,45)=$ "REPORT SUMMARY"; $\operatorname{SET} S(6,26)=$ "ECOR NUMBER".;

SET $S(6,52)=$ "TOTAL BA"; SET $S(6,72)="$ "TOTAL BO";

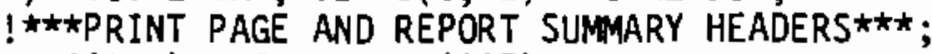

TFORM; SET $B 4(127)=P .6$; SET $B 4(127)="$

PRINT B4(1).132; PRINT S $(4,1) .1$;

PRINT B4(271).132; PRINT B4(406).132;

PRINT B1(1).132;

PRINT S $(4,1) .1$;

PRINT S( 5,1$) .80$;

PRINT S $(4,1) .1$;

PRINT $5(4,1) .1$;

PRINT S( 4,1$) .1$;

PRINT B4(136).132;

PRINT 5 $(4,1) .1$;

PRINT S(4,1).I;

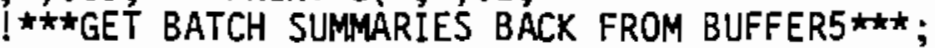

SET $L=0 ;$ SET $M=1$;

!M POINTERS TO BUFFER5 POSITIONS;

WHILE LUK(

SET $S(7,26)=B 5(M) .15 ; \operatorname{SET} S(7,48)=B 5(M+15) .12$;

IF $\mathrm{L}<19$

THEN SET $S(7,68)=B 5(M+27) .12$

ELSE SET $S(7,68)=\operatorname{SAC5}(1) .12$;

PRINT $S(7,1) .80$;

SET $L=L+1$; SET $M=M+39$; );

!IF 20TH BATCH, BO COMES FROM SAC5; !PRINT BATCH SUMMARY ENTRY;

IEND. WHILE;

$\operatorname{SET} S(7,26)=" R E P O R T$ TOTAL:"; SET $S(7,39)=\& .42$; ISET UP REPORT TOTAL LINE;

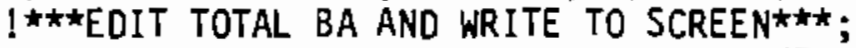

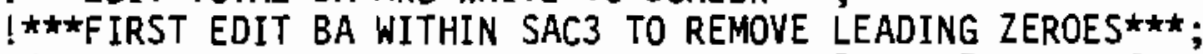

SET I $=2$; SET $\mathrm{J}=1$;

II ITERATES WHILE STMT, J IS A MARKER;

SET $\operatorname{SAC} 3(1)="$ ";

WHILE IK13(

IF (SAC3(I)า"0" AND SAC3(I-1)=" ")

THEN (SET $\operatorname{SAC3}(I-1)="-"$; SET $\mathrm{J}=1-1$;);

IF $($ SAC3(I) $=" 0 "$ AND SAC3(I-1)=" ")

THEN SET SAC3(I)=" ";

SET $\mathrm{I}=\mathrm{I}+1$; );

IF $(\operatorname{SAC} 3(12)\rangle=" 0 "$ AND $\operatorname{SAC} 3(12)\langle=" 9 ")$

THEN SET SAC3 $(J)="$ ";

IF $\operatorname{SAC} 3(12)="$ "

THEN SET SAC3(12) = "O"

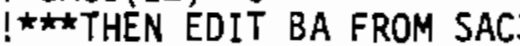

$\operatorname{SET} S(7,57)=\operatorname{SAC} 3(10) \cdot 3$;

IF $(\operatorname{SAC} 3(9)="$ "OR $\operatorname{SAC} 3(9)="-")$

THEN (IF SAC3( 9$)="-"$

THEN SET $S(7,56)="-"$;)

$\operatorname{ELSE}(\operatorname{SET} 5(7,56)=", "$;

SET $5(7,53)=\operatorname{SAC} 3(7) .3$;

(IF $(\operatorname{SAC} 3(6)="$ " OR SAC3(6) $="-4$ )

THEN (IF SAC3(6) $="-"$

THEN SET $S(7,52)="-" ;)$

ELSE (SET $S(7,52)=", "$;

SET $S(7,48)=\operatorname{SAC} 3(3) .4$;) ;) ;) ;

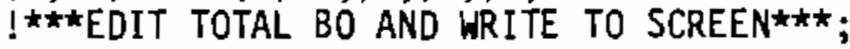

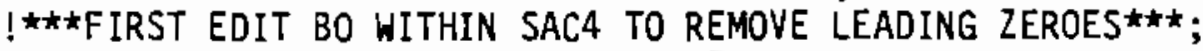

SET I $=2 ; \operatorname{SET} \mathrm{J}=1$;

SET $\operatorname{SAC} 4(1)="$ ";
!WHILE STMT EOITS TOTAL BA IN SAC3;

!J MARKS LAST BLANK POSITION;

!REMOVE LEADING ZEROES;

!END WHILE STATEMENT;

!REMOVE MINUS SIGN FOR POSITIVE \#S;

IINSERT ZERO IF \# IS 0 ;

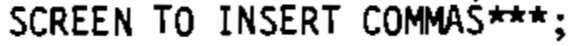

!INSERT NEGATIVE SIGN BELOW IF NEEDED;

!RESET I AND J; 
441

442

443

444

445

446

447

448

449

450

451

452

453

454

455

456

457

458

459

460

461

462

463

464

465

466

467

468

469

470

471

472

473

474

475

476

477

478

479

480

481

482

483

484

485

486
WHILE I $<13($ IF (SAC4(I) ᄀ"0" AND SAC4(I-1)=" ") THEN (SET SAC4(I-1)="-"; SET $\mathrm{J}=1-1$;); IF ( SAC4(I) $=$ "0" AND SAC4(I-1) =" ") THEN SET SAC4(I)=" "; SET $I=I+1 ;)$; IF (SAC4(12) $\rangle=" 0 "$ AND SAC4(12) $<=" 9 ")$

THEN SET $\operatorname{SAC4}(\mathrm{J})="$ "; IF SAC4(12) =" "THEN SÉT SAC4(12) ="0";

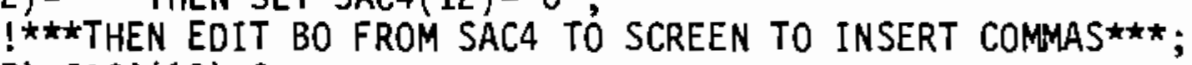

SET $S(7,77)=\operatorname{SAC} 4(10) .3$;

IF $(\operatorname{SAC} 4(9)="$ "OR SAC4(9) $="$ " $)$

THEN (IF SAC4 (9) =" -"

THEN SET $S(7,76)="-"$;)

ELSE (SET S(7,76)=" ";

SET $S(7,73)=\operatorname{SAC} 4(7) .3$;

(IF (SAC4(6) =" "OR SAC4(6)="-")

THEN (IF SAC4(6)="-"

THEN SET $S(7,72)=", " ;)$

$\operatorname{ELSE}(\operatorname{SET} S(7,72)=", "$;

SET $5(7,68)=\operatorname{SAC}(3) .4$;) ;) ;) ; ITOTAL BO COMPLETED;

PRINT $S(4,1) .1$; PRINT $S(7,1) .80 ;$ !PRINT REPORT TOTALS;

! $\star \star \star$ GET NAME AND DATE FROM USER ${ }^{\star \star \star}$;

SET $S(13,26)=$ "REPORT DATE:";

SET $S(14,26)=$ "PREPARED BY:";

SET $S(21,2)=$ "ENTER TODAY'S DATE" ; LOOP(

TYPEIN; SET $S(13,48)=S(22,2) .25$;

SET $S(21,2)=\& \quad .79 ;$ SET $S(22,2)=\& \quad .79$;

SET $S(21,2)=" E N T E R$ YOUR NAME";

TYPEIN; SET $S(14,48)=S(22,2) .25$;

!LOOP REQUESTS DATE/NAME UNTIL VALID; !COPY DATE TO SCREEN LINE 14;

!COPY NAME TO SCREEN LINE 14;

SET $S(21,2)=\& .79 ;$ SET $S(22,2)=\& .79$;

SET $S(21,2)=$ "ARE NAME AND DATE CORRECT? ENTER YES OR NO";

TYPEIN;

IF $S(22,2)=$ "YES" THEN

EXIT

ELSEl

SET $S(13,48)=\& .25 ;$ SET $S(14,48)=\& .25$;

SET $S(21,2)=\& \quad .79 ;$ SET $S(22,2)=\& \quad .79$;

SET $S(21,2)=" T R Y$ AGAIN - ENTER TODAY'S DATE";) ;) ; IEND LOOP;

$\operatorname{SET} S(22,2)=\& \quad .79$;

SET $S(21,2)=" H I T$ MODE KEY TO EXIT WHEN 'SEND ENCOUNTERED' APPEARS BELOW";

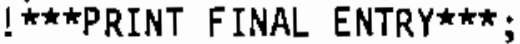

PRINT S(4,1).1; PRINT S(4,1).1; PRINT S(4,1).1; PRINT S(13,1).80;

PRINT S(14,1).80; PRINT S(4,1).1; PRINT S(4,1).1; PRINT BI(1).132;

\$END 
SOURCE CODE FROM MASTER,ECPG84

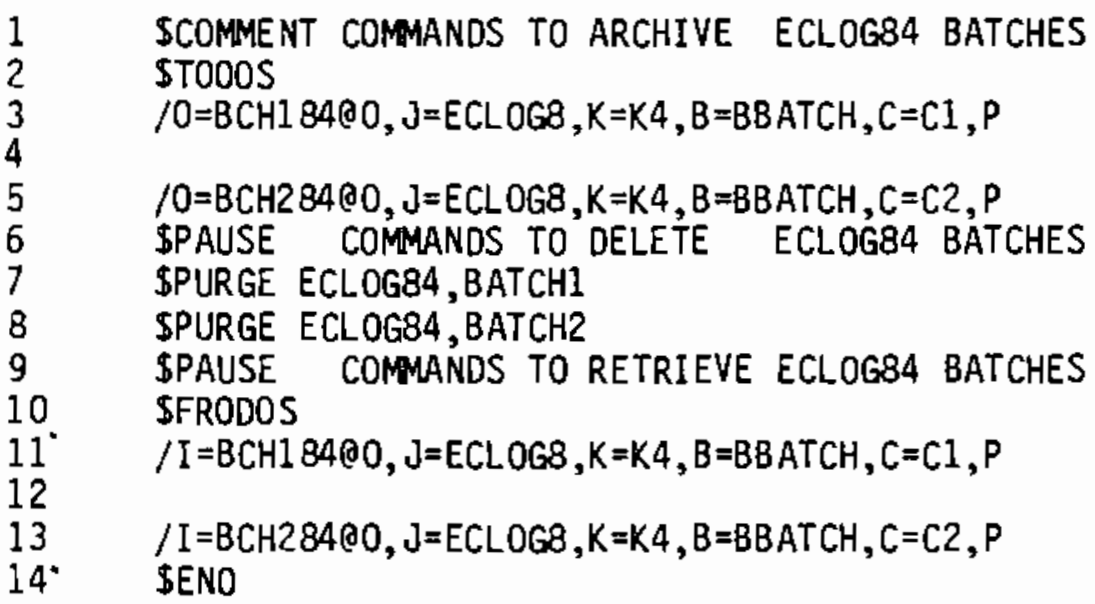


1 SCOMMENT CODE TO CREATE ECLOG84 JOB, IN MASTER,ECJB84

2 \$PURGE ECLOG84,0-ZZZZZZ

3 SDELETE JOB ECLOG84

\$DEFJDB ECLOG84 \$MAXSIZ 281 \$FORMAT C11,C12 \$VALUES 011 \$ACCUMS 2

\$PAUSE FORMATIING FOR PROGRAM LEVEL 1

\$DELETE FORMAT C11

\$FORMAT C11 \$SIZE 139

ASD INTEN L E22,80

GETBUF ( $S I Z E=49$ )

P1,24 "SUMMARY FOR ECOR NUMBER"

P3,1"ECOR NUMBER:"

P5, 1 "ANALYST:"

P5,39"PHONE NUMBER:"

$P 7,1^{\text {"FY" }}$

P7,9"APPROPRIATION AMOUNT:"

$P 7,5111 *$ "

P9,1"APPROPRIATION NUMBER:"

P11,1 "FY"

P11,9"UNOBLIGATED CARR YOVER AMOUNT:"

P11,51"*"

P13,1"TOTAL ECOR AVAILABILITY:"

P13,51"**

P16,1"*NUMERIC FIELDS: ENTER AMOUNTS WITHOUT USING COMMAS"

P17,18"ENTER A ZERO IF AN AMOUNT IS NOT NEEDED"

a3, $14 \quad \mathrm{G}(\mathrm{H}) 15$

a $5,10 \quad G(H) 20$

ఏ5, $53 \quad G(H) 15$

a $7,4 \quad$ II $(\mathrm{H}) 4 \mathrm{~F}$

a $7,392 \mathrm{~L}(\mathrm{H}) 9$

Q9,39 $\mathrm{G}(\mathrm{H}) 15$

a1i,4 I(H) 4GF 1

a11,39 $3 \mathrm{~L}(\mathrm{H}) 9$

(a) $13,394 \mathrm{~L}(\mathrm{H}) 10$

$\operatorname{SET} B(2,9)=F 2$

IF $B(10,1)<" 0 " \mid>" 9 "$ THEN SET $B(1,1)="-"$

$\operatorname{SET} B(12,9)=F 3$

ELSE SET $B(1,1)=" 0 "$

If $B(20,1)<" 0 " \mid>" 9 "$ THEN SET $B(11,1)="-"$

SET $B(22,10)=F 4$

ELSE SET $B(11,1)=" 0 "$

IF $B(31,1)<" 0 " \mid>" 9 "$ THEN SET $B(21,1)="$-"

ELSE SET $B(21,1)=" 0 "$

(222,1 5N(B) 125 EDIT $F 5=B(1,10)$ USING -..--,--.,---

B1 $6 N(B) 12 S$ EDIT $F 6=B(11,10)$ USING $\ldots . . ., \ldots, \ldots$

B1 $7 N(B) 14 S$ EDIT $F 7=8(21,11)$ USING $--, \ldots,-\ldots, \ldots$

F2

\$PAUSE FORMATTING FOR PROGRAM LEVEL 2

SDELETE FORMAT C12

\$FORMAT C12 \$SIZE 281

ASD INTEN L E22,80

PI,20"INDIVIDUAL CONTRACT INFORMATION"

P3,8"CONTRACTOR:"

$P(H) 3,25 " \# " P(-) 3,39 " \# "$

$P(H) 4,25 " \# " P(-) 4,39 " \# "$

P4,46"PROGRAM MANAGER:" 


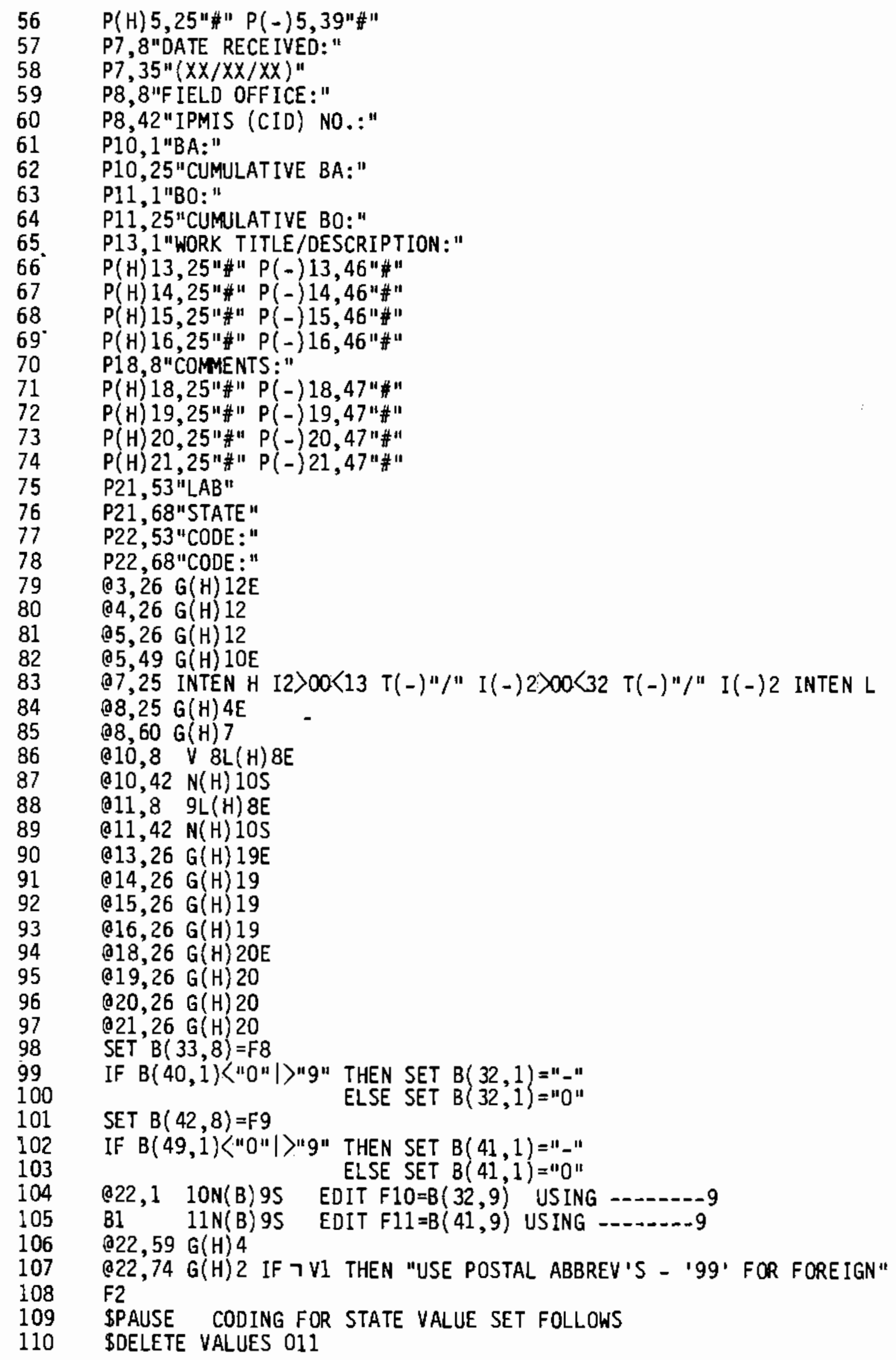


SOURCE CODE FROM MASTER, ECJB84

111 \$VALUES 011 \$SIZE 2

112

113 CA

114 IL

115 TN

116 WA

117 AL

118 AK

119 AZ

120 AR

$121 \quad \mathrm{CO}$

122 CT

123 DE

$124 \mathrm{FL}$

$125 \mathrm{GA}$

126 HI

127 ID

128 IN

129 IA

130 KS

$131 \mathrm{KY}$

132 LA

$133 \quad \mathrm{ME}$

$134 \quad M D$

135 MA

136 MI

137 MN

138 MS

$139 \quad M 0$

140 MT

$141 \mathrm{NE}$

142 NV

$143 \quad \mathrm{NH}$

144 NJ

$145 \mathrm{NM}$

$146 \mathrm{NY}$

147 NC

148 ND

$149 \mathrm{OH}$

150 OK

151 OR

152 PA

153 RI

154 SC

155 SD

156 TX

157 UT

158 VT

159 VA

160 WV

161 WI

162 WY

163 DC

16499

165 \$END 
PNL -5223

UC-95a

\section{DISTRIBUTION}

No. of

Copies

OFF SITE

5 Terry Levinson CE-142

Department of Energy 1000 Independence Avenue SW Washington, DC 20585

5 Mary Honablew

CE-14

Department of Energy 1000 Independence Avenue SW

Washington, DC 20585

Mattie Hill

CE-73

Department of Energy

1000 Independence Avenue SW

Washington, DC 20585

Laura Duncan

CE-11

Department of Energy

1000 Independence Avenue SW

Washington, DC 20585

2 DOE Technical Information Center
No. of

Copies

DOE Richland Operations Office

H. E. Ransom

Pacific Northwest Laboratory

W. B. Ashton

S. L. Beck

J. L. Eisenhauer (ESD-BWO)

C. Winter (ESD-BWO) (5)

Publishing Coordination (1)

Technical Information (3) 
